\title{
Wages and European integration : a study on the distributional impact of a trade liberalisation scheme
}

Citation for published version (APA):

van Mourik, A. (1994). Wages and European integration : a study on the distributional impact of a trade liberalisation scheme. [Doctoral Thesis, Maastricht University]. BIV Publications.

https://doi.org/10.26481/dis.19941110am

Document status and date:

Published: 01/01/1994

DOI:

10.26481/dis.19941110am

Document Version:

Publisher's PDF, also known as Version of record

\section{Please check the document version of this publication:}

- A submitted manuscript is the version of the article upon submission and before peer-review. There can be important differences between the submitted version and the official published version of record.

People interested in the research are advised to contact the author for the final version of the publication, or visit the DOI to the publisher's website.

- The final author version and the galley proof are versions of the publication after peer review.

- The final published version features the final layout of the paper including the volume, issue and page numbers.

Link to publication

\footnotetext{
General rights rights.

- You may freely distribute the URL identifying the publication in the public portal. please follow below link for the End User Agreement:

www.umlib.nl/taverne-license

Take down policy

If you believe that this document breaches copyright please contact us at:

repository@maastrichtuniversity.nl

providing details and we will investigate your claim.
}

Copyright and moral rights for the publications made accessible in the public portal are retained by the authors and/or other copyright owners and it is a condition of accessing publications that users recognise and abide by the legal requirements associated with these

- Users may download and print one copy of any publication from the public portal for the purpose of private study or research.

- You may not further distribute the material or use it for any profit-making activity or commercial gain

If the publication is distributed under the terms of Article $25 \mathrm{fa}$ of the Dutch Copyright Act, indicated by the "Taverne" license above, 

WAGES AND EUROPEAN INTEGRATION 



\title{
WAGES AND EUROPEAN INTEGRATION
}

\author{
A Study on the Distributional Impact of a \\ Trade Liberalisation Scheme
}

\begin{abstract}
PROEFSCHRIFT
ter verkrijging van de graad van doctor aan de Rijksuniversiteit Limburg, op gezag van de Rector Magnificus, Prof. dr. H. Philipsen, volgens het besluit van het College van Dekanen, in het openbaar te verdedigen op donderdag 10 november 1994 om 16.00 uur
\end{abstract}

door

Adrianus van Mourik 
Promotores: Prof. dr. W.T.M. Molle (Erasmus Universiteit Rotterdam)

Prof. dr. F. Abraham (Katholieke Universiteit Leuven (B))

Beoordelingscommissie:

Prof. dr. J.A.H. Maks (voorzitter)

Prof. dr. C. de Neubourg

Prof. dr. J.L.M. Pelkmans

Prof. dr. H. Visser (Vrije Universiteit Amsterdam)

CIP-GEGEVENS KONINKLIJKE BIBIOTHEEK, DEN HAAG

Mourik, Adrianus van

Wages and European integration : a study on the distributional impact of a trade liberalisation scheme / Adrianus van Mourik. - Maastricht : BIV Publications. Fig. tab.

Proefschrift Maastricht. - Met lit. opg. Met

samenvatting in het Nederlands.

ISBN 90-9007475-9

NUGI 681

Trefw.: internationale handel / salarissen ; Europese

Gemeenschappen / handelspolitiek.

(2) Aad van Mourik, Maastricht

c. Lay out by Aad van Mourik, Maastricht

Printed by Febodruk, Enschede

Published by BIV Publications, Maastricht 


\section{CONTENTS}

List of Tables $\quad$ vii

List of Figures $\quad$ ix

Preface $\quad x$ xiii

CHAPTER 1 INTRODUCTION

1.1 Introduction 1

1.2 The problem of this study 2

1.3 Economic integration and international trade theory 3

1.4 Outline of the study 5

CHAPTER 2 FACTOR PRICES IN THE THEORY OF INTERNATIONAL TRADE

2.1 Introduction 7

2.2 Heckscher and Ohlin 8

2.3 Samuelson's provocations 10

2.4 Alternative approaches to factor price equalisation 15

2.5 Generalisation to higher dimensions 21

2.6 The Stolper-Samuelson theorem 27

2.6.1 The standard version of the theorem 27

2.6.2 Generalisations of the theorem 31

2.7 The specific-factors model 34

2.8 Conclusions 39

CHAPTER 3 DID WAGE CONVERGENCE OCCUR?

THE EXPERIENCE OF EC-5

3.1 Introduction 41

3.2 International comparison of wages:
conceptual issues and measuring problems

3.3 Developments in wage differentials 45

3.3.1 Gross hourly wages and hourly labour costs

3.3.2 Wages in EFTA countries 57

3.3.3 Labour cost per manyear 61

$\begin{array}{ll}3.4 \text { Conclusions } & 67\end{array}$

CHAPTER 4 SOME EMPIRICAL REGULARITIES

4.1 Introduction 69

4.2 The theory of wage structures 70

4.3 The empirical importance of factor intensity reversals 73,

4.4 Studies relating foreign trade and wages 76

$\begin{array}{ll}\text { 4.5 Production and cost function studies } & 79\end{array}$

4.6 A North-South model of aggregate wage differentials
applied to the EC

4.6.1 Introduction 82

4.6.2 An estimable model of wage differentials 83

4.6.3 Empirical application of the model B7

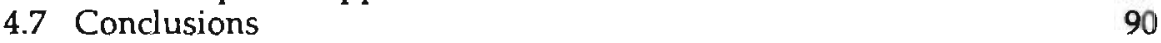




\subsection{Introduction 93}

5.2 The model and its assumptions 94

5.3 Short-run factor price effects of trade policies 99

5.3.1 Short-run comparative statics 100

5.3.2 Capturing the integration effects 105

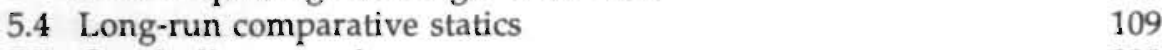

5.5 Concluding remarks 111

CHAPTER 6 ESTIMATION OF THE MODEL

6.1 Introduction 113

6.2 The functional form for the cost functions 114

6.3 Estimated equations 116

6.3.1 The share equations 116

6.3.2 The treatment of technical change 118

6.4 Data and estimation techniques 120

6.4.1 The data 120

6.4.2 Estimation technicalities 123

6.5 Estimation results 125

6.6 Conclusions 143

CHAPTER 7 SOME SIMULATION EXPERIMENTS

7.1 Introduction 145

7.2 Tariff and non-tariff barriers in the EC, 1958-1992 146

7.2.1 Tariffs and the creation of the customs union 146

7.2.2 Non-tariff barriers and the 1992 programme 150

7.3 Methodology for simulations 156

7.4 Static effects: the creation of the customs union 160

7.5 Static effects: the programme for the completion
of the internal market

7.6 A critical assessment of our results 167

$\begin{array}{ll}7.7 \text { Conclusions } & 170\end{array}$

CHAPTER 8 SUMMARY AND CONCLUSIONS 173

$\begin{array}{ll}\text { References } & 177\end{array}$

$\begin{array}{ll}\text { Samenvatting } & 185\end{array}$ 


\section{LIST OF TABLES}

Table 3.1 Rank order of sectors by gross hourly wages and hourly labour costs (EC-5, ISIC industrial sectors)

Table 3.2 Coefficients of variation: intra-sectoral gross hourly earnings (EC5, ISIC industrial sectors)

Table 3.3 Coefficients of variation: intra-sectoral hourly labour costs (EC-5, ISIC industrial sectors)

Table 3.4 Gross hourly wages relative to EC-5 average

Tabel 3.5 Rank ordering of EFTA-5 gross hourly earnings (EFTA-5, ISIC industrial sectors)

Tabel 3.6 Coefficients of variation: Intra-sectoral gross hourly earnings (EFTA-5, ISIC industrial sectors)

Table 3.7 Coefficients of variation: intra-sectoral labour cost per manyear (NACE industrial sectors)

Table 3.8 Labour cost per manyear relative to Eur-5 average

Table 4.1 Production function parameters in Minhas' study

Table 4.3 Re-estimation results of the Gremmen model

Table 4.4 Average annual growth rates of wages and capital-labour ratios, 1959-1979

Table 4.5 Model predictions

Table 5.1 A taxanomy of factor price effects of the imposition of a common external tariff in a customs union between a high-wage and a low-wage country

Table 6.1 Manufacturing sectors according to the NACE R25 classification in the Eurostat National Accounts Database.

$\begin{array}{ll}\text { Table 6.2 } & \text { Estimation results for manufacturing sectors: Germany } \\ \text { Table 6.3 } & \text { Summary of technical progress biases: Germany }\end{array}$

Table 6.4 Estimated values of the Allen-Uzawa elasticities of substitution, 1970 and 1985: Germany

Table 6.5 Estimation results for manufacturing sectors: Italy

Table 6.6 Summary of technical progress biases: Italy

Table 6.7 Estimated values of the Allen-Uzawa elasticities of substitution, 1970 and 1985: Italy

Table 6.8 Estimation results for manufacturing sectors: Belgium

Table 6.9 Summary of technical progress biases: Belgium

Table 6.10 Estimated values of the Allen-Uzawa elasticities of substitution, 1970 and 1985: Belgium

Table 6.11 Estimation results for manufacturing sectors: the Netherlands

Table 6.12 Summary of technical progress biases: the Netherlands

Table 6.13 Estimated values of the Allen-Uzawa elasticities of substitution, 1970 and 1985: the Netherlands

Table 6.14 Estimation results for manufacturing sectors: France

Table 6.16 Estimated values of the Allen-Uzawa elasticities of substitution, 1970 and 1985: France

Table 7.1 Average ad-valorem (equivalents of) tariff barriers (1958) in the industrial sectors of the EC (NACE-R25) effective rates of protection, CET and value shares 
Table 7.2 Tariff equivalents of 1992 non-tariff barriers on final and intermediate goods, effective tariff equivalents, and value shares

Table 7.3 Sign-determining elasticities of substitution and factor shares:

1970 and 1985

Tabel 7.4 Percentage price changes of final goods $(\hat{\mathrm{p}})$, intermediate goods $(\hat{q})$ and changes in nominal wages $(\hat{w})$; customs union antimonde

Table 7.5 Coefficients of variation; customs union's anti-monde

Tabel 7.6 Percentage price changes of final goods ( $\hat{p})$, intermediate goods $(\hat{q})$ and changes in nominal wages ( $\hat{w})$; internal market programme

Table 7.7 Coefficients of variation; internal market programme 


\section{LIST OF FIGURES}

Figure 2.1 Unit isoquants 12

Figure 2.2 Unit cost functions 17

Figure 2.3 The factor allocation box in a $2 \times 2 \times 2$ world 19

Figure 2.4 The Lerner diagram for $\mathrm{n}>\mathrm{m} \quad 23$

Figure 2.5 The factor price diagram for $n>m$

Figure 2.6 Production indeterminacy in the $\mathrm{n}>\mathrm{m}$ factor price equalisation model 25

Figure 2.7 The three commodity, two factor box diagram 26

Figure 2.8 The Stolper-Samuelson theorem in the factor price diagram 30

Figure 2.9 The likelyhood of factor price equalisation in the specific-factors model 34

Figure 2.10 The specific-factors model 38

Figure 5.1 Short-run factor price responses following trade policy measures 104 
$=$ 


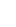


To the memory of Hester Kamerling To Elly 


\section{Preface}

This book has grown out of more than eight years of research in the subject area of European integration economics. The project was set up by Prof. Willem Molle in 1984, and I joined it in 1985. Its origin goes back to Willem Molle's textbook on European Integration Economics.

Over the last decade or so, many persons, in one way or another, contributed to my intellectual development. I greatly regret that there is not enough space to express my appreciation to all those persons whose knowledge, advice and encouragements has contributed to the completion of this book. I hope those persons whose name has been omitted below, will forgive me for this. The ommission is certainly not due to lack of gratitude, rather it signifies lack of space. First and foremost, professor Willem Molle, my thesis supervisor, significantly influenced my thinking on economics in general and European integration economics in particular by setting the modern standard in the last field, but also by numerous discussions, encouragements, and by providing stimulating help and, most of all, exihibiting extreme patience all the time. Professor Filip Abraham (Catholic University of Leuven), my thesis co-supervisor, acted as my maths coach, gave invaluable comments, scrutenised the manuscript more than once and drew my attention to a prodigious number of slips and absurdities. I completed the book as a part of my work in the labour market research programme of the Department of Economics at the University of Limburg. Dr Guido Wolfs, drs Rombout de Wit, dr Siebrand Schim van der Loeff, drs Geert Woltjer, dr Hans van Mierlo, professor Hans Maks, professor Joan Muysken, professor Jacques Pelkmans, professor Luc Soete, drs Erik de Regt, dr Peter de Gijsel, professor Chris de Neubourg, and dr Adriaan van Zon, who are all Economic Faculty members in Maastricht, acted as discussion partners on so many occasions. Drs Marcel Jansen provided computational assistence and also read and criticised a substantial part of the manuscript. Needless to say, all the usual disclaimers apply to the above-mentioned people.

My former collegue at the University of Utrecht, professor Jacques Siegers, taught me the basics of economic theory and applied economics research. His never-ending advice and warm friendship have always been extremely important to me.

The Department of Economics at the University of Hull extended its hospitality to me for two consecutive years, and so contributed enormously to my knowledge of both micro and international economics. I benefitted a lot from discussions with dr Tapan Biswas and dr Manolis Pikoulakis, who became dear friends. Dr Eric Evans and dr Keith Neild enabled my stay at Hull University.

I would also like to express my gratitude to the Commission of the European Communities, who financially supported part of the research through a grant, along with the Raad voor Europese Gemeenten (Maastricht) who supplied me with datamaterial. Dr Carlos Meira and dr Klaus Löhning, who are both of Eurostat at Luxemburg, provided invaluable advice in the interpretation of the data.

Finally, I am seriously in debt to my mother and my sister, whose steady encouragement, throughout my years as a student, have always been indispensible for me. To them this book is dedicated. 


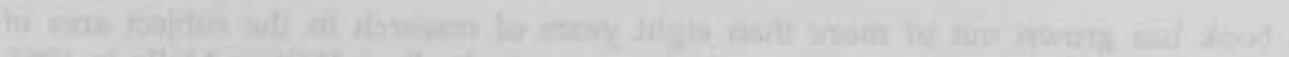

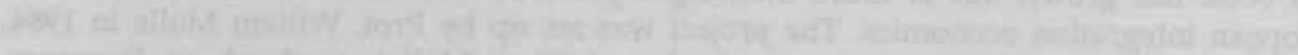

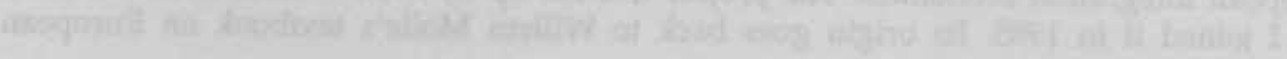

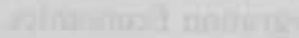

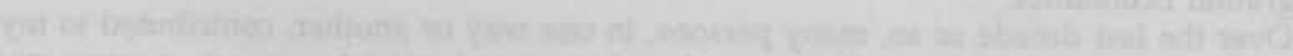

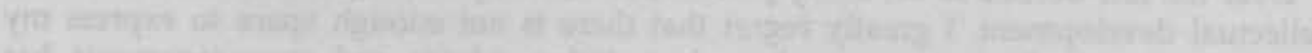

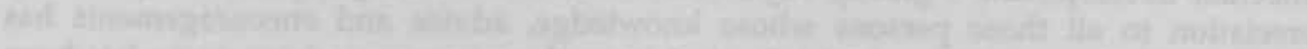

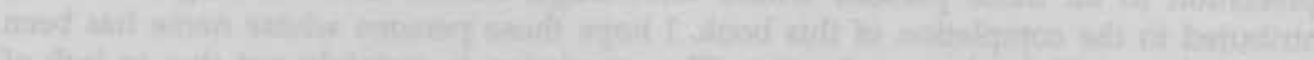

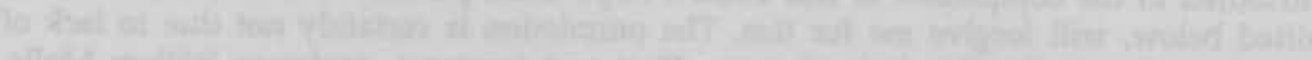

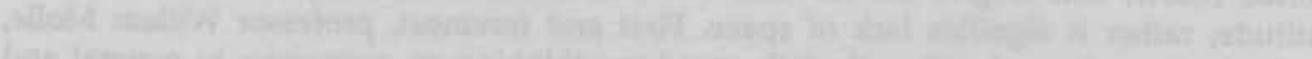

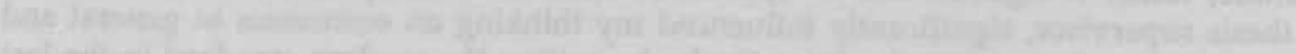

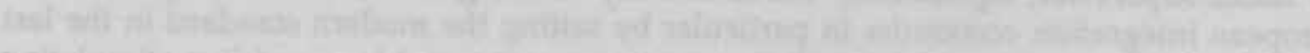

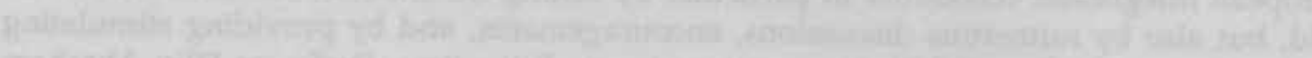

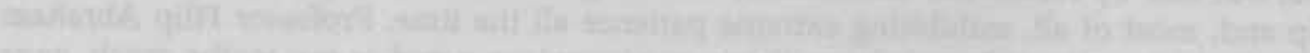

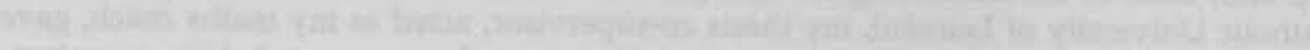

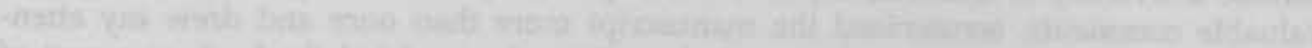

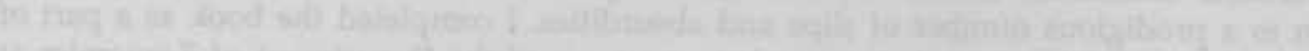

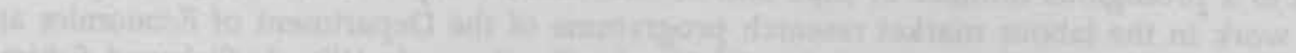

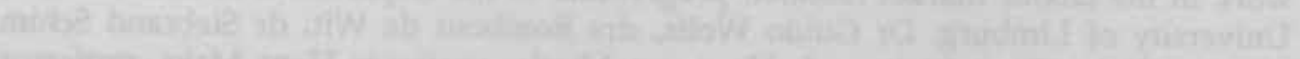

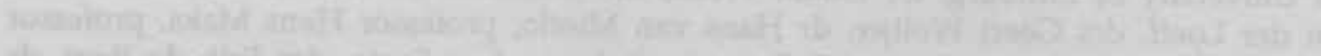

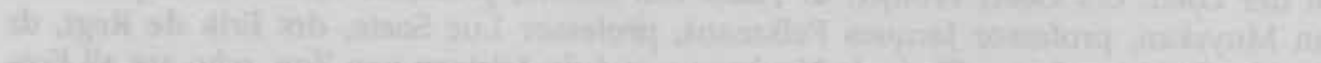

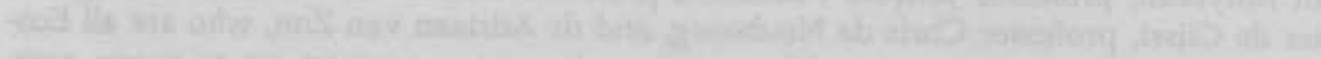

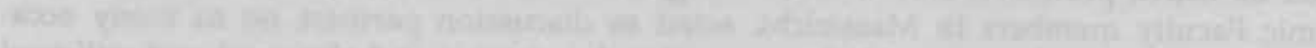

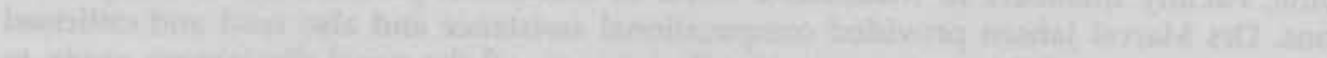
Wh

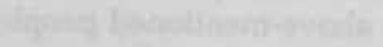

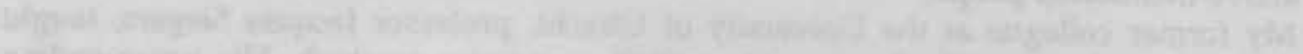

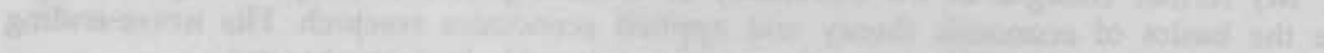

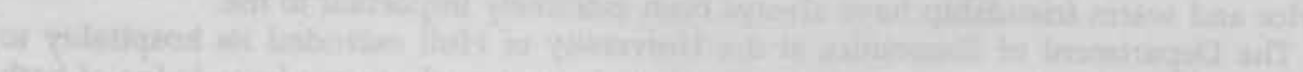

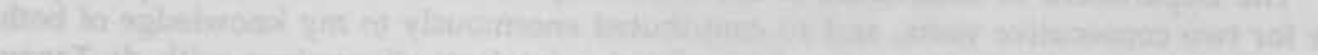

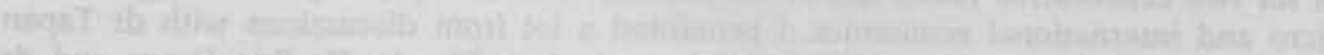

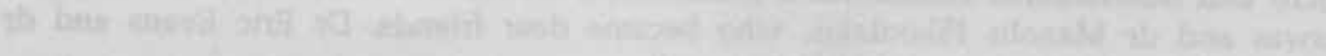

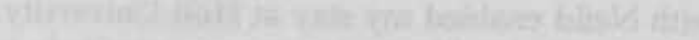

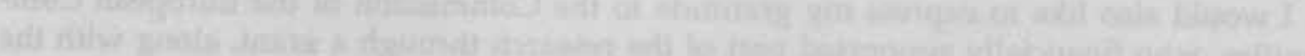

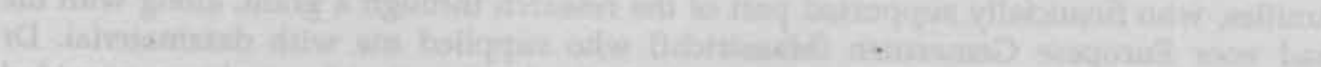

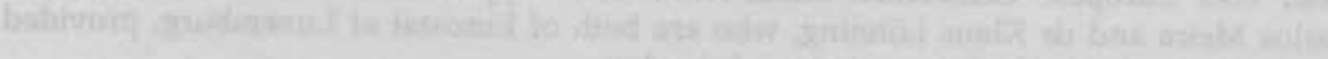

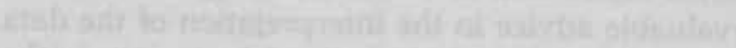

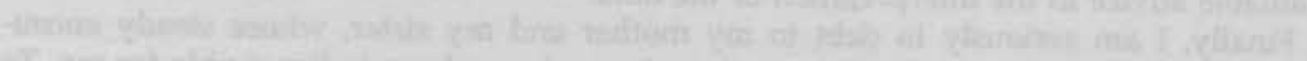

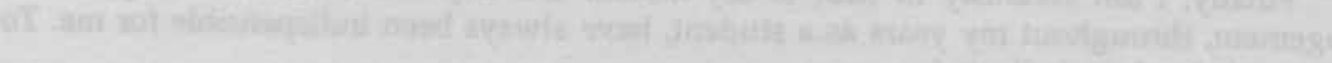

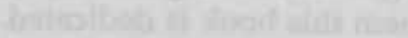

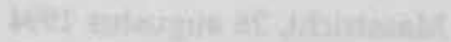

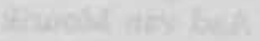




\subsection{Introduction}

Contrary to the USA, where the supposed wage effects of the NAFTA treaty have given rise to a great deal of controversy, the wage effects of the European integration process have hardly attracted any attention in the (empirical) literature. Although early discussions of European economic integration were in addition to the question of the welfare effects of trade liberalisation also concerned with the problem of a European movement towards factor price equalisation, the behaviour of wages, and the related issue of larbour mobility, has ran into an increasing neglect by students of the integration process.

In so far as factor prices have been the subject of study, there are, broadly speaking, two views. Firstly, there are those who believe that factor prices tend to converge as a result of the liberalisation of trade in the Community (see, for instance, Meyer and Willgerodt (1954), Fisher (1966)). This view, which has been the dominant school of thought, was based on predictions derived from the (Heckscher-Ohlin-Samuelson) theory of international trade. According to the conventional wisdom of that body of economics, there are at least two factors producing a movement in the direction of equalised factor prices (convergence of factor prices). Firstly, there is of course the liberalisation of factor movements after the Community had been set up. Factors of production, it was argued, would always move in the direction of countries where the returns to their employment. would be higher than in their home region. This would tend to eliminate the differences: in scarcity of factors and would thus lead to an equalisation of factor prices. Secondly, and more importantly, if countries specialise according to their comparative advantage, there may be factor price equalisation through free commodity trade. Thus it is believed that trade tends to be a perfect substitute for factor migration.

The dorninance of the factor price equalisation school has had its counterpart in the policy sphere. Indeed, it can hardly be denied that the distributional consequences of the integration process had a low priority in the past three decades. However, there is some evidence that things are changing now and that politicians and EC officials become increasingly aware of the distributional consequences of the completion of the internal market in Europe in 1992.

According to the second opinion, factor prices will tend to diverge rather than converge as a consequence of trade liberalisation. The reasons for this is that the conditions for factor price equalisation may fail to be fulfilled in practice. Trade may be impeded 
by the collusive practices of firms, by import duties (on third country goods) and transportation costs. Technology may be monopolised by large firms. Those are essentially the factors highlighted by the divergence school. Their arguments go back to the work of, among others, Myrdal $(1956,1957)^{1}$, who pointed out that a system marked by large initial disparities, certain rigidities and the absence of countervailing government policies, tends towards progressively unbalanced development, a process labelled "cumulative causation". Technological elements from the spatial variant of the life-cycle theory have revealed the tendency of advanced countries to perpetuate the gap between them and backward nations by selecting new products with high value added as soon as they emerge, whilst at the same time pushing away products as soon as their value added declines and no longer can sustain high wages.

\subsection{The problem of this study}

Whatever the correct view may be, it is interesting to observe an increasing awareness of the social consequences of the formation of the EC and its internal market. It is in the light of this revived interest for the social consequences of trade liberalisation that this study should be seen. Its aim is the analysis of the interrelationship between the behaviour of factor prices and the trade liberalisation process in the European Community. More specifically, the study focuses on the impact of the economic integration process on wages, in other words, we shall try to answer the question in what direction wages might change in response to the EC's economic integration scheme. Thus, we shall primarily be concerned with the behaviour of one possible factor price and ignore any effect on other factor prices than wages. Apart from a rather narrow definition of factor prices, we shall also interpret the term "economic integration" in a narrow sense, in that we shall confine the analysis to the wage effects of liberalisation of commodity trade in customs unions and free trade areas. Thus, we shall ignore the effects of all integration attempts beyond the stage of customs unions (i.e., the effects of liberalisation of factor movements and the integration of economic and monetary policies).

The study of factor prices in a setting of international economic integration is important for several reasons. The most obvious one is that the inclusion of international elements is a dimension that has been neglected by most previous (empirical) analyses, which have mostly been concerned with the study of factor prices or wage structures within a single country. Thus, wage structure analyses have almost exclusively been concerned with the testing of labour economics theories and have mostly ignored testing the implications of international integration and international trade theory. Therefore, our attempt to asses the distributional effects of the formation of the $\mathrm{EC}$ at the same time encompasses a test of some of the theorems of the theory of international integration and international trade. Secondly, the present work hopes to contribute to the increasing prominence of labour-market issues in European integration research now that EC countries are well on their way to complete the internal market. That development will probably shift away the orientation of research from the national labour markets to the European labour market. Moreover, the political interest in "social" Europe has got an impetus as a result of the attempts to establish the internal market. It is obvious, even to the most casual observer, that the further liberalisation of commodity trade in Europe will have certain distributional consequences. In addition, it is conceivable

${ }^{1}$ See also Giersch (1949). 
that the orientation of trade unions and employer orgarizations, which has up till now almost completely been a national one, will shift ever more towards a European focus, and that in the near future European bargaining processes may well become a reality.

\subsection{Economic integration and international trade theory}

The lack of interest in distributional consequences of trade liberalisation is paradoxical, since the modern theory of international trade was primarily developed to provide a more conclusive answer to the question of the distributional consequences of internaticnal trade and trade policy than classical trade theory had been able to give. Classical trade theory, with its emphasis on the labour theory of value, was ill-equipped to shed some light on this question. The publication of two serninal works by Swedish economists Heckscher and Ohlin at the beginning of this century, however, turned away economists' attention from the one-factor Ricardian world and greatly contributed to our knowledge of the distributional consequences of international trade and international trade policies.

The theory of Heckscher and Ohlin predicts a tendency towards international equalisation of factor returns under free trade. The most remarkable aspect of this result is due to the fact that the movement towards equalisation is caused by trade in commodities and that international factor mobility is therefore not required. Commodity movements, in Mundell's words, substitute for factor trade. Samuelson, in a formalisation of Heckscher-Ohlin theory, succeeded in the exact proof that under free trade, factor pricesi must necessarily be equalised, given, of course, that Heckscher-Ohlin assumptions hold.

Heckscher-Ohlin theory has been the dominant international trade theory paradigrn for several decades. The theory of international economic integration, whose first and most important occupation has been with commodity trade, has always tended to rely' heavily on insights from trade theory. Not surprisingly then, it has emphasised the forces which lead to a convergence of factor prices. As a result, the above mentioned lack. of interest in income distribution issues and in the effects of economic integration might. partly be explained by Heckscher-Ohlin dominance, with its emphasis on factor price equalising tendencies. Most experts on economic integration believed that factor price differentials between countries would automatically disappear when trade between these countries is liberalised. Indeed, under a variety of circumstances, the HeckscherOhlin trade model predicts that factor prices will be equalised under free trade. ${ }^{2}$

Closely linked up to the development of Heckscher-Ohlin theory is a result called the Stolper-Samuelson theorem. This theorem, which deals with the income distribution consequences of commodity price changes, predicts that the factor used intensively in the production of a certain commodity will gain in real terms if the relative price of that commodity increases, whereas the non-intensive factor will loose in real terms, and vice versa.

It would appear then, that Heckscher-Ohlin theory has put heavy emphasis on forces leading to a convergence of factor prices. Yet other branches of the literature, which have departed from the standard (restrictive) Heckscher-Ohlin trade model assumptions, have found numerous reasons for the persistence of factor price differentials. In

2 The notion of factor price equalisation being a credible outcome of an integration process strongly persists, even in the most modern treatments of the theory of economic integration. The reader compare, for instance, Molle (1990). 
this respect, two departures capable of explaining intersectoral factor price differentials between countries are worthy of mentioning. According to the first, intra-sectoral international differences in production functions could lead to internationally differentiated factor prices. ${ }^{3}$ For one thing, countries using different production technologies will only by coincidence have identical factor prices. In addition to that, differences in production technology have been shown to reverse the substitution relationship between commodity and factor trade into a complementary relationship, i.e., increases in commodity trade tend to go hand in hand with increases in factor movements. For the other thing, differences in elasticities of substitution may result in factor intensity reversals. The latter will in turn break down the one-to-one relationship between factor prices and commodity prices, a relationship which is crucial for the proof of factor price equalisation.

A second departure from the Heckscher-Ohlin model was formed by the possibility of imperfect intersectoral factor mobility. The implication of the introduction of imperfect intersectoral factor mobility is that factors will reallocate only as the retums exceed the costs. The consequence is that factor-price differentials will persist in the long-run. That possibility becomes more plausible in the extreme case of firm- of sector-specific capital. In such circumstances, factor prices are most unlikely to equalise, unless labour becomes highly mobile among countries. However, that labour would become highly mobile nationally as well as internationally is not very probable.

The distributional consequences of this imperfect intersectoral factor mobility are completely different from the predictions of the Heckscher-Ohlin model. Perfect mobility of labour implies that there will be no intersectoral wage differentials, and hence wages in all industries will react identically to any change in output prices. If labour is imperfectly mobile, that may no longer be true. In other words, the Stolper-Samuelson theorem breaks down. If the price of a certain sector's output rises -for instance because a levy is imposed on it-, wages may rise more in that particular sector than in others. If one assumes complete intersectoral labour immobility, wages in other sectors may not even rise at all. The interests of workers in different industries are then likely to diverge. Likewise, an increase in the capital stock of a certain industry may increase the wages in that industry more than in other industries. Similar conclusions apply to the effects of technological progress, wages rising relatively more in the industry which advances technically.

The two departures from Heckscher-Ohlin theory discussed above, have remained largely within the confines of the general equilibrium standard trade model. Recently, another element has been added to the development of international trade theory by the emergence of the so-called "new" trade theories, which put a heavy emphasis on the influence of imperfect competition (see for an excellent review Helpman and Krugman (1985)). Although much theoretical work in this field is still on its way, some tentative conclusions may, however, be drawn from this branch of theory. First, the introduction of external economies of scale may be inconsistent with factor price equalisation, but it need not interfere with the validity of the Stolper-Samuelson theorem provided "there

${ }^{3}$ Differences in production functions manifest themselves, among others, in different values for the elasticities of substitution. High substitution elasticities will limit the extent of wage increases, for production will be immediately rationalised as soon as wages are rising, for instance by a change in the factor proportions. With a low elasticity of substitution, on the contrary, there is but little chance of substituting capital for labour, so that wage increases do not necessarily entail a serious drop in the demand for labour. 
are not too much economies of scale". Second, the introduction of internal economies of scale, while being inconsistent with perfect competition on commodity markets, is not necessarily inconsistent with factor price equalisation and with the Stolper-Samuelson results (see Batra (1973), ch. 11). For factor price equalisation to hold, all that is necessary is the condition of identical technology in production. The Stolper-Samuelson result is in principle unaffected, too. Third and finally, the implications of imperfections on factor markets have hardly played any role whatsoever in the trade literature.

\subsection{Outline of the study}

The point of departure of this study is based on the standard model of international trade theory (for "classic" discussions of this model, see Jones (19965) and Woodland (1982)). As we saw above, that body of economics has produced valuable insights into issues of distributional nature. The study begins with a (selective) survey of these insights in Chapter 2. The controversies regarding the factor price equalisation theorem will be reviewed in that chapter. The discussion of this model is useful, since the factor price equalisation theorem has either been readily applied to the EC. by many authors, or has at least considered to describe effectively the tendencies in factor prices that might be expected after countries would join up in an economic integration scheme. We shall give a selective and predominantly chronological review of the vast number of publications that have dealt with factor price equalisation. In this respect, we shall primarily emphasise the contributions which were initiated by Samuelson's $(1948,1953)$ treatment of the topic. Attention is therefore focused on rather technical aspects of the debate, such as the question of invertibility of cost functions and the issue of dimensionality. It will turn out that the assumptions of the factor price equalisation model are very restrictive indeed, and a full equalisation of factor prices might be an unrealistic prediction. Hence, the best one can hope for probably is a tendency in the direction of factor price equalisation.

Chapter 2 also surveys some extensions of the basic factor price equalisation model. Two extensions will pass in review, notably the Stolper-Samuelson result (both in even and odd dimensions) and the standard specific factors model. Obviously, the standard factor price equalisation model has been extended in a great many more directions than the ones mentioned here. There are, however, two main reasons to confine the discussion to the topics mentioned. For one thing, a complete discussion of all conceivable extensions is prohibited for reasons of space. For the other, the extensions that we discuss will prove useful for a full comprehension of our own model that is the topic of Chapter 5.

Chapter 3 is devoted to a study of the temporal behaviour of wages in the most important founding members of the European Community. Using some crude data material pertaining to wage behaviour in NACE 2-digit industries since the $1960 \mathrm{~s}$, it will be shown that gross hourly wages, hourly labour costs and labour costs per manyear all tended to converge considerably when wages are converted with the aid of the purchasing power parity exchange rate. However, when wages are converted with the aid of the current exchange rate, this tendency is much less clear. A comparison of the EC and EFTA wage experiences will reveal that EFTA countries' wages also converged quite considerably.

Chapter 4 will elaborate upon some regularities that were found in the empirical literature. Most of the studies discussed in that chapter have one thing in common, which is their inability to capture the effects of an economic integration scheme. As far as their 
have been attempts to empirically measure the effects of economic integration on factor prices, these have been very ad hoc, if not artificial. As a result, the few studies that have tried to incorporate the effects of integration, are not based on optimising behaviour on the part of consumers and producers. This is serious shortcoming of the literature, since the factor price equalisation theorem and the related Stolper-Samuelson theorem are and have always been propositions concerning a general equilibrium economy.

In Chapter 5 we develop an empirically implementable model capable of predicting the wage effects of economic integration. The formulation of the model relies heavily on the duality results of international trade theory (cf. Woodland, 1982). Contrary to most existing empirical models in the field, this model does reflect optimising behaviour of both consumers and producers. Following some suggestions in the literature, the distributional effects are brought into the model through the use of both final and intermediate products, which may either be produced at home, in partner countries or in nonpartner countries. Another characteristic of the model is its assumption of complete intersectoral factor immobility in the short-run. It turns out, that the effects of geographically discriminating tariff liberalisation schemes may be rather ambiguous, indeed. Factors influencing the outcome are partial elasticities of factor substitution, factor endowments and the change of effective protection rates. The long-run version of the model resembles a Heckscher-Ohlin-Samuelson model with intermediate products.

In Chapter 6 the parameters of the model will be estimated using data from the National Accounts Statistics. The dual formulation of our theorefical model requires the estimation of cost functions, for which we shall use a translog functional form. These cost functions are estimated for 13 industrial sectors in the five main founding countries of the EC. The cost functions allow us to calculate Allen-Uzawa elasticities of substitution, which we shall need in Chapter 7 for our simulations of the effects of economic integration.

Chapter 7 reports the results of two simulation experiments. First of all, we shall discuss the wage effects of the customs union's anti-monde, i.e., we try to obtain estimates of wage changes that might occur if the custorns union would be undone in 1970 and if the EC countries would re-implernent the pre-customs union tariff rates. Secondly, we shall analyze the potential wage responses to the immediate implementation of the internal market programme in 1985. Needless to say, a comparison of the results of both simulation experirnents allows us to infer which of these two integration attempts produced the most significant wage effects. In this respect, it is first of all found that the wage effects of the customs union were considerable in that the creation of the customs urion seems to have resulted in a substantial amount of wage convergence. Secondly, we find that the expected wage effects of the completion of the internal market are negligible. Thus, a good deal of integration had already followed the implementation of the customs union. Chapter 8 , finally summarises the main statement of the thesis. 


\section{CHAPTER}

2

\section{FACTOR PRICES IN THE TRADITIONAL THEORY OF INTERNATIONAL TRADE}

\subsection{Introduction}

In the literature on economic integration, the factor price consequences of free trade areas and customs unions have always been discussed with the aid of the theory of international trade. More specifically, the integration literature has always either explicitly or implicitly assumed that the Heckscher-Ohlin-Samuelson results on factor price equalisation are directly applicable to most integration schemes. Therefore, a discussion of the basic factor price equalisation model, as well as some important departures from this model, could prove to be a useful exercise.

The purpose of this chapter is twofold. First, we shall discuss the standard factor price equalisation model as it has been put forward in the literature. Second, one extension and one departure from the basic assumptions of the the standard model, viz, the Stolper-Samuelson theorem and the specific-factor model, will be discussed at the end of this chapter. Although the standard model has been modified in a variety of other directions ${ }^{1}$, we shall confine the exposition to those elements which are usefuil for a full comprehension of our own model that will be the topic of Chapter 5 .

Until fairly recently most of the international trade literature was concerned with the possibility of factor price equalisation within the framework of the $2 \times 2$ model. However, in recent years attention has shifted to more general models of $n$ factors and $m$ commodities. The results of these models show that the conditions for factor price equalisation are very restrictive indeed. This has provoked two types of comments on the relevance of factor price equalisation theory. Haberler (1961, p. 37), for instance, expressed the view that "we must thus conclude that Lerner-Samuelson theory, though formally correct, rests on such restrictive and unrealistic assumptions that it can hardly be regarded as a valuable contribution to economic theory." In the same vein, Caves (1960, p. 92) evaluated the whole factor price equalisation controversy as "arid" and "an extreme example of inoperational theorizing". Chipman $(1965$, p. 479) on the other hand, believes

1 For the introduction of elements of imperfect competition, see Helpman and Krugman (1985). 
that it "represents probably the most complex and impressive theoretical structure that has yet been developed in economic thought".

What reasons are there for this diversity in views? To answer this question, we start with an introduction outlining the basic structure of Heckscher and Ohlin's arguments in section 2.2. That brings us to Samuelson's formal arguments for factor price equalisation and the theoretical contributions to which his analysis gave rise (section 2.3). Samuelson's contributions to the subject have almost completely set the tone of the debate. Many papers following his analysis have tended to focus on the importance of factor intensity reversals and the related issue of (global) invertibility of systems of cost functions. It appears that, although there are some flaws in Samuelson's first papers on the subject, his most important conclusions have stood up against criticism. Section 2.4 discusses some alternative treatments of the theorem which have surfaced in the literature more or less independently of Samuelson's papers. Section 2.5 is concerned with the issue of dimensionality, which has dominated a good deal of the theoretical literature on the subject. Section 2.6 discusses the celebrated Stolper-Samuelson theorem, which is a comparative-static extension of the factor price equalisation theorem. In section 2.7, finally, we investigate the role of inter-sectoral factor mobility, and outline the consequences of factor specificity. The concluding remarks follow in section 2.8 .

\subsection{Heckscher and Ohlin}

The factor price equalisation theorem is due to the work of Heckscher (1919). Contrary to many classical analyses, Heckscher's major purpose was to see how international trade works out on the (functional) distribution of income within trading nations. Due to its assumption of only one factor of production, classical trade theory was illequipped to provide a clear-cut answer to this question. Therefore, Heckscher extended the number of factors to three, viz. land, labour and capital. Another departure from classical trade theory was constituted by the assumption of identical techniques in use in the production process. Implicitly, Heckscher also assumed fixed coefficient production functions (see Mackscheidt (1967), p. 13). Also implicit was the assumption of identical preference structures in the trading countries. The remaining assumptions, however, were all in line with classical trade theory (e.g., complete internal mobility of production factors, and complete international immobility).

On the basis of these assumptions, Heckscher advanced two main theorems of international trade. The first maintained that if factor prices would be identical internationally, then goods should be produced with the same cost conditions everywhere. But this equality of production costs cannot give rise to international trade. Therefore differences in costs should arise from different distributions of production factors over the countries involved in trade. However, this conclusion strongly rests on the condition that factor intensities in the production of any good are unique, that is, factor intensities should differ from commodity to commodity. This is a crucial condition, because without it, no differences in comparative advantage would exist, whatever the endowments of countries with factors of production.

Since Heckscher did not elaborate upon this condition, his analysis of the effects of foreign trade on the behaviour of factor prices was to remain a rudimentary analysis, as we shall see soon. However, as countries will specialise in the production of commodities that make an intensive use of the abundant factor, the opening up of trade will tend to cause an equalisation of factor prices, the second main theorem, since the demand for the abundant factor increases at the expense of the demand for the scarce factor. Hence, 
after the adjustment process is complete, the scarce factor will become unemployed. Allowing international factor migration would cause the scarce factor to move abroad, so "when supply reactions are taken into account, foreign trade tends to increase the relative differences in the supply of factors of production in different countries" (Heckscher (1949), p. 293).

Ohlin, in his seminal work "Interregional and International Trade" extended and sharpened Heckscher's analysis. Although he agrees that factor endowments are the most prominent determinant of international trade, he also discusses other determinants, such as the influence of demand structures and mass production. According to Ohlin, international trade results from differences in prices, and these in turn depend on differences in demand and supply between regions. Demand for goods is determined by consumer preferences, whereas supply depends on the supply of factors of production and the techniques used in production. Here we see the three basic determinants that are traditionally distinguished in international trade theory. Since Ohlin assumed international equality of preference structures and absence of differences in techniques, he was able to reduce the causes of trade to factor endowments. ${ }^{2}$

As to the feedback of international trade on factor prices, Ohlin argued that international trade would merely tend to equalise factor prices internationally. Due to the existence of transport costs and other barriers to international trade, he did not believe in a complete equalisation of factor prices. But that is, as Samuelson pointed out, posing the wrong question, since the question is not whether imperfect mobility of goods will lead to equalisation of factor prices, but whether perfect mobility is capable of doing so, that is, whether full equalisation of commodity prices also results in complete equalisation of factor prices.

Ohlin's analysis did not stop with the arguments paraphrased above. In fact Ohlin's discussion of factor price equalisation is surrounded by so many qualifications, that "the logic and the consequences of his arguments escaped general notice" (Chipman (1966), p. 19). Although the various extensions made his analysis rather complex, we mention four other factors which he also explicitly considered.

Firstly, Ohlin paid explicit attention to mass-production, or what we would call economies of scale to day. In this respect, he concluded that these scale effects may both increase as well as decrease the possibility of factor price equalisation. The possibilities increase in the case scale effects tend to be complementary to comparative advantage conveyed by factor proportions. This means that when as a result of economies of scale the demand for the abundant factor increases, this will be an independent force contributing to factor price equalisation. On the other hand, whenever enterprises experiencing scale economies choose their location in countries where the most intensively used factor is not relatively abundant, factor prices might just as well diverge, because the demand for the relatively scarce factor increases in this case.

A second complicating factor Ohlin has introduced in his analysis of the feedback of trade on factor prices concerns the reversal of factor intensities, although there are reasons to believe that he did not understand the serious consequences of this point. Production functions with factor intensity reversals (FIRs) imply that factor intensities change in such a direction after a certain change in factor prices, that, for example, a labour-intensive commodity turns into a capital-intensive commodity. Ohlin believed

${ }^{2}$ Thus, contrary to what some believe, factor proportions theory is only a special case of Ohlin's theory. 
that FIRs are more likely in the case factors are close substitutes for one another. ${ }^{3}$ However, Ohlin considered FIRs explicitly as exception to the rule (Ohlin (1933), p. 100). In Heckscher's analysis, the problem of FIRs did not pose itself since he assumed fixed coefficients in production.

A third direction in which Ohlin extended his basic model was the introduction of different qualities of factors of production. International comparisons of factors of production reveal (some) differences in the quality of these factors. For instance, labour may be subdivided in skilled and unskilled labour, and capital can be split up according to the level of associated risk. Ohlin proposed to solve the problem of different qualities of factors in two ways. Firstly, he proposed to distinguish several groups of factors which would more or less be available in all countries. This procedure would entail that some factors of production would still not be comparable among countries, with all the obvious consequences for his factor price equalisation theorem. A second procedure would be to desaggregate factors in a very detailed way. However, this would entail the risk that certain factors would simply not be available in some countries, and would therefore also imply the impossibility of factor price equalisation in a number of instances.

A fourth extension of the basic model concerns the possibility of a variable factor supply. Factor supply is of course sensitive to (changes in) its remuneration. Because trade increases the price of the relatively abundant factor, the latter's price will rise, and this will, depending upon the value of the relevant supply elasticity, lead to an even "greater unevenness internationally as to the factor equipment, and a strengthening of the tendency to trade" (Ohlin (1933), p. 119).

\subsection{Samuelson's contributions}

In his celebrated (1949) contribution, as well as in the articles following this pathbreaking work, Samuelson proves that if commodity trade is able to equalise commodity prices, this would imply that factor prices are also equalised, given the usual assumptions as regards production technology, factor endowments and tastes. The beauty of his analysis is due to the fact that he was able to show that the factor price equalisation model is a very general model, not depending on the validity of the HeckscherOhlin theorem. In essence, his proof of factor price equalisation rests on showing that a system of two equations (for prices) has a unique solution. Samuelson in essence proved that under a certain set of assumptions, we are able to impose a functional relationship between (a vector of) commodity prices $p$ and (a vector of) factor prices $w$, such that $p$ $=c(w)$. If production functions would be identical internationally, this functional relationship would also be identical internationally. However, due to differences in factor endowments and consumer tastes, $\mathrm{p}$ and $\mathrm{w}$ would be different internationally, as long as there is no commodity trade or factor mobility between countries. The factor price equalisation theorem is concerned with the question whether an equalisation of $p$ as a result of commodity trade will also lead to an equalisation of $w$.

Samuelson's proof consisted of three steps. It was first assumed that factor prices are equal internationally. Second, the argument proceeded by proving equality of commodity prices in this case. Third, prove was reversed in that it was shown that equal com-

3 This is a mistake, as Mackscheidt (1967), p. 31, points out. In the case of limitational production functions FIRs are impossible, but this does not imply that greater substitution possibilities increase the likelihood of FIRs. 
modity prices must necessarily be accompanied by equal factor prices. Hence, if free trade equalises commodity prices it will also equalise factor prices.

Samuelson's most definitive proof appears in his (1953) article "Prices of Factors and Goods in General Equilibrium". Below, we shall present a summary of his argument as it has given rise to most comments that have been made in the literature.

To start with, let us assume there are $n$ commodities $Y_{i}$, which are produced by $m$ factors $x_{i j \cdot}$. The production functions, which may be written as $Y_{i}=f_{i}\left(x_{i 1}, \ldots, x_{i m}\right)$ are assumed to be homogenous of degree one. Factor prices $w_{i j}$ are given. The minimisation of cost, subject to the usual constraints, results in a total cost function for each commodity, $C_{i}=C_{i}\left(Y_{i}, w_{i 1}, \ldots, w_{i m}\right)$. Due to the assumption of linear homogeneity, this function may be written as $C_{i}=Y_{i} \cdot c_{i}\left(w_{i 1}, \ldots, w_{i m}\right)^{4}$, where $c_{i}(.$.$) , the unit cost function, is homo-$ geneous of degree one in its arguments. Minimum unit cost, $c_{i}=C_{i} / Y_{i}$ is constant and therefore equal to marginal cost and hence, under perfect competition, equal to the price, provided of course that the commodity under consideration is produced ${ }^{5}$ The assumptions of perfect competition on all markets and perfect inter-sectoral mobility of factors of production will ensure that factor prices are the same in all industries (i.e., $w_{i j}$ $=w_{\mathrm{j}}$, for all $j$ ). In vector notation this implies

$$
\underline{p} \leq \mathrm{c}(\underline{w})
$$

where $p$ is the commodity price vector and $w$ is the factor price vector.

If all commodities are produced, so that there is no complete specialisation, the equality sign in (2.1) will hold and each country will have the same function $c_{i}$, which means that there is a unique mapping from factor prices to commodity prices. However, in order to have factor price equalisation, the relationship must also be reversible, i.e., from commodity prices to factor prices. According to Sarnuelson (and also according to McKenzie (1955), p. 252), if this reversibility applies, then

".. without mentioning factor endowments of the country ..., we have uniquely determined its factor prices from knowledge of its commodity prices alone." (1953/54), pp. 5-6).

This comment, which states that factor price equalisation may be proved without reference to factor endowments, although formally correct, is rather confusing and doesn't give us the whole truth. Incidentally, Chipman (1965b) has shown that the mapping from factor prices to commodity prices is reversible when a) there is no complete specialisation in both countries, and b) when the system (2.1) is globally invertible. Chipman added to this that these conditions are sufficient, and not necessary (Chipman (1966), pp. 20-21). The first condition is a condition of diversification, the second is that of univalence of the cost functions and rules out the possibility of FIRs. ${ }^{6}$ Below, we shall discuss both conditions in greater detail.

Let us first focus on the diversification condition. Consider Figure 2.1 which is a graphical illustration of the two-by-two case, using unit value isoquants. Given the relative com-

\footnotetext{
${ }^{4}$ This is result is also due to Shephard (1953).

${ }^{5}$ Note that $c_{i}>p_{i}$ implies that a commodity will not be produced.

${ }^{6}$ Note that the problem of invertibility of (systems of cost functions did not pose itself in Heckscher's analysis since he assumed fixed coefficients in production. As Pearce (1971, p. 481) points out, cost functions which exhibit this property will always be invertible.
} 
modity price ratio, both commodities will be produced provided that a) there exists an isocost line which is tangential to both unit isoquants, and b) the overall factor endowment ratio lies between the capital-labour ratios of both commodities. Assume that the slope of the isocost line, or the factor price ratio $w / r$, is given by the line $P Q$. In that case points $R$ and $S$ are points of tangency with the isocost line. Assume next that the overall factor endowment ratio is given by the slope of the ray OA. Given the factor price ratio, the equilibrium capital-labour ratios of commodities $X$ and $Y$ are given by the slopes of the rays OR and OS, respectively. The cone which is formed by the points ROS is usually called the "cone of diversification" (McKenzie/Lerner/Chipman). The allocation of the factors of production may be obtained by completing a parallelogram at $\mathrm{W}$, which is the point of intersection of OA with the common isocost line PQ. Thus, the combinations of factors employed by the industries $\mathrm{X}$ and $\mathrm{Y}$ are given by points $\mathrm{U}$ and $\mathrm{V}$ respectively.

Now let us assume that factor endowments in the foreign country are given by the ray $\mathrm{OB}$. If $\mathrm{OB}$ lies inside the domestic diversification cone, factor prices will be identical in the home and foreign countries and there will be incomplete specialisation. The allocation of factors of production in the foreign country is then given by $\mathrm{U}^{\prime}$ and $\mathrm{V}^{\prime}$.

Figure 2.1 Unit isoquants

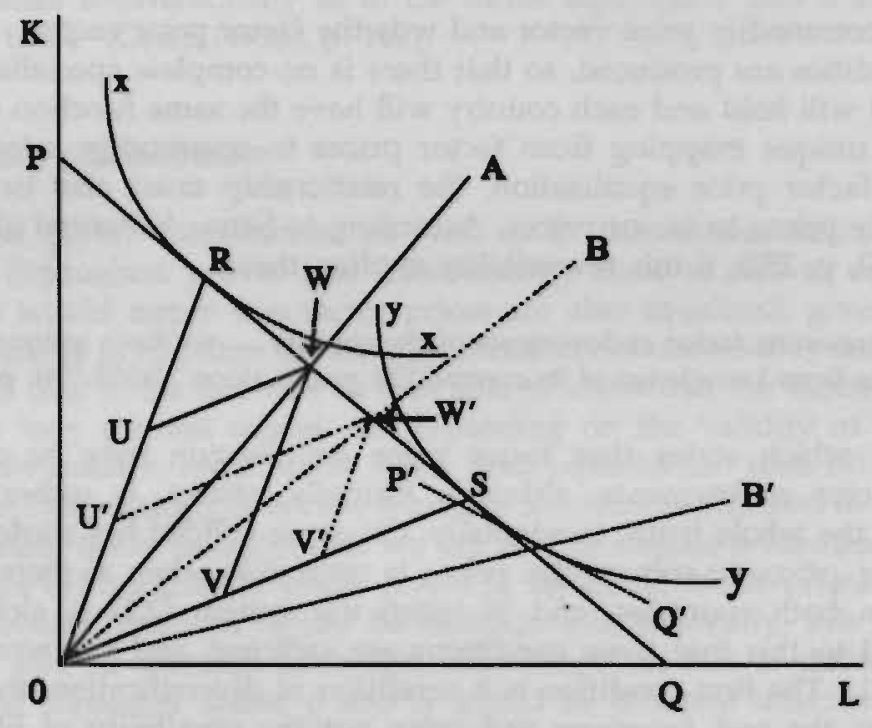

An interesting case comes up if it is assumed that the endowment ray of one of the two countries coincides with one of the two equilibrium capital-labour ratios. Suppose the foreign country's endowment ray coincides with the ray OS. Under those circumstances, the foreign country would completely specialise in the production of commodity $Y$. However, despite this complete specialisation, factor prices will still be identical internationally. That conclusion changes, however, if the endowment ray in one of the two countries lies outside the diversification cone, as is the case with the ray $\mathrm{OB}^{\prime}$. Under these circumstances, the foreign country will completely specialise in commodity $Y$, and factor prices will not be equalised internationally since $P Q$ does not represent an equili- 
brium factor price vector in the foreign country. The factor price vector which does result in full employment of all factors in the foreign country is given by $\mathrm{P}^{\prime} \mathrm{Q}$ '.

The conclusion is therefore that factor prices can only be equalised internationally if the factor endowment rays are in the same cone of diversification. The larger this cone, the greater the chances for international factor price equalisation.

Let us now discuss the question of the invertibility or univalence of the cost function. This question is of extreme importance for the overall argument, since the whole factor price equalisation debate is centred around the problem of whether or not the equation system (2.1) has a single, unique solution. Samuelson, in a discussion of the two-by-two case, maintained that the assumption of non-reversal of factor intensities would ensure a non-vanishing Jacobian determinant of the equation system and therefore uniqueness of its solution. Most of the pre-1965 literature followed Samuelson in this assumption of non-reversal of factor intensities. However, as Gale and Nikaido (1965) showed using a counterexample, the theorem concerning the non-vanishing Jacobian is not correct. Gale and Nikaido also provided a correct set of conditions which are not met in the presence of a factor intensity reversal and which we shall discuss any moment. The attack on factor price equalisation through the possibility of FIRs is therefore not without foundation, since FIRs preclude invertibility of the cost function.

It may be useful to devote some space to a brief discussion of the whole debate on the conditions for univalence. ${ }^{7}$ Samuelson's discussion of uniqueness made use of the implicit function theorem. To use his own words (1949, p. 191-192)

".. two suitably continuous equations of the form $w_{1}\left(y_{1}, y_{2}\right)=w_{2}\left(y_{1}, y_{2}\right)=0$, possessing a solution $\left(y_{1}^{0}, y_{2}^{0}\right)$ cannot have any other solution provided that

$$
\Delta=\left|\begin{array}{cc}
\frac{\partial w_{1}}{\partial y_{1}} & \frac{\partial w_{1}}{\partial y_{2}} \\
\frac{\partial w_{2}}{\partial y_{1}} & \frac{\partial w_{2}}{\partial y_{2}}
\end{array}\right| \neq 0^{\prime \prime 8}
$$

This condition of a non-vanishing Jacobian determinant, as is well-known by now, is a condition for local invertibility of cost functions and does by no means guarantee a global univalence of those functions. By 1953, Samuelson seems to have realised his error as the following quote goes to prove (1953, p. 16)

".... the non-vanishing Jacobian and the usual version of the implicit function theorem does not guarantee uniqueness of the solution in the large, but only that multiple solutions - if they exist - will be locally isolated..... . However, all of the elements of the Jacobian .... were eventually one-signed; and this condition combined with the non-vanishing determinant, turns out to be sufficient to guarantee uniqueness in the large."

7 See also Ethier (1984), and Takayama (1973).

8 Note that in terms of our cost functions for sector 1 and 2, the Jacobian determinant is formed from the derivatives $\partial c_{i} / \partial w_{i j}, i, j=1,2$. 
Thus Samuelson in fact adds a condition of non-negativity of the elements of the Jacobian determinant in order for global univalence to be assured. This non-negativity is, of course, motivated by sound economic reasons, since in the cost minimization process, only non-negative factor prices are usually considered to be of greatest interest to the researcher. However, using a counterexample and exploiting the (row) stochastic property of the Jacobian, McKenzie (1955) was able to prove that Samuelson had also erred in the development of this theorem.

In the celebrated Gale-Nikaido (1965) article, it was shown where Samuelson had gone wrong in deriving his theorem. Gale and Nikaido pointed out that Samuelson's condition in fact came to saying that "univalence holds if the upper left-hand principal minors of the Jacobian do not vanish in a region" $(1965$, p. 82). Using a counterexample, they then went on to show that this need not be true, even in simple two dimensional regions. Gale and Nikaido also offered the correct theorem: a sufficient condition for global univalence of a differentiable mapping $\mathrm{p}=\mathrm{c}(\mathrm{w})$, where both $\mathrm{p}$ and $\mathrm{w}$ are $n$ dimensional vectors, is that the Jacobian matrix will only have positive principal minors, or, in other words

$$
c_{\mathrm{ii}}>0, \quad\left|\begin{array}{ll}
c_{11} & c_{12} \\
c_{21} & c_{22}
\end{array}\right|>0 \quad\left|\begin{array}{ll}
c_{11} \cdots & c_{1 n} \\
\vdots & \vdots \\
c_{n 1} \cdots & c_{n n}
\end{array}\right|>0
$$

As their counterexample shows, the Gale-Nikaido condition does not ensure nonnegativity of w. To obtain non-negativity one should also invoke Kuhn's (1959) uniqueness theorem, which states that, under certain conditions, it is possible to find a unique $\mathrm{w}$ for any $\mathrm{p}$, that is to find a unique inverse function. Kuhn's theorem in fact proves the possibility of the existence of various combinations of factor endowments for which, under competitive conditions, a complete diversification of production will be likely.

It is interesting to apply the Gale-Nikaido conditions to Samuelson's two-by-two example, since this will reveal that the problem of invertibility did not pose itself due to Samuelson's strong factor intensity assumption. Assume once more that the economy produces $X$ and $Y$, using $K$ and $L$. Let $L_{x}$ be the labour input in sector $X$, and so on. The Gale-Nikaido condition for this $2 \times 2$ case is simply

$$
c_{11}>0 \text {, and }\left|\begin{array}{ll}
c_{11} & c_{12} \\
c_{21} & c_{22}
\end{array}\right|>0
$$

Note that due to Shephard's lemma, $c_{\mathrm{ij}}$ represents the amount of the $j$-th input to produce the $i$-th output, or, e.g., $c_{11}=L_{x} / x$. Thus, the Gale-Nikaido condition implies the following

$$
\begin{aligned}
& c_{11}=L_{x} / X>0, \\
& c_{22}=K_{y} / Y>0,
\end{aligned}
$$

and

$$
c_{11} c_{22}-c_{12} c_{21}=\left(L_{x} / X\right) \cdot\left(K_{y} / X\right)-\left(K_{x} / X\right) \cdot\left(L_{y} / Y\right)>0
$$

The first two conditions are, of course, easily met. The third may be rewritten as 
$k_{y}-k_{x}>0$ for all factor prices,

where $k_{y}=K_{y} / L_{y}$, and so on. Since the names of industries $X$ and $Y$ may be used interchangeably, the Gale-Nikaido condition thus simply implies the condition for non-reversibility of production factors. In the two-by-two case, this requires imperfect specialisation (complete diversification). To put things differently, in the exceptional case of a two-by-two model, local univalence implies global univalence. If the dimension of the model is lifted beyond the two-by-two framework, however, local univalence does no longer also guarantee global univalence (the reverse is, needless to say, always true).

The Gale-Nikaido conditions resulted in a number of contributions in which the conditions for global univalence are examined more closely. One extension was put forward by Inada (1971), who emphasized that the Gale-Nikaido univalence theorem is only one of many univalence theorems. To be more precise, the Gale-Nikaido conditions are concerned with the case where the inverse of the production coefficient matrix has the Minkowski property, i.e., is a matrix whose inverse has positive diagonal elements and nonpositive off-diagonal elements. However, as Inada points out, confining the discussion to Minkowski matrices seriously restricts it to a very special case. Another generalisation of factor price equalisation theory might be obtained by studying matrices with the Metzler property, that is, matrices with negative diagonal elements and non-negative off-diagonal elements. Obviously, Minkowski and Metzler matrices are two sides of the same coin, so, in Inada's words (p. 220) "if we concern ourselves only with the first one, there is left unexplored an area as big as that explored".

As was pointed out by Gale and Nikaido, a Minkowski matrix has only positive principal minors, that is, a Minkowski matrix is a so-called P-matrix. Inada proves that if a matrix is PN, i.e., whenever its principal minors of odd orders are positive and its principal minors of even order are negative, then global univalence of the system of cost functions will hold as well. Thus the Gale-Nikaido conditions are only one set of conditions which guarantee univalence, while Inada's conditions may produce exactly the same result.

In a second line of contributions following the Gale-Nikaido paper, efforts were made to weaken their conditions, taking into account the fact that these conditions are only sufficient for global univalence. In this respect, Mas-Colell's (1979) paper points out that the non-vanishing Jacobian determinant may be sufficient after all if one considers only strictly positive factor prices. In those circumstances, the requirement that all principal minors of order less than $\mathrm{n}$ are positive is in fact too strong. When, in addition to strictly positive factor prices, it is also assumed that all commodity prices are strictly positive, global univalence obtains if the determinant of factor shares is non-zero.

\subsection{Alternative approaches to factor price equalisation}

Apart from Samuelson, several authors have played important roles in the factor price equalisation debate. In some cases their arguments were of decisive influence in the debate, so it is interesting to give these approaches a separate treatment. In this section, we shall discuss the more formal treatments by McKenzie (1955), and Uzawa (1959), as well as some popular graphical proofs that may be found in the literature, notably the contributions of Schweinberger (1975), Mussa (1979), Neary (1978) and Woodland (1982), Travis (1965), and Dixit and Norman (1980). 
McKenzie (1955) used linear activity analysis to solve the same problem as Samuelson. Like the latter he approaches the problem of factor price equalisation through deriving a unique relationship between commodity and factor prices. McKenzie's most important assumptions are that each country is confronted with a fixed vector of factor endowments, absence of impediments to trade, and linear homogeneous production functions which are identical between countries.

Using the competitive equilibrium zero profit conditions and the definition of linear independence of vectors, McKenzie is able to prove what he calls "theorem I" which implies

"...that if there is a competitive equilibrium, free of specialisation, with $\mathrm{P}$ (a given price vector $\mathrm{P}-\mathrm{AvM}$ ) and equalised factor prices, there cannot be another equilibrium with $\mathrm{P}$ and factor prices not equalised." (1955, p. 243)

Like Samuelson, McKenzie proves factor price equalisation without making direct and explicit reference to factor endowments (1955, p. 252). However, like Samuelson, McKenzie explicitly invoked the assumptions of complete diversification and absence of FIRs. Utilizing an $n$-dimensional framework, McKenzie discussed the conditions which should be met for factor endowments to lie in the interior of the same cone of diversification. Hence, his assumptions of complete diversification and non-cross overs of factor intensities simply imply the restrictions which should underlie the supply of factors of production if factor price equalisation is to occur at all.

Uzawa (1959) approached the factor price equalisation theorem as a problem of welfare economics. Central to his analysis is the world welfare function, which he maximizes under three different trade regimes, viz. 1) complete absence of international trade; 2) international trade in commodities; and, 3) international trade in both commodities and factors of production. Uzawa proves that if welfare could be increased by moving from regime 2) to regime 3 ), factor prices could not have been equalised under regime 2), or in his own words:

"The present study shows ... that the complete factor-price equalization occurs only in the cases in which the factor endowments in the countries are precisely the ones that arise in an equilibrium position of world trade when factors of production as well as the commodities can move internationally". (1959, p. 448).

Uzawa concluded that a "complete equalization of the prices of the factors of production is rather unlikely to occur" (p. 449), since this would require that "neither of both countries has great comparative advantage in any commodity" (p. 465), "that is, complete factor price equalization will occur if and only if the initial factor endowments in all cuuntries are the same" (p. 468). Therefore, Uzawa postulates that a partial equalisation of factor prices would be the more likely result. Chipman considered this "difficult to accept" (1966, p. 43), since his assumptions are overly strong, especially where they concern the nature of Uzawa's excess demand functions for commodities. However, in defence of Uzawa it should be noted that the latter in fact introduced the concept of "integrated equilibrium", a concept central to the modern treatments like those of Dixit and Norman (1980) and Helpman and Krugman (1985). ${ }^{9}$ In addition to that, Uzawa discusses factor price e'yualisation by explicitly considering not only the supply of commodi-

${ }^{9}$ We shall discuss these approaches soon. 
ties, but also their demand in a two country world. Thus, contrary to Samuelson c.s. commodity prices are endogenous in his analysis in stead of given exogenously. Finally, Uzawa's employment vectors of production factors are endogenously determined, which is not the case in the models of Dixit and Norman (see below).

In the previous section we presented a graphical proof for factor price equalisation in terms of the K-L space. Following Schweinberger (1975), Mussa (1979) and Neary (1978) the theorem may also be proved in terms of the dual of the production function model. The dual of the production function model makes use of the unit cost functions, which may be plotted in the $\mathrm{w}$-r space in stead of in the K-L space. This representation of the factor price equalisation theorem is discussed here, since it has become increasingly popular (see Woodland's (1982) textbook, which discusses most theorems in terms of the dual of the production function model). Figure 2.2 is such a diagram showing the unit cost functions $c^{x}$ and $c^{y}$ for sector $X$ and $Y$ respectively.

Figure 2.2 Unit cost functions

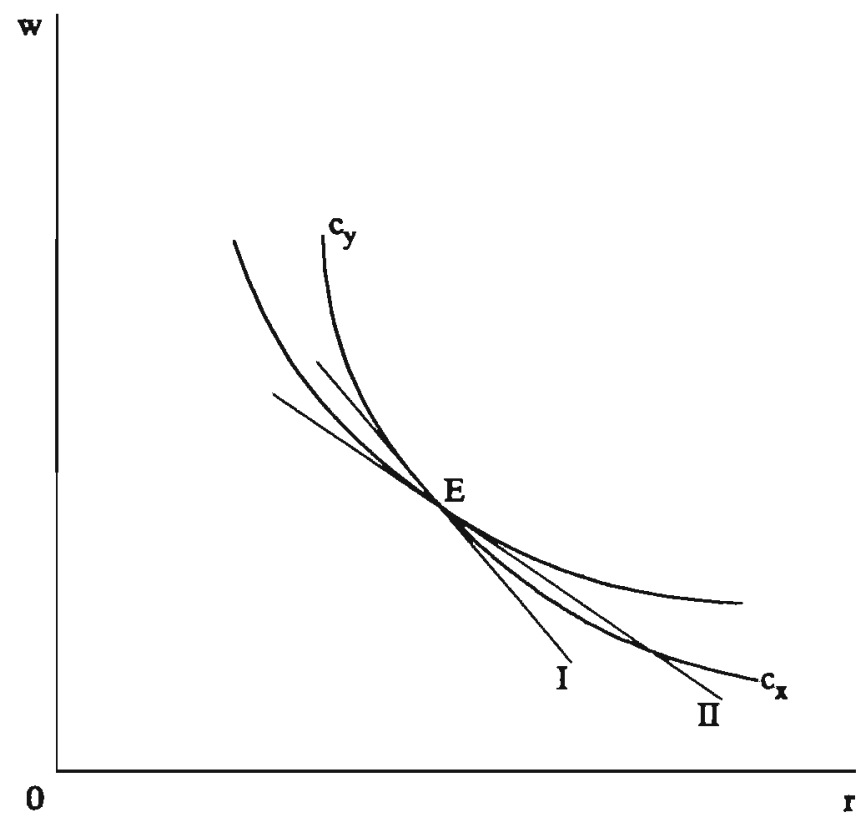

Note that the slope of the unit cost curve at any point gives the capital-labour ratio in that industry. If the production functions are linear-homogeneous then the cost functions will be linear-homogeneous as well, so that relative factor intensities are independent of the factor price ratio. The feasible set of factor prices is bounded by the line $c_{y} E c_{x}$ and includes all points to the right and above this boundary. Evidently, if one would assume identical production functions and international equalised commodity prices then the same unit cost functions would apply to all trading countries.

If the endowment ratio of these trading countries are less than the slope of $c_{y}$ at $\mathrm{E}$ and more than the slope of $c_{x}$ at $E$, then a competitive trade equilibrium with equalised 
factor prices is possible. Thus, in this case the cone of diversification may be obtained from the slopes, of the lines I and II.

Dixit and Norman (1980) have extended the concept of diversification cones to a two country world. They criticized the conventional analysis of factor price equalisation on the ground that its result is "conditional on exogenous product prices" (p. 52). In other words, the objection they raise is that the analysis starts from a one country world with given product prices. Rather than treating these product prices as given, they suggest that international trade theory should explain these product prices. Since commodity prices are usually treated as exogenous, the proof of factor price equalisation rests on a description of production technology and production equilibrium in one country only in stead of two. In addition to that, they point out that the diversification cones are themselves dependent on relative commodity prices.

In their analysis, Dixit and Norman assume that all the usual assumptions as regards production technology, preferences, inter-sectoral mobility of factors of production, etc. are met. The kernel of their arguments, which is based on Travis' discussion of the factor allocation box, may be paraphrased with the aid of Figure $2.3{ }^{10}$ The factor allocation box in that figure considers the production equilibrium in the entire (i.e., two country) world. Assume that world supply of capital and labour are given. The total availability of these factors of production determines the magnitude of the box. As usual, the commodity price ratio determines uniquely the factor price ratio $w / r$. The latter determines the capital-labour ratios in both industries. These $\mathrm{K} / \mathrm{L}$ ratios are equal in both countries due to the assumption of identical production technology in both sectors. The home country capital-labour ratios are drawn as rays through the lower-left origin $\mathrm{O}_{\mathrm{H}}$, foreign country capital-labour ratios as rays through the upper-right origin $\mathrm{O}_{\mathrm{F}}$. Note that commodity $\mathrm{X}$ is produced with a capital-intensive production technique. The capital-labour ratios form a parallelogram $\mathrm{O}_{\mathrm{H}} \mathrm{AO}_{\mathrm{F}} \mathrm{BO}_{\mathrm{H}}$.

The next step in the analysis involves the construction of a set of factor price equalisation on the basis of a hypothetical construct known as the "integrated equilibrium". The integrated equilibrium is the resource allocation in the world that would dominate if both gocds and factors were perfectly mobile across all countries of the world. Subsequently, the proof of factor price equalisation is obtained by answering the question whether it is possible to achieve the same resource allocation of factors if the latter are completely immobile internationally. If this turns out to be the case, international trade in commodities will equalise factor prices. Dixit and Norman show that, in the standard $2 \times 2$ model of international trade there are a great deal of resource allocations for which this is possible. This set of resource allocations, which replicate the integrated equilibrium under the assumption of complete international factor immobility, is what they label the "factor price equalisation set".11

In Figure 2.3, the parallelogram $\mathrm{O}_{\mathrm{H}} \mathrm{AO}_{\mathrm{F}} \mathrm{BO}_{\mathrm{H}}$ is the graphical representation of this factor price equalisation set. Note that the factor price equalisation set is never empty, since it always has the diagonal as element, i.e., it is always possible to achieve interna-

${ }^{10}$ The figure is slightly adapted and may be found in Dixit and Norman (1980), p. 112, or in Helpman and Krugman (1985), p. 16.

11 Travis (1964, chapters 1 and 2) called this set the "factor price equalisation region". Note that the size and shape of the parallelogram are primarily influenced by two factors. First, differences in factor intensities are important. The larger their differences, the larger will be the magnitude of the parallelogram in relation to the size of the box. Second, the endowments are important, since they determine the size of the box. 
tional factor price equalisation through perfect mobility of factors of production. Also note, that the size of the parallelogram vis-a-vis the size of the box in principle determines the likelihood of factor price equalisation; the larger the parallelogram, the larger will be the likelihood of factor price equalisation.

Figure 2.3 The factor allocation box in a $2 \times 2 \times 2$ world

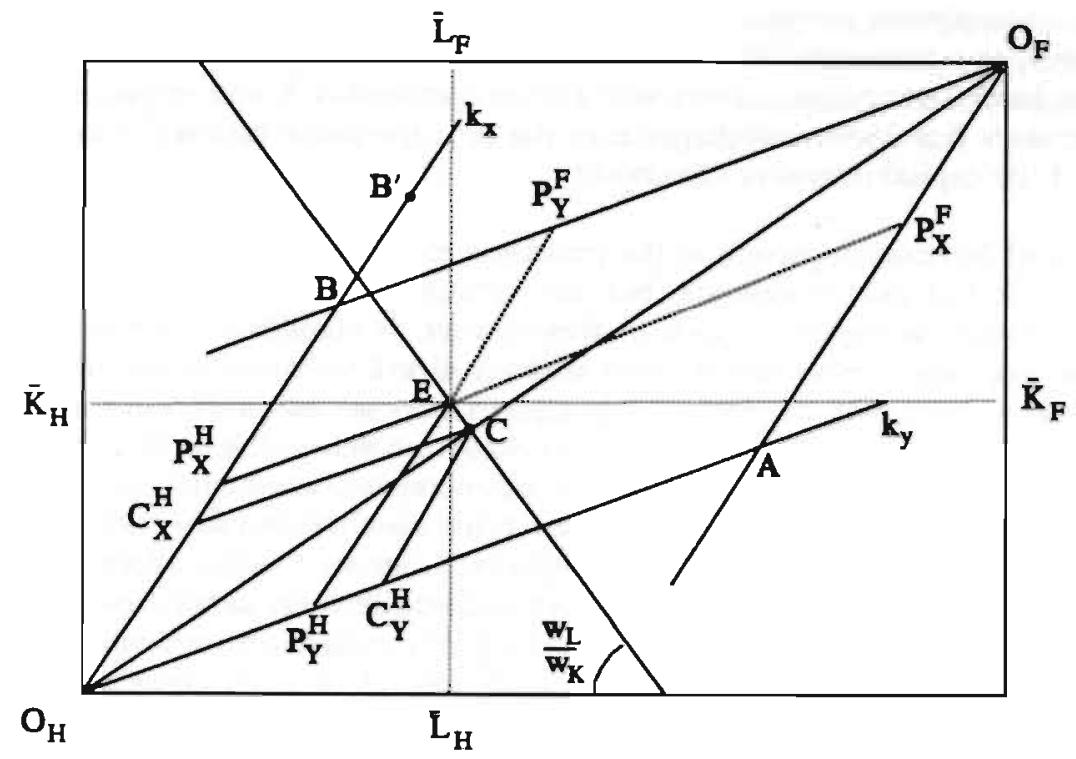

Having established the proof of factor price equalisation, Dixit and Norman proceed to outline the basic characteristics of the allocation both at home and abroad. The integrated equilibrium employment level in sector $X$, the capital-intensive sector, is given by $\mathrm{O}_{\mathrm{H}} \mathrm{B}$, whereas the integrated equilibrium level of employment in sector $\mathrm{Y}$ is given by $\mathrm{O}_{\mathrm{H}} \mathrm{A}$. Let $\mathrm{E}$ be the endowment point of the home country (measured from the origin $\mathrm{O}_{\mathrm{H}}$ ) and the foreign country (measured from the origin $\mathrm{O}_{\mathrm{F}}$ ). In the integrated equilibrium, the total world production of commodity $X$ is measured by the distance $\mathrm{O}_{H} \mathrm{~B}$ (or $\mathrm{O}_{\mathrm{F}} \mathrm{A}$ ), whereas world production of commodity $\mathrm{Y}$ is measured by $\mathrm{O}_{\mathrm{H}} \mathrm{A}$ (or $\mathrm{O}_{\mathrm{F}} \mathrm{B}$ ). Now if endowments are given by $\mathrm{E}$, it is possible to decompose production of both goods into a part that is produced at home and a part that is produced abroad. Graphically, this decomposition is accomplished by the construction of two components which are parallel to $\mathrm{O}_{\mathrm{H}} \mathrm{B}$ and $\mathrm{O}_{\mathrm{H}} \mathrm{A}$. At $\mathrm{E}$, the home country production of commodity $\mathrm{X}$ equals $\mathrm{O}_{\mathrm{H}} \mathrm{P}_{\mathrm{X}}^{\mathrm{H}}$, whereas the foreign production of this commodity is measured by $\mathrm{O}_{\mathrm{F}} \mathrm{P}_{\mathrm{X}}^{\mathrm{F}}$. Hence, the home country's share in world production is $\mathrm{O}_{\mathrm{H}} \mathrm{P}_{x}^{\mathrm{H}} / \mathrm{O}_{\mathrm{H}} \mathrm{B}$. Similarly, the home country production of commodity $\mathrm{Y}$ equals $\mathrm{O}_{\mathrm{H}} \mathrm{P}_{\mathrm{Y}}^{\mathrm{F}}$, and the foreign country production of $\mathrm{Y}$ is $\mathrm{O}_{\mathrm{F}} \mathrm{P}_{\mathrm{Y}}^{\mathrm{F}}$. Thus, the home country's share in world production of commodity $\mathrm{Y}$ equals $\mathrm{O}_{\mathrm{H}} \mathrm{P}_{\mathrm{Y}}^{\mathrm{F}} / \mathrm{O}_{\mathrm{H}} \mathrm{A}$. Note that production points outside the parallelogram, such as $\mathrm{B}^{\prime}$, are not feasible, since they would imply that the home country's share in world production of one or both commodities would exceed one. Clearly, such an allocation would be most peculiar. The same is true for all points outside the parallelogram. 
The Dixit and Norman approach to general equilibrium and factor price equalisation also enables one to predict the trade flows in the world, as Helpman and Krugman (1985) have shown. Given the assumptions of identical and homothetic tastes, identical technology, and identical factor prices (given by the slope of the line passing through $\mathrm{E}$ with slope $w_{L} / w_{K}$ ), one can construct point $C$, where the diagonal of the box intersects with the factor price line. Point $\mathrm{C}$ gives an indication of a country's relative GDP level. For example, $\mathrm{O}_{\mathrm{H}} \mathrm{C} / \mathrm{CO}_{\mathrm{F}}$ is the home country's GDP level relative to the foreign country's GDP level. Construction of another parallelogram gives the home (and foreign) country's consumption points of both goods. Hence $\mathrm{O}_{\mathrm{H}} \mathrm{C}_{X}^{\mathrm{H}}$ measures the home country's consumption of commodity $\mathrm{X}$ and $\mathrm{O}_{\mathrm{H}} \mathrm{C}_{Y}^{\mathrm{H}}$ gives that country's consumption of commodity $Y$. Evidently, the home country will export commodity $X$ and import commodity $Y$. Note that, since $\mathrm{E}$ is above the diagonal of the box, the home country is capital-rich and will export the capital-intensive commodity.

The Dixit and Norman approach to the problems of general equilibrium and factor price equalisation is not only ingenious, but has certain distinct advantages in comparison with the univalence approach, too. In this respect, it should be noted that Dixit and Norman prove factor price equalisation without direct reference to the univalence problem. In concentrating on the factor price equalisation set the problem of univalence can be ignored, since all allocations in the interior of the set will lead to diversification of production. Outside the factor price equalisation region, production is not diversified, and univalence (and consequently also factor price equalisation) does not hold.

Another important advantage of the approach lies in the treatment of commodity prices as endogenous variables. If the integrated equilibrium factor price ratio is given by $w_{L} / w_{K}$, then simple application of the marginal productivity principle goes to prove that commodity prices are also equalised. If $\mathrm{P}_{X}^{\mathrm{H}}$ and $\mathrm{P}_{Y}^{\mathrm{H}}$ are the home country production points, and $\mathrm{P}_{X}^{\mathrm{F}}$ and $\mathrm{P}_{Y}^{\mathrm{F}}$ the foreign country's production points, and if factors of production are rewarded the value of their marginal products, then it follows that the equality of physical marginal productivities in the optimal production points in combination with the equalised factor prices (ratios), must necessarily be accompanied by equal commodity price (ratios).

The endogeneity of commodity prices, as well as the focus on a two-country integrated equilibrium constitutes an important improvement upon earlier studies of the subject indeed. However, it should also be noted, that Dixit and Norman do not analyze the properties of the equilibrium sectoral employment vectors. In fact, these sectoral employment vectors are determined exogenously. Consequently, the concept of the "factor price equalisation set" remains as hypothetical as the concept of the "integrated equilibrium" itself. To put it differently, the size of the factor price equalisation set is for a large part determined by the exogenously specified employment vectors. Obviously, it is a questionable procedure to determine the magnitude of the set in such a fashion, and the sectoral employment vectors should be endogenously determined. If that is not properly done, the model of production is not able to predict how large the factor price equalisation set actually will be, and how "similar" factor endowments should be in order to have factor price equalisation.

Wu (1988) has attempted to solve this problem by developing a model in which one of the employment vectors is exogenously determined and the other endogenously. Thus, he is able to show, how sufficiently similar factor endowments should be if there is to be factor price equalisation, or how dissimilar they should be in order to prevent it. Hence, he is able to construct actual diversification cones, which are not mere hypothetical constructs. Contrary to Dixit and Norman's analysis, the size of these diversification 
cones depends on all the primitives of the economy, i.e., their size depends on both technology and preferences. Incidentally, Wu also proves that even when factor prices are not equalised, trade may bring about a convergence of factor prices. However, this result is conditional on some special assumptions regarding demand conditions, since it only applies if there is "balanced demand" in both countries. ${ }^{12}$ However, if there is no "balanced demand" factor prices may actually diverge as a result of trade.

Another disadvantage of the technique employed by Dixit and Norman concerns the fact that their analysis does not lend itself very easily to a generalisation beyond the two-country, two-factor model. The Edgeworth box technique only applies to a twocountry, two-factor world, which may, needless to say, unnecessarily restrict the focus of the analysis on too simple cases. For nxnxn generalisations of the factor price equalisation theorem, the univalence approach does remain a very useful device.

\subsection{Generalisation to higher dimensions}

In this section some of the assumptions underlying the factor price equalisation theorem will be relaxed. The basic model of international trade has often been criticized for its reliance on a two-by-two-by-twoness, and an important question one must ask is whether an increase in dimensions leaves the basic conclusions in tact.

As to the increase in the number of countries, we can be very brief, since it is wellknown that such an extension does not invalidate the basic conclusions of the model. The appropriate procedure to prove factor price equalisation would in this case be to compare any two sets of countries and to establish factor price equalisation for these countries and extending this result to any other combination of two countries.

Turn to the second generalisation now, where the model is extended to an $n x n$ framework. All that is required for factor price equalisation in this case is that the diversification condition and the conditions for global univalence of systems of cost functions are fulfilled. Since these conditions have been discussed at great length in the previous sections, we need not ponder on them here.

It is useful to stress, that the Heckscher-Ohlin theorem need not be invalidated as well in this $n x n$ case, although some suitable qualifications to the theorem will be required. Basically, when generalised to higher (but even) dimensions, the HeckscherOhlin theorem states that a country will export the services of the abundant factor and import the services of the scarce factor. Speaking with Leamer (1984, p. 15) the higher dimension generalisation of the theorem "properly emphasizes the point that it is factor services that are being exchanged through trade. Commodities serve only as bundles within which factor services are wrapped." This (slight) modification of the HeckscherOhlin theorem is also known as the "Heckscher-Ohlin-Vanek" theorem.

Let us next consider the case where there are more factors than commodities. As is wellknown by now, factor price equalisation is impossible, or at least very unlikely in this case. Strictly speaking, as Woodland (1982) points out, factor price equalisation may still be possible when factors outnumber commodities, since the theorem puts no limits on the number of goods nor on the number of factors. However, it can be shown that in this case commodity price equalisation is compatible with an arbitrary number of factor

\footnotetext{
${ }^{12}$ Needless to say, Wu's results are also highly dependent on the exogenously specified employment vector.
} 
price ratios. This implies that under these circumstances factor price equalisation would be a pure coincidence. In mathematical terms one could say that the system of equations determining the factor prices is under-determined. This result becomes intuitive if one considers the case of one good and two factors. Under those circumstances, one commodity price should determine two factor prices, which is impossible without further information. In the two-by-two model, two commodity prices were all that was needed to determine the two factor prices. In a model where the number of commodities is less than the number of factors, demand and supply conditions on the factor markets must be taken into consideration in order to determine the factor prices. In other words, the commodity market equilibrium conditions do no longer suffice to solve uniquely for factor prices, and factor market equilibrium conditions should be invoked to establish equilibrium factor prices.

This conclusion is readily extended to the more general two good, three factor model. Suppose that commodity $\mathrm{X}$ and $\mathrm{Y}$ are produced with labour, capital and land, and that country $I$ is relatively well endowed with capital and land. The ratio of capital to labour and capital to land will be higher in both sectors in country I, implying (much) higher productivities of labour and land in that country. In country II the productivity of capital will be higher. Although total production costs and commodity prices will be equalised in all sectors in both countries after trade is opened up, the relatively high costs for land and labour need not disappear in country I, since they could be matched by relatively low capital costs. In country II, where capital costs are high, the relatively low costs or land and labour can also remain without any consequences for commodity prices. This implies that, although commodity prices will be equalised after trade is taken up, factor price differentials need not necessarily decrease. In case one would increase the number of factors even more than just three, it is obvious that the probability for factor price equalisation will grow smaller. Thus, one must conclude that factor price equalisation is likely to be a coincidence when factors outnumber commodities. In this connection, Woodland (1982, p. 75) remarks that the cone of diversification "degenerates" in case factors outnumber commodities.

Let us turn to the case where the number of goods exceeds the number of factors. From an analytical point of view, this case is considered to be the most interesting one by the majority of theorists. The results for this case are more or less confusing, at least at first sight. This confusion is probably the result of the fact that production may become indeterminate. Melvin (1968) showed this production indeterminacy in a $3 \times 2$ model. Using the Edgeworth box, he demonstrated that under these circumstances, the production possibility surface is a so-called "ruled" surface, which means that every point on the production possibility surface lies on a line of which every point is on the production surface, that is, there is an infinite number of combinations of outputs of the three goods consistent with any given factor price ratio.

As far as the possibility of factor price equalisation when commodities outnumber factors is concerned, Chipman gives a good summary of the views adhered to by different authors:

"Tinbergen (1949) held that factor price equalisation would be less likely, Samuelson (1949) that it would be more likely; and Meade (1950) that it would be equally likely". (1966, p. 31). 
"... the question of whether adding more commodities makes factor price equalisation less likely reduces to the question of whether it makes specialisation more likely ..... and one can expect the possibility of specialisation to be the normal outcome .... . (R)elative numbers of factors and products turn out to be very crucial; and .... this result seems artificial". (Ibid, p. 34).

In mathematical terms one might say that the equation system determining factor prices is over-determined when there more goods than factors. Some authors have suggested, that the consequences of this overdeterminacy for factor prices depend crucially on the role of specialisation in the model. Samuelson (1953/54), for instance, solves the problem of over-determinacy by assuming that some industries will shut down, causing the system to be determinate again. However, he does not point out what the precise consequences of the specialisation are for the factor prices. Tinbergen (1949) also believes that specialisation will be necessary.

Figure 2.4 The Lerner diagram for $n>m$

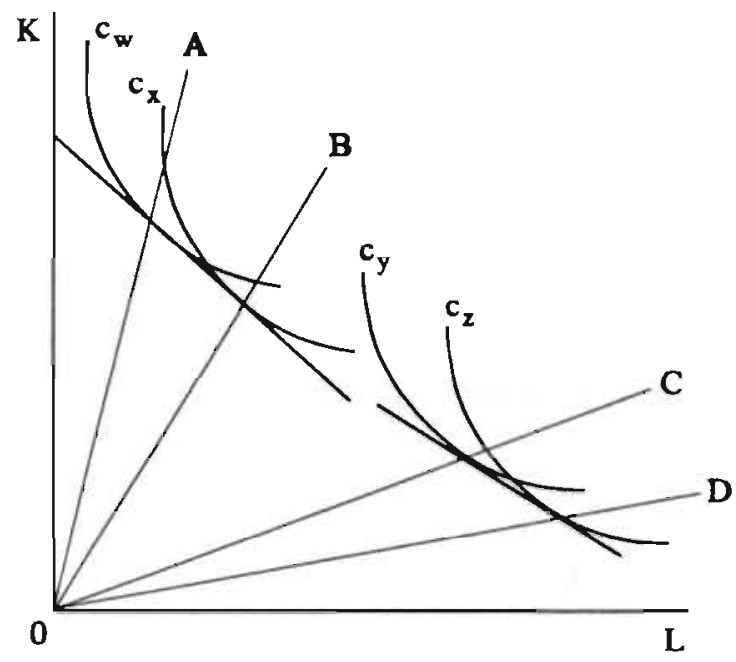

Much of the controversy, however, can again be resolved with the aid of the concept of the cone of diversification, a concept introduced by Lerner and McKenzie, as we saw before. Let us use the familiar Lerner diagram to prove the point. In Figure 2.4 four unit cost isoquants $c_{\mathrm{w}}, \mathrm{c}_{\mathrm{x}}, \mathrm{c}_{\mathrm{y}}, \mathrm{c}_{\mathrm{z}}$ are shown, which are no longer tangent to the one and the same factor price line. Cones of diversification are solely defined by common tangents to two isoquants if the number of factors equals two. In Figure 2.4, two cones of diversification are shown, viz. $A O B$ on one hand and $C O D$ on the other. Assume that the endowment ray for country $I$ is in the interior of $A O B$, and that the endowment ray for country II is in the interior of COD. In that case, country I will produce only commodities $W$ and $X$, whereas country II will only produce $Y$ and $Z$. Obviously, HeckscherOhlin theory is satisfied, since country I will tend to specialise in relatively capital-intensive goods, whereas country II will tend to specialise in relatively labour-intensive goods. Also note, that factor prices are clearly not equalised. 
Another possibility arises, when both countries' endowment rays are in the interior of the same cone of diversification, for instance, in $\mathrm{AOB}$. Both countries will then specialise in the production of commodities $W$ and $X$, even if country $I$ is relatively well endowed with capital. Both countries would import commodities $Y$ and $Z$ from the rest of the world. Consequently, imports from the rest of the world would be more labour-intensive than their exports. However, the precise amount of production of $W$ and $X$ would not be determinate in both countries. This indeterminacy of production might be avoided, if both countries would completely specialise, which might happen, as we showed above, when their endowment rays would lie in the interior of different diversification cones. This would imply that each country would specialise in the production of only two goods and that no two countries would produce the same two goods. However, in that case, factor price equalisation is impossible.

The same point may be proven with the aid of the isocost functions in the factor price diagram. In Figure 2.5 we have depicted the four unit cost functions of the same commodities in the $w-r$ space. Note that the feasible set of factor prices is bounded by the line $C_{w} A B C c_{z}$ and again includes all points to the right and above this line. If the endowment ratios of both countries are less than the slope of $C_{W}$ at $A$ and more than the slope of $c_{z}$ at $C$ then if a competitive equilibrium occurs at one of the vertices $A, B$ or $C$ only two out of four commodities may be produced. This situation corresponds to the case where endowments are in the same cone of diversification.

If the endowment ratio of a country happens to be in tangent to a cost function between two vertices, then it follows that the country will completely specialise in one good. This case corresponds to the situation where an endowment ratio coincides with a factor intensity ratio.

Figure 2.5 The factor price diagram for $n>m$

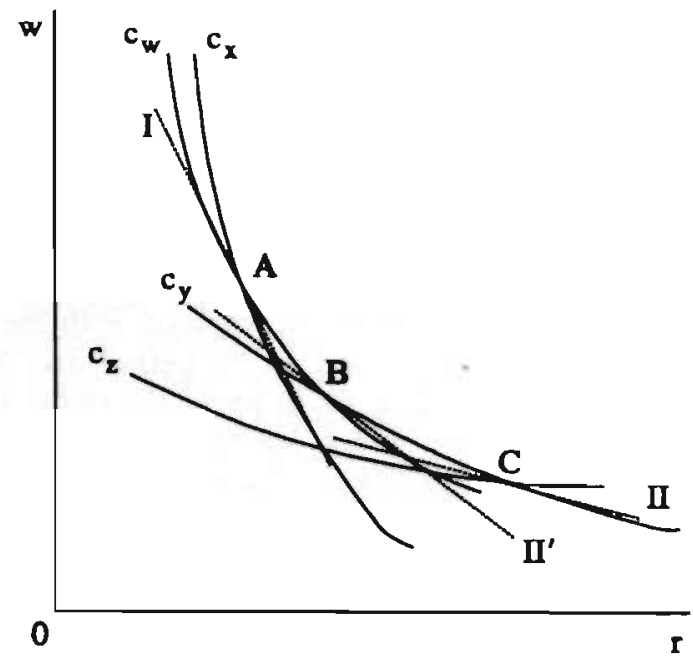

Now let countries I and II have endowment ratios which are represented by the slopes of lines I and II respectively. As a result, country I will specialise in the production of 
both $W$ and $X$, whereas country II will specialise in commodities $Y$ and $Z$. Hence, production is determinate. However, factor prices are not equalised, since country I will end up in point $A$ and country II will end up in point B.

An interesting case arises, when country I's endowment ratio is given by the slope of line I and country II's endowment ratio by the slope of line II'. In that case country I will produce $W$ and $X$ and country II will produce commodities $X$ and $Y$. Country I will export $W$ and country II will export $Y$. However, both countries will also export $X$ to the rest of the world. Hence, there is a production indeterminacy. This situation corresponds to the case where the two cones of diversification have a common boundary. Schweinberger (1975) has proven that under these circumstances, a determinate production equilibrium is possible only when $X$ is a pure intermediate good.

Figure 2.6 Production indeterminacy in the $n>m$ factor price equalisation model

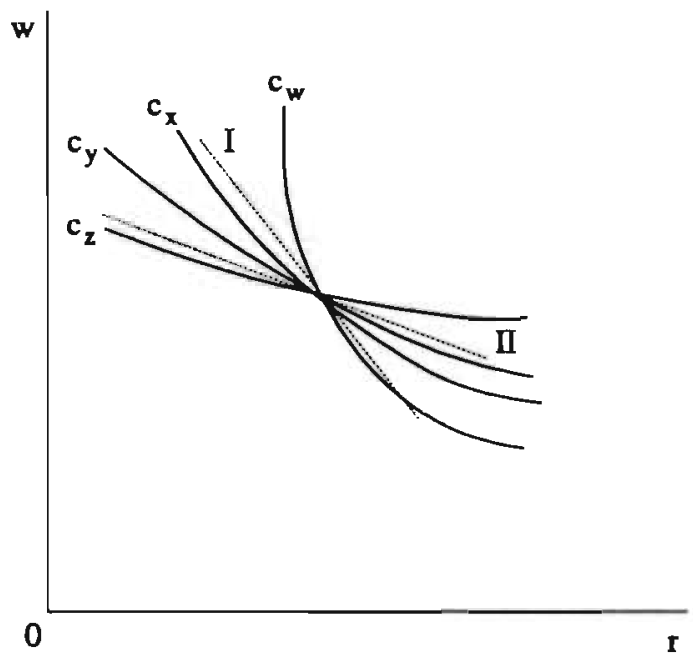

A final interesting case arises when there is only one vertex. This case is depicted in Figure 2.6. If the endowment ratio of country I is given by the slope of line I and that of country II by the slope of line II, factor prices will clearly be equalised. However, since both countries will produce all four commodities, production and trade will be indeterminate. To put it in perspective, in this case a large number of possible factor use combinations is consistent with a single factor price ratio and therefore a large number of output combinations are consistent with a competitive equilibrium. Also note that only two prices are independent, since the existence of only two cost functions is all that is required to determine the factor price ratio. The implication is that the prices of the two remaining goods must equal their cost at this factor price ratio if they are to be produced at all, i.e., supply and demand for only two goods determine the price for all goods. The consequence of all this is that a change in the price of one good would require a change in the price of at least two other goods if all goods are still to be produced.

Dixit and Norman (1980) have seriously criticized the traditional analysis of the case of more goods than factors. In their own words, they have the following problems with this analysis 
"On the one hand, it might appear that we have too many equations, one for each good, in too few unknowns, the factor prices. This raises the danger of inconsistency. On the other hand, it might appear that, at fixed output prices, optimum production choices must involve specialization, thereby removing any guarantee that the two courtries produce sufficiently many goods in common, which is the basis of the univalence discussions. The trouble with both these points is that no account is taken of the fact that the product price vector that is relevant to the discussion is the trade equilibrium one". (1980, p. 114, italics added).

Figure 2.7 The three commodity, two factor box diagram

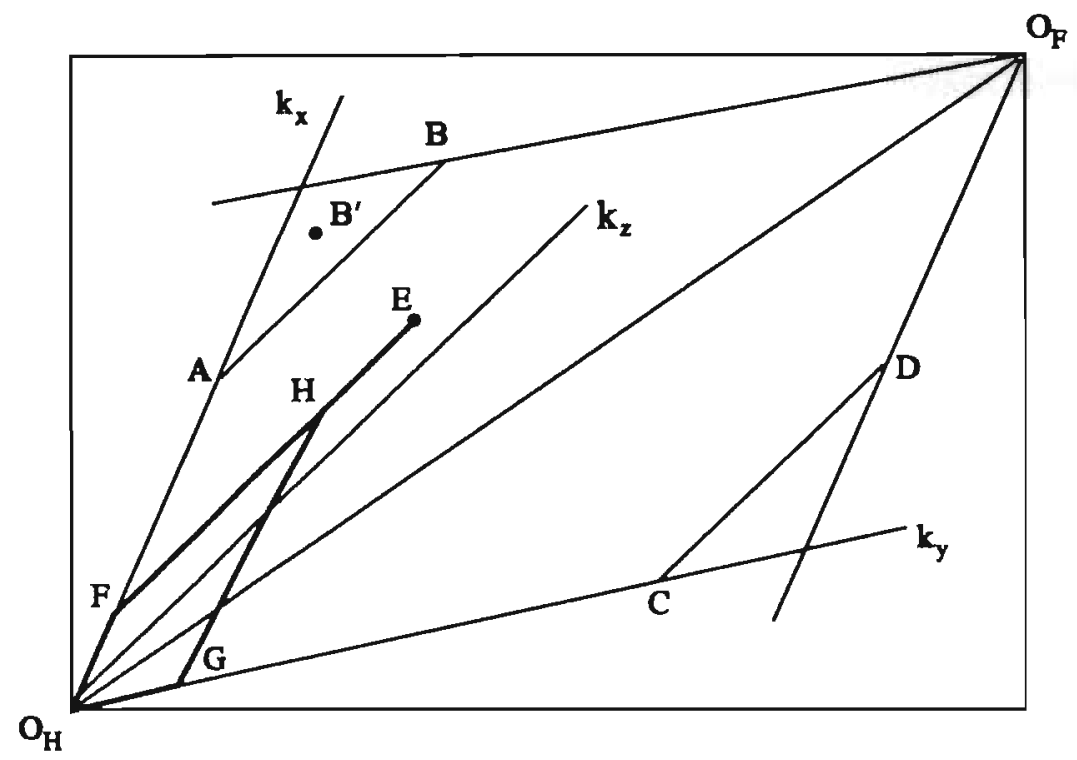

In their analysis of the case of more goods than factors, they use the factor allocation box to show that factor price equalisation is still possible. If one assumes three commodities and two factors, for instance, then there will be three sectoral employment vectors that must be considered to solve the problem of factor price equalisation. The trick is to investigate how adding a third commodity changes the factor price equalisation set. In Figure 2.7 we have plotted the employment vectors in an allocation box. Analogous to the two commodity, two factor case, the integrated equilibrium employment vectors add up to the length of the diagonal of the box.

As is easily seen, the parallelogram becomes polyhedral when the number of commodities exceeds two. In Figure 2.7, this polyhedral is given by $\mathrm{O}_{\mathrm{H}} \mathrm{CDO}_{\mathrm{F}} \mathrm{BAO}_{\mathrm{H}}$. Again, the conclusion must be that as long as the endowment point is in the interior of polyhedral, factor price equalisation must prevail. Interestingly, the indeterminacy of production comes up once more. For instance, if $E$ is the endowment point, full employment may occur if goods $X$ and $Z$ are produced, with employment vectors $\mathrm{O}_{H} F$ and $F E$, respectively. On the other hand, the home country may also produce all three goods and still have factor market equilibrium, when the employment vectors are $\mathrm{O}_{\mathrm{H}} \mathrm{G}$, $\mathrm{GH}$ and 
or, in matrix terms, $\boldsymbol{\theta} . \mathbf{w}=p$, where $\boldsymbol{\theta}$ denotes the $(2 \times 2)$ matrix of factor shares, $\mathbf{w}$ denotes the factor price vector, and $\mathrm{p}$ is the commodity price vector. The solution of the system, i.e., $\underline{w}=\Theta^{-1} . \underline{p}$, gives the following reduced form equations for $\hat{w}$ and $\hat{r}$

$$
\hat{\mathrm{w}}=\frac{\theta_{2 \mathrm{r}}}{|\boldsymbol{\theta}|} \cdot \hat{\mathrm{p}}_{1}>0
$$

and

$$
\hat{\mathbf{r}}=-\frac{\theta_{2 \mathrm{w}}}{|\boldsymbol{\theta}|} \cdot \hat{\mathrm{P}}_{1}<0
$$

where $|\Theta|$ is the determinant of the matrix of factor shares. Eqs. (2.12)-(2.13) show that labour and capital have conflicting interests. Also, the direction of the relative change of factor prices depends on whether or not the sign of $|\theta| \geqslant 0$. The sign of this determinant is determined as follows

$$
\operatorname{sign}|\theta|=\operatorname{sign}\left(\theta_{2 r} \theta_{1 w}-\theta_{1 r} \theta_{2 w}\right)=\theta_{1 w} \cdot \theta_{2 w} \text {.w.r. }\left(k_{2}-k_{1}\right)
$$

with $\mathrm{k}_{\mathrm{i}}=\mathrm{K}_{\mathrm{i}} / \mathrm{L}_{\mathrm{i}}(i=1,2)=$ the capital intensity in sector $i$. If sector 1 is labour intensive, i.e., $k_{2}>k_{1}$, a tariff will tend to increase the nominal wage rate and decrease the rental rate. This is the essence of the Stolper-Samuelson theorem. ${ }^{13}$

It is also possible to predict the change in real factor prices, viz. by subtracting $\hat{\mathrm{p}}_{1}$ from both sides in both equations. This will give

$$
\hat{\mathrm{w}}-\hat{\mathrm{p}}_{1}=\frac{\theta_{1 \mathrm{r}}}{\boldsymbol{\Theta}_{1}} \cdot \hat{\mathrm{p}}_{1}>0
$$

and

$$
\hat{\mathbf{r}}-\hat{\mathrm{p}}_{1}=-\frac{\theta_{1 \mathrm{w}}}{|\theta|} \cdot \hat{\mathrm{p}}_{1}<0
$$

which is obtained using the fact that $\theta_{i \mathrm{w}}+\theta_{\mathrm{ir}}=1$ in both sectors. Hence, if sector 1 is labour-intensive, the increase in the nominal wage rate due to a tariff also constitutes an increase in the real reward for labour, whereas capital will loose in real terms. One will find that $\hat{w}>\hat{p}_{1}>\hat{p}_{2}=0>\hat{r}$. Jones (1965) called this result the "magnification effect".

${ }^{13}$ In their original paper, Stolper and Samuelson (1941) stated the theorem with reference to the Heckscher-Ohlin theorem. According to their version of the theorem, a tariff will tend to favour the scarce factor and will be harmful to the interests of the owners of the abundant factor. However, formulating the theorem in terms of equations (2.10)-(2.13), a tariff will favour the intensive factor of the sector where the tariff is imposed and harm the other factor. Contrary to the Stolper and Samuelson, the formulation in the text does not depend on the validity of the Heckscher-Ohlin theorem, and therefore has a greater validity. In the trade literature both alternative formulations may be found. 
Figure 2.8 The Stolper-Samuelson theorem in the factor price diagram

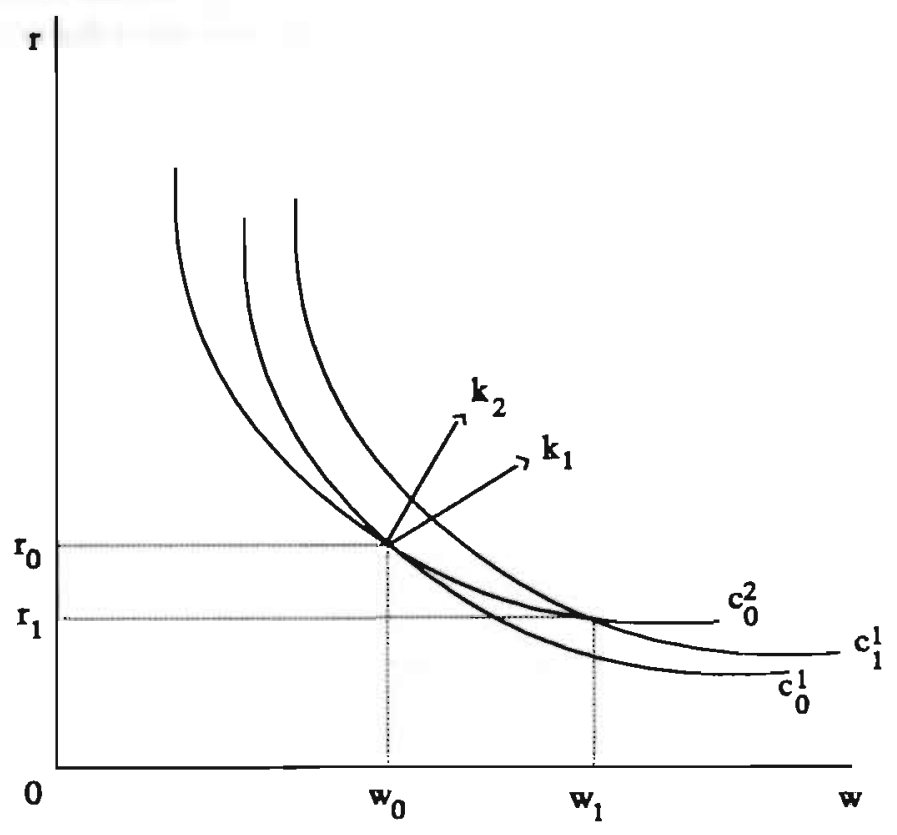

Graphically, the theorem has been illustrated in a variety of ways. In Figure 2.8, we use the factor price diagram to show the effects of the tariff in sector $1 .{ }^{14}$ The diagram shows the graphical representations of the unit cost functions for both sectors, viz. the isocost curves. Let both commodities be produced, so that production is diversified. Then, initial equilibrium is at $\left(w_{0}, r_{0}\right)$. Note that the cost minimising input vectors in both sectors are given by $k_{1}$ and $k_{2}$, which are the gradients of $c_{1}(w)$ and $c_{2}(w)$ evaluated at $\left(w_{0}, r_{0}\right)$. Thus, using Shephard's lemma, the slopes of the isocost curves imply that sector 2 utilises a capital-intensive technique. These sectoral employment vectors, as we have seen in the previous chapter, form a cone of diversification. The increase in $\mathrm{p}_{1}$ is indicated by a shift to the right of the isocost curve from $c_{0}^{1}$ to $c_{1}^{1}$. As can easily be observed, the new equilibrium occurs at $\left(w_{1}, r_{1}\right)$, where the wage rate has increased and the rental rate has decreased. Since the change in $w$ and $r$ are proportionally higher than the change in $\mathrm{p}_{1}$, the nominal changes in the factor rewards will at the same time be changes in their real magnitudes.

It should be noted, that the question of specialisation in production is also relevant for the validity of the Stolper-Samuelson theorem. Assume that there is complete diversification of production in the initial equilibrium, so both commodities are produced at the outset. Then, as we saw in the previous chapter, there will normally be factor price equalisation. However, depending on the location of the factor endowment point and on the magnitude of the change in the commodity price, specialisation might very well occur, as Woodland (1977, pp. 61-62) has shown. Needless to say, if this happens, factor price equalisation might easily break down. When complete specialisation in sector 1 oc-

\footnotetext{
${ }^{14}$ Similar diagrams may be found in Woodland (1977, 1982) and Mussa (1979).
} 
curs, however, a further increase in the relative price of commodity 1 will no longer have an effect on the ratio of marginal productivities of labour and capital. It has been shown that in beyond the point of complete specialisation both factors will become better off after an increase of the relative price of commodity 1 (see, e.g., Chacholiades (1978), p. 489).

In addition to the issue of specialisation, it should be remarked, that the theorem may also be endangered if there are FIRs. Note that if these occur, $k_{1}=k_{2}$, which implies that the determinant $|\boldsymbol{\theta}|=0$. Consequently, the factor price reactions following the imposition of a tariff in one sector are not defined. As a result, anything might happen with nominal and real factor rewards.

\subsubsection{Generalisations of the theorem}

The Stolper-Samuelson theorem discussed in the previous subsection is closely linked up to the $2 x 2$ world. In this subsection we shall be concerned with attempts that have been made to generalise the Stolper-Samuelson theorem. Like the problem of factor price equalisation, higher dimensional generalisations of the theorem may reflect situations of even dimensions on one hand and odd dimensions on the other. Both kinds of generalisation will be discussed below.

In a sense, the question of the generalisation of the Stolper-Samuelson theorem is concerned with a non-issue. As Jones and Scheinkman (1977) correctly point out, the magnification effect is valid regardless the number of commodities, at least as long as there is no joint production. This assertion may be established simply by inspection of the marginal cost condition contained in equations ( 2.8 and 2.9). For all commodities produced, prices will equal unit cost. As a result, price changes are the weighted average of factor price changes, and the change in prices takes an intermediate value between two extreme changes in factor prices. This relationship is, needless to say, true for all commodities which are produced in positive quantities, and independent of the dimensionality of the model. But this general formulation of the Stolper-Samuelson theorem is almost tautological, and one would wish to determine which factors will gain and which will loose. Thus, the question is which restrictions should be placed on the specification of technology, in order to find the above generalisation of the Stolper-Samuelson theorem.

Let us start with the case of (even) nxn models. Like before, it will be assumed that, given the factor price vector $w=\left(w_{1}, \ldots, w_{n}\right)$, producers will select those input-output coefficients $\mathrm{a}_{\mathrm{ij}}$ such that the cost of producing commodity $j$ is minimised. Therefore, $\mathrm{a}_{\mathrm{ij}}=$ $a_{i j}(w)$, where $a_{i j}$ is homogeneous of degree zero; also, as before, $c^{i}=\Sigma_{j} w_{j} a_{i j}(w)=c^{i}(w)$ is the unit cost function which will be assumed to be linearly homogeneous and concave in factor prices. Moreover, note that $\partial c^{i} / \partial w_{j}=a_{i j}$ (Shephard's lemma). Under perfect competition, a commodity market equilibrium with all goods produced requires $\underline{p}=$ $c(w)$. The Jacobian matrix is again defined by $A \equiv\left[a_{i j}\right]=\partial c / \partial w$.

The classic reference concerning the generalisation of the Stolper-Samuelson theorem is Chipman (1969). According to the latter, the theorem may be valid locally and globally. The conditions for the validity of both the local and the global version are the same as those for local vs. global univalence of systems of cost functions. Since these conditions have been explored in the previous chapter, we shall not dwell upon them here too long. To recall, local validity implies validity of the theorem in the neighbourhood of a specified equilibrium. The requirement is that the Jacobian determinant of the system of cost functions will not vanish at this equilibrium point. Global validity implies that the 
association between commodity and factor prices will hold for all conceivable $\mathrm{p}$ and $\mathrm{w}$, or that all principal minors of the Jacobian matrix are strictly positive.

Chipman distinguished two versions of the generalised Stolper-Samuelson theorem. According to the first, the weak version of the theorem, an increase in the price of the $i$ th commodity gives rise to an unambiguous rise in the price of the $i$-th factor. This requires that $\boldsymbol{\Theta}^{-1}$ possesses all diagonal elements larger than unity. According to the second version of the theorem, the strong version, an increase in the price of the $i$-th commodity will result in both an unambiguous increase in the price of the $i$-th factor as well as an unambiguous decline in the prices of all other factors. ${ }^{15}$ This happens if and only if the inverse matrix $\Theta^{-1}$ has all diagonal elements in excess of unity and all off-diagonal elements negative. Needless to say, the strong version of the theorem implies the weak one, since if all off-diagonal elements of $\boldsymbol{\Theta}^{-1}$ are negative, then its diagonal elements must necessarily exceed unity by virtue of the property that $\boldsymbol{\theta}^{-1}$ (like $\theta$ ) is a stochastic matrix.

Most of the generalisations of the Stolper-Samuelson theorem have mainly been concerned with the strong version of the theorem. As may be recalled from our discussion of factor price equalisation, row stochastic matrices possessing diagonal elements larger than unity and negative off-diagonal elements are usually called Minkowski matrices. Lots of effort has been devoted to finding the necessary and sufficient conditions for $\boldsymbol{\theta}^{-1}$ to meet the required conditions. ${ }^{16}$ These discussions have shown that, when the conditions for global concavity of the cost function are met, even generalisations of the Stolper-Samuelson theorem are in principle possible, and $\boldsymbol{\Theta}^{-1}$ will be Minkowski, i.e., an increase in any commodity price, all other commodity prices held constant, will tend to increase the reward of a corresponding factor in real terms and lower the rewards of all other factors.

Ethier (1985) has suggested a different way of generalising the Stolper-Samuelson theorem. His argument is as follows. Consider an initial equilibrium with a price vector $p^{0}$ and factor price vector $w^{0}$. These vectors are denoted $p^{1}$ and $w^{1}$ in another equilibrium. It follows that $\mathrm{p}^{0}=A\left(w^{0}\right) w^{0}$ and that $p^{1}=A\left(w^{1}\right) w^{1}$. Invoking the mean-value theorem, Ethier is able to prove that $\left(w^{1}-w^{0}\right) A(\bar{w})\left(p^{1}-p^{0}\right)>0$, i.e., there is a positive correlation between the elements of the vector $\left(w^{1}-w^{0}\right)$ and the elements of $A(\bar{w})\left(p^{1}-p^{0}\right)$, or, alternatively, between elements of $\left(w^{1}-w^{9}\right) A(\bar{w})$ and $\left(p^{1}-p^{0}\right)$. The implication of this is that, on average, high values of $\left(w^{1}-w^{0}\right)$ on the one hand go hand in hand with high values of $\left(p^{1}-p^{0}\right)$ and $a_{i j}$, or both, on the other hand. Thus, changes in commodity prices will generally lead to high increases in the rewards of those factors which are used intensively by the goods whose prices have risen.

This result is intuitively appealing since it is very general: it does not depend on the dimensionality of the model, nor upon special restrictions on technology. Needless to say, this formulation of the Stolper-Samuelson theorem is weaker than the original theorem, and strips it of some of its analytical rigor.

15 Note that several variants of this strong Stolper-Samuelson criterion have surfaced in the trade literature. Uekawa (1971) has defined the strong version as an increase in the price of the $i$-th commodity giving rise to an unambiguous increase in the price of the $i$-th factor price, while the proportionate increase of this factor price increase exceeds all other factor price changes. Therefore, Uekawa allows the other factor price changes to be positive. It will be recalled from the previous chapter, that Inada (1971) distinguished a strong version of the theorem in which all diagonal elements of $\Theta$ were negative and all off-diagonal elements were positive.

16 See, a.o., Chipman (1969), Kemp and Wegge (1969), Uekawa (1971), Wegge and Kemp (1969), Inada (1971), Uekawa, Kemp and Wegge (1973), Ethier (1974) and Chang (1979). 
General and weak results can also be obtained for real factor rewards. Consider for example a good which is produced in both the initial and the terminal equilibrium. Assume that this good is produces by $m$ factors of production, whose reward is $w_{m}$. The price of this good, call it good 1, must be equal to or above unit cost, so $\theta_{11} \hat{w}_{1}+\ldots .+$ $\theta_{1 m} \hat{w}_{m} \leq \hat{p}_{1}$. The $\theta_{i j}$ are all positive and sum up to unity. Therefore, this equation implies that there must exist some factor, call it the first, for which $\hat{w}_{1} \geq \hat{p}_{1}>0=\hat{p}_{2}=\ldots$ $=\hat{p}_{n}$. Hence, a rise in the price of a good that was initially produced must raise the reward of at least one factor in terms of this good and lower it in terms of no good. For the second good, which we also assume to be produced in the initial and terminal equilibrium, we must have $\theta_{21} \hat{w}_{1}+\ldots .+\theta_{2 m} \hat{w}_{m} \leq \hat{p}_{2}=0$. Since $\hat{w}_{1}>0$ and $\theta_{12}>0$, and since $\theta_{\mathrm{j} 2}>0$ and sum up to unity, it follows that there exists some factor reward, call it the second, which must fall, i.e., $\hat{w}_{2}<0=\hat{p}_{2}=\ldots=\hat{p}_{n}<\hat{p}_{1}$. In conclusion, every good is friend to some factor and enemy to another.

Note that the Stolper-Samuelson theorem formulated in this way is weaker than the original formulation, since we leave open the possibility that factor 1 does not gain in real terms, i.e., that its reward might remain constant in terms of $\hat{p}_{1}$. However, if it is assumed that factor owners spend their income on at least two goods and that at least two factors are used in the production of all goods, the probability that factor 1 will be faced with a constant real income in terms of $\hat{p}_{1}$ is very low, indeed.

The weak results concerning the general validity of the Stolper-Samuelson theorem are, as we noted above, quite insensitive to the dimensionality of the model. As Ethier (1985) points out, increasing the number of commodities does not invalidate the theorem. The same is in principle true for the situation wherein factors outnumber goods. However, it is possible that the duality results must be changed when dimensions become odd. In the case of factors outnumbering goods, for instance, the result that each good is friend to a certain factor and enemy to another factor remains true, but the result that each factor has a distinct enemy can no longer be uphold. In addition, factor prices can no longer be solved in this case without invoking the factor market equilibrium conditions.

The above discussion of the Stolper-Samuelson theorem shows that the theorem can, in one way or another, be generalised to accommodate to higher dimensions than the $2 \times 2$ framework, but that the strong results are only preserved in case technology is even, i.e., when the number of goods equals the number of factors. That is a most inconvenient state of the art. As we saw in this section, an increase in the number of goods resulted only in small changes in the weak results. Conversely, an increase in the number of factors led to relatively substantial changes in the weak results. It follows therefore that for the Stolper-Samuelson theorem to be true, the key issue is whether or not the number of goods is at least as large as the number of factors.

However, Ethier (1985, pp. 178-181) has proved that the technological distinction between goods and factors is not the crucial issue. Rather, as he is able to show, the validity of the factor price equalisation and Stolper-Samuelson theorem can be reduced to the question whether or not the number of international markets for both (primary) inputs and final goods is larger than the number of (non-traded) factors. This implies that if the number of factors is larger than the number of final goods, but some or all factors are internationally traded, factor price equalisation and Stolper-Samuelson results may still hold. 


\subsection{The specific-factors model}

As we have seen, the Stolper-Samuelson theorem and the factor price equalisation theorem are frequently used to derive the factor price effects of commercial policies. Both theorems assume that factors of production may instantaneously and costlessly be relocated between sectors. In the last two decades or so, several contributions to the literature have been made, in which the implications of factor specificity were analyzed. These include Jones (1971), Samuelson (1971), Mayer (1974) and Mussa $(1978,1982)$ and Neary (1978). There are several reasons why factors of production may be sector-specific. Factors may be embodied in a particular physical form (capital), or may simply be unwilling to work in a certain sector (compensating wage differentials), or may be immobile because of certain government measures.

Figure 2.9 The likelihood of factor price equalisation in the specific-factors model (Source: Dixit and Norman (1980), p. 123)

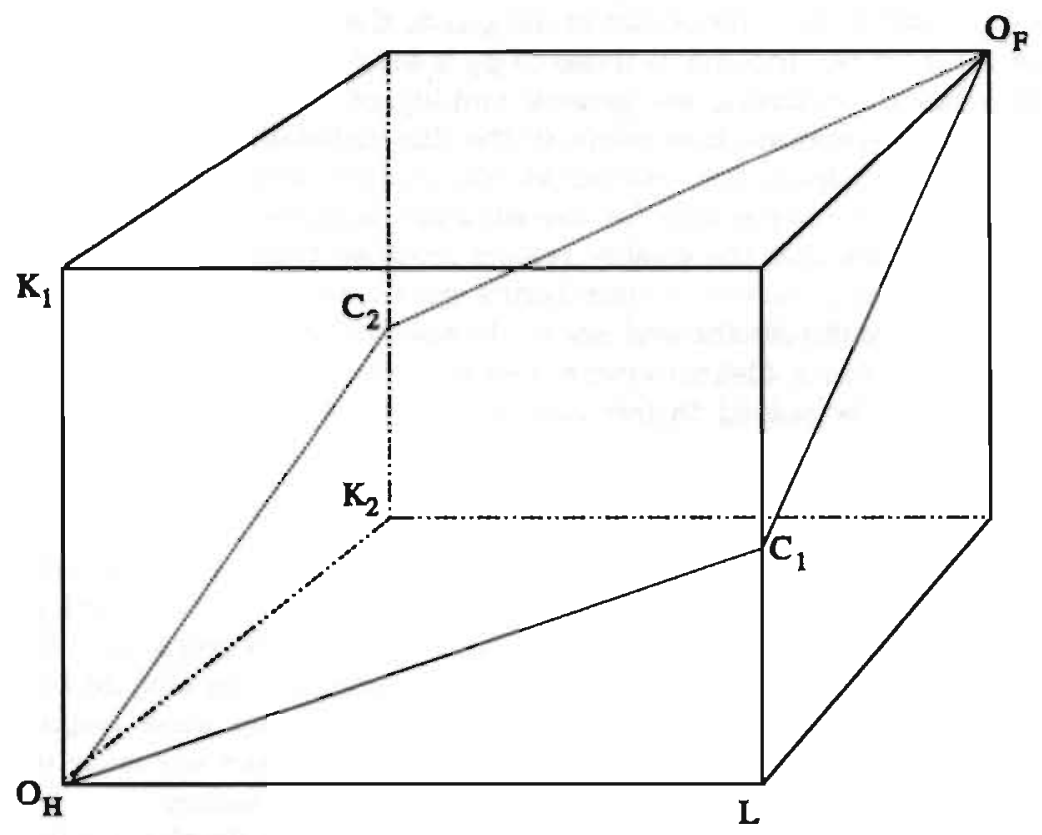

In the standard version of the specific-factors model, or the Ricardo-Viner model as it has been labelled by Samuelson, it is assumed that there are barriers to factor movements for certain factors in the sense that some factors are completely immobile in the short-run, and that these barriers do not extend to the long run. One of the earliest versions of the model, the Jones (1971) model, assumed that there are three factors; one, labour, is assumed to be perfectly mobile between the two sectors, while each sector also employs a certain amount of sector specific capital. This sector specific capital is tied to the production in that sector, and cannot move in the short-run. Obviously, in this kind of model, there are three distinct factors, while there are only two goods. As 
was shown in section 2.5, factor price equalisation is precluded in that case. In addition, as was shown in Mussa (1974), the direction and magnitude of factor price changes in response to commodity price changes tends to depend on the degree of substitutability between capital and labour on the one hand and the factor intensities in each industry on the other. Hence, in the specific-factor model, factor price equalisation and StolperSamuelson results are only obtained in the long-run, and do not apply to the short-run. Below, we shall discuss both the impossibility of factor price equalisation and the modification of the Stolper-Samuelson result.

Let us start with a focus on the likelihood of factor price equalisation when there are specific factors. More specifically, one must prove that factor price equalisation reduces to a fluke in the presence specific factors. We would suggest the use of the factor allocation box to prove the point. ${ }^{17}$ The box in Figure 2.9 refers to a situation where labour is the mobile factor and capital is the sector-specific factor. Since the model in fact distinguishes three factors (and two commodities), the box will become three dimensional. The quantity of labour available to the world is measured along the horizontal axis. Let the amount of capital used in sector 1 be measured along the vertical axis. Capital employed by sector 2 is measured along the third direction. The home country origin is again $\mathrm{O}_{\mathrm{H}}$, and the foreign country origin is $\mathrm{O}_{\mathrm{F}}$.

Since the first sector employs specific capital, the employment vector for that sector, measured from the origin $\mathrm{O}_{\mathrm{H}}$, must lie at the front side of the box. Measured from the origin $\mathrm{O}_{F}$, however, the employment vector for sector 1 is at the back side of the box. For sector 2 one finds that the employment vector, as measured from $\mathrm{O}_{\mathrm{H}}$, lies on the left side in the third direction of the box. Measured from $\mathrm{O}_{\mathrm{F}}$, this employment vector lies on the right hand side in the third direction of the box. Thus, the direction and length of the employment vector $\mathrm{O}_{\mathrm{H}} \mathrm{C}_{1}$ is identical to the direction and length of $\mathrm{C}_{2} \mathrm{O}_{\mathrm{F}}$, whereas $\mathrm{O}_{\mathrm{H}} \mathrm{C}_{2}$ and $\mathrm{C}_{1} \mathrm{O}_{\mathrm{F}}$ bear a similar relationship to one another. The figure clearly shows the emergence of a parallelogram, viz. $\mathrm{O}_{\mathrm{H}} \mathrm{C}_{1} \mathrm{O}_{\mathrm{F}} \mathrm{C}_{2} \mathrm{O}_{\mathrm{H}}$. This parallelogram is a two dimensional plane in a three dimensional space, and represents the factor price equalisation set. If factor endowments are located on the plane, it will be possible to replicate the integrated equilibrium through international trade in commodities, and factor price equalisation will obtain. Off the plane, this is clearly not possible. Needless to say, the requirement that endowments be on the parallelogram plane would only be met by coincidence. Hence, the possibility of factor price equalisation is not completely excluded, but it is most unlikely. 18

Having established the virtual impossibility of factor price equalisation in the specificfactors model, we proceed to outline the comparative static results of this model. We shall use Jones' (1975) version of this model in the context of a two commodity, three factor formulation. Note. that contrary to Jones' analysis, we shall use the duality formulation which exploits the derivatives of the unit cost functions (cf. Woodland (1977), (1982)). It will be assumed, that all the usual assumptions regarding production techno-

${ }_{18}^{17}$ The following is based on Dixit and Norman (1980), pp. 123-124.

${ }^{18}$ Dixit and Norman also raise the question of whether or not international factor migration might increase the likelihood of factor price equalisation. The answer is: yes, for the mobile factor and: yes/no for the specific factors. In other words, "... international migration of the factor which is mobile across uses within one country always does the trick, whereas that of a factor which is specific to the production of one of the goods may or may not suffice". (1980, p. 124.) 
logy, tastes, and the existence of perfect competition are met. The model starts with two commodity market clearance conditions, which read as

$$
c^{1}\left(w, r_{1}\right)=p_{1}
$$

and

$$
c^{2}\left(w, r_{2}\right)=p_{2}
$$

in which $c^{i}$ denotes the unit cost function of both sectors. Thus commodity market clearance requires that commodities are priced according to the marginal cost $=$ marginal revenue rule. It will be convenient to write these equations in terms of relative changes of variables. Total differentiation of the system will give

$$
\theta_{1,} \hat{r}_{1}+\theta_{1 w} \hat{w}=\hat{p}_{1}
$$

and

$$
\theta_{2 \mathrm{r}} \hat{\mathbf{r}}_{2}+\theta_{2 w} \hat{w}=\hat{\mathrm{p}}_{2}
$$

The endogenous variables in these two equations are $\hat{\mathbf{r}}_{1}, \hat{\mathbf{r}}_{2}$ and $\hat{\mathbf{w}}$. Clearly, there are more endogenous variables than equations, so the commodity market clearance conditions do not suffice to solve for all endogenous variables. One needs at least one extra equation. To obtain that third equation, consider the factor market clearance conditions, which state that the total supply of every factor should equal total demand for that factor. Note that Shephard's lemma will give unit demand for a factor. For example, $\partial c^{i} / \partial w \equiv c_{w}^{i}=$ unit demand for labour in sector $i$. When multiplies by total output of sector $i, \mathrm{y}_{\mathrm{i}}$, one obtains total labour demand by sector $i$. Bearing all this in mind, the factor market clearance conditions may be written as

$$
\begin{aligned}
& c_{\mathrm{r}}^{1}\left(\mathrm{w}, \mathrm{r}_{1}\right) \cdot \mathrm{y}_{1}=\overline{\mathrm{K}}_{1} \\
& c_{\mathrm{r}}\left(\mathrm{w}, \mathrm{r}_{2}\right) \cdot \mathrm{y}_{2}=\overline{\mathbf{K}}_{2}
\end{aligned}
$$

and

$$
c_{w}^{1}\left(w, r_{1}\right) \cdot y_{1}+c_{w}^{2}\left(w, r_{2}\right) \cdot y_{2}=\bar{L}
$$

The third equation that one needs to solve the system easily be obtained by substitution of (2.18) and (2.19) in equation (2.20). This will give

$$
\frac{c_{w}^{1}\left(w, r_{1}\right)}{c_{r}^{1}\left(w, r_{1}\right)} \cdot \bar{K}_{1}+\frac{c_{w}^{2}\left(w, r_{2}\right)}{c_{r}^{2}\left(w, r_{2}\right)} \cdot \bar{K}_{2}=\bar{L}
$$

It will be convenient to write this equation in terms of relative changes as well and subsequently solve the system formed by equations $\left(2.16^{\prime}\right)-\left(2.17^{\prime}\right)$ and $(2.21)$. Now define factor employment ratios in both sectors as $k_{1} \equiv c_{w}^{1}\left(w, r_{1}\right) / c_{r}^{1}\left(w, r_{1}\right)$ and $k_{2} \equiv c_{w}^{2}(w$, $\left.r_{2}\right) / c_{k}^{2}\left(w, r_{2}\right)$. Then from the definition of the elasticity of substitution, one will recall that $k_{1}=\sigma\left(\hat{w}_{1}-\hat{w}_{3}\right)$ and $\hat{k}_{2}=\sigma_{2}\left(\hat{w}_{2}-\hat{w}_{3}\right)$, with $\sigma$ denoting the elasticity of substitution 
between both factors in both industries. Totally differentiating equation (2.21) and writing the system $\left(2.16^{\prime}\right)-\left(2.17^{\prime}\right)$ and $(2.21)$ in matrix form gives ${ }^{19^{\circ}}$

$$
\left[\begin{array}{llc}
\theta_{1 \mathrm{r}} & 0 & \theta_{1 \mathrm{w}} \\
0 & \theta_{2 \mathrm{r}} & \theta_{2 \mathrm{w}} \\
\lambda_{1 w} \sigma_{1} & \lambda_{2 w} \sigma_{2} & -\left(\lambda_{1} \sigma_{1}+\lambda_{2} \sigma_{2}\right)
\end{array}\right]\left[\begin{array}{l}
\hat{\mathrm{r}}_{1} \\
\hat{\mathrm{r}}_{2} \\
\hat{w}
\end{array}\right]=\left[\begin{array}{l}
\hat{\mathrm{p}}_{1} \\
\hat{\mathrm{p}}_{2} \\
0
\end{array}\right]
$$

where $\theta_{\mathrm{ij}}$ is the share of factor $j$ in unit cost of sector $i$, and where $\lambda_{\mathrm{i}}$ denotes the employment share of the mobile factor (labour) in the total use of that factor, i.e., $\lambda_{i} \equiv$ $\mathrm{L}_{\mathrm{i}} / \mathrm{L}$. System (2.22) may easily be solved by inverting the matrix of coefficients on the left hand side.

Now assume that a tariff is imposed on sector 1 and that this tariff tends to increase the price of that commodity, the other sector's price remaining the same. Then, one obtains the following expressions for the reduced forms of $\hat{\mathbf{r}}_{1}, \hat{\mathbf{r}}_{2}$, and $\hat{w}$

$$
\begin{aligned}
& \hat{\mathrm{r}}_{1}=\frac{\theta_{2 \mathrm{r}} \lambda_{1} \sigma_{1}+\lambda_{2} \sigma_{2}}{\theta_{2 \mathrm{r}} \lambda_{1} \sigma_{1}+\theta_{1 \mathrm{r}} \lambda_{2} \sigma_{2}} \cdot \hat{\mathrm{p}}_{1} \\
& \hat{\mathrm{r}}_{2}=\frac{-\theta_{2 \mathrm{w}} \lambda_{1} \sigma_{1}}{\theta_{2 \mathrm{r}} \lambda_{1} \sigma_{1}+\theta_{1 \mathrm{r}} \lambda_{2} \sigma_{2}} \cdot \hat{\mathrm{p}}_{1}
\end{aligned}
$$

and

$$
\hat{w}=\frac{\theta_{2 r} \lambda_{1} \sigma_{1}}{\theta_{2 r} \lambda_{1} \sigma_{1}+\theta_{1 \mathrm{r}} \lambda_{2} \sigma_{2}} \cdot \hat{p}_{1}
$$

Note that $\theta_{2 \mathrm{r}} \lambda_{1} \sigma_{1}+\theta_{1 \mathrm{r}} \lambda_{2} \sigma_{2}$ is the determinant of the coefficient matrix on the left hand side of 2.22 .

The reduced forms in eqs. (2.23)-(2.25) are complicated expressions in primarily three variables, viz. $\theta_{i r} \lambda_{i}$ and $\sigma_{i}$ and may be hard to interpret at first sight. However, at this stage, it is already justified to conclude that in addition to factor proportions (as measured by distributive shares $\theta_{i j}$ ), the substitutability between the mobile and the specific factor in both sectors seems to be crucially determining the response of factor prices to changes in commodity prices. Equations (2.23)-(2.25) have been derived in different ways by different authors. However, the system is formally equivalent to, for instance, Mayer's (1974), Mussa's (1974), and Jones' (1975) systems, which are all classic references.

What can be said about the factors who loose or win? Let us first consider the capital specific to sector 1. As equation (2.23) shows, $\hat{r}_{1} / p_{1}=\left(\theta_{2 r} \lambda_{1} \sigma_{1}+\lambda_{2} \sigma_{2}\right) /\left(\theta_{2 r} \lambda_{1} \sigma_{1}+\right.$ $\left.\theta_{1 \mathrm{r}} \lambda_{2} \sigma_{2}\right)$. This expression $>1$, since $\theta_{1 \mathrm{r}}<1$. Clearly, the specific factor of the sector who's price increases gains in real terms as a result from the tariff. Capital specific to sector 2, however, will loose as a result of the change in $p_{1}$ since $\hat{r}_{2} / \hat{p}_{1}=-\theta_{2 r} \lambda_{1} \sigma_{1} /\left(\theta_{2 r} \lambda_{1} \sigma_{1}+\right.$

${ }^{19}$ Since we are concerned here with the issue of the distributional effects of commodity price. changes, $d \bar{L}=d \bar{K}_{1}=d \bar{K}_{2}$ have been set equal to 0 . 
$\left.\theta_{1 \mathrm{r}} \lambda_{2} \sigma_{2}\right)$, which is clearly negative. Finally, the effect of the commodity price change on the wage rate is given by $\hat{w} / \hat{p}_{1}=\theta_{2 r} \lambda_{1} \sigma_{1} /\left(\theta_{2 r} \lambda_{1} \sigma_{1}+\theta_{1} \lambda_{2} \sigma_{2}\right)<1$. Evidently, the nominal wage will increase, but not proportionally to the increase in the price of commodity 1. Hence, it is not clear whether or not labour gains in real terms. That depends on worker's tastes. If they are biased against the output of sector 1, labour will gain, whereas labour will loose in real terms in the opposite case. Thus, if one is to determine whether or not labour will gain, there is an index number problem. This result, which is clearly different from the Stolper-Samuelson theorem, has also been labelled as "neoclassical ambiguity" (Ruffin and Jones (1977)) or the "Haberler theorem" (Kenen (1989), p. 77).

Ruffin and Jones (1977) have analyzed the precise nature of the index problem that is inherent in the specific-factor model. They show that labour will gain when the fraction of the worker's income spent on commodity $j$ is less than the increase in $\mathrm{p}_{\mathrm{j}}$. This will normally be the case when a) the elasticity of the value of marginal product of labour curve in the protected sector is larger than the economy-wide average; $b$ ) when the protected sector is more labour intensive than the economy-wide average; and, c) labour's preferences are not biased in the direction of the protected commodity.

Figure 2.10 The specific-factors model

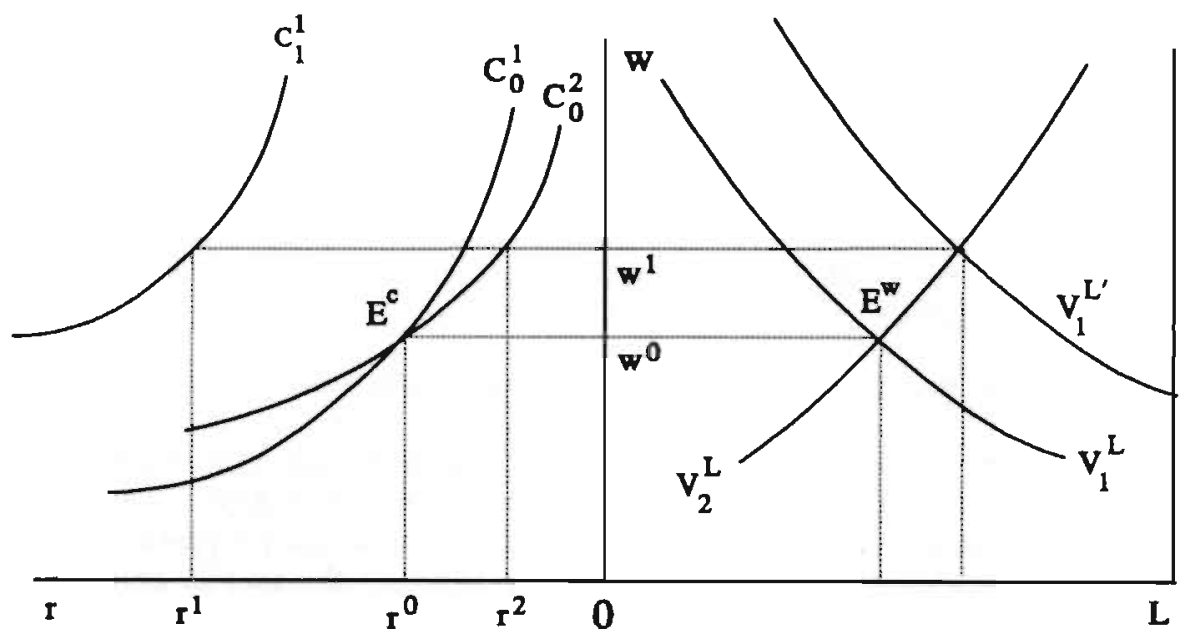

In Figure 2.10 the specific-factors model commodity-factor price relationships have been depicted. The graph has a left-hand section and a right-hand section. Both have been used separately in the literature to illustrate the effects of commercial policies in the specific-factors model. The right hand side of the graph refers to the situation on the labour market and shows the value of marginal product (VMP) curves in both sectors. The length of the horizontal axis corresponds to the availability of labour. $\mathrm{V}_{\mathrm{i}}^{\mathrm{L}}$ is the value of marginal product for sector $i(=1,2)$. Whenever a sector's commodity price changes, the VMP curve of that sector will shift up- or downwards, depending on the price change being an increase or a decrease respectively. Consider a price increase in 
sector 1. The VMP curve of that sector will shift to $V_{1}^{L}$. Since the price of sector 2 does not change, the VMP curve for that sector will be unaffected and stay in place. The wage rate will increase to $w^{1}$. One cannot tell, whether this increase in the nominal wage will be a real wage increase or a real wage decrease. Clearly, in terms of good one, the real wage will fall (the vertical distance between the $V_{1}^{L}$ and $V_{1}^{L}$ curve is less than the increase in wages), and in terms of good two, the wage rate will go up.

The left hand side of the graph shows that, due to the increase in the price of the first commodity, the unit cost function of that sector will move away from the origin. Given that the wage rate increases to $w^{1}$, the rental rate in the first sector will increase, whereas the rental rate in the second sector will do the opposite. Clearly, in terms of both commodities, the real rental rate of sector two will fall, whereas the rental rate of sector one will move in the opposite direction.

\subsection{Conclusions}

The factor price equalisation theorem has occupied a prominent place in the post-war development of international trade theory. Although the theorem is based on rather restrictive assumptions regarding the production technology and dimensionality, it has stood up against a substantial amount of criticism. The only serious challenge posed to the theory concerns the case where factors outnumber goods, which precludes the occurrence of factor price equalisation. The theorem does accommodate easily to the case of (tradeable) goods (in the wide sense of the word) outnumbering (non-traded) factors, and if one follows Ethier, this may be the relevant case.

Closely connected to the factor price equalisation discussion is the analysis pertaining to the Stolper-Samuelson theorem. This theorem, which predicts that active trade policies will tend to benefit in real terms the intensive factor and harm in real terms the non-intensive factor, has also stood up against a good deal of scrutiny. It has been shown, that the dimensionality problem has no influence on weak formulations of this theorem, and that the basic message contained in it seems to remain in tact when dimensions are changes beyond the $2 \times 2$ framework.

However, it should be noted that these results are conditional upon the exis-tence of full inter-sectoral factor mobility. As our discussion of the specific-factors model has shown, both the factor price equalisation theorem and the Stolper-Samuelson theorem may break down if specific factors are taken into consideration. The implication of all this, as Samuelson has put it, is that "Ohlin was right" when it comes to his prediction of the influence of free trade on factor prices, i.e., that factor prices tend to be equalised as a result of free international trade. 



\section{CHAPTER}

3

\section{DID WAGE CONVERGENCE OCCUR? THE EXPERIENCE OF EC-5}

\subsection{Introduction}

In the 1950s there used to be considerable factor price disparities in European countries (see, o.a., Dollar, Wolff and Baumol (1988)). In this chapter we shall attempt to discern some tendencies in one factor price, viz. the wage rate. We confine the analysis to only one single factor price for reasons of space and data availability.

International comparisons of wages and capital costs are extremely scarce in the literature. Although there have been several studies aiming to compare wages internationally, these studies are usually not covering the last decades and mostly date back to the first fifty years of this century. Some exceptions may be found, but in the most recent decades economists have not spent a a lot of time carrying out these comparisons. That is all the more true for international comparisons of capital costs, which one will hardly encounter in the literature. Most of the work that has been done in this area relates to returns on financial investments. Since we are interested in the relationship between production technology and factor prices, this line of analysis will not occupy us in the present chapter. Rather, we shall try to analyze the behaviour of wages in the various EC countries.

Both international comparisons of wages and of capital costs are fraught with many methodological difficulties which may be the prime reason for the scarcity of this kind of studies. We shall devote some words to these methodological problems for wage comparisons in section 3.2. In addition, the reader is introduced into the wage data used in our comparisons in that section. In section 3.3 we proceed to present the actual wage comparisons itself and try to discern some tendencies in the available data material. We shall conclude that our data confirm some tendencies found by other students of international wage differentials, notably international convergence, similarity and stability of the wage hierarchy. Section 3.4 sums up our conclusions. 
3.2 International comparison of wages: conceptual issues, measuring problems and availability of data

An international comparison of wages and labour costs is fraught with many measuring problems and conceptual caveats. This section seeks to outline the most important problems involved and explores the limits of these international comparisons. In addition, we shall describe the sources and basic characteristics of our data material.

We commence our analysis by defining the concept of "wages". As is well-known, wages may be interpreted as a source of income on the one hand or as the cost of labour on the other. Thus, the wage rate has both an income and a cost aspect. International comparisons of wages can therefore relate to both aspects. For one thing, they may refer to a comparison of the real income of the populations from different countries. These comparisons enable us to draw conclusions as to differences in the standard of living. For the other, international comparisons of wages may refer to a confrontation of labour costs, which may give an indication of a country's competitiveness vis-a-vis other countries. Both kinds of comparisons are fundamentally different from one another, and must necessarily employ different methods of comparison. The implication of this requirement for different methods is that real wages cannot be used as a source of reference in international labour cost comparisons and vice versa (see, among others, Bowley (1930)).

Most international comparisons of wages that have been reported in the economic and statistical literature, are international comparisons of real wages, i.e., the purchasing power of wages, or what we labelled "income" above. Some studies have tried to compare the real wages of nations on a certain point in time. Others have tried to compare the development of real wages in the nations concerned. Yet other studies have combined both comparisons. Whatever the object of comparison may be, however, all real wage comparisons seek to make (implicit) statements about the utility that workers in different countries may derive from their income. Needless to say, this is almost, if not completely, an impossible task. Indeed, as is well-known, interpersonal comparisons of utility are impossible, and for that reason, the international comparisons have to confine themselves to a comparison of the bundles of goods that a certain wage will buy in a certain country.

The earliest international wage comparisons did not always take the distinction between wages as a source of income and wages as a cost factor into account (see, e.g., Carey (1835)). One of the first analyses was a study by the British Board of Trade, which was undertaken for the years 1905-1909. The study took some basic foodstuffs and contract wages as a starting point and calculated the number of hours that workers in the countries under consideration would have to work in order to buy a particular quantity of these foodstuffs. Needless to say, a major drawback of this study was its inability to take different national consumption habits into account, as well as its focus on contract wages. The British Ministry of Labour introduced a more sophisticated methodology, which allowed for country-specific differentiation in consumption habits.

The ILO started international real wage comparisons in 1924 (see ILO (1954) for details). The international conference of labour statisticians had in 1923 agreed upon the adoptation of a recommendation which requested countries to supply the ILO with annual data on hourly wages, weekly hours of work and the prices of a number of products which made up the largest share of workers' budgets. However, these data did not supply the ILO with adequate material for comparisons and they were stopped being collected in 1931.

The ECSC (1955) provided one of the first comparisons of real wages in the Member States of the Community. The study concentrated on particular types of wage earners and used two definitions of purchasing power parities. For one thing, purchasing power parities were defined using a basket of commodities in a particular country, and applying this bas- 
ket in a fellow Member State. For the other, a basket defined for another Member State would be applied to the first country. The purchasing power parities defined in both ways were subsequently used to compare nominal wages in the Member States.

The ECSC study constituted a major improvement on older studies of wage comparisons, since it was not based on a compilation and comparison of national wage statistics. The value of these national wage statistics for purposes of international wage comparisons is very limited, indeed. Their use would lead to the emergence of at least three problems, which bias the results of the comparison. First of all, the different national statistical offices do not use identical definitions of wages. Different treatments of premiums on wages, allowances, contract wages or actual wages all hamper an adequate international comparison of the wage rates. Secondly, differential treatment of social security contributions seriously distort the picture. Thirdly and finally, the quantitative and qualitative meaning of these social security contributions influence the results of national wage statistics.

To overcome the above mentioned problems relating to the use of national statistics, the Statistical Office of the European Communities has undertaken special surveys on wages and labour costs using harmonized definitions of these concepts. These surveys were conducted on a regular basis since 1966 . However, the main problem with the Eurostat data is their incomplete coverage of sectors and their unreliability, especially in the years of their first appearance. Several institutions have tried to overcome the problem of incompleteness by compiling their own data on the basis of harmonized sources and national sources. The most well-known are the data collected by the Statistisches Bundesamt and the data collected by the Swedish Employers Federation (SAF). Below, we shall use both Eurostat and SAF data.

Even if one has the advantage of working with data that have been compiled on the basis of harmonized definitions, at least three problems thwart an international comparison of wages. First of all, to avoid an aggregation bias, the data should preferably be corrected for differences in countries' industrial structures. Wages for the aggregate manufacturing sector, for instance, are made up of the average of the wages in textile, chemical, transport equipment etc. industries, so that the industrial composition of countries might turn out to be a prominent force behind national manufacturing wage differentials. Preponderance of many low-wage industries might therefore bias the manufacturing wage rate downwards, whereas dominance of high-wage industries may do the opposite. In Hanna (1951) and Gallaway (1963) techniques were developed to correct for the biases described above. In the context of international wage differentials, these techniques would imply calculation of a nation's wage rate as if that nation had the same industrial composition as the entire EC. Therefore the calculated wage rates would indicate to what extent a wage differential is attributable to differences in the industry mix of countries.

Secondly, the data should in principle also be corrected for the occupational (or skill) mix of a country or industry. Differential skill mixes could also bias wage rates in the countries concerned. The preponderance of high skill, high wage industries would thus bias the wage rates upwards, while the preponderance of low skill, low-wage industries might do the opposite. In addition, changes in the skill composition might change the industrial wage structure in the course of time.

Having data on sectoral wage rates, output and employment, the correction technique described here should in principle be applied to the wage rates used in this chapter. However, that would only be possible for the wage rate of the entire manufacturing sector (NACE 03), and would not be possible for the wage rates of the various sub-sectors. Obviously, the aggregation problem applies just as much to these sub-sectors as to the manufacturing sector as a whole. Unfortunately data limitations prevent such a correction. For this reason we decided not to correct the data. As a further justification for this procedure 
it could be argued that analyses of regional wage differentials in the USA have revealed that adjustments of wage rates only eliminated as much as one quarter of the North-South wage differential, so that seventy five per cent remained. ${ }^{1}$ Finally, as was shown by Jacobs, (1985), although the skill composition of the labour force in the EC countries and industrial branches showed substantial changes in the last decades (which through time all go in the direction of more indirect and maintenance staff), the relative wages of the categories were rather stable. ${ }^{2}$ In addition, in many countries the sectoral composition of the manufacturing sector, measured by the share of various sub-sectors in total manufacturing industry value added, also seemed to have changed, without showing a correlation with the relative wages of the various sectors.

Thirdly, and finally, even if one is able to use harmonized statistics, the problem remains which wage concept should be used. In this respect it is possible to use gross or net (of taxes and other deductions) wages on the one hand or (total) labour costs on the other. However, for reasons of availability of data, net wages can be ruled out at the outset. That leaves us with a choice between labour costs and gross wages. If (gross) wages were chosen as the relevant variable, it might be argued that actual wage data are irrelevant because the parties involved tend to consider costs and benefits over a longer period (think for example of the Contract Theory) and/or ignore important components of labour cost and that the compensation effects of non-wage labour cost undermine the conclusions drawn from statistical sources. As was shown in Jacobs (1985) these effects should not be exaggerated. Detailed analyses led him to conclude that (1) contributions for social security and pensions are largely determined on the basis of the (real) wages of workers; (2) wage concepts which differ in terms of taxes, social security, overtime, holiday allowances, hours of work, hourly or weekly income , show a high correlation; (3) analysis of labour-cost statistics gave largely identical results for relative wages as analysis of statistics of hourly real wages; (4) the non-wage component of labour costs does not seem to vary much between sectors and through time, although the overall share of non-labour costs in total wages increased in the period that Jacobs investigated. Thus it does not seem to matter very much which definition of wages is adopted. For reasons of data-availability, we therefore decided to restrict the analysis to labour costs.

The above analysis makes clear, that different methods of comparison and the use of different sources may yield different conclusions. In what follows, we shall work with three definitions of wages:

1. gross hourly earnings for manual and non-manual workers;

2. hourly labour costs for manual and non-manual workers;

3. yearly labour costs for manual and non-manual workers.

Hourly earnings and hourly labour costs data were taken from Swedish Fmployers Federation $(1972,1982,1992)$ and are available for the 1964-1989 period. These data refer to twelve two- and three-digit ISIC industrial sectors. Yearly labour costs were taken from Eurostat National Accounts, Detailed Tables by Branch, various years, and refer to twelve NACE-R25

${ }^{1}$ Additionally, it could be argued that preponderance of low-wage industries is likely to be accompanied by relatively labour-intensive techniques, causing a high correlation between capital-labour ratios, on the one hand and skill and industry mix on the other. Therefore, the use of capitallabour ratios is likely to catch up a significant portion of the influence of industry and skill mix, see below.

${ }^{2}$ See also Saunders and Marsden (1981), chapter 4. 
sectors of industries (availability: 1969-1989). The industrial classifications of the UN and Eurostat do not overlap entirely, but coincide for several industries.

The advantage of the use of three definitions is that it allows a possibility of checking for the consistency of the results. All wage data were converted with the aid of two exchange rates:

1. The official ECU exchange rate. Obviously, when wages are converted with the aid of the official current exchange rate, the value of an international wage comparison is due to remain limited. However, if the objective of the investigation is to compare pay levels as an element of cost competitiveness, the use of official exchange rates may give some information, provided, of course, that other elements of competitiveness are also taken into consideration.

2. Purchasing power parity exchange rates (PPPs). Wages were converted with the aid of PPPs, since the official exchange rate does not necessarily reflect the relative domestic purchasing powers of the currencies involved. The Statistical Office of the European Communities has compiled PPPs for a variety of purposes (comparisons of GDP, investment data, capital stocks, etc.). Unfortunately, purchasing power parities for the comparison of wages and labour costs were not published by Eurostat. Therefore, we were forced to construct these series ourselves. In doing so, we assumed that the experience of the EC- 5 could serve as a benchmark. The year 1985 was chosen as our base year, since in this year exchange rates had more or less stabilised after the turbulence of the 1970s and the EMS had been in operation for six years and seemed to have functioned well. Thus, we assumed that PPP existed in 1985 . The ECU exchange rate was subsequently adjusted for a countries relative (to EC-5) inflation performance with the aid of the consumer price index. The resulting exchange rate is what we called the PPP exchange rate for the year in question.

The countries that we shall cover in our analysis are the five main founding members of the European Community, viz. Belgium, Germany, France, Italy and The Netherlands (hereafter: EC-5). The reason for this limited focus of the analysis is a practical one: sufficiently long data series could not be constructed for the other member states, which renders their inclusion in the analysis meaningless. In addition, the five countries mentioned above will be central to the empirical analysis in Chapters 6 and 7.

\subsection{Developments in wage differentials}

\subsubsection{Gross hourly wages and hourly labour costs}

In this sub-section we focus on the developments of gross hourly wages and hourly labour costs. The data used in the analysis were taken from the Swedish Employers Federations' publications on international comparisons of wages (Swedish Employers Federation SAF, $1972,1982,1992)$ and refer to twelve two- and three-digit ISIC industrial sectors.

We start our analysis with some comments on Table 3.1, which reveals the rank orders of the sectors in the five main founding countries of the EC (EC-5) for the years 11964, 1975 and 1989. The information in this table does not show how the pay level of a certain sector in one country compares with that in another country, but orders pay levels within each individual country. The gross hourly wages and hourly labour costs refer to all workers, i.e., manual and non-manual workers. 
$\begin{array}{llllllllllllll}64 & \text { B } & 75 & 89 & 64 & \text { D } & & & \text { F } & & & 1 & & \text { NL. }\end{array}$

Food, beverages \& tobacco

Textiles

Wearing apparel, except footwear

Leather and products of leather, leather substitutes, fur and footwear

Wood \& wood products, incl. furniture

Paper and paper products

Printing, publishing \& allied products

Chemicals and chemical, petroleurn, coal, rubber and plastic products

Non-metallic mineral products, except products of petroleum \& coal

Basic metal industries

Fabricated metal products, machinery \& equipment

Motor vehicles

Note:

i) ghw = gross hourly wage; hlc = hourly labour costs

$\begin{array}{lrrrrrrrrrrrrrrr}\text { ghw }{ }^{1} & 9 & 9 & 7 & 9 & 9 & 9 & 8 & 8 & 8 & 7 & 6 & 5 & 9 & 5 & 5 \\ \text { hlc } & 9 & 6 & 8 & 7 & 7 & 9 & 8 & 3 & 8 & 7 & 3 & 7 & 8 & 4 & 6 \\ \text { ghw } & 11 & 10 & 9 & 11 & 10 & 10 & 10 & 10 & 11 & 9 & 9 & 10 & 7 & 9 & 9 \\ \text { hlc } & 11 & 10 & 10 & 11 & 10 & 10 & 12 & 9 & 11 & 9 & 9 & 10 & 10 & 8 & 9 \\ \text { ghw } & 12 & 12 & 12 & 12 & 12 & 12 & 12 & 12 & 12 & 12 & 12 & 12 & 11 & 11 & 11 \\ \text { hic } & 12 & 12 & 12 & 12 & 11 & 12 & 11 & 12 & 12 & 12 & 12 & 12 & 12 & 11 & 11 \\ \text { ghw } & 10 & 11 & 10 & 10 & 11 & 11 & 11 & 11 & 10 & 11 & 11 & 11 & \text { na } & \text { na } & \text { na } \\ \text { hlc } & 10 & 11 & 11 & 10 & 12 & 11 & 10 & 11 & 10 & 10 & 11 & 11 & 11 & 10 & \text { na } \\ \text { ghw } & 8 & 8 & 8 & 7 & 7 & 8 & 9 & 9 & 9 & 10 & 10 & 9 & 10 & 10 & 10 \\ \text { hlc } & 8 & 9 & 9 & 9 & 9 & 8 & 9 & 10 & 9 & 11 & 10 & 9 & 9 & 9 & 10 \\ \text { ghw } & 7 & 6 & 4 & 8 & 8 & 7 & 7 & 3 & 2 & 6 & 4 & 4 & 4 & 4 & 4 \\ \text { hlc } & 7 & 7 & 7 & 7 & 8 & 6 & 7 & 6 & 3 & 6 & 6 & 4 & 6 & 3 & 5 \\ \text { ghw } & 4 & 3 & 2 & 3 & 2 & 2 & 1 & 1 & 1 & 1 & 1 & 1 & 5 & 3 & 2 \\ \text { hlic } & 4 & 3 & 2 & 4 & 4 & 4 & 1 & 2 & 1 & 1 & 1 & 1 & 5 & 6 & 3 \\ \text { ghw } & 3 & 4 & 3 & 4 & 4 & 5 & 3 & 4 & 4 & 5 & 3 & 3 & 2 & 2 & 3 \\ \text { hlc } & 3 & 4 & 3 & 2 & 3 & 5 & 3 & 4 & 5 & 4 & 5 & 3 & 2 & 2 & 2 \\ \text { ghw } & 6 & 6 & 6 & 6 & 6 & 6 & 6 & 6 & 5 & 8 & 8 & 8 & 6 & 7 & 6 \\ \text { hlc } & 6 & 8 & 5 & 6 & 6 & 7 & 6 & 7 & 4 & 8 & 8 & 8 & 7 & 7 & 7 \\ \text { ghw } & 1 & 1 & 1 & 2 & 3 & 3 & 5 & 2 & 3 & 2 & 2 & 2 & 1 & 1 & 1 \\ \text { hlic } & 1 & 1 & 1 & 2 & 2 & 2 & 4 & 1 & 2 & 3 & 2 & 2 & 1 & 1 & 1 \\ \text { ghw } & 5 & 5 & 6 & 5 & 5 & 4 & 4 & 7 & 7 & 4 & 7 & 7 & 8 & 8 & 8 \\ \text { hlc } & 5 & 5 & 6 & 5 & 5 & 3 & 4 & 8 & 7 & 5 & 7 & 6 & 4 & 5 & 8 \\ \text { ghw } & 2 & 2 & 5 & 1 & 1 & 1 & 2 & 4 & 6 & 3 & 5 & 6 & 3 & 6 & 7 \\ \text { hlc } & 2 & 2 & 4 & 1 & 1 & 1 & 2 & 5 & 6 & 2 & 4 & 5 & 3 & \text { na } & 4\end{array}$


The table shows some very interesting points which were also found by other students of branch wage differentials. Although there exist some national peculiarities, the information in Table 3.1 seems to represent something like a more or less similar hierarchy of branches in all countries. We find some notorious low-wage sectors in all countries, which turn out to be roughly the same everywhere. These sectors include: wearing apparel, which is at the very bottom of the wage hierarchy in all countries, textiles and leather, and to a lesser extent, wood and wood products. Several branches may be classified as intermediate-wage industries: paper and paper products, non-metallic minerals, and fabricated metal products. High-wage industries include basic metals, chemicals, printing and publishing, and, in some cases, motor vehicles.

Note also that this hierarchy is rather stable in the course of time. Most industries that were low-wage industries in 1964 also tended to be low-wage industries in 1975 and 1989. Conversely, high-wage industries in 1964 tended to remain in the top-end of the wage hierarchy in 1975 and 1989.

The similarity of industry wage structures is well evidenced. Butler (1967) found, for instance, that the ranking of industries by labour cost was largely identical in the different countries of Europe, despite international differences in collective bargaining procedures, extent of unionisation, and government wage policy. Similarity of wage structures was also found by Saunders and Marsden (1980), and is in fact apparent from many international comparisons of wage structures (cf. Papola and Bharadwaj (1970), see also Krueger and Summers (1987)). Many others found a remarkable stability of industry wage structures, that is, the ranking of industries by wage levels appears relatively constant in time (OECD (1965), OECD (1985), Reder (1962)).

This result, which is known as the "stability" thesis, leaves the possibility of narrowing or broadening intersectoral wage differentials open. To obtain an idea of the development of the magnitude of international wage differentials, consider Table 3.2, which gives an indication of the relative dispersion between EC-5 nations of gross hourly wages in several sectors of industry. The relative dispersion in this table is measured by the coefficients of variation, defined as the standard deviation divided by the five countries, average wage in the relevant sector. Let us first discuss the all-industry average for the manufacturing sector (ISIC 3).

Consider the first definition of wages, i.e., wages converted by the official current exchange rate. A quick glance at the table reveals that the wage dispersion at the beginning and at the end of the observation period was relatively small, something in the order of some 15 per cent. However, between 1964 and 1989 there is hardly any movement in the direction of convergence of wages. On the contrary, starting in 1970, there is clear evidence of divergence, which lasts until 1978. In that year developments seem to reverse to convergence again, but in 1985/86, there is another reversal in the trend towards divergence. On balance, therefore, the wage dispersion is just as high in 1989 as it was in 1964.

Things look completely different if one looks at wages converted by the PPP exchange rates. If we employ PPP converted wages, there is some evidence of divergence until 1968, but after that year there is clear and strong evidence of a movement towards convergence. ${ }^{3}$ Between 1968 and 1984 the dispersion decreases from 25 per cent to 11 per cent, which is a reduction of more than 50 per cent. Starting in 1985, there seems to be a reversal in this trend, but the observation period ends in 1989, so it is impossible to conclude that we are dealing here with a structural trend reversal in the direction of divergence.

\footnotetext{
${ }^{3} \mathrm{Cf}$. Leamer (1992) who found similar results.
} 


\begin{tabular}{|c|c|c|c|c|c|c|c|c|c|c|c|c|c|}
\hline \multirow{2}{*}{\multicolumn{2}{|c|}{$\begin{array}{l}\text { ISIC Nol) } \\
\text { Definition: }{ }^{3} \text { (1) }\end{array}$}} & \multirow{2}{*}{ (2) } & \multicolumn{2}{|c|}{31} & \multicolumn{2}{|c|}{321} & \multicolumn{2}{|c|}{322} & \multirow{2}{*}{$\begin{array}{l}323+324^{33} \\
(1)(2)\end{array}$} & \multicolumn{2}{|c|}{33} & \multicolumn{2}{|c|}{341} \\
\hline & & & (1) & (2) & & (2) & (1) & (2) & & (1) & (2) & & (2) \\
\hline 1964 & 0.16 & 0.23 & 0.14 & 0.22 & 0.17 & 0.26 & 0.19 & 0.25 & 0.220 .30 & 0.22 & 0.28 & 0.13 & C.21 \\
\hline 1965 & 0.16 & 0.25 & 0.14 & 0.23 & 0.17 & 0.27 & 0.19 & 0.26 & $0.23 \quad 0.31$ & 0.22 & 0.30 & 0.14 & 0.23 \\
\hline 1966 & 0.17 & 0.25 & 0.15 & 0.24 & 0.19 & 0.28 & 0.20 & 0.27 & $0.23 \quad 0.32$ & 0.23 & 0.31 & 0.15 & 0.24 \\
\hline 1967 & 0.16 & 0.25 & 0.15 & 0.25 & 0.19 & 0.29 & 0.17 & 0.25 & 0.230 .31 & 0.23 & 0.31 & 0.15 & 0.24 \\
\hline 1968 & 0.16 & 0.25 & 0.14 & 0.24 & 0.19 & 0.29 & 0.17 & 0.24 & 0.210 .30 & 0.21 & 0.29 & 0.13 & 0.23 \\
\hline 1969 & 0.17 & 0.23 & 0.15 & 0.22 & 0.20 & 0.27 & 0.18 & 0.23 & 0.220 .28 & 0.21 & 0.27 & 0.13 & 0.20 \\
\hline 1970 & 0.18 & 0.21 & 0.17 & 0.21 & 0.22 & 0.26 & 0.22 & 0.23 & $0.25 \quad 0.27$ & 0.25 & 0.28 & 0.16 & 0.20 \\
\hline 1971 & 0.19 & 0.20 & 0.19 & 0.20 & 0.21 & 0.23 & 0.19 & 0.19 & $0.22 \quad 0.22$ & 0.24 & 0.25 & 0.18 & 0.19 \\
\hline 1972 & 0.19 & 0.19 & 0.18 & 0.19 & 0.21 & 0.23 & 0.19 & 0.18 & 0.220 .22 & 0.25 & 0.25 & 0.17 & 0.18 \\
\hline 1973 & 0.21 & 0.17 & 0.21 & 0.18 & 0.23 & 0.21 & 0.21 & 0.17 & 0.250 .20 & 0.27 & 0.24 & 0.18 & 0.16 \\
\hline 1974 & 0.23 & 0.18 & 0.22 & 0.17 & 0.26 & 0.22 & 0.22 & 0.17 & 0.250 .19 & 0.28 & 0.23 & 0.21 & 0.16 \\
\hline 1975 & 0.21 & 0.17 & 0.19 & 0.16 & 0.23 & 0.21 & 0.19 & 0.16 & $0.21 \quad 0.17$ & 0.26 & 0.22 & 0.17 & 0.13 \\
\hline 1976 & 0.24 & 0.16 & 0.22 & 0.15 & 0.26 & 0.19 & 0.21 & 0.14 & $0.24: 0.15$ & 0.27 & 0.20 & 0.23 & 0.15 \\
\hline 1977 & 0.24 & 0.15 & 0.23 & 0.14 & 0.26 & 0.17 & 0.20 & 0.12 & $0.24 \quad 0.13$ & 0.27 & 0.18 & 0.24 & 0.14 \\
\hline 1978 & 0.24 & 0.14 & 0.22 & 0.13 & 0.25 & 0.17 & 0.20 & 0.12 & 0.230 .12 & 0.26 & 0.17 & 0.21 & 0.11 \\
\hline 1979 & 0.23 & 0.15 & 0.20 & 0.13 & 0.24 & 0.17 & 0.19 & 0.12 & 0.220 .12 & 0.25 & 0.18 & 0.20 & 0.12 \\
\hline 1980 & 0.20 & 0.15 & 0.17 & 0.13 & 0.21 & 0.17 & 0.16 & 0.12 & 0.190 .14 & 0.23 & 0.19 & 0.21 & 0.15 \\
\hline 1981 & 0.17 & 0.14 & 0.14 & 0.11 & 0.17 & 0.14 & 0.13 & 0.10 & 0.170 .13 & 0.20 & 0.18 & 0.15 & 0.12 \\
\hline 1982 & 0.15 & 0.13 & 0.13 & 0.10 & 0.15 & 0.12 & 0.11 & 0.09 & 0.130 .10 & 0.18 & 0.15 & 0.14 & 0.11 \\
\hline 1983 & 0.14 & 0.12 & 0.12 & 0.09 & 0.14 & 0.11 & 0.09 & 0.07 & 0.110 .09 & 0.16 & 0.14 & 0.10 & 0.08 \\
\hline 1984 & 0.12 & 0.11 & 0.10 & 0.09 & 0.12 & 0.11 & 0.08 & 0.07 & 0.110 .10 & 0.15 & 0.14 & 0.11 & 0.10 \\
\hline 1985 & 0.12 & 0.12 & 0.10 & 0.10 & 0.12 & 0.12 & 0.08 & 0.08 & 0.100 .10 & 0.15 & 0.15 & 0.10 & 0.10 \\
\hline 1986 & 0.13 & 0.13 & 0.11 & 0.11 & 0.13 & 0.13 & 0.09 & 0.09 & 0.110 .11 & 0.16 & 0.16 & 0.10 & 0.10 \\
\hline 1987 & 0.15 & 0.14 & 0.13 & 0.12 & 0.15 & 0.14 & 0.10 & 0.09 & 0.130 .12 & 0.18 & 0.17 & 0.11 & 0.10 \\
\hline 1988 & 0.16 & 0.15 & 0.13 & 0.12 & 0.15 & 0.15 & na & na & 0.130 .13 & 0.18 & 0.18 & 0.12 & 0.12 \\
\hline 1989 & 0.15 & 0.16 & 0.12 & 0.13 & 0.15 & 0.16 & na & na & 0.120 .13 & 0.17 & 0.18 & 0.11 & 0.13 \\
\hline
\end{tabular}

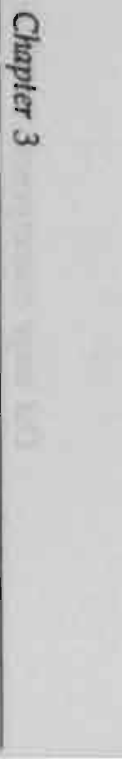




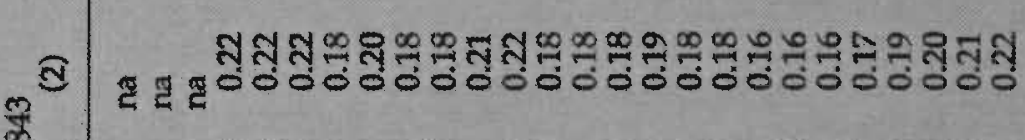

ल

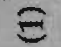

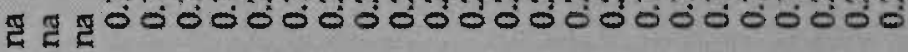

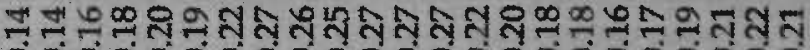

$\widehat{\mathbb{N}}$

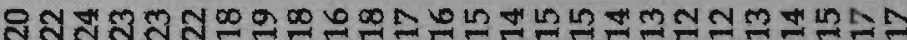
象

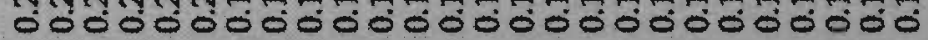

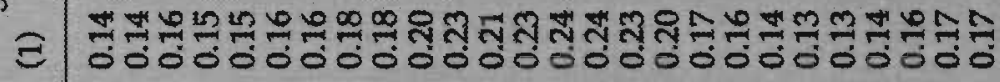
is

I $\mathbb{2}$

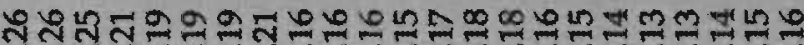

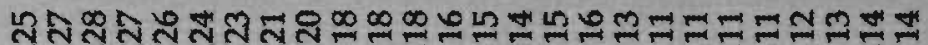
ก้

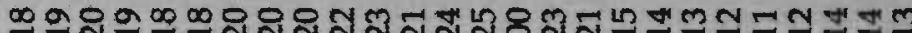

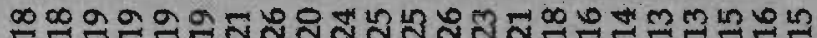

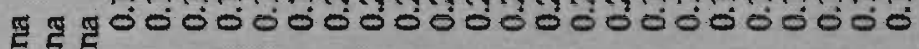

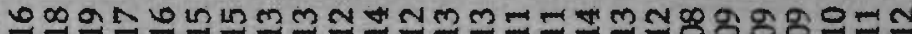
is

ब

มี艹 ปี艹

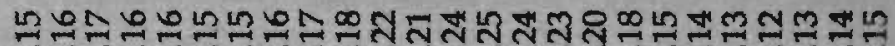

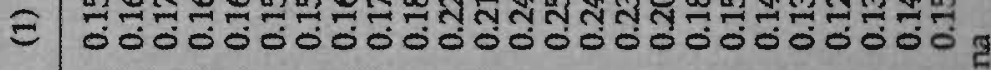
ले

ब

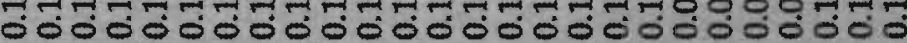

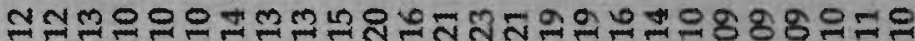

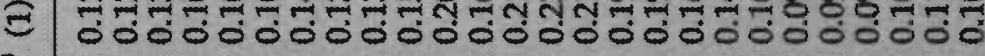
= กิร $\ddot{z}$ 


\section{Table 3.2 (continued)}

Explanatory notes:

1) The ISIC numbers represent the sectors:

3 Manufacturing,

31 Food, beverages \& tobacco

321 Textiles

322 Wearing apparel, except footwear

$323 / 4$ Leather and products of leather, leather substitutes, fur and footwear

33 Wood \& wood products, incl. furniture

341 Paper and paper products

342 Printing, publishing and allied products

35 Chemicals and chemical, petroleum, coal, rubber and plastic products

36 Non-metallic mineral products, except products of petroleum and coal

37 Basic metal industries

38 Fabricated metal products, machinery and equipment

3843 Motor vehicles

2) Definitions of wages used:

(1) nominal wages at current ECU rate

(2) nominal wages at PPPs

3) The Netherlands not included

The above general picture is confirmed if we consider the individual sectors of industry. The average dispersion, measured at current exchange rates, is somewhat between 10 and 20 per cent. In most industries, the 1970 s implied a divergence in wages. Thus, there is a great degree of similarity in the international wage developments of various sectors. Additionally, the dispersion at the end of the 1980s roughly equals that of the beginning of the observation period. Exceptions are ISIC 322 (wearing apparel, except footwear), 323/324 (leather and products of leather, leather substitutes, fur and footwear), and, to a much less extent, 33 (wood and wood products, including furniture) and 36 (non-metallic mineral products, except products of petroleum and coal). Interesting is also the development of the wage dispersion in the motor vehicles industry (ISIC 3843), which seems to have increased.

Expressed in PPP exchange rates, most industries also exhibit a diverging trend until $1967 / 68$ and a converging trend after that year. In addition, in the majority of industries the converging trend in gross hourly wages ends in 1985/86, which seerns to mark the start of divergence again. The motor vehicles industry, however, provides also in this case the exception to the rule.

Summarizing so far, it seems that there is evidence of a converging trend in gross hourly wages. In Table 3.3 we have repeated the exercise from Table 3.2 for hourly labour costs. Note that the dispersion in hourly labour costs is significantly lower than the dispersion in gross hourly earnings. Whereas the coefficient of variation for gross hourly earnings was about 16 per cent (current official ECU exchange rate) in 1964, it turns out to be some 9 per 


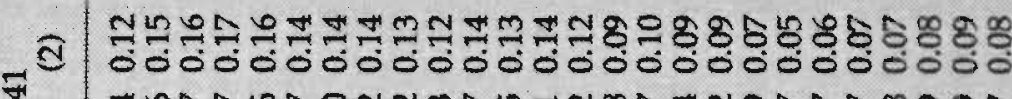
" E $m$

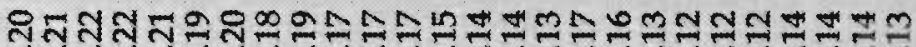

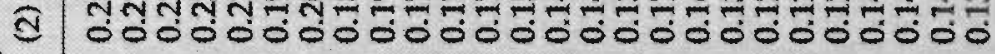

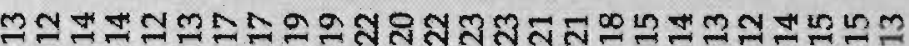

- :

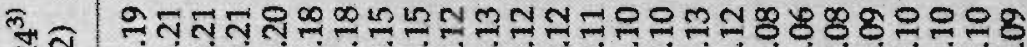

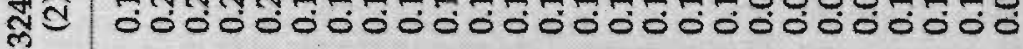

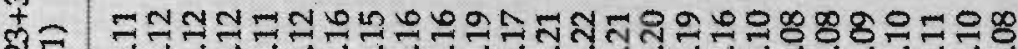

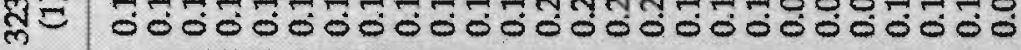

(2) y 000000000000000000000000 I

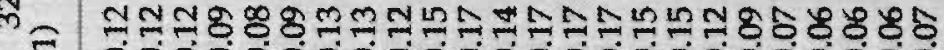

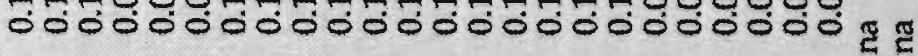

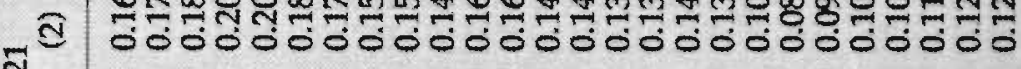
N E

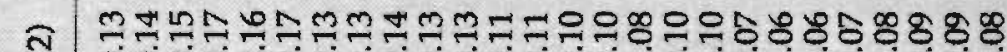
- 00000000000000000000000000 क E

ป

MNN $m$

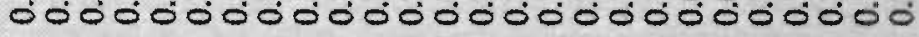

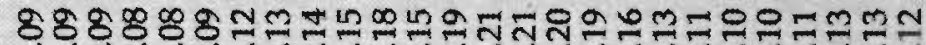
$\approx$

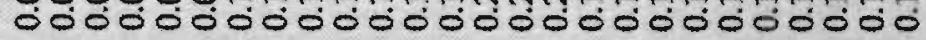




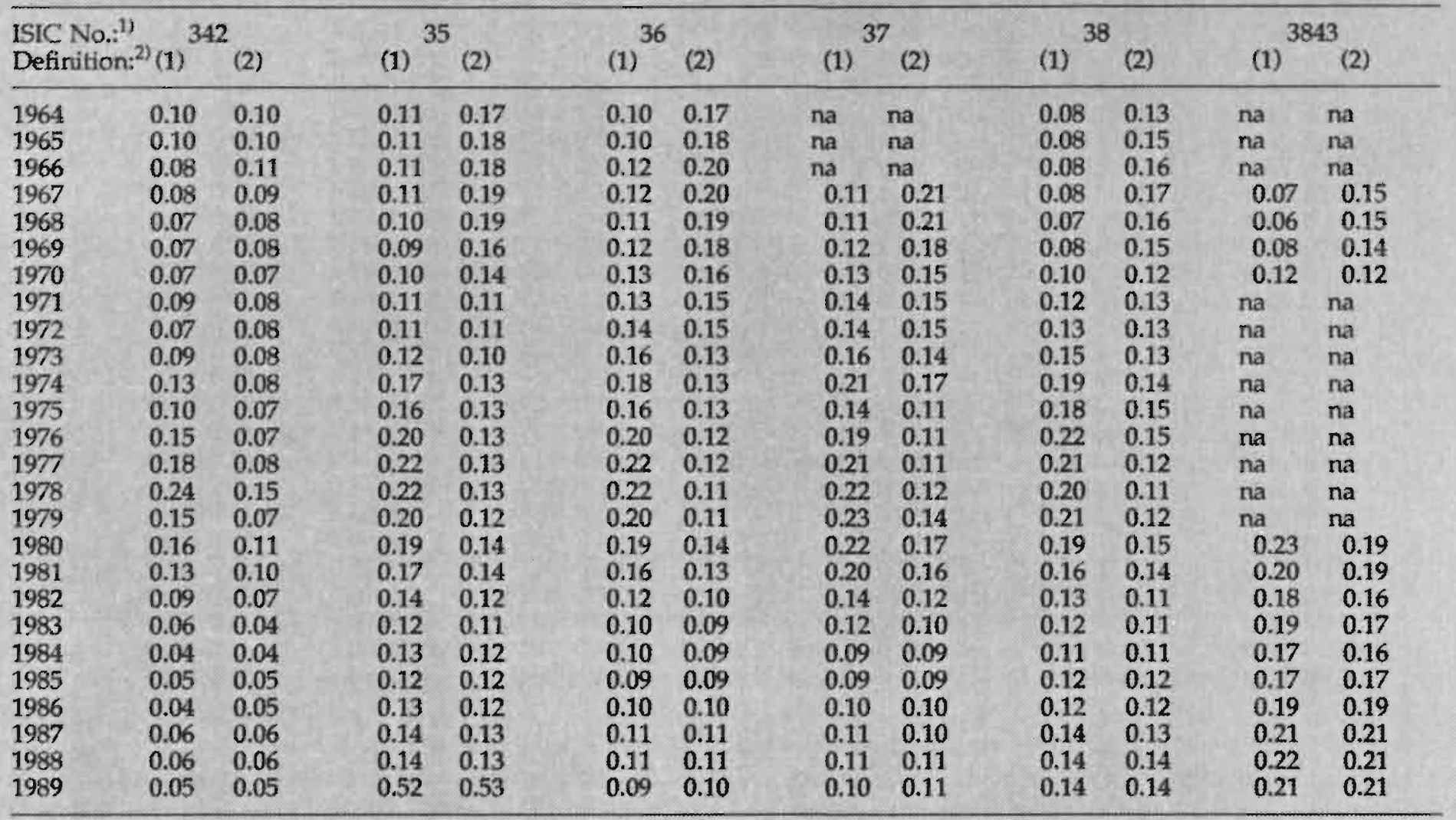

1), 2), 3) See explanatory notes to Table 3.2. 
cent only for hourly labour costs. The same is true for labour costs expressed in PPPs exchange rates. Thus, wage dispersion is smaller when one looks at labour costs as compared to gross hourly earnings.

Note also, that, on balance, the trend in hourly labour costs, converted by the current official ECU exchange rate, is roughly similar to the trend in gross hourly wages. Most industries show a strong diverging trend in the 1970s, which reverses in 1978/79 to convergence, and, finally, seems to turn back into (slight) divergence again after 1985. The exceptions to this trend are the same as in the case of gross hourly earnings. Thus, if one is interested in the development of relative wage dispersion, gross hourly earnings and hourly labour costs seem to yield almost identical results.

The trends for labour costs expressed in PPPs are also identical to those in gross hourly earnings. Note that, at the end of the 1980s, the dispersion in PPP wages has decreased to less than 10 per cent.

Table 3.4 gives an indication of the magnitude of the pay differential between countries for the same sectors of industry. Consider first the pay differential for the all-industry average. Expressed in the current official exchange rate, Germany clearly should be characterised as a high-wage country during the entire period of observation. Interestingly, Germany's relative position declined steadily until 1985, but after that year German wages increased again relative to the EC- 5 average. The Netherlands and Belgium are both average at the beginning and the end of the period, but had wages that were substantially above the average in the 1970s. In the 1980s, their relative position declined again. Italy and France clearly should be characterised as low-wage countries for the entire observation period. As far as Italy's experience is concerned, note that this country seemed to catch up with the highwage countries during the $1960 \mathrm{~s}$, but that its relative position seems to deteriorate again in the 1970s, a development which is probably due to the exchange rate turbulence of that decade. In the 1980s, however, Italy's relative position seems to have improved considerably. For France, on the other hand, one may observe a steady decline in its relative position, the beginning of the 1980s marking an exception to this trend.

Expressed in PPPs, the above picture changes but marginally. Germany remains a highwage country whose relative position declines until 1985, and improves afterwards. Dutch wages are also substantially above average, but after 1975, The Netherlands' position seems to deteriorate. Belgian wages are around average at both the beginning and the end of the observation period, and seem to be above average during the 1970s. Furthermore, the PPP wages confirm Italy's catching up with the high-wage countries, and we do not observe the set-back that occurs if one would express wages in current exchange rates. Finally, the PPP wage definition also confirms France's decline towards the average during the beginning of the 1970s, be it that this decline seems to be less dramatic than according to the current exchange rate definition of wages. Thus, it seems that the decline in the relative dispersion of wages may be traced back to reduced differences between the highest and the lowest wages in the EC.

If we look at individual industries in greater detail, the general all-industry picture is roughly confirmed. During the 1964-1985 period, German supremacy, both measured in current and PPP exchange rates, seems to decline in all (but one) industries and seems to increase again after 1985. Although there is a sharp increase in German relative (to EC-5) wages in some industries after 1985, the relative position of German industry wages is not as high as it was in 1964. Belgian wages increase relatively in the 1970s, and seem to decrease after 1980. The same pattern may be observed for Dutch wages, except that the decline of relative wages seems to set in a few years earlier than in Belgium. In the 1964-85 period, Italian PPP wages seem to catch up substantially in most sectors, and seem to fall 
Table 3.4

Gross hourly wages relative to EC-5 average

\begin{tabular}{|c|c|c|c|c|c|c|c|c|c|c|}
\hline & \multicolumn{5}{|c|}{ Current exchange rates } & \multicolumn{5}{|c|}{ Purchasing power parities } \\
\hline & B & D & F & I & NL & B & D & $F$ & I & NL \\
\hline \multicolumn{11}{|c|}{ Manufacturing } \\
\hline 1964 & 1.06 & 1.26 & 0.93 & 0.77 & 0.98 & 1.00 & 1.35 & 0.85 & 0.67 & 1.12 \\
\hline 1970 & 1.04 & 1.31 & 0.83 & 0.79 & 1.04 & 1.01 & 1.30 & 0.83 & 0.73 & 1.13 \\
\hline 1975 & 1.16 & 1.18 & 0.81 & 0.69 & 1.15 & 1.10 & 1.17 & 0.80 & 0.78 & 1.15 \\
\hline 1980 & 1.19 & 1.16 & 0.84 & 0.70 & 1.12 & 1.10 & 1.16 & 0.84 & 0.80 & 1.10 \\
\hline 1985 & 1.04 & 1.16 & 0.88 & 0.84 & 1.07 & 1.04 & 1.16 & 0.88 & 0.84 & 1.07 \\
\hline 1989 & 1.01 & 1.24 & 0.84 & 0.85 & 1.06 & 1.01 & 1.24 & 0.86 & 0.80 & 1.09 \\
\hline \multicolumn{11}{|c|}{ Food, beverages \& tobacco } \\
\hline 1964 & 1.03 & 1.21 & 0.92 & 0.80 & 1.04 & 0.97 & 1.2 .9 & 0.84 & 0.70 & 1.19 \\
\hline 1970 & 0.99 & 1.26 & 0.84 & 0.80 & 1.11 & 0.96 & 1.26 & 0.83 & 0.74 & 1.21 \\
\hline 1975 & 1.10 & 1.11 & 0.82 & 0.74 & 1.23 & 1.04 & 1.09 & 0.81 & 0.83 & 1.23 \\
\hline 1980 & 1.17 & 1.10 & 0.86 & 0.73 & 1.14 & 1.08 & 1.10 & 0.86 & 0.83 & 1.13 \\
\hline 1985 & 1.01 & 1.09 & 0.89 & 0.89 & 1.12 & 1.01 & 1.09 & 0.89 & 0.89 & 1.12 \\
\hline 1989 & 0.99 & 1.14 & 0.85 & 0.90 & 1.12 & 0.99 & 1.14 & 0.87 & 0.85 & 1.15 \\
\hline \multicolumn{11}{|c|}{ Textiles } \\
\hline 1964 & 1.01 & 1.19 & 0.92 & 0.71 & 1.16 & 0.95 & 1.27 & 0.84 & 0.62 & 1.32 \\
\hline 1970 & 1.00 & 1.27 & 0.77 & 0.73 & 1.22 & 0.97 & 1.26 & 0.76 & 0.67 & 1.33 \\
\hline 1975 & 1.13 & 1.10 & 0.79 & 0.67 & 1.31 & 1.07 & 1.08 & 0.78 & 0.76 & 1.32 \\
\hline 1980 & 1.13 & 1.10 & 0.80 & 0.71 & 1.27 & 1.04 & 1.10 & 0.80 & 0.81 & 1.25 \\
\hline 1985 & 1.04 & 1.12 & 0.86 & 0.87 & 1.13 & 1.04 & 1.12 & 0.86 & 0.87 & 1.13 \\
\hline 1989 & 1.00 & 1.19 & 0.81 & 0.86 & 1.14 & 1.00 & 1.19 & 0.83 & 0.81 & 1.16 \\
\hline \multicolumn{11}{|c|}{ Wearing apparel, except footwear } \\
\hline 1964 & 1.00 & 1.32 & 1.04 & 0.75 & 0.89 & 0.95 & 1.43 & 0.96 & 0.65 & 1.02 \\
\hline 1970 & 1.04 & 1.36 & 0.94 & 0.69 & 0.97 & 1.01 & 1.36 & 0.93 & 0.64 & 1.06 \\
\hline 1975 & 1.10 & 1.21 & 0.84 & 0.71 & 1.14 & 1.04 & 1.19 & 0.84 & 0.80 & 1.14 \\
\hline 1980 & 1.14 & 1.14 & 0.85 & 0.76 & 1.12 & 1.05 & 1.14 & 0.84 & 0.86 & 1.10 \\
\hline 1985 & 1.04 & 1.13 & 0.94 & 0.91 & 0.98 & 1.04 & 1.13 & 0.94 & 0.91 & 0.98 \\
\hline 1987 & 1.00 & 1.17 & 0.92 & 0.89 & 1.02 & 1.00 & 1.16 & 0.94 & 0.88 & 1.02 \\
\hline \multicolumn{11}{|c|}{ Leather and products of leather, leather substitutes, fur and footwear } \\
\hline 1964 & 1.05 & 1.30 & 0.97 & 0.68 & na & 1.03 & 1.44 & 0.91 & 0.62 & \\
\hline 1970 & 1.11 & 1.34 & 0.85 & 0.70 & na & 1.10 & 1.37 & 0.86 & 0.66 & \\
\hline 1975 & 1.22 & 1.19 & 0.87 & 0.71 & na & 1.16 & 1.17 & 0.87 & 0.80 & \\
\hline 1980 & 1.22 & 1.15 & 0.89 & 0.74 & na & 1.13 & 1.15 & 0.89 & 0.84 & \\
\hline 1985 & 1.07 & 1.12 & 0.94 & 0.87 & na & 1.07 & 1.12 & 0.94 & 0.87 & \\
\hline 1989 & 1.04 & 1.17 & 0.90 & 0.88 & na & 1.06 & 1.18 & 0.93 & 0.83 & \\
\hline
\end{tabular}


Table 3.4 (Continued)

\begin{tabular}{|c|c|c|c|c|c|c|c|c|c|c|}
\hline & \multicolumn{5}{|c|}{ Current exchange rates } & \multicolumn{5}{|c|}{ Purchasing power parities } \\
\hline & $\mathbf{B}$ & $\mathrm{D}$ & F & 1 & NL & B & $\mathrm{D}$ & $\mathrm{F}$ & I & NL \\
\hline \multicolumn{11}{|c|}{ Wood \& wood products, incl. furniture } \\
\hline 1964 & 1.11 & 1.29 & 0.91 & 0.64 & 1.05 & 1.04 & 1.38 & 0.83 & 0.56 & 1.20 \\
\hline 1970 & 1.09 & 1.37 & 0.82 & 0.63 & 1.09 & 1.06 & 1.36 & 0.81 & 0.58 & 1.19 \\
\hline 1975 & 1.19 & 1.25 & 0.76 & 0.62 & 1.17 & 1.13 & 1.24 & 0.76 & 0.70 & 1.18 \\
\hline 1980 & 1.19 & 1.23 & 0.80 & 0.66 & 1.11 & 1.11 & 1.24 & 0.80 & 0.75 & 1.10 \\
\hline 1985 & 1.03 & 1.23 & 0.87 & 0.81 & 1.06 & 1.03 & 1.23 & 0.87 & 0.81 & 1.06 \\
\hline 1989 & 0.99 & 1.30 & 0.84 & 0.83 & 1.03 & 1.00 & 1.30 & 0.86 & 0.78 & 1.06 \\
\hline \multicolumn{11}{|c|}{ Paper and paper products } \\
\hline 1964 & 1.06 & 1.17 & 0.89 & 0.82 & 1.06 & 1.00 & 1.26 & 0.82 & 0.71 & 1.21 \\
\hline 1970 & 1.03 & 1.22 & 0.82 & 0.80 & 1.13 & 1.00 & 1.21 & 0.81 & 0.74 & 1.23 \\
\hline 1975 & 1.16 & 1.06 & 0.85 & 0.76 & 1.17 & 1.10 & 1.04 & 0.84 & 0.85 & 1.17 \\
\hline 1980 & 1.33 & 1.03 & 0.86 & 0.72 & 1.06 & 1.24 & 1.04 & 0.85 & 0.82 & 1.05 \\
\hline 1985 & 1.06 & 1.08 & 0.87 & 0.89 & 1.11 & 1.06 & 1.08 & 0.87 & 0.89 & 1.11 \\
\hline 1989 & 1.02 & 1.13 & 0.87 & 0.86 & 1.11 & 1.03 & 1.13 & 0.90 & 0.81 & 1.14 \\
\hline \multicolumn{11}{|c|}{ Printing, publishing and allied products } \\
\hline 1964 & 0.94 & 1.19 & 1.08 & 0.90 & 0.88 & 0.90 & 1.29 & 1.00 & 0.80 & 1.01 \\
\hline 1970 & 0.95 & 1.26 & 0.98 & 0.87 & 0.93 & 0.92 & 1.26 & 0.97 & 0.81 & 1.02 \\
\hline 1975 & 1.17 & 1.13 & 0.85 & 0.76 & 1.09 & 1.10 & 1.11 & 0.85 & 0.85 & 1.09 \\
\hline 1980 & 1.22 & 1.15 & 0.88 & 0.69 & 1.06 & 1.13 & 1.15 & 0.87 & 0.79 & 1.05 \\
\hline 1985 & 1.06 & 1.12 & 0.93 & 0.87 & 1.02 & 1.06 & 1.12 & 0.93 & 0.87 & 1.02 \\
\hline 1989 & 1.01 & 1.16 & 0.96 & 0.85 & 1.02 & 1.02 & 1.15 & 0.98 & 0.80 & 1.05 \\
\hline \multicolumn{11}{|c|}{ Chemicals and chemical, petroleum, coal, rubber and plastic products } \\
\hline 1964 & 1.05 & 1.23 & 0.97 & 0.75 & 1.01 & 0.99 & 1.32 & 0.88 & 0.65 & 1.15 \\
\hline 1970 & 1.06 & 1.22 & 0.84 & 0.81 & 1.08 & 1.03 & 1.21 & 0.84 & 0.75 & 1.18 \\
\hline 1975 & 1.18 & 1.12 & 0.78 & 0.72 & 1.20 & 1.12 & 1.11 & 0.77 & 0.81 & 1.20 \\
\hline 1980 & 1.26 & 1.10 & 0.82 & 0.72 & 1.10 & 1.17 & 1.10 & 0.82 & 0.82 & 1.08 \\
\hline 1985 & 1.10 & 1.11 & 0.86 & 0.85 & 1.08 & 1.10 & 1.11 & 0.86 & 0.85 & 1.08 \\
\hline 1988 & 1.08 & 1.17 & 0.81 & 0.83 & 1.11 & 1.09 & 1.16 & 0.83 & 0.82 & 1.11 \\
\hline \multicolumn{11}{|c|}{ Non-metallic mineral products, except products of petroleum and coal } \\
\hline 1964 & 1.08 & 1.26 & 0.93 & 0.70 & 1.03 & 1.01 & 1.35 & 0.85 & 0.62 & 1.17 \\
\hline 1970 & 1.05 & 1.28 & 0.86 & 0.71 & 1.09 & 1.02 & 1.28 & 0.85 & 0.66 & 1.20 \\
\hline 1975 & 1.19 & 1.16 & 0.84 & 0.67 & 1.15 & 1.12 & 1.15 & 0.83 & 0.75 & 1.15 \\
\hline 1980 & 1.25 & 1.13 & 0.87 & 0.66 & 1.09 & 1.17 & 1.13 & 0.87 & 0.76 & 1.08 \\
\hline 1985 & 1.05 & 1.14 & 0.92 & 0.83 & 1.07 & 1.05 & 1.14 & 0.92 & 0.83 & 1.07 \\
\hline 1989 & 1.02 & 1.19 & 0.88 & 0.84 & 1.06 & 1.02 & 1.19 & 0.90 & 0.79 & 1.09 \\
\hline
\end{tabular}


Table 3.4

(Continued)

\begin{tabular}{|c|c|c|c|c|c|c|c|c|c|c|}
\hline & \multicolumn{5}{|c|}{ Current exchange rates } & \multicolumn{5}{|c|}{ Purchasing power parities } \\
\hline & B & D & F & I & NL & B & D & F & I & NL \\
\hline \multicolumn{11}{|c|}{ Basic metal industries } \\
\hline 1964 & na & 2.13 & 1.46 & 1.41 & na & na & 2.35 & 1.38 & 1.27 & na \\
\hline 1970 & 1.12 & 1.27 & 0.72 & 0.86 & 1.03 & 1.09 & 1.27 & 0.71 & 0.80 & 1.13 \\
\hline 1975 & 1.22 & 1.10 & 0.79 & 0.73 & 1.16 & 1.15 & 1.08 & 0.79 & 0.82 & 1.17 \\
\hline 1980 & 1.27 & 1.09 & 0.79 & 0.68 & 1.17 & 1.18 & 1.10 & 0.79 & 0.78 & 1.15 \\
\hline 1985 & 1.13 & 1.11 & 0.84 & 0.84 & 1.07 & 1.13 & 1.11 & 0.84 & 0.84 & 1.07 \\
\hline 1989 & 1.09 & 1.18 & 0.80 & 0.85 & 1.08 & 1.09 & 1.18 & 0.82 & 0.80 & 1.11 \\
\hline \multicolumn{11}{|c|}{ Fabricated metal products, machinery and equipment } \\
\hline 1964 & 1.08 & 1.21 & 0.94 & 0.81 & 0.95 & 1.02 & 1.31 & 0.87 & 0.71 & 1.09 \\
\hline 1970 & 1.06 & 1.27 & 0.85 & 0.81 & 1.00 & 1.03 & 1.27 & 0.84 & 0.75 & 1.10 \\
\hline 1975 & 1.19 & 1.19 & 0.81 & 0.69 & 1.12 & 1.12 & 1.17 & 0.80 & 0.78 & $\mathbf{1 . 1 3}$ \\
\hline 1980 & 1.20 & 1.18 & 0.86 & 0.69 & 1.07 & 1.12 & 1.19 & 0.85 & 0.79 & 1.05 \\
\hline 1985 & 1.06 & 1.21 & 0.91 & 0.83 & 0.99 & 1.06 & 1.21 & 0.91 & 0.83 & 0.99 \\
\hline 1989 & 1.00 & 1.30 & 0.85 & 0.84 & 1.00 & 1.01 & 1.30 & 0.87 & 0.79 & 1.03 \\
\hline \multicolumn{11}{|c|}{ Motor vehicles } \\
\hline 1967 & 1.13 & 1.21 & 0.81 & 0.83 & 0.92 & 1.07 & 1.35 & 0.81 & 0.73 & 1.04 \\
\hline 1970 & 1.10 & 1.31 & 0.83 & 0.87 & 0.89 & 1.08 & 1.31 & 0.82 & 0.81 & 0.98 \\
\hline 1975 & 1.24 & 1.30 & 0.76 & 0.66 & 1.04 & 1.18 & 1.28 & 0.75 & 0.74 & 1.05 \\
\hline 1980 & 1.18 & 1.28 & 0.86 & 0.66 & 1.02 & 1.10 & 1.28 & 0.86 & 0.76 & 1.01 \\
\hline 1985 & 1.03 & 1.29 & 0.89 & 0.79 & 1.00 & 1.03 & 1.29 & 0.89 & 0.79 & 1.00 \\
\hline 1989 & 1.00 & 1.40 & 0.83 & 0.81 & 0.97 & 1.00 & 1.40 & 0.85 & 0.76 & 0.99 \\
\hline
\end{tabular}

back slightly after 1985 . Measured in current exchange rates, Italian relative wages go down in the 1970s, increase sharply at the beginning of the 1980 s and fall back marginally after 1985. French relative wages, both measured in current exchange rates and PPPs also show a setback in the 1970 s, a recovery at the beginning of the 1980 s, and a small decline again after 1985.

In sum, we may conclude that the available material indicates a movement in the direction of wage convergence. This tendency is less visible if we employ current official ECU exchange rates, but is clearly observable in case wages are expressed in PPPs and constant (1985) exchange rates. Obviously, the convergence of wages is the result of a relative decline in Germany's relative position and an improvement of Italy's relative position in the EC-5 wage hierarchy. 


\subsubsection{Wages in EFTA countries}

In the previous sub-section we discussed the development of wage differentials in the EC-5. It would be interesting to see in how far the developments reported above are unique for the EC-5 region and whether or not they carry over to other areas as well. In this respect, a comparison of EC- 5 wage developments with the developments in another major integrating area naturally comes to mind. Fortunately, the SAF wage database contains sufficiently long and relatively complete series on gross hourly wages in five EFTA countries, viz. Norway, Sweden, Finland, Switzerland, and Austria. ${ }^{4}$

In Table 3.5 we analyze the rank ordering of sectors in these countries. We observe a similar pattern as we came across in the EC-5. Once more, one may identify notorious lowwage sectors like textiles, leather, and wearing apparel industries. In the high-wage and intermediate-wage sectors, the degree of similarity is much less than in the EC-5. Furthermore, note that, as far as the stability issue is concerned, quite a bit of capricious turbulence may be observed in some countries. The Norwegian, Finnish and Austrian wage structures are clearly the most stable. However, in Sweden, we observe that the 1964 number one industry (printing and publishing) is replaced by an intermediate-wage industry (paper and paper products) in 1985. In Switzerland, an intermediate-wage industry manages to penetrate into the top of the wage hierarchy. Finally, some industries appear to be in the top of the wage spectrum in most countries. These are: printing and publishing, basic metal industries, and metal products.

Table 3.6 reveals the coefficients of variation for gross hourly wages and highlights some interesting similarities and differences with the EC- 5 experience as well. Let us again start with the all-industry average. Measured in the current official ECU exchange rate, the wage disparity in EFTA-5 decreases between 1964 and 1989 from some 29 to 17 per cent. This implies a reduction of wage dispersion with approximately one third, and stands in contrast with the development of the EC- 5 wage differential. In addition, we may observe that EFTA-5 dispersion was much larger (almost twice as large) than EC- 5 wage dispersion in 1964. At the end of the observation period, however, wage dispersion in the two areas have become roughly the same ( 15 and 17 per cent for EC-5 and EFTA-5, respectively). Note also, that EFTA-5 wage dispersion tended to increase until 1969, and starts to decrease after that year. In the 1969-89 period one may observe a steady and continuous decline in wage dispersion.

Measured in PPPs, the data reveal a considerable convergence. Apart from the 1968/69 period, which marks a short and marginal divergence, the coefficient of variation decreased from some 47 per cent in 1964 to some 14 per cent in 1989, a reduction of approximately two thirds. Hence, it appears that the EFTA-5 PPP wages converged to a much larger extent than the EC-5 PPP wages, where the reduction amounts to roughly one third of the initial wage dispersion.

In the individual sectors of industry, the above described pattern shows up in the majority of cases. Note that the dispersion, measured in current official exchange rates, is higher in EFTA-5 than in EC-5 in practically all industries at the end of the observation period. However, EFTA-5's achievements in terms of current and PPP exchange rates are certainly not less impressive than those of EC-5, and it seems fair to conclude that EFTA-5 wages converged at least as much as did EC-5 wages.

${ }^{4}$ Below we do not focus attention on hourly labour costs in EFTA-5, since these data are far from complete and sufficiently long series could not meaningfully be produced. 
Table 3.5 Rank ordering of EFTA-5 gross hourly earnings (EFTA-5, ISIC industrial sectors)

\begin{tabular}{|c|c|c|c|c|c|c|c|c|c|c|c|c|c|c|c|}
\hline & 67 & $\begin{array}{l}\mathrm{N} \\
75\end{array}$ & 89 & 67 & $\begin{array}{c}S \\
75\end{array}$ & 89 & 67 & $\begin{array}{l}\mathrm{FI} \\
75\end{array}$ & 89 & 67 & $\frac{\mathrm{CH}}{75}$ & 89 & 67 & $\frac{\mathrm{AU}}{75}$ & 89 \\
\hline Food, beverages \&: tobacco & 9 & 6 & 7 & 91 & 9 & 7 & 7 & 7 & 7 & 6 & 6 & 6 & 9 & 6 & 6 \\
\hline Textiles & 8 & 8 & 9 & 11 & 10 & 10 & 10 & 9 & 9 & 9 & 9 & 8 & 7 & 8 & 8 \\
\hline Wearing apparel, except footwear & 10 & 10 & 10 & 12 & 12 & 12 & 11 & 11 & 11 & 10 & 10 & 10 & 10 & 10 & 10 \\
\hline \multicolumn{16}{|l|}{ Leather and products of leather, } \\
\hline leather substitutes, fur and footwear & 7 & 9 & 11 & 10 & 11 & 11 & 9 & 10 & 10 & 8 & 8 & 9 & 8 & 9 & 9 \\
\hline Wood wood products, incl. furniture & 6 & 7 & 8 & 7 & 8 & 9 & 8 & 8 & 8 & 4 & 5 & 7 & 6 & 7 & 7 \\
\hline Paper and paper products & 4 & 3 & 5 & 6 & 3 & 1 & 2 & 1 & 2 & 5 & 7 & 3 & 2 & 2 & 2 \\
\hline Printing, publishing \& allied products & 1 & 1 & 1 & 1 & 1 & 3 & 1 & 4 & 3 & 7 & 2 & 1 & na & na & na \\
\hline \multicolumn{16}{|l|}{ Chemicals and chemical, petroleum, } \\
\hline coal, rubber and plastic products & 5 & 5 & 3 & 8 & 7 & 4 & 6 & 6 & 6 & 1 & 1 & 2 & 5 & 4 & 3 \\
\hline \multicolumn{16}{|l|}{ Non-metallic mineral products, } \\
\hline except products of petroleum \& coal & 3 & 4 & 6 & 5 & 6 & 6 & 5 & 5 & 5 & 3 & 3 & 5 & 3 & 3 & 4 \\
\hline Basic metal industries & na & na & 2 & 3 & 2 & 2 & 4 & 2 & 1 & na & na & na & 1 & 1 & 1 \\
\hline \multicolumn{16}{|l|}{ Fabricated metal products, } \\
\hline machinery \& equipment ${ }^{13}$ & 2 & 2 & 4 & 4 & 5 & 8 & 3 & 3 & 4 & 2 & 4 & 4 & 4 & 5 & 5 \\
\hline Motor vehicies & na & na & 5 & 2 & 4 & 5 & na & na & na & na & na $r$ & na & na & na & na \\
\hline
\end{tabular}

1) Until 1979 including basic metal industries 
Table 3.6 Coefficients of variation: Intra-sectoral gross hourly earnings (EFTA-5, ISIC industrial sectors)

\begin{tabular}{|c|c|c|c|c|c|c|c|c|c|c|c|c|c|c|}
\hline \multicolumn{3}{|c|}{ ISIC No.: ${ }^{11}$} & \multicolumn{2}{|c|}{31} & \multicolumn{2}{|c|}{321} & \multicolumn{2}{|c|}{322} & \multicolumn{2}{|c|}{$323+324$} & \multicolumn{2}{|c|}{33} & \multicolumn{2}{|c|}{341} \\
\hline Defini & ${ }^{2)}(1)$ & (2) & (1) & (2) & (1) & (2) & & (2) & (1) & (2) & (1) & (2) & & (2) \\
\hline 1964 & 0.29 & 0.47 & 0.28 & 0.46 & 0.29 & 0.47 & 0.32 & 0.49 & 0.32 & 0.49 & 0.29 & 0.46 & 0.29 & 0.48 \\
\hline 1965 & 0.29 & 0.46 & 0.30 & 0.47 & 0.29 & 0.47 & 0.33 & 0.49 & 0.33 & 0.49 & 0.28 & 0.45 & 0.28 & 0.47 \\
\hline 1966 & 0.29 & 0.46 & 0.33 & 0.49 & 0.27 & 0.45 & 0.30 & 0.47 & 0.31 & 0.47 & 0.29 & 0.45 & 0.27 & 0.46 \\
\hline 1967 & 0.30 & 0.46 & 0.33 & 0.49 & 0.29 & 0.46 & 0.32 & 0.48 & 0.32 & 0.48 & 0.29 & 0.45 & 0.28 & 0.45 \\
\hline 1968 & 0.32 & 0.47 & 0.35 & 0.49 & 0.34 & 0.50 & 0.35 & 0.50 & 0.35 & 0.49 & 0.33 & 0.46 & 0.29 & 0.46 \\
\hline 1969 & 0.33 & 0.48 & 0.32 & 0.47 & 0.35 & 0.51 & 0.35 & 0.50 & 0.37 & 0.51 & 0.33 & 0.47 & 0.30 & 0.47 \\
\hline 1970 & 0.32 & 0.46 & 0.31 & 0.45 & 0.35 & 0.49 & 0.35 & 0.48 & 0.36 & 0.49 & 0.32 & 0.45 & 0.29 & 0.45 \\
\hline 1971 & 0.31 & 0.45 & 0.30 & 0.43 & 0.34 & 0.46 & 0.34 & 0.47 & 0.35 & 0.47 & 0.31 & 0.43 & 0.27 & 0.42 \\
\hline 1972 & 0.31 & 0.44 & 0.31 & 0.44 & 0.35 & 0.48 & 0.35 & 0.48 & 0.35 & 0.47 & 0.32 & 0.43 & 0.29 & 0.44 \\
\hline 1973 & 0.27 & 0.41 & 0.27 & 0.40 & 0.31 & 0.44 & 0.32 & 0.44 & 0.31 & 0.43 & 0.28 & 0.39 & 0.25 & 0.40 \\
\hline 1974 & 0.25 & 0.39 & 0.24 & 0.37 & 0.28 & 0.41 & 0.29 & 0.42 & 0.30 & 0.41 & 0.26 & 0.37 & 0.23 & 0.39 \\
\hline 1975 & 0.25 & 0.39 & 0.24 & 0.38 & 0.29 & 0.42 & 0.30 & 0.43 & 0.28 & 0.40 & 0.26 & 0.37 & 0.24 & 0.39 \\
\hline 1976 & 0.26 & 0.39 & 0.25 & 0.38 & 0.30 & 0.42 & 0.31 & 0.44 & 0.31 & 0.43 & 0.26 & 0.37 & 0.26 & 0.40 \\
\hline 1977 & 0.25 & 0.35 & 0.22 & 0.33 & 0.29 & 0.39 & 0.30 & 0.42 & 0.30 & 0.39 & 0.25 & 0.34 & 0.23 & 0.35 \\
\hline 1978 & 0.26 & 0.29 & 0.24 & 0.27 & 0.29 & 0.33 & 0.30 & 0.35 & 0.33 & 0.34 & 0.27 & 0.29 & 0.22 & 0.28 \\
\hline 1979 & 0.23 & 0.27 & 0.22 & 0.24 & 0.27 & 0.31 & 0.29 & 0.34 & 0.31 & 0.33 & 0.25 & 0.26 & 0.20 & 0.26 \\
\hline 1980 & 0.21 & 0.26 & 0.21 & 0.24 & 0.26 & 0.29 & 0.28 & 0.33 & 0.27 & 0.30 & 0.23 & 0.24 & 0.19 & 0.24 \\
\hline 1981 & 0.22 & 0.25 & 0.21 & 0.23 & 0.26 & 0.28 & 0.27 & 0.31 & 0.27 & 0.29 & 0.24 & 0.25 & 0.20 & 0.23 \\
\hline 1982 & 0.21 & 0.22 & 0.21 & 0.21 & 0.25 & 0.24 & 0.25 & 0.27 & 0.26 & 0.26 & 0.25 & 0.24 & 0.19 & 0.20 \\
\hline 1983 & 0.21 & 0.21 & 0.22 & 0.21 & 0.25 & 0.24 & 0.25 & 0.25 & 0.27 & 0.26 & 0.27 & 0.25 & 0.19 & 0.18 \\
\hline 1984 & 0.20 & 0.25 & 0.21 & 0.20 & 0.24 & 0.23 & 0.25 & 0.30 & 0.26 & 0.24 & 0.25 & 0.21 & 0.18 & 0.21 \\
\hline 1985 & 0.20 & 0.20 & 0.19 & 0.19 & 0.23 & 0.23 & 0.25 & 0.25 & 0.25 & 0.25 & 0.23 & 0.23 & 0.17 & 0.17 \\
\hline 1986 & 0.19 & 0.18 & 0.20 & 0.20 & 0.23 & 0.24 & 0.23 & 0.22 & 0.25 & 0.26 & 0.24 & 0.25 & 0.17 & 0.17 \\
\hline 1987 & 0.19 & 0.18 & 0.20 & 0.21 & 0.23 & 0.24 & 0.24 & 0.22 & 0.26 & 0.26 & 0.24 & 0.25 & 0.17 & 0.17 \\
\hline 1988 & 0.18 & 0.17 & 0.19 & 0.20 & 0.23 & 0.24 & 0.25 & 0.22 & 0.25 & 0.26 & 0.23 & 0.24 & 0.15 & 0.15 \\
\hline 1989 & 0.17 & 0.14 & 0.17 & 0.17 & 0.22 & 0.22 & 0.25 & 0.22 & 0.24 & 0.24 & 0.20 & 0.21 & 0.15 & 0.14 \\
\hline
\end{tabular}

1), 2) See explanatory notes to Table 3.2 . 


\begin{tabular}{|c|c|c|c|c|c|c|c|c|c|c|c|c|}
\hline \multicolumn{3}{|c|}{ ISIC No.:") 342} & \multicolumn{2}{|c|}{35} & \multicolumn{2}{|c|}{36} & \multicolumn{2}{|c|}{37} & \multicolumn{2}{|c|}{38} & \multicolumn{2}{|c|}{3843} \\
\hline Definit & ${ }^{2)}(1)$ & (2) & (1) & (2) & (1) & (2) & (1) & (2) & (1) & (2) & (1) & (2) \\
\hline 1964 & 0.17 & 0.32 & 0.26 & 0.43 & 0.27 & 0.45 & na & na & 0.29 & 0.47 & na & na \\
\hline 1965 & 0.17 & 0.31 & 0.26 & 0.42 & 0.28 & 0.45 & na & na & 0.29 & 0.46 & na & na \\
\hline 1966 & 0.18 & 0.32 & 0.27 & 0.42 & 0.28 & 0.45 & na & na & 0.29 & 0.46 & na & na \\
\hline 1967 & 0.19 & 0.32 & 0.28 & 0.42 & 0.29 & 0.45 & na & na & 0.30 & 0.46 & na & $\mathrm{na}$ \\
\hline 1968 & 0.21 & 0.34 & 0.29 & 0.43 & 0.31 & 0.46 & na & na & 0.32 & 0.47 & na & na \\
\hline 1969 & 0.23 & 0.36 & 0.29 & 0.43 & 0.32 & 0.47 & na & na & 0.32 & 0.47 & na & na \\
\hline 1970 & 0.24 & 0.35 & 0.29 & 0.42 & 0.32 & 0.45 & na & na & 0.32 & 0.46 & na & na \\
\hline 1971 & 0.22 & 0.32 & 0.28 & 0.40 & 0.30 & 0.43 & na & na & 0.31 & 0.44 & na & na \\
\hline 1972 & 0.23 & 0.32 & 0.29 & 0.40 & 0.29 & 0.42 & na & na & 0.30 & 0.43 & na & na \\
\hline 1973 & 0.20 & 0.28 & 0.26 & 0.35 & 0.25 & 0.37 & na & na & 0.27 & 0.40 & na & na \\
\hline 1974 & 0.18 & 0.28 & 0.26 & 0.34 & 0.23 & 0.36 & na & na & 0.26 & 0.38 & na & na \\
\hline 1975 & 0.19 & 0.29 & 0.25 & 0.34 & 0.24 & 0.36 & na & na & 0.25 & 0.38 & na & na \\
\hline 1976 & 0.19 & 0.28 & 0.28 & 0.36 & 0.25 & 0.36 & na & na & 0.26 & 0.38 & na & na \\
\hline 1977 & 0.20 & 0.28 & 0.26 & 0.32 & 0.23 & 0.32 & na & na & 0.25 & 0.35 & na & na \\
\hline 1978 & 0.24 & 0.23 & 0.30 & 0.29 & 0.26 & 0.27 & na & na & 0.26 & 0.29 & na & na \\
\hline 1979 & 0.22 & 0.20 & 0.28 & 0.27 & 0.24 & 0.25 & na & na & 0.23 & 0.26 & na & na \\
\hline 1980 & 0.20 & 0.19 & 0.23 & 0.24 & 0.21 & 0.24 & na & na & 0.22 & 0.25 & na & na \\
\hline 1981 & 0.19 & 0.16 & 0.22 & 0.23 & 0.22 & 0.23 & na & na & na & na & na & na \\
\hline 1982 & 0.22 & 0.19 & 0.24 & 0.23 & 0.22 & 0.22 & na & na & na & na & na & na \\
\hline 1983 & 0.26 & 0.24 & 0.27 & 0.25 & 0.24 & 0.23 & na & na & na & na & na & $\mathrm{na}$ \\
\hline 1984 & 0.23 & 0.23 & 0.24 & 0.19 & 0.22 & 0.20 & na & na & na & na & na & na \\
\hline 1985 & 0.21 & 0.21 & 0.23 & 0.23 & 0.21 & 0.21 & $\mathrm{na}$ & na & na & na & na & na \\
\hline 1986 & 0.23 & 0.24 & 0.24 & 0.25 & 0.21 & 0.22 & na & na & na & na & na & na \\
\hline 1987 & 0.25 & 0.25 & 0.24 & 0.25 & 0.22 & 0.23 & na & na & na & na & na & na \\
\hline 1988 & 0.23 & 0.24 & 0.23 & 0.25 & 0.21 & 0.21 & na & na & na & na & na & na \\
\hline 1989 & 0.19 & 0.21 & 0.19 & 0.20 & 0.18 & 0.18 & na & na & na & na & na & na \\
\hline
\end{tabular}

${ }^{11,2)}$ See explanatory notes to Table 3.2. 


\subsubsection{Labour cost per manyear}

In this sub-section we shall discuss the development of labour costs per manyear. The data for this analysis were taken from the National Accounts, Detailed Tables by Branch, which are published by Eurostat. This source contains sectoral data on a variety of variables and has been published by Eurostat on a regular basis since 1970. The yearly labour costs were calculated by dividing the amount of compensation of employees by the total number of salary earners in manyears. The wage rates that were obtained in this way pertain to 14 NACE R-25 manufacturing sectors.

In Table 3.7 we have listed the coefficients of variation for the sectors under consideration. For each sector, we converted wages by the official current ECU exchange rate and the PPP exchange rate (definitions 1 and 2, resp.). Let us start with the all-industry average wage for the manufacturing sector (NACE 3). Expressing wages in current ECU exchange rates, we observe a marginal decline in dispersion in 1970, but a strong increase in dispersion after that year. This diverging tendency continues until 1978/79, which marks the start of a strong convergence in wages. This converging trend continues until the end of the observation period. All in all, wage dispersion decreases from 11 per cent in 1970 to some 5 per cent in 1989, which implies a reduction of more than half of the initial dispersion.

The dispersion of PPP wages shows a continuous trend downwards. In 1969, dispersion equals 13 per cent, and this percentage seems to decline to some 8 per cent in 1989, which is a reduction of approximately $\mathbf{4 0}$ per cent. There is a short and marginal increase in dispersion after the second oil shock in 1979, but that event could not reverse the structural downward trend in the direction of convergence. Hence, it seems fair to say, that the yearly labour cost information strongly supports the converging trend that we found for gross hourly wages and hourly labour costs.

By and large, the individual manufacturing sectors display a similar pattern. In most cases, dispersion expressed in both exchange rates seems to decline. Exceptions to this tendency may be found in the following cases: a. for wages expressed in current exchange rates, dispersion increases in the chemical sector (NACE 17), agricultural and industrial machinery (NACE 21), and transport equipment (NACE 28); b. for PPP wages, dispersion increases in the chemical sector (NACE 17), agricultural and industrial machinery (NACE 21), and office and dataprocessing machines, precision and optical instruments (NACE 23). Therefore, it seems safe to conclude that wages have converged in the vast majority of cases.

Table 3.8 lists the labour costs in each country relative to the EC-5 average. These data reveal some interesting similarities and differences with the gross hourly wages and hourly labour costs. First of all, note that the German supremacy in the hourly wage hierarchy largely disappears if we look at labour costs per manyear. German wages are, over the entire observation period, roughly equal to the average EC. -5 wage rate. However, some German branches clearly show a lower or higher wage than the EC-5 average. Significantly below average are the ferrous and non-ferrous ores and metal (NACE 13), the electrical goods (NACE 25), the food, beverages and tobacco (NACE 36), the textiles and clothing (NACE 42), and the paper and printing (NACE 47) industries. Distinctly higher than average are agricultural and industrial machinery (NACE 21), and the transport equipment (NACE 28) industry. 
Table 3.7 Coefficients of variation: intra-sectoral labour cost per manyear (NACE industrial sectors)

\begin{tabular}{|c|c|c|c|c|c|c|c|c|c|c|c|c|c|c|}
\hline \multicolumn{3}{|c|}{$\begin{array}{l}\text { NACE No. }{ }^{11} 30 \\
\text { Definition: }^{23}(1) \quad(2)\end{array}$} & & (2) & \multicolumn{2}{|c|}{15} & & \multicolumn{2}{|c|}{19} & & (2) & $(1)^{2}$ & 3 \\
\hline 1969 & 0.11 & 0.13 & 0.12 & 0.11 & 0.12 & 0.15 & 0.04 & 0.08 & 0.10 & 0.12 & 0.07 & 0.07 & 0.48 & 0.42 \\
\hline 1970 & 0.09 & 0.13 & 0.08 & 0.12 & 0.11 & 0.15 & 0.05 & 0.09 & 0.13 & 0.16 & 0.08 & 0.09 & 0.37 & 0.36 \\
\hline 1971 & 0.10 & 0.13 & 0.10 & 0.13 & 0.13 & 0.16 & 0.07 & 0.09 & 0.16 & 0.18 & 0.09 & 0.09 & 0.36 & 0.36 \\
\hline 1972 & 0.11 & 0.12 & 0.11 & 0.12 & 0.14 & 0.15 & 0.09 & 0.10 & 0.17 & 0.18 & 0.09 & 0.09 & 0.33 & 0.33 \\
\hline 1973 & 0.14 & 0.12 & 0.13 & 0.12 & 0.16 & 0.14 & 0.12 & 0.10 & 0.18 & 0.17 & 0.13 & 0.10 & 0.29 & 0.28 \\
\hline 1974 & 0.16 & 0.13 & 0.14 & 0.12 & 0.18 & 0.14 & 0.16 & 0.11 & 0.19 & 0.15 & 0.14 & 0.09 & 0.22 & 0.23 \\
\hline 1975 & 0.15 & 0.11 & 0.16 & 0.13 & 0.17 & 0.13 & 0.11 & 0.07 & 0.18 & 0.14 & 0.12 & 0.07 & 0.24 & 0.23 \\
\hline 1976 & 0.18 & 0.10 & 0.17 & 0.10 & 0.20 & 0.12 & 0.15 & 0.07 & 0.19 & 0.12 & 0.17 & 0.09 & 0.28 & 0.25 \\
\hline 1977 & 0.20 & 0.11 & 0.18 & 0.10 & 0.22 & 0.13 & 0.19 & 0,09 & 0.20 & 0.11 & 0.18 & 0.10 & 0.29 & 0.25 \\
\hline 1978 & 0.20 & 0.11 & 0.20 & 0.11 & 0.22 & 0.12 & 0.18 & 0.09 & 0.20 & 0.11 & 0.18 & 0.09 & 0.30 & 0.25 \\
\hline 1979 & 0.18 & 0.10 & 0.19 & 0.11 & 0.19 & 0.11 & 0.16 & 0.08 & 0.18 & 0.11 & 0.16 & 0.08 & 0.31 & 0.27 \\
\hline 1980 & 0.17 & 0.12 & 0.18 & 0.12 & 0.17 & 0.11 & 0.16 & 0.11 & 0.17 & 0.12 & 0.15 & 0.10 & 0.28 & 0.26 \\
\hline 1981 & 0.15 & 0.11 & 0.15 & 0.10 & 0.14 & 0.10 & 0.14 & 0.11 & 0.15 & 0.11 & 0.13 & 0.09 & 0.29 & 0.27 \\
\hline 1982 & 0.14 & 0.10 & 0.12 & 0.09 & 0.12 & 0.09 & 0.12 & 0.10 & 0.13 & 0.10 & 0.10 & 0.08 & 0.27 & 0.27 \\
\hline 1983 & 0.11 & 0.10 & 0.11 & 0.11 & 0.11 & 0.09 & 0.10 & 0.09 & 0.12 & 0.11 & 0.09 & 0.09 & 0.24 & 0.25 \\
\hline 1984 & 0.09 & 0.09 & 0.09 & 0.10 & 0.09 & 0.09 & 0.09 & 0.09 & 0.10 & 0.10 & 0.08 & 0.08 & 0.25 & 0.27 \\
\hline 1985 & 0.09 & 0.09 & 0.08 & 0.08 & 0.09 & 0.09 & 0.09 & 0.09 & 0.10 & 0.10 & 0.09 & 0.09 & 0.25 & 0.25 \\
\hline 1986 & 0.09 & 0.09 & 0.08 & 0.08 & 0.09 & 0.10 & 0.11 & 0.11 & 0.11 & 0.11 & 0.10 & 0.10 & 0.24 & 0.25 \\
\hline 1987 & 0.09 & 0.09 & 0.09 & 0.09 & 0.10 & 0.10 & 0.11 & 0.11 & 0.10 & 0.10 & 0.10 & 0.10 & na & na \\
\hline 1988 & 0.08 & 0.09 & 0.08 & 0.08 & 0.10 & 0.11 & 0.12 & 0.12 & 0.08 & 0.09 & 0.10 & 0.11 & na & na \\
\hline 1989 & 0.05 & 0.088 & 0.07 & 0.08 & 0.09 & 0.11 & 0.10 & 0.11 & 0.07 & 0.09 & 0.09 & 0.10 & na & na \\
\hline
\end{tabular}


$\infty$

(3)

E

g

ब

E

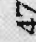

ने

$\bar{E}$

त

ली

$\pm$

ฮิ

号

5

त) in

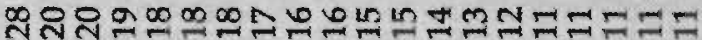

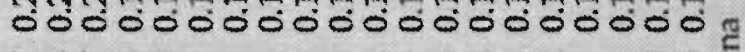

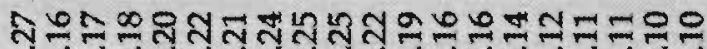

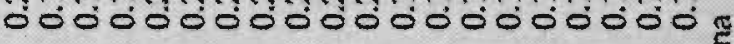

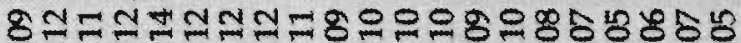

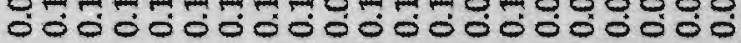

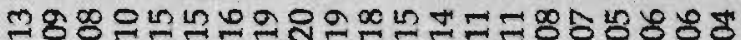

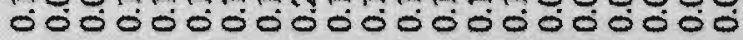

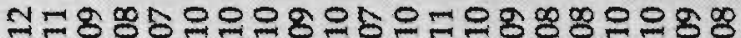

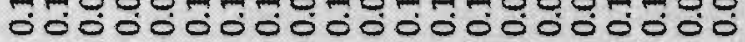

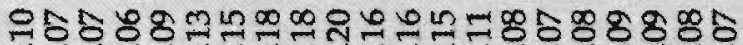

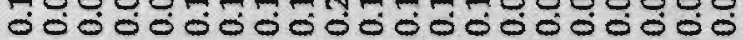

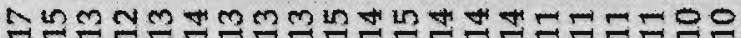

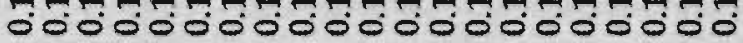

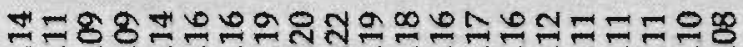

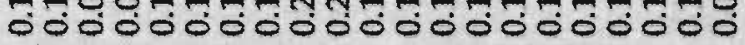

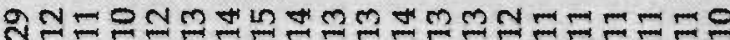

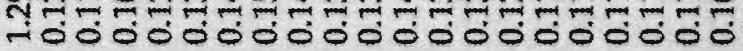
1

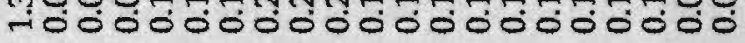

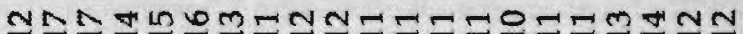

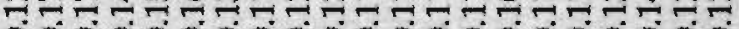
000000000000000000000

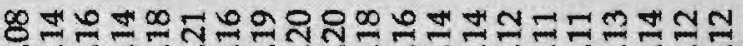

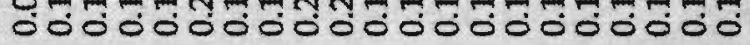

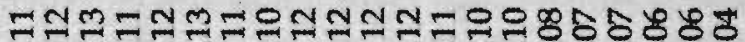

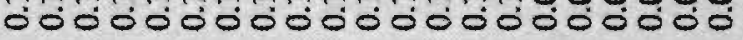

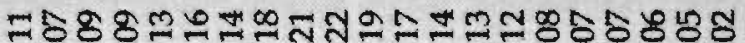

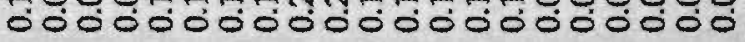


Table 3.7 (Continued)

Notes:

1) The sector classification codes refer to the following NACE R-25 sectors:

30 Marufacturing products

13 Ferrous and non-ferrous ores, and metals, other than radioactive

15 Non-metallic minerals and mineral products

17 Chemical products

19 Metal products, except machinery and transport equipment

21 Agricultural and industrial machinery

23 Office and data processing machines, precision and optical instruments

25 Electrical goods

28 Transport equipment

36 Food, beverages and tobacco

42 Textiles and clothing, leather and footwear

47 Paper and printing products

49 Rubber and plastic products

48 Other manufacturing products

2) Definitions of wages used:

(1) nominal wages at current ECU rate

(2) nominal wages at PPPs

Secondly, note that French wages are generally higher than average, although there seems to be a decreasing tendency in French relative wages. This result is in contrast with what we found for hourly wages and labour costs, where it was concluded that French relative wages were below average. Apparently, the weekly hours of work offered by French workers exceed those of German workers.

For Italy we find a confirmation of its convergence towards the average. In many sectors, this convergence is quite substantial, indeed. Although most Italian sectors show a set back in the $1970 \mathrm{~s}$, convergence re-emerges in the $1980 \mathrm{~s}$, and more than makes up for the loss which marked the 1970 s.

Finally, Dutch and Belgian wages also reveal a similar pattern as what we found for hourly wages and labour costs. Expressed in current exchange rates both countries have considerably higher wages than the average in the 1970s, and experience a decline again in the 1980s, although the magnitude of this decline varies per sector. PPP wages in The Netherlands were clearly above average in the 1970 s, and subsequently declined towards the average. In some sectors, Dutch wages even decline below average, and occasionally even below the level of Italian wages (agricultural and industrial machinery, transport equipment, and other manufacturing products). Except in the transport equipment and textiles and clothing industries, Belgian wages remain higher than the average.

In sum, we may conclude that our data imply a considerable decline in EC- 5 wage differentials. This decline is primarily caused by Italy's catching up with the average, and with a relative decline in the position of high-wage countries. 
Table 3.8 Labour cost per manyear relative to EC-5 average; NACE R-25 sectors

\begin{tabular}{|c|c|c|c|c|c|c|c|c|c|c|}
\hline & & urrent & excha & ige rat & & Pu & chasin & g pow & er pari & ties \\
\hline & B & D & F & 1 & NL & B & D & $F$ & I & NL \\
\hline 30 & & nufact & uring & roduc & & & & & & \\
\hline 1970 & 0.99 & 1.06 & 1.06 & 0.83 & 1.06 & 0.95 & 1604 & 1.06 & 0.79 & 1.16 \\
\hline 1975 & 1.10 & 1.00 & 1.03 & 0.72 & 1.15 & 1.04 & 0.98 & 1.02 & 0.81 & 1.15 \\
\hline 1980 & 1.16 & 1.02 & 1.04 & 0.68 & 1.11 & 1.07 & 1.02 & 1.04 & 0.77 & 1.10 \\
\hline 1985 & 1.04 & 1.03 & 1.05 & 0.83 & 1.05 & 1.04 & 1.03 & 1.05 & 0.83 & 1.05 \\
\hline 1989 & 1.04 & 1.05 & 0.99 & 0.90 & 1.01 & 1.05 & 1.05 & 1.02 & 0.85 & 1.03 \\
\hline 13 & & rous a & nd non & -ferro & $s$ ores & als, of & ner the & n radi & Dactive & \\
\hline 1969 & 1.00 & 0.86 & 1.19 & 0.90 & 1.05 & 0.98 & 0.94 & 1.09 & 0.84 & 1.16 \\
\hline 1975 & 1.06 & 0.92 & 1.17 & 0.73 & 1.12 & 1.00 & 0.91 & 1.15 & 0.82 & 1.12 \\
\hline 1980 & 1.23 & 0.94 & 1.04 & 0.70 & 1.10 & 1.14 & 0.94 & 1.04 & 0.80 & 1.08 \\
\hline 1985 & 1.11 & 0.98 & 1.02 & 0.87 & 1.02 & 1.11 & 0.98 & 1.02 & 0.87 & 1.02 \\
\hline 1989 & 1.12 & 0.94 & 0.93 & 0.98 & 1.03 & 1.12 & 0.94 & 0.96 & 0.92 & 1.06 \\
\hline 15 & & n-mets & llic mi & nerals & and $\mathrm{m}$ & oducts & & & & \\
\hline 1969 & 1.02 & 1.02 & 1.14 & 0.78 & 1.04 & 0.99 & 1.11 & 1.03 & 0.73 & 1.14 \\
\hline 1975 & 1.16 & 0.99 & 0.99 & 0.69 & 1.17 & 1.09 & 0.98 & 0.98 & 0.78 & 1.17 \\
\hline 1980 & 1.17 & 1.02 & 1.04 & 0.68 & 1.08 & 1.09 & 1.03 & 1.04 & 0.78 & 1.07 \\
\hline 1985 & 1.03 & 1.01 & 1.09 & 0.84 & 1.03 & 1.03 & 1.01 & 1.09 & 0.84 & 1.03 \\
\hline 1989 & 1.12 & 0.87 & 1.06 & 0.92 & 1.02 & 1.13 & 0.87 & 1.08 & 0.87 & 1.05 \\
\hline 17 & & mical & produ & & & & & & & \\
\hline 1969 & 0.95 & 0.97 & 1.07 & 0.98 & 1.03 & 0.92 & 1.06 & 0.97 & 0.91 & 1.13 \\
\hline 1975 & 1.11 & 1.06 & 0.97 & 0.79 & 1.07 & 1.04 & 1.04 & 0.96 & 0.88 & 1.07 \\
\hline 1980 & 1.16 & 1.08 & 1.03 & 0.69 & 1.03 & 1.08 & 1.09 & 1.03 & 0.79 & 1.02 \\
\hline 1985 & 1.05 & 1.13 & 0.99 & 0.85 & 0.98 & 1.05 & 1.13 & 0.99 & 0.85 & 0.98 \\
\hline 1989 & 1.09 & 1.14 & 0.93 & 0.90 & 0.94 & 1.09 & 1.14 & 0.96 & 0.85 & 0.96 \\
\hline 19 & & tal pro & ducts, & excep & mach & trans & gort ec & uipme & & \\
\hline 1969 & 1.11 & 0.96 & 1.07 & 0.84 & 1.03 & 1.08 & 1.04 & 0.98 & 0.78 & 1.13 \\
\hline 1975 & 1.17 & 0.99 & 0.94 & 0.70 & 1.19 & 1.10 & 0.98 & 0.94 & 0.79 & 1.19 \\
\hline 1980 & 1.19 & 1.04 & 1.02 & 0.68 & 1.07 & 1.10 & 1.05 & 1.02 & 0.77 & 1.05 \\
\hline 1985 & 1.10 & 1.04 & 1.06 & 0.80 & 1.00 & 1.10 & 1.04 & 1.06 & 0.80 & 1.00 \\
\hline 1989 & 1.07 & 1.07 & 1.01 & 0.88 & 0.97 & 1.07 & 1.07 & 1.03 & 0.83 & 0.99 \\
\hline 21 & & icultu & al and & indus & trial n & & & & & \\
\hline 1969 & 0.95 & 1.01 & 1.12 & 1.01 & 0.91 & 0.92 & 1.11 & 1.03 & 0.94 & 1.00 \\
\hline 1975 & 1.15 & 1.05 & 1.04 & 0.78 & 0.97 & 1.09 & 1.03 & 1.03 & 0.88 & 0.97 \\
\hline 1980 & 1.17 & 1.08 & 1.08 & 0.73 & 0.94 & 1.08 & 1.08 & 1.07 & 0.84 & 0.92 \\
\hline 1985 & 1.09 & 1.07 & 1.05 & 0.89 & 0.90 & 1.09 & 1.07 & 1.05 & 0.89 & 0.90 \\
\hline 1989 & 1.11 & 1.09 & 0.98 & 0.96 & 0.85 & 1.12 & 1.09 & 1.01 & 0.91 & 0.87 \\
\hline
\end{tabular}


Table 3.8 (Continued)

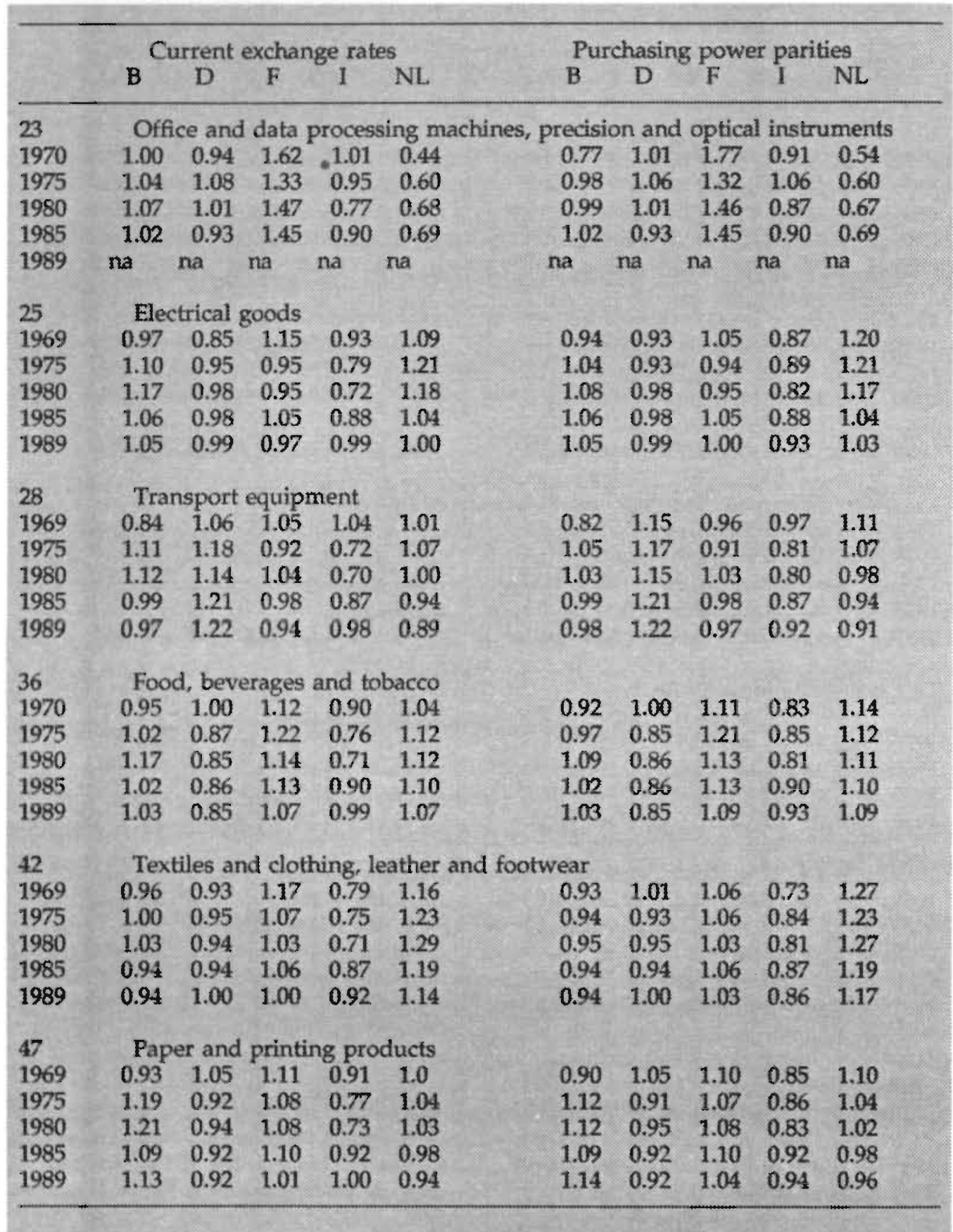


Table 3.8 (Continued)

\begin{tabular}{|c|c|c|c|c|c|c|c|c|c|c|}
\hline & \multicolumn{5}{|c|}{ Current exchange rates } & \multicolumn{5}{|c|}{ Purchasing power parities } \\
\hline & B & $\mathrm{D}$ & F & 1 & NL & B & $\mathrm{D}$ & $\mathrm{F}$ & I & NL \\
\hline 49 & \multicolumn{5}{|c|}{ Rubber and plastic products } & & & & & \\
\hline 1969 & 1.05 & 0.82 & 1.21 & 0.94 & 0.98 & 1.02 & 0.90 & 1.11 & 0.88 & 1.08 \\
\hline 1975 & 1.18 & 0.91 & 0.93 & 0.80 & 1.19 & 1.12 & 0.89 & 0.92 & 0.89 & 1.18 \\
\hline 1980 & 1.18 & 0.97 & 0.97 & 0.75 & 1.14 & 1.09 & 0.97 & 0.96 & 0.85 & 1.13 \\
\hline 1985 & 1.07 & 0.96 & 0.98 & 0.90 & 1.09 & 1.07 & 0.96 & 0.98 & 0.90 & 1.09 \\
\hline 1989 & 1.07 & 0.99 & 0.94 & 1.00 & 1.01 & 1.08 & 0.99 & 0.96 & 0.94 & 1.03 \\
\hline 48 & \multicolumn{5}{|c|}{ Other manufacturing products } & & & & & \\
\hline 1969 & 1.03 & 0.96 & 1.34 & 0.52 & 1.15 & 0.99 & 1.05 & 1.22 & 0.48 & 1.26 \\
\hline 1975 & 1.17 & 0.97 & 1.09 & 0.60 & 1.17 & 1.11 & 0.96 & 1.08 & 0.68 & 1.18 \\
\hline 1980 & 1.13 & 1.01 & 1.00 & 0.64 & 1.21 & 1.05 & 1.02 & 1.00 & 0.74 & 1.19 \\
\hline 1985 & 0.93 & 1.02 & 1.06 & 0.83 & 1.15 & 0.93 & 1.02 & 1.06 & 0.83 & 1.15 \\
\hline 1989 & na & na & na & na & na & na & na & na & na & na \\
\hline
\end{tabular}

\subsection{Conclusions}

In this chapter we analyzed the development of the wage differential in the five most important founding countries of the EC. We worked with a relatively high level of aggregation, notably NACE 2 digit and ISIC 2 and, occasionally, 3 digit industries. Although our data material is therefore quite crude, we found some interesting tendencies. These may be summarized as follows:

a. for gross hourly wages and hourly labour costs:

- expressed in current official ECU exchange rates, wages did not show much convergence in the EC-5 region. However, since current exchange rates to a large extent reflect inflation differentials between countries, one should be extremely careful in the interpretation of dispersion measures based upon this method of comparison.

- expressed in PPP exchange rates, we found evidence of a considerable convergence in wage rates. This convergence takes place in the vast majority of industrial sectors and is primarily due to low-wage countries which catch up with the EC-5 average and high-wage countries which fall back to the EC-5 average.

b. as far as yearly labour costs per manyear in the EC-5 area are concerned, we also find clear and convincing evidence of convergence according to both exchange rate definitions of wages.

c. Finally, we found evidence of convergence in the EFTA-5 region as well. Thus, it appears that convergence was not restricted to the $\mathrm{EC}$, and that this phenomenon is seen between other countries than EC-5 as well. 



\section{CHAPTER}

\subsection{Introduction}

In the previous chapter we pointed at three regularities in the available data material. As far as a country's internal wage structure was concerned, we found that there is a considerable stability in that wage structure. As far as an international comparison of the wage structure was concerned, the evidence indicated a considerable amount of similarity between countries. Finally, as far as the development of (international) wage differentials was concerned, we found considerable evidence of international wage convergence, be it that existing wage differentials did not totally disappear and therefore also seem to be quite persistent.

The three dimensions of wage differentials which are mentioned above have been discussed in two branches of economic literature. The theory of labour economics has primarily dealt with the explanation of the stability and similarity of wage structures. International trade theory has primarily adressed the persistence and development of international wage differentials. This chapter's purpose is to review the most important contributions from both branches of the literature. Since our point of departure is a trade theoretical one, contributions from that part of the literature will receive most of our attention.

The theory of labour economics offers two types of explanations for the stability and similarity of wage structures, viz. competitive explanations and non-competitive explanations. In explanations of the first type, factors like compensating wage differentials and different quality levels of workers are emphasized. In explanations of the second type, factors like labour market institutions, insider-outsider relations and firms' abilities to pay economic rents have surfaced as explanatory variables. These studies will be surveyed in section 4.2 .

In the international trade literature four types of study have addressed the problem of the persistence and development of wage differentials. All these studies could, in one way or another, be regarded as tests of (certain aspects of) the factor price equalisation theorem. First, one could try to find out whether or not the most important assumptions underlying factor price equalisation theory are fulfilled. This kind of test has occupied a substantial part of the empirical literature and will be the topic of section 4.3. 
The second kind of test that has been used assumes that the conditions underlying factor price equalisation theory are fulfilled and consists of a test of the implications of that theory. These implications will be discussed in section 4.4. In addition to that, we shall try to improve on these studies and attempt to evaluate their contribution. We shall conclude that, with a few exceptions, their nature is ad hoc, rather than based on optimising behaviour on the part of economic agents. Thus, one could argue that these studies do not test the predictions of the theory they are pretending to test.

The third kind of model takes the microeconomic production and cost theory as a starting point and attempts to derive values for the Stolper-Samuelson elasticities directly from estimates of the parameters of production or cost functions. These studies, which shall be discussed in section 4.5 , are able to yield precise estimates of the distributional effects of trade policies.

Finally, one could try to estimate the parameters of a growth model, to see how this model explains factor price behaviour, and to investigate whether or not it predicts a convergence of factor prices when trade is liberalised. Section 4.6 contains a discussion of a model that is inspired on models of the development of regional wage differentials in the USA. The model concerns aggregate wage differentials and is applied to the founding countries of the EC.

\subsection{The theory of wage structures}

In the previous chapter we found evidence of a considerable similarity and stability of the national wage structures in the EC-5 and EFTA-5 regions. This finding is by no means a peculiarity of our study and has been well-documented in the literature (cf. Butler (1967), Saunders and Marsden (1980), Papola and Bharadway (1970), OECD (1965, 1985), Reder (1962), Molle and Van Mourik (1989)). Many of the studies addressing the problem of international wage structure comparisons have confined themselves to the measurement of wage differentials as such, and do not pass beyond mere speculation as to the causes of the tendencies they claim to observe, for instance the influence of economic integration. An exception is Bouteiller (1971), who put forward and tested some hypotheses about industrial structures of wages in each national economy. He found that in each of the five founding countries of the EC, the variation of earnings among industries was, on average, reasonably well explained by the same factors, namely: sectoral differences in labour productivity, the quality of labour, the percentage of females, the concentration degree of industries, and a measure of the capital-labour ratio of each industry. Bouteiller's study suffers from two serious drawbacks, however. First, like most studies, it limits the explanation to separate national wage structures and, therefore, cannot be said to have tested a theory of international wage differentials. Second, Bouteiller's empirical analyses are based on cross-sectional evidence, whereas a theory of international interindustry wage differentials would give an indication of the temporal adjustment process. However, the question of the temporal development of wage structures is left untouched in his analysis.

Recently the OECD (1985) gave a new impetus to the study of this matter by explaining the changes in relative wages with the help of a model, in which changing productivity, concentration of sectors, changing import penetration and export performance, and changes in the value of shipments were significant explanatory variables. However, the differences among countries in the sizes of coefficients and the mix of explanatory variables, and the fact that of the European countries only the UK has been considered, leave many questions unanswered. 
In Molle and Van Mourik $\left(1989^{a}\right)$ several studies were brought together which gave a fresh look on the matter. The empirical analyses for the EC countries revealed that significant wage differentials between these countries still existed in the 1970s and 1980s. The analysis showed that there are three high-wage countries, viz. The Netherlands, Belgium and Germany. The countries with wages below EC-average were France, the U.K. and Italy. As to the sectoral composition of international wage differentials, the conclusion seemed warranted that although there have been some changes in the European wage structure in the 1970-1985 period, high-wage countries tended to remain highwage countries, whereas low-wage countries also tended to keep their position in the wage hierarchy. Despite the fact that there seems to have been a narrowing of wage differentials in some sectors, the overall picture was one of stability.

As far as the internal wage structure in these countries is concerned, the overall picture was also one of stability. It turned out that high-wage sectors generally remained being so in the course of time and that low-wage sectors also tended to keep their position in the bottom of the wage hierarchy.

As Vasille (1989) has shown, these results hold, regardless of the definition of wages. The sectoral wage hierarchy, whether expressed in terms of (gross) hourly earnings or hourly labour costs, or in terms of worker compensation per manyear proves to be rather stable in the course of time, although there are countries where the magnitude of the sectoral wage differential has declined.

The question arises, of course, what factors might account for the observed similarity and stability of the wage structure. Broadly speaking, one could argue that wages are the result of competitive forces, i.e., interaction of demand and supply, and non-competitive forces. As far as competitive forces are concerned, a distinction between factors determining the supply and factors determining the demand for labour may be useful, as Molle and Van Mourik $\left(1989^{\mathrm{a}}\right)$ have suggested. As far as non-competitive forces are concerned one might think of the influence of the institutional structure or culture and traditions.

Supply determining forces causing sectoral wage differentials that have been prominent in the literature are the following. First, imperfect intersectoral mobility of labour precludes reallocation of labour in response to a wage differential when the returns exceed the costs of such a movement. As a consequence, factor price differentials will persist, even in the long-run. Second, the skill structure is another important supply determining force of branch wage differentials. As Vasille's (1989) analysis has confirmed, high-wage industries frequently require higher skills from their workers than lowerwage ones. In this respect, an interesting correlation that has been found on many occasions is the one between the high wages for skilled and unskilled workers. Industries that make an intensive use of skilled workers frequently tend to pay high wages to their unskilled workers as well.

Closely related to the skill factor is that of human capital accumulation at the workplace, or average length of service of workers. A worker who remains in a company's employ for a long period of time probably receives a good deal of on-the-job-training, an investment which may be expected to pay off in the form of higher wages. The implication is that such demographic factors as the age distribution of workers employed by an industry may be important for the analysis of wage intersectoral differentials.

Third, the gender composition of a sector's workforce is an important determinant of wage differentials. It is a well-documented fact that females are traditionally over-represented in such industries as textiles, clothing, etc. Consequently these branches will have 
an ample supply of workers, and their wages will not rise above the all-industry average.

As far as demand determining factors are concerned, Vasille (1989) has confirmed that productivity is a factor which has a significant influence on the sectoral structure of wages. Productivity in turn depends heavily on the industry's capital-labour ratio and the possibilities of substitution between these factors of production. Technical progress is another factor. That element has been neglected in most empirical analyses of longterm developments in sectoral wage structures, although such concepts as rate and bias of technical progress were originally developed in a study on the theory of wages (Hicks (1932)). A final factor operating on the demand side is the size of establishments. Most probably, individual branches of industry show significant differences on that score. Several conditions might work towards higher wages in industries with relatively large firms. For one thing, large firms might be able to employ a high proportion of skilled workers. For the other, if they occupy a monopoly position, this will enable them to charge higher prices than under perfect competition, which would normally result in higher wages, as Dunlop (1944) already has pointed out. Vasille $\left(1989^{b}\right)$ has presented some evidence in support of this hypothesis.

An important institutional or non-competitive factor operating on the supply side which may account for the stability of wage structures is the nature of collective bargaining. ${ }^{1}$ Two outcomes, both leading to a stable wage structure, may be envisaged in this respect. If wage bargaining is strongly centralised, i.e., wage agreements being concluded in nation-wide negotiations, the outcomes are likely to be moderate wage changes in industries with high productivity growth rates on the one hand, and relatively high wage increases in sectors with relatively low productivity growth rates. If, on the other hand, bargaining is relatively decentralised, imitation effects may become more important. In that context, the so-called wage-leadership hypothesis has become popular, according to which high pay increases in strong industries will be imitated by weaker ones. Needless to say, such a development, too, readily results in stable wage structures.

The efficiency wage model constitutes an other interesting recent example of models emphasizing non-competitive factors explaining the wage structure. Starting point in this literature is the observation that it may be beneficial for high-wage firms to pay wages in excess of marginal labour productivity and that it would be unprofitable to cut these high wages. According to this literature, reducing wages may in itself be beneficial for the firm, but the resulting decline in productivity might be a considerable cost associated with wage reductions. The efficiency wage literature has put forward several reasons why firms might find it profitable to pay efficiency wages (see, o.a., Katz and Summers (1989)). Among others, we may point at the firms desire to deter the workers from shirking, high costs for monitoring workers' performance, labour turn-over costs, ease of recruiting, and adverse selection.

Another possible explanation for the inter-industry wage structure which emphasizes non-competitive elements is offered by the so-called insider-outsider theory. According to this theory, wages are the result of a bargaining process in which firms and their "insiders" share the economic rents from insider employment. Consequently, when firms stand to lose considerably from a breakdown of these negotiations, insiders' wages will

${ }^{1}$ The importance of labour market institutions as a determinant of labour market performance was stressed in, 0.a., Bruno and Sachs (1985), Calmfors and Driffil (1988). See also Seidel (1983) for a comparative analysis of labour market institutions in EC countries. 
be higher. Thus, insiders' power is an important factor determining wages. Insiders' power in turn depends on industry specific conditions, like profit opportunities, production technology, industry concentration and workers' market power in their industries. Therefore, it is likely that inter-industry wage differentials reflect these differences in sectoral conditions.

Apart from the supply and demand determining factors mentioned above, Jacobs (1989) has pointed at some non-economic factors determining the wage structure. Conceivably, such factors as tradition or ideas of fair pay exert some influence on the structure of wages. Tradition may account for wage differentials that are not justified by productivity differentials or other objective economic criteria, but represent a society's conservative tendency to preserve relics from the past. Fair pay ideas frequently converge in governments and through them exert some influence on the structure of wages. Inflexible ideas of fair pay have given rise to protection of weak industries on many occasions, thus securing higher wages than would have been achieved otherwise under conditions of international competition.

\subsection{The debate on factor intensity reversals}

In the preceding section we saw that most empirical studies explain wage structures using productivity or some approximation of this, plus some non-competitive factors as explanatory variables. It is a remarkable feature of the empirical literature, however, that non of the studies mentioned has attempted to explain wage differentials using the elements from the theory of international trade mentioned in Chapter 2. In this respect, the most obvious candidates for such an explanation are limited mobility and the existence of factor intensity reversals. In this section we shall concentrate on the latter and try to formulate a position as to the empirical relevance of factor intensity reversals.

Although Ohlin, did not pay much attention to the possibility of factor intensity reversals, other authors after him did. In his paper on factor price equalisation, Lerner (1933) showed awareness of the possibility of factor intensity reversals, in that he drew several figures in which isoquants would intersect more than once. However, he also expressed the believe that this case would be highly unlikely in reality. This position was initially also taken by the majority of Lerner's successors. In this respect, Samuelson argued that, though an interesting theoretical possibility, factor intensity reversals would not be very likely as an empirical phenomenon. It was not until Leontief's $(1953,1964)$ studies on the factor content of US foreign trade that economists started worrying about the possibility of factor intensity reversals.

At the same time it was realised that the strong factor intensity assumption was rather unrealistic. Harrod (1958) expressed it as his belief that this assumption makes the whole notion of factor price equalisation inapplicable to reality. In this respect, Pearce (1959) also pointed out that an increase in the number of factors would increase the possibility of factor intensity reversals. As a matter of fact, factor-intensities are extremely difficult to measure once there are more than two factors. To eliminate the large number of potential cross-overs, very special production functions might be necessary, so that one might end up having a theory without any empirical foundation whatsoever.

Since the concept of factor intensities becomes rather troublesome in the case more than two production factors are distinguished, all empirical analyses of factor intensity reversals limit the number of factors to two. A special problem in the first empirical studies was the choice of a functional form for the production function. This production 
function should be capable of displaying the reactions of factor-intensities on changes in factor price ratios for every distinguished commodity and should have no a priori restrictions as regards to the value of the elasticity of substitution. The CES production function, which was introduced by Arrow, Chenery, Minhas and Solow (1961) (hereafter: ACMS) seemed particularly well-suited to meet these requirements. As is wellknown, the Cobb-Douglas production function always exhibits a unitary elasticity of substitution. This implies that although the distribution coefficients might differ be tween sectors, all sectors would still exhibit an elasticity of substitution of 1 . However, this need not be the case with the CES function. The CES function can be written as follows:

$$
\mathrm{Y}=\left[\alpha_{1} \mathrm{~L}^{-B_{\mathrm{i}}}+\alpha_{2} \mathrm{~K}^{-B_{\mathrm{i}}}\right]^{\left(-1 / B_{\mathrm{i}}\right)}
$$

Since factors are rewarded their marginal products, we may also write for sector $i$

$$
(K / L)_{i}=\left(\alpha_{1} / \alpha_{2}\right)_{i} \cdot(w / r)^{1 /\left(8_{i}+1\right)}=\left(\alpha_{1} / \alpha_{2}\right)_{i} \cdot(w / r)^{\sigma_{i}}
$$

where $1 /\left(B_{i}+1\right)$ is the elasticity of substitution $\sigma$.

Taking double logaritms yields:

$$
\log (K / L)_{i}=\sigma_{i} \log \left(\alpha_{1} / \alpha_{2}\right)_{i}+\sigma_{i} \log (w / r)_{i}
$$

Now recall that in the case of factor intensity reversals, the capital-intensities in industries $i$ and $j$ will be the same in the cross-over point, so that we have

$$
\begin{aligned}
& \log (K / L)_{i}=\sigma_{i} \log \left(\alpha_{1} / \alpha_{2}\right)_{i}+\sigma_{i} \log (w / r)_{i} \\
& \log (K / L)_{j}=\sigma_{j} \log \left(\alpha_{1} / \alpha_{2}\right)_{j}+\sigma_{i} \log (w / r)_{j}
\end{aligned}
$$

and $\log (K / L)_{i}=\log (K / L)_{j}$ from which we can solve for $w / r$ and obtain the following expression

$$
\log (w / r)=-1 /\left(\sigma_{i}-\sigma_{j}\right)\left[\sigma_{i} \log \left(\alpha_{1} / \alpha_{2}\right)_{i}-\sigma_{j} \log \left(\alpha_{1} / \alpha_{2}\right)_{j}\right]
$$

This equation shows at which factor price there will be a reversal of factor intensities. In case this factor price would be a very "realistic" one, we say that factor intensity reversals are in the "relevant range", and therefore they may be very likely to occur in reality.

In a book on this subject, Minhas (1963) has tried to obtain plausible empirical estimates for the parameters of the production function using cross-section data from 19 countries. The estimated values for $\alpha_{1}, \alpha_{2}$ and $\sigma$ for the six industries in his sample are reported in Table 4.1. An inspection of this table clearly reveals that the coefficients found by Minhas differ across industries, indicating that factor intensity reversals might certainly occur.

In Table 4.2 the cross-over points that were found to be within the relevant range are given. These relate to five industry combinations. The relevant range was constituted by the highest and the lowest possible factor price ratio in the sample. 
Table 4.1 Production function parameters in Minhas' study

\begin{tabular}{lllll}
\hline ISIC & Name of Industry & $\alpha_{1}$ & $\alpha_{2}$ & $\sigma_{\mathrm{i}}$ \\
\hline 202 & Dairy Products & 0.874 & 0.262 & 0.721 \\
205 & Grain Mill Products & 0.720 & 0.337 & 0.909 \\
$231 / 232$ & Textiles & 0.648 & 0.411 & 0.797 \\
271 & Pulp and Paper & 0.649 & 0.320 & 0.965 \\
311 & Basic Chemicals & 0.850 & 0.280 & 0.831 \\
342 & Primary Non-ferrous Metals & 0.548 & 0.431 & 1.011 \\
\hline
\end{tabular}

Source: Minhas (1963), p. 35.

Table 4.2 Cross-over points in Minhas' study

\begin{tabular}{lrr}
\hline & $\$ w / r$ & $\$ K / L$ \\
\hline Textiles-Non-ferrous metals & 1,350 & 1,720 \\
Dairy Products - Pulp and Paper & 2,136 & 4,117 \\
Dairy Products - Non-ferrous Metals & 8,665 & 11,308 \\
Pulp and Paper - Basic Chemicals & 5,370 & 9,997 \\
Basic Chemicals - Grains Mill Products & 20,400 & 30,410 \\
\hline
\end{tabular}

Source: Minhas (1963), p. 38.

In addition to the evidence mentioned above, Minhas performed a separate test of the relevance of factor intensity reversals. He noted that if the assumption that the optimal capital-labour ratio in industry $i$ is always greater than that of industry $j$ (no matter what factor price ratio prevails), i.e., the strong factor intensity hypothesis, were true, then the rankings of industries by their capital intensities in each of the two countries should match, even when these countries were having widely different relative costs of capital and labour. This turned out not to be the case.

Leontief (1964) questioned Minhas' method of indirectly estimating the elasticity of substitution from the marginal productivity condition for labour alone, while not at the same time also using the marginal productivity condition for capital. This argument had also been elaborated in the celebrated ACMS article, where the authors found substantial evidence for factor neutral differences in production functions for similar commodities between the USA and Japan. They showed that under these conditions, the measurement of the elasticity of substitution from wage, employment and output data is not valid, because this will lead to biased estimates for $\sigma$. Therefore, the elasticity of substitution must be measured using data on output, wages, employment, capital utilised and rates of return to capital. Although a co-author of the AMCS article, Minhas completely ignored these results.

Fortunately, however, Minhas included data on rates of return in his study, which enabled Leontief, together with the implied $\mathrm{K} / \mathrm{L}$ ratios, to re-estimate the elasticity of substitution avoiding the bias resulting from factor neutral differences in productive effi- 
ciency. This he did for 21 industries in stead of the 6 industries considered by Minhas. Thus he was able to conclude that "Of the theoretically possible 210 crossover points (.....) only 17 are found to be located within the range of factor price ratios spanned on the one end by those observed in the United States and on the other by those reported from India" (1964, p. 242), and hence that the elasticity of substitution did not differ significantly from one, and that the empirical support for the existence of factor intensity reversals was not so evident as on might be led to conclude on the basis of Minhas' study.

The literature following this controversy between Minhas and Leontief has firstly concentrated on attempts to prove that either one of these authors did make a point. ${ }^{2}$ Secondly, there have also been attempts to criticize the whole concept of factor intensity reversals arguing that the concept of factor intensity only makes sense in the two factor framework and that this concept of factor intensity becomes meaningless in an empirical model distinguishing more than just two factors. In this respect, Leontief argues that Minhas treated the manyears of labour in the various countries of his sample as if it would concern a perfectly homogenous factor of production. In the case it is realised that labour may be very heterogeneous and may be very different internationally (India vs. USA) then this would make Minhas' results even more implausible.

\subsection{Studies relating foreign trade and wages}

In an interesting article, Gremmen (1985) put forward a different test of the factor price equalisation theorem for the EC countries. Gremmen's methodology was also used by Mokhtari and Rassekh (1989), who applied it to the OECD area. ${ }^{3}$ Gremmen's article was a reaction on a paper by Tovias (1982), in which the latter had posed himself the question whether factor prices had tended to converge in the EC since the Rome Treaty had become effective. Calculations of the coefficient of variation of inter-country intra-industry wage differentials in the EC for the years since 1958 led Tovias to conclude that convergence had indeed taken place until 1968 but that after that year wages tended to diverge again.

Gremmen, however, argued that Tovias used a black box, that is, Tovias' conclusion of converging wages was not accompanied by any statistical evidence that this convergence was a possible result of the establishment of the EC. Ideally, a statistical relationship should exist between, say, the reduction in intra-EC tariff barriers and the behaviour of wages. Gremmen argued that there should be a quantifiable relationship between the extent to which the integration process had proceeded and the convergence of wages. He measured the degree of integration by a variable indicating the intensity of trade relationships between countries, i.e., the sum of the average propensities to import each-others product. Owing to the lifting of trade barriers, this variable should obtain a higher value as the integration process proceeds. Next, Gremmen argued that, in case of a high trade involvement, differences in the capital-labour ratios between countries should be less capable of explaining wage differentials between countries. Hence, their coefficient in an equation explaining wage differentials should be insignificantly diffe-

2 Studies confirming Leontief's finding are, e.g., Hutcheson (1969), and conclusions similar to Minhas are, among others, to be found in Yeung and Tsang (1972).

3 Gremmen's method has applied to the problem of the relationship between commodity trade and factor mobility in a paper by Molle and Van Mourik (1989b). 
rent from zero, whereas the coefficient of the trade intensity variable should be significant. The results of the empirical analysis confirmed the expectation of an insignificant coefficient of the capital labour ratio and a significant coefficient of the trade intensity variable. The elasticitofy the international wage differential with respect to the trade intensity variable had a value of approximately 0.7 , implying that a one per cent increase in trade intensity would result in a $\mathbf{0 . 7}$ per cent decline in the international wage differential between any two countries.

In Van Mourik (1987) we have argued that Gremmen's approach, although ingenious, suffered from four limitations, which might make his hypothesis not entirely consistent with the theory it is supposed to test. First of all, Gremmen's analysis confined itself to an investigation of the relationship between wages and trade intensities. It would have been interesting to extend the analysis to also include profits and wage/profit ratios. Secondly, Gremmen regressed nominal wage differentials as a function of the capital-stock calculated on a sort of replacement cost basis. That is, he deflated the capital-stock but forgot to do the same with wages. Obviously, this could cause biased regression results because the data on nominal wage differentials are seriously distorted by different inflation rates in the 1970s and it is not a priori clear to what extent these different inflation rates were offset by subsequent exchange rate changes. The insignificance of the coefficient of the capital-labour ratio might well be explained by this procedure. Thirdly, as the literature on the North-South wage differential in the USA has revealed, the expectation of an insignificant $\mathrm{K} / \mathrm{L}$ ratio is incorrect. Using some simple mathematics of production functions one can show that, in a one commodity-two factors setting (like Gremmen's model), and in a perfectly competitive situation, wage differentials must necessarily be determined by differing factor endowments, that is, by different overall capital-labour ratios. In that case, as we saw in Chapter 2, factor prices cannot be solved without referee ncto the factor market clearing conditions. If wage differentials are absent, this simply implies absence of differences in capital-labour ratios. Thus Gremmen's contention that "in cases where trade involvement is high the significance of the capital-labour ratio should be low" (p. 281) does not necessarily hold. Fourthly and finally, it would be interesting to see in how far Gremmen's results are dependent on the specification of this trade intensity index, which was as the sum of the countries' average propensities to import each-others goods. On sound grounds he also might have used country $i$ 's imports to country $j$ as a percentage of country $i$ 's total imports, summed with the same quotient for country $j$. Only in case such alternative indices produce the same results one could accept his conclusion that the "presented material did not provide an argument to doubt the validity of the Factor Price Equalisation Theorem" (Gremmen 1985, p. 84).

In view of the remarks made above, we suggested to extend Gremmen's analysis such as to take the above remarks into account. Therefore, we re-estimated several variants of the Gremmen model. All variants we have estimated had the following general structure:

$$
\ln \left(F_{i} / F_{j}\right)=\alpha+\beta_{1} \ln \left(k_{i} / k_{j}\right)+\beta_{2} \ln \left(t_{i j}^{k}\right)+\mu_{t}
$$

where:

$\mathrm{F}=$ factor price in country $i$ or $j$;

$t_{i j}^{k}=$ trade intensity index between country $i$ and $j, k=1,2$;

$\mathrm{k}_{\mathrm{i}, j}=$ capital-labour ratio in country $i$ or $j$;

$\alpha=$ constant;

$\mu_{\mathrm{t}}=$ stochastic error term. 
The factor price variable was specified alternatively as:

1. nominal wage levels;

2. real wage levels;

3. nominal wage-rental ratios;

4. nominal rental (profit) ratios.

The trade intensity index was specified alternatively as:

1. the sum of the countries' marginal propensities to import each others goods $\left(=\operatorname{tr}_{\mathrm{ij}}^{1}\right.$, Gremmen's index), and

2. the sum of country $i$ 's imports to country $j$ as a percentage of country i's total imports and the same quotient for country $j\left(=\mathrm{tr}_{\mathrm{ij}}^{2}\right)$.

Table 4.3 Re-estimation results of the Gremmen model

\begin{tabular}{|c|c|c|c|c|c|c|c|}
\hline & & $\begin{array}{c}E X \boldsymbol{E} \\
\text { Nom. K-L. }\end{array}$ & $\begin{array}{l}\text { LANATO } \\
\text { Real K-L }\end{array}$ & $\begin{array}{c}R Y \text { VAR } \\
\mathrm{Tr}_{\mathrm{ij}}^{1}\end{array}$ & $\begin{array}{c}\text { ULABLE: } \\
\mathrm{Tr}_{\mathrm{ij}}^{2}\end{array}$ & Intercept & $\mathrm{R}^{2}$ \\
\hline \multicolumn{8}{|c|}{ Variant: } \\
\hline & Nominal wage rate & & $\begin{array}{r}0.450 \\
(17.20)\end{array}$ & $\begin{array}{r}-0.057 \\
(-4.16)\end{array}$ & & $\begin{array}{r}-0.049 \\
(-2.14)\end{array}$ & 0.64 \\
\hline 2 & Nominal wage rate & & $\begin{array}{r}0.351 \\
(10.34)\end{array}$ & & $\begin{array}{r}0.025 \\
(5.49)\end{array}$ & $\begin{array}{r}0.076 \\
(6.41)\end{array}$ & 0.66 \\
\hline 3 & Nominal wage rate & $\begin{array}{r}0.797 \\
(28.17)\end{array}$ & & $\begin{array}{c}-0.034 \\
(-3.51)\end{array}$ & & $\begin{array}{r}-0.046 \\
(-2.80)\end{array}$ & 0.82 \\
\hline 4 & Nominal wage rate & $\begin{array}{r}0.843 \\
(18.73)\end{array}$ & & & $\begin{array}{l}-0.002 \\
(-0.42)\end{array}$ & $\begin{array}{c}0.003 \\
(0.25)\end{array}$ & 0.81 \\
\hline 5 & Nominal wage/profit & $\begin{array}{r}1.260 \\
(35.62)\end{array}$ & & $\begin{array}{r}-0.044 \\
(-3.58)\end{array}$ & & $\begin{array}{c}0.056 \\
(2.71)\end{array}$ & 0.87 \\
\hline 6 & Nominal wage/profit & $\begin{array}{r}1.138 \\
(20.88)\end{array}$ & & & $\begin{array}{c}0.019 \\
(3.75)\end{array}$ & $\begin{array}{r}0.155 \\
(12.15)\end{array}$ & 0.88 \\
\hline 7 & Real wage & & $\begin{array}{r}0.851 \\
(47.41)\end{array}$ & $\begin{array}{r}-0.034 \\
(-3.60)\end{array}$ & & $\begin{array}{r}-0.047 \\
(-2.94)\end{array}$ & 0.92 \\
\hline 8 & Real wage & & $\begin{array}{r}-0.067 \\
(-1.09)\end{array}$ & & $\begin{array}{r}0.083 \\
(9.88)\end{array}$ & $\begin{array}{r}0.330 \\
(15.40)\end{array}$ & 0.43 \\
\hline 9 & Nominal profit rates & $\begin{array}{r}-0.445 \\
(-9.21)\end{array}$ & & $\begin{array}{r}0.011 \\
(0.64)\end{array}$ & & $\begin{array}{r}-0.103 \\
(-3.68)\end{array}$ & 0.31 \\
\hline 10 & Nominal profit rates & $\begin{array}{r}-0.266 \\
(-3.65)\end{array}$ & & & $\begin{array}{r}-0.022 \\
(-3.29)\end{array}$ & $\begin{array}{r}-0.159 \\
(-9.01)\end{array}$ & 0.34 \\
\hline
\end{tabular}

Note: $\mathrm{t}$-values between brackets

Source: Van Mourik (1987).

These alternative specifications, leaving us with 8 equations to be estimated, were estimated for the same period as Gremmen's estimation and were also applied to the founder countries of the EC. In addition, we re-estimated Gremmen's equation, that is, we regressed nominal wage differentials as a function of the deflated capital-labour ratio, using both Gremmen's trade intensity index and the alternative specification. 
Hence, we estimated a total number of 10 equations. The number of observations is also 210.

The results of the estimations are given in Table 4.3. The first point that draws the attention is again the remarkable difference in the sign of the trade intensity variable. In a number of instances our estimations yield conflicting signs with respect to the alternative specifications of the trade intensity indices. In addition, in most cases the significance of this variable is rather low, at least compared to the significance of the capital-labour ratio, whereas the elasticity of wage differentials with respect to changes in the trade intensity index is in nearly all cases less than the seven percent Gremmen found in his analysis. As a minimum, our results indicate that the relationship between trade intensity and wage differentials is not so straight-forward as Gremmen assumes.

Secondly, it goes without saying that the differences in capital-labour ratios appear to be highly significant in all our estimations. However defined, the capital-labour ratios do seem to be quite important determinants of both nominal and real wage differentials, as well as differences in the wage/profit ratios and profits. In accordance with the theory, the sign of this ratio is positive for the explanation of wages and wage/profit ratios and negative in case of profit differences.

The results presented here therefore indicate 1) that the relationship between trade intensity and factor price differentials might be ambiguous, and, 2) that the overall capital-labour ratio remains an important determinant of factor price differentials even when the integration process has proceeded as far as it has in the Common Market.

To summarize, Gremmen's hypothesis concerning the trade intensity variable is very ingenious indeed. However, his expectation of an insignificant capital-labour ratios in not very plausible and needs modification. In our estimation of the model we found capital-labour ratios to be extremely important determinants of international wage differentials. Unfortunately, the relationship between trade and factor price differentials cannot be established on the basis of the data used by Gremmen. Therefore, before embarking upon the postulation of any hypotheses as to the influence of an increased volume of trade on wage differentials it would, in our opinion, be necessary to investigate whether the conditions for factor price equalisation are likely to be met in the European Community. In this respect, estimation of the parameters of production functions would be the first logical step. The second step could then consist of determining the influence of increased trade relations between countries. Thus it is not denied that increasing trade relations lead to decreasing wage differentials, but that trade intensity must be considered in conjunction with differences in capital-labour ratios.

\subsection{Production and cost function studies}

There have been a (relatively small, but growing) number of studies that have addressed the distributional impact of trade policies by directly or indirectly estimating the parameters of cost or production functions. Since we shall adopt this approach ourselves in Chapters 5-7, a review of these studies might be a fruitful exercise.

Burgess (1975) used the duality between transformation and cost functions in order to asses the distributional impact of tariffs in the US. He distinguished two outputs, durables and non-durables on the one hand and non-government services and structures on the other. His cost function was defined on the assumption that the production process requires capital and labour inputs, as well as imported intermediate inputs. Burgess estimated two model specifications. In the first, he assumed a joint technology in 
outputs, which is at the same time characterized by a separability between outputs and inputs. In the second model specification, technology is assumed to be non-joint in both inputs and outputs, the model thus being identical to the one presented in Jones' (1965) seminal paper and with which all trade theorists are familiar. The incidence of a tariff in Burgess' model occurs through the price of imported intermediate inputs.

From the joint production model specification, Burgess concluded that US tariffs tend to make labour better off. The same conclusion was obtained for the non-joint model specification. Although both models therefore yield similar predictions, the reason behind this result differs for each model. In the joint model, labour's gain is a consequence of the complementarity between capital services and imported intermediate inputs: tariffs raise import prices, which in turn increase the demand for labour while at the same time reducing the demand for capital. In the non-joint model, the labour-intensive sector (services and structures) uses relatively small amounts of imports. As a result, tariffs raise unit costs more in the capital-intensive sector, thereby forcing down capital costs and raising wages.

Leamer (1984, pp. 207-214), using a production model which is non-joint in outputs, estimated the impact of tariffs on the behaviour of wages. Leamer distinguished between three kinds of labour, viz. profession/technical workers, nonprofessional literate workers and illiterate workers. The approach to the estimation of the distributional impact of tariff changes rested on Samuelson's reciprocity relations between the StolperSamuelson effect and the Rybczinski effect, which asserts that the derivative of final output $y_{i}$ with respect to the total supply of factor $x_{i}$ is equal to the derivative of the return to that factor with respect to the output price, i.e., $\partial y_{j} / \partial x_{i}=\partial w_{i} / \partial p_{j}$. Bearing this reciprocity in mind, it is evident that the Stolper-Samuelson effect may be estimated either directly by linking factor and output prices, or indirectly through the Rybczinski effect. Since product prices exhibit a substantial degree of collinearity, Leamer estimated the Stolper-Samuelson effect indirectly.

Leamer (1992) uses the same methodology to assess the wage effects of the US-Mexican free trade agreement (NAFTA). He assumes that this agreement will reduce the relative price of labour-intensive goods in the US. Leamer conducts several experiments which indicate that low-skilled US labour is likely to loose between $\$ 232$,- and $\$ 9,312$,per year. Conversely, skilled US labour is likely to gain between $\$ 959$,- and $\$ 30,384,-$. Finally, US capital stands to gain between 0.01 and 0.67 per cent as a result of the free trade agreement. Leamer admits that these results are rather tentative, but remarks that a reduction in earnings of low-skilled US workers of some $\$ 1,000$,- per year is very plausible.

Leamer's results were reviewed with skepticism in Lawrence and Slaughter (1993). They also find considerable evidence of an international convergence of wages but suggest that this development has little to do with international trade. Inspection of American wage and terms of trade data leads these authors to the conclusion that the StolperSamuelson process did not have much influence on American relative wages in the 1980 s. Rather, they suggest that the convergence of wages is the result of the nature and extent of technological progress as well as the declining productivity growth in the American service sectors.

An interesting study is Kohli's (1991, ch. 10) version of the Heckscher-Ohlin-Samuelson production model. Although Kohli estimated this model on US aggregate national accounts data and therefore does not pertain to the EC, his study is worth mentioning since the structure of his empirical models is based on the models of international trade. Kohli distinguished consumption goods and investment goods, which were assumed to be produced with capital and labour. Investment goods were produced with labour-in- 
tensive production techniques, whereas consumption goods were capital-intensive. Kohli found that an increase in the price of investment goods would lead to an absolute reduction in the rental price of capital, and an absolute increase in the price of labour. The relevant Stolper-Samuelson elasticities ${ }^{4}$ took values of approximately -2.0 and +1.8 , respectively. Also, an increase in the price of consumption goods was found to result in an absolute fall in the remuneration of labour (Stolper-Samuelson elasticity: app. -0.9) and an increase in the rental price of capital (Stolper-Samuelson elasticity: +3.0 ). Kohli admits that these estimates might be unreasonably large, but attributes these results to a rejection of the hypothesis of non-jointness in input quantities. However, it should be added that elasticities in excess of one are by definition the rule in the context of a Heckscher-Ohlin-Samuelson model, as was shown by Jones' (1965) magnification effect.

Kohli also estimated the parameters of a specific factors model. To our knowledge, this is one of the very few tests available in the empirical literature of this trade model. Capital was assumed to be sector specific and labour was assumed to be the mobile factor. Interestingly, the estimates seem to give support to this model. An increase in the price of both investment goods and consumption goods would tend to increase the price of labour, be it less than proportionally (relevant Stolper-Samuelson elasticities: +0.55 and +0.45 , respectively). An increase in the price of consumption goods tended to increase the price of capital more than proportionately (Stolper-Samuelson elasticity: appr. +1.2). However, an increase in the price of investment goods would tend to reduce the price of capital in that sector, which is a rather strange result.

Köhler (1991) also used the specific factors model to predict the income distribution effects of Austrian pre- and post-Tokyo Round tariff protection. In his analysis, he did not only focus on nominal tariff protection, but also considered the influence of the entire tariff structure, i.e., effective rates of protection. Thus, Köhler explicitly introduced the existence of intermediate goods. It turned out, that the tariff structure of the Austrian economy seemed to have a moderate (nominal) wage increasing effect, the nominal tariff exceeding the nominal wage increase in a number of sectors. The implication of this is that tariff protection might involve a real wage loss for Austrian workers. As far as (sector-specific) capital rentals were concerned, Köhler found that even small nominal tariffs might have substantial effects on the capital rental. The sectors that were most favourable effected by tariff protection witness capital rental increases of well over a hundred per cent. These sectors also happened to have comparatively high tariff rates. Conversely, the least affected sectors turned out to have low tariffs.

In an international comparative empirical study of factor prices, Kopits (1982) attempted to establish a relationship between factor prices and factor endowments. He found that the evidence on factor price ratios was broadly consistent with the view that these reflect relative factor endowments. In addition, the relatively large and systematic variation in factor prices seemed to reflect the insufficient mobility of factors of production across national borders. This conclusion was also applicable to the EC. where, due to the absence of integrated factor markets, significant differences between factor prices were found. Since Kopits found a stronger price-quantity relationship for labour than for capital, he concluded that there are probably greater impediments to labour

${ }^{4}$ The Stolper-Samuelson elasticity of the rental price of capita! with respect to the price of investment goods measures the percentage change in the reintal price of capital when the price of investment goods changes with 1 per cent. Similarly, the Stolper-Samuelson elasticity of wages with respect to the price of investment goods measures the percentage change in wages when the price of investment goods changes with 1 per cent. 
than to capital movements. Finally, Kopits also found clear evidence that factor prices, at least in the long run, seemed to be responsive for changes in commodity prices.

In a study testing the factor price equalisation theorem, Dollar et al. (1988) investigated cross-country differences in labour productivity at the industry level. Their study involved thirteen countries and twenty-eight industries. As might intuitively be expected, they found considerable international differences in labour productivity. Their evidence seemed to suggest that the factor price equalisation model might not be device to explain these large international differences in labour productivity and that a model incorporating the economies of scale hypothesis helped considerably in explaining the deviations from the predictions of the factor price equalisation model. However, they obtained the best results by employing a model in which they assumed constant returns to scale and which allowed for differences in technology used in production. This suggests that industries in different countries use different techniques in production and that for this reason factor prices are not equalised. Incidentally, this result emerged since all countries that tended to have higher overall capital-labour ratios predominantly tended to use capital-intensive techniques. That phenomenon is, it will be recalled from our discussion in Chapter 2, not consistent with the factor price equalisation model and will result in higher labour productivity in capital abundant countries.

Dollar c.s. also found that among the largest industrial countries in the world, differences in labour productivity had narrowed substantially in the post-war period. They could not explain the convergence of labour productivity by changes in the employment mix across industries. Dollar c.s. also rejected the hypothesis of converging K-L ratios. It turned out that the US had a large productivity lead in all sectors of industry in 1963 and that the US was using more capital per worker in all industries. Dollar c.s. primarily explained the international variations in labour productivity in terms of variations in technology. Consequently, they explained the convergence in labour productivity as a result of the international diffusion of technology. Technologically backward countries tended to imitate technologies from the more advanced ones and were thus able to catch up with the more advanced countries.

To sum up our findings, we can conclude that production and cost function models seem to provide a useful framework for analyzing the interrelationship between factor prices and trade. However, the empirical models that have been developed in the recent empirical trade literature differ in their individual specifications and do not allow us to make clear-cut inferences as to what production factor will stand to gain and what production factor will stand to loose after a liberalization of trade.

\subsection{A North-South model of aggregate wage differentials applied to the EC}

\subsubsection{Introduction}

In this section we review a model that was developed in Van Mourik (1989). We shall confine the attention to the founding countries of the EC and will ask try to answer the question how the convergence of wages in these countries could be explained. Taking the simplest possible model as a theoretical starting-point, we commence with the identification of the sources of the wage differential. This is done for several reasons. First of all, before we present a more sophisticated multisectoral model in the next chapter, it might be interesting to test the theory of factor price behaviour using the simplest possible (i.e., one sector) model. If the results are encouraging, the laborious undertaking of 
the estimation of a multisectoral model is justified. Second, aggregate wage data are readily available in the statistics.

The plan for the section is as follows. First, we shall briefly outline the structure and comparative statics of the model in the next subsection, which is followed by a brief discussion of the estimation results and predictions of the model in section 4.6.3. For details concerning the estimation and model predictions, the reader is referred to Van Mourik (1989).

\subsubsection{An estimable model of wage differentials}

Before we noted that, although a clear tendency of international wage convergence may be discerned, international wage differentials are quite persistent. This is also true for regional wage differentials, whose existence is well-documented in the literature. In the USA, for instance, the wage differential between the north and the south has attracted a lot of attention, and inspired many researchers to build models that could explain this phenomenon and its development. ${ }^{5}$ Unfortunately, the latter is hardly true for the EC wage differentials. In principle, models explaining the magnitude and development of the US north-south wage differential could be used to explain the EC experience as well.

The model that we shall employ below, is based on these analyses of the regional wage differential in the USA, where there has been a tendency to explain these differentials along very neo-classical lines. Gallaway (1963), for instance, found that differing capital labour ratios were a prominent cause of the regional wage differential. This result was confirmed by Scully (1969), who extended the Gallaway model to incorporate human capital as well. He found that differences in human capital endowments may explain a substantial part of the wage differential, whereas differences in physical capital-labour ratios seemed to exert only a minor influence. It is an interesting feature of Scully's study that, by 1958 , the physical capital-labour ratio was on average higher in the South than in the North. This fact had also been found by other students of the North-South wage differential (see, e.g., Gallaway) and would imply, other things being equal, that the South would have a higher wage rate than the North. However, this was not the case and may be due to the existence of differences in production functions as was shown in Scully (1971) and Batra and Scully (1973).

Differences in production functions may arise for various reasons. First, they may be caused by different elasticities of substitution. A low value of the elasticity of substitution, for instance, implies that the employers will hardly display any reaction in terms dismissing labour after a wage increase has occurred. This will increase the possibility of wage increases. On the other hand, a high value of the elasticity of substitution means that a small increase in the price of labour is immediately followed by large amounts of labour being laid off and substituted by capital, and may therefore be said to limit the scope for wage increases.

Second, countries may experience different rates of technological progress, or experience the same rate of technical progress but with a different bias. High-wage countries with a higher rate of technical progress than a low-wage country will have a higher rate of growth of wages than the low-wage country. Likewise, a labour-saving bias of techni-

${ }^{5}$ References include Fuchs and Perlman (1962), Gallaway (1963), Moroney (1970), McCulloch and Yellen (1977), Scully (1969, 1971), Smith (1975, 1976), Polzin (1972), Ghali et al. (1978), and Hanham and Chang (1981). 
cal progress in the high-wage country and a capital-saving bias in the low-wage country will inhibit a movement towards factor price equalisation. we shall soon come back to these statements.

Third, different growth rates of endowment ratios may affect the development of the wage differential between countries. Low-wage countries enjoying a higher growth rate of the overall capital labour ratio will have higher wage growth rates than high-wage countries with low capital-labour ratio growth rates.

The above mentioned influences on international wage differentials may easily be illustrated with the aid of a simple production model. ${ }^{6}$ Below we shall formulate such a model in general terms and in the next sub-section we shall apply it to the EC-5 experience.

Consider an economy $i$ producing a single output with the following linear-homogeneous production function:

$$
Y_{i}=F_{i}\left(K_{i}, L_{i}, t\right)=L_{i} f_{i}\left(k_{i}, t\right)
$$

where $Y_{i}$ denotes the output of the economy, $K_{i}$ denotes capital, $L_{i}$ denotes labour, $k_{i}=$ $K_{i} / L_{i}$, and $\mathbf{t}$ refers to the level of disembodied (neutral or non-neutral) technical progress. The subscripts $i$ and $j$, which will be omitted hereafter when they are not strictly necessary, refer to countries $i$ and $j$.

In the case inputs are rewarded their marginal products, and the supply of production factors is fixed, one may write

$$
w_{i}=f_{i}-k_{i} f_{i}^{\prime}
$$

Whenever a wage differential exists between two countries $i$ and $i$, and in case this wage differential favours region $i$, we write $w_{\mathrm{i}}=\gamma w_{\mathrm{i}}$, where $\gamma>1$. Thus the wage differential may be written as

$$
\gamma=\left(\mathrm{f}_{\mathrm{i}}-\mathrm{k}_{\mathrm{i}} \mathrm{f}_{\mathrm{i}}\right) /\left(\mathrm{f}_{\mathrm{j}}-\mathrm{k}_{\mathrm{j}} \mathrm{f}_{\mathrm{i}}\right)
$$

This equation shows the most elementary sources of international wage differentials. It implies that the latter may be due to differences in the capital-labour ratios and to differences in the technology used in production.

As we are mainly interested here in the development of this wage differential, it is useful to "dynamise" the model. Recall first, however, that the elasticity of substitution is for both countries defined as

$$
\sigma=(\partial \mathrm{k} / \partial \omega)(\omega / \mathrm{k})=\left(\mathrm{F}_{\mathrm{K}} \mathrm{F}_{\mathrm{L}} /\left(\mathrm{FF}_{\mathrm{KL}}\right)\right.
$$

${ }^{6}$ The methodology of the model developed in this section follows that of Batra and Scully. Thus we will confine the attention in the explanation of wage differentials to the effects of different capital-labour ratios, differences in elasticities of substitution, and technological progress. The formulation of the model developed in this section, however, is taken from Ferguson (1979), who developed a general model of technical progress which may easily be applied to the phenomenon of wage differentials. 
where $\omega$ is the wage-rental ratio, and where $\mathrm{F}_{\mathrm{K}}$ and $\mathrm{F}_{\mathrm{L}}$ are defined in the usual way as the partial derivatives of $F$ with respect to $K$ and $L$, respectively.

Now let us define the rate of technical progress, denoted by $R$, as the partial derivative of $F(K, L, t)$ with respect to time. Thus the rate of technological progress is simply defined as the proportionate rate of growth of output in time, while keeping the quantity of the various inputs constant, or stated mathematically (Ferguson (1979, p. 225)):

$$
\mathrm{R}=\mathrm{F}_{\mathrm{t}} / \mathrm{F}=\left(\mathrm{KF}_{\mathrm{Kt}_{\mathrm{t}}}+\mathrm{LF}_{\mathrm{Lt}}\right) /\left(\mathrm{KF}_{\mathrm{K}}+\mathrm{LF}_{\mathrm{L}}\right)
$$

As the reader may well recall, Hicks analyzed technical progress by its effects for relative factor efficiency or by its effects on the ratio of the marginal product of capital to that of labour. He classified technological progress as labour-saving, neutral or capital-saving in the case at a constant capital-labour ratio its effect is to increase, leave unchanged or decrease the ratio of the marginal product of capital to that of labour. Suppose that technical progress can, in our model, best be described in Hicks' terms. In that case the bias of technical progress, denoted by B, may be defined by (Ferguson (1979), p. 225):

$$
B=\left\{\partial / \partial t\left(F_{K} / F_{L}\right)\right\} /\left(F_{K} / F_{L}\right)=\left(F_{K_{t}} / F_{K}\right)-\left(F_{L t} / F_{L}\right)
$$

Note that technical change is called Hicks neutral, in case B $=0$, labour-saving (capital-using) in case B $>0$, and capital-saving (labour-using) in case B $<0$.

Assuming perfect competition and making the appropriate substitutions one may eventually arrive at the following expression for the rate of change of wages (see Ferguson (1979), pp. 224-227, for the derivation of this result): ${ }^{7}$

$$
\hat{w}=R-\beta B+(\beta / \sigma) \hat{k}
$$

where $\beta$ refers to the partial elasticity of output with respect to the capital input or, stated alternatively, capital's share in production. Throughout the paper a hat $\left(^{\wedge}\right)$ denotes a proportionate rate of change, i.e., $\hat{w}=(\mathrm{dw} / \mathrm{w})(1 / \mathrm{dt})$.

Since we are interested in the rate of change or the direction of the movement of the wage differential between countries $i$ and $j$ and as $w_{i}=\gamma w_{j}$, we may write $\hat{\gamma}=\hat{w}_{i}-\hat{w}_{i}$. Hence

$$
\hat{\gamma}=\left\{R_{i}-\beta_{i} B_{i}+\left(\beta_{i} / \sigma_{i}\right) \hat{k}_{i}\right\}-\left\{R_{j}-\beta_{j} B_{j}+\left(\beta_{j} / \sigma_{j}\right) \hat{k}_{j}\right\}
$$

Although this expression may seem rather complicated at first sight, it can be very instructive when several simplifying values for its parameters are considered alternatively. First, let us assume that the standard conditions of an elementary textbook on interna-

${ }^{7}$ Note that we took the formula for $\gamma$ from Batra and Scully, but that the expression for the rate of change of wages was taken from Ferguson. In doing so, one obtains a different formula for the rate of change of wages than the one used in Batra and Scully. This is motivated by two reasons. Firstly, Batra and Scully's formula for the rate of change of wages does not distinguish between the rate of technical progress on the one hand and the bias of technical progress on the other. However, despite this omission in their analysis, they do discuss the effects of differential overall rates of productivity growth (Batra and Scully (1972, p. 383)). Secondly, their formula for the rate of change of wages is derived under the assumption of equalised rental rates between regions. That assumption does not underlie the formula used here. 
tional economics hold, that is, assume that $\sigma_{i{ }^{\prime} j}=1, \beta_{i}=\beta_{j}$, and $B_{i, j}=R_{i, j}=0$, so that the (identical) production functions are of a Cobb-Douglas type and technological progress is absent or proceeding at the same (neutral) rate in both countries. In this case (8) reduces to

$$
\hat{\gamma}=\hat{k}_{\mathrm{i}}-\hat{\mathrm{k}}_{\mathrm{j}}
$$

Now, a positive value of $\hat{\gamma}$ implies that wages in high-wage countries rise at a faster pace than those in low-wage countries and hence implies a movement in the direction of divergence. Thus, the wage differential increases, remains constant or decreases, depending upon whether $\hat{\gamma}>0, \hat{\gamma}=0$, or $\hat{\gamma}<0$, or

$$
\hat{\gamma} \gtreqless 0 \text { if } \hat{k}_{\mathrm{i}} \gtreqless \hat{\mathrm{k}}_{\mathrm{j}}
$$

As $i$ is the country with the higher wage, the convergence condition simply states that in high-wage countries the capital-labour ratio should grow less in this country than in country $j$. Convergence of capital-labour ratios is thus a sufficient condition for the convergence of wages.

Secondly, consider the case where $R_{i, j}=B_{i, j}=0$ and $\sigma_{i}=/ \sigma_{j}$, but $\beta_{i}=\beta_{j}$. In this case (8) reduces to

$$
\hat{\gamma}=\left(\sigma_{i} \hat{k}_{i}-\sigma_{i} \hat{k}_{j}\right)
$$

from which it is readily seen that

$$
\hat{\imath} 0 \text { if } \hat{\mathrm{k}}_{\mathrm{i}} / \hat{\mathrm{k}}_{\mathrm{j}} \gtreqless \sigma_{\mathrm{i}} / \sigma_{\mathrm{j}}
$$

This equation clearly shows that a higher rate of growth of the capital-labour ratio in the low-wage country is in itself not a sufficient condition for the convergence of wage rates. If the high-wage country has a lower elasticity of substitution, this may offset the influence of the higher growth rate of the capital-labour ratio in the low-wage country. Thus, a higher rate of growth of the capital-labour ratio in the low-wage country may go hand in hand with an increasing wage differential. Only in case both elasticities of substitution are equal, a narrowing wage differential is guaranteed.

Let us next assume that the rate of growth of the capital-labour ratio is equal in both countries, for instance such that $\hat{k}_{i}=\hat{k}_{j}=0$. In this case (8) may be converted into

$$
\gamma=\left\{R_{i}-\beta_{i} B_{i}\right\}-\left\{R_{i}-\beta_{j} B_{j}\right\}
$$

This expression clearly shows that the wage differential increases, remains constant or decreases depending upon whether

$$
\gamma \geqslant 0 \text { if }\left\{R_{i}-\beta_{i} B_{i}\right] \geqslant\left\{R_{j}-\beta_{j} B_{j}\right\}
$$

If technical progress is neutral in both countries $\left(B_{i, j}=0\right)$ this requirement is simply synonymous with region $i$ having a higher, equal or lower overall rate of productivity growth or technical progress. If, however, the rates of technical progress are equal but technical progress is biased in both countries, things become more complicated. The condition for divergence, stability or convergence then becomes: 
$\hat{\gamma} \frac{\geqslant}{2}$ if $\beta_{j} B_{j}-\beta_{i} B_{i} \frac{\gtrless}{2} 0$

When both $\beta_{i}$ and $\beta_{j}$ are positive, the convergence condition is always fulfilled when $B_{i}$ $>0$ and $\mathrm{B}_{\mathrm{i}}<0$, or, in other words, with technical progress labour-saving in country $i$ and capital-saving in country $j$, a converging trend in wages is always assured. Notice that in the case technological progress is labour-saving in both countries, the condition for convergence is equivalent to country $i$ having a larger labour-saving bias than country $j$. In the case technical progress should turn out to be capital-saving in both countries, this bias should be stronger in country $j$ if convergence is to occur.

Let us finally turn to the most general case. Here, the condition for divergence, stability or convergence of the intercountry wage differential is given by

$$
\hat{\gamma} \geqq 0 \quad \text { if } \quad\left\{R_{i}-\beta_{i} B_{i}+\left(\beta_{i} / \sigma_{i}\right) \hat{k}_{j}\right\} \gtreqless\left\{R_{j}-\beta_{j} B_{j}+\left(\beta_{j} / \sigma_{i}\right) \hat{k}_{j}\right\}
$$

Summarizing so far, one may safely state that the development of intercountry wage differentials may be attributed to at least ten factors, viz., $\hat{k}_{j}, \hat{k}_{i}, \sigma_{i}, \sigma_{j}, R_{i}, R_{j}, B_{i}, B_{j}, \hat{\beta}_{i}$, and $\beta_{i}$. One may infer from the model that the influence of a high rate of growth of the capital-labour ratio in a low-wage country is counteracted by

1. a relatively low rate of technical progress;

2. a (relatively stronger) labour-saving bias in technical progress;

3. a relatively high elasticity of substitution;

4. a relatively low initial share of labour in national income.

\subsubsection{Empirical application of the model}

In Van Mourik (1989) we have applied the above model to the development of the wage differential in the five main founding countries of the EC and tried to infer empirically plausible values for the $\sigma$ 's, B's and R's. This enabled us to answer the question whether production structures in these countries were such as to favour a movernent towards factor price equalisation. The analysis was conducted with data which were taken from the National Accounts Statistics, Aggregates published by Eurostat. The period of investigation was 1959-1979.

Table 4.4 shows the average annual development of labour costs per manyear in the 1959-1979 period. Not shown in that table is the fact that, during the period of investigation, The Netherlands is the country with the highest labour costs per worker, followed by Belgium and Germany. In 1959, Italy was a low-wage country. Table 4.4 reveals that, while not being exceptionally dramatic, a convergence of wages occurred in the case of Italian wages, i.e., Italian wages increased at a faster pace than wages in all other countries. Italian wages, which were about 56 per cent of the EC average in 1959, had steadily increased to some 66 per cent at the end of the observation period. Belgian and German wages as a percentage of the EC average remained relatively stable, while French wages decreased from above average to slightly below average. Finally, Dutch wages increased from approximately 115 per cent of the EC average to 120 per cent.

Turn to the capital-labour ratios now. Inspection of the growth rates of K/L ratios reveals that the countries with the highest increase in wages (Italy and The Netherlands) did not have the highest growth rates of capital-labour ratios. This is paradoxical, since the standard model of factor price equalisation would predict that a high growth rate of 
wages be accompanied by a high growth rate of $\mathrm{K} / \mathrm{L}$ ratios. ${ }^{8}$ Hence, it does not seem unreasonable to suggest that the convergence which has taken place in the course of: time was not so much the result of converging $\mathrm{K} / \mathrm{L}$ ratios, and that other factors must be held responsible for the high growth rates of wages in The Netherlands and in Italy.

Table 4.4 also reveals estimates of the elasticity of substitution, $\sigma_{i}$, and the bias of technical progress, $\mathrm{B}_{\mathrm{i}}$ for each country. These estimates were obtained using the fact that (optimal) capital-labour ratios are a unique function of $(\omega, t)$, so that $k=k(\omega, t)$, where $\omega$ is the wage-rental ratio. ${ }^{9}$ Total differentiation of this relationship yields (Takayama (1974), p. 632, Batra and Scully (1972), p. 579):

$$
\hat{k}_{i}=\sigma_{i} \omega_{i}+B_{i}
$$

where again $\sigma_{\mathrm{i}}>\mathbf{0}$ and where $\mathrm{B}_{\mathrm{i}}=\left(1 / \mathrm{k}_{\mathrm{i}}\right)\left(\partial \mathrm{k}_{\mathrm{i}} / \partial \mathrm{t}\right) \mathrm{dt}=\left(\mathrm{F}_{\mathrm{Kt}} / \mathrm{F}_{\mathrm{K}}\right)-\left(\mathrm{F}_{\mathrm{Lt}} / \mathrm{F}_{\mathrm{L}}\right) \gtreqless 0$. The term $\left(1 / \mathrm{k}_{\mathrm{i}}\right)\left(\partial \mathrm{k}_{\mathrm{i}} / \partial \mathrm{t}\right) \mathrm{dt}$ is the change in the capital-labour ratio due to a change in the shift parameter $t$ and refers to a situation where factor prices are kept constant. It is by definition equal to the Hicks measure of the bias of technological progress. Positive values of B indicate a labour-saving bias of technical change, negative values imply a capital-saving bias, and a value of zero points at neutrality.

Table 4.4 Average annual growth rates of wages and capital-labour ratios, 1959-1979

\begin{tabular}{lcccccc}
\hline & Wages & $\begin{array}{c}K / L \\
\text { ratios }\end{array}$ & $\begin{array}{c}W / R \\
\text { ratios }\end{array}$ & $\sigma_{i}$ & $B_{i}$ & $R_{i}$ \\
\hline Belgium & 0.047 & 0.045 & 0.082 & 0.550 & 0.012 & 0.018 \\
Germany & 0.047 & 0.046 & 0.074 & 0.608 & 0.009 & 0.023 \\
France & 0.044 & 0.042 & 0.074 & 0.504 & 0.013 & 0.020 \\
Italy & 0.056 & 0.043 & 0.079 & 0.427 & -0.026 & 0.034 \\
Netherlands & 0.052 & 0.039 & 0.080 & 0.538 & 0.012 & 0.027 \\
\hline
\end{tabular}

Equation (4.17) was estimated using OLS. The resulting estimates for the elasticities of substitution are presented in Table 4.4. Note that the elasticities that were found all had positive signs, and took values well below 1 . Also note that the elasticity of substitution had a rather low value in the case of Italy, whereas its value was found to be substantially higher in the high-wage countries The Netherlands, Belgium, France and Germany. Compared to empirical studies of technical progress relating to other countries, the estimated values of $\sigma$ do not appear unreasonable (for instance, David and Van de Klundert (1965), p. 377, found a value of 0.32 for the US manufacturing sector).

As far as the bias of technological progress (B) was concerned, all values of B turned out to be positive, except in Italy. This implies that technological progress has been labour-saving in four cases, and that Italy has experienced a (relatively large) capitalsaving bias in technical progress.

\footnotetext{
${ }^{8}$ Similar paradoxical developments were also found for the USA, see, e.g., Borts (1960).

${ }^{9}$ We refer to Van Mourik (1989) for a comprehensive discussion of all data used in the estimations, as well as the estimation procedures and a discussion of the results.
} 
The last column of Table 4.4 reveals the estimates for the overall rate of technical progress. This parameter was calculated following a methodology suggested by David and Van de Klundert (1965). ${ }^{10}$ The calculated values of $R$, which are independent of our estimations of the values of B, reveal that in addition to her favourable bias, Italy also had the highest rate of growth of total productivity (3.4 per cent). The Dutch rate of technical progress ( 2.7 per cent) is slightly higher than the average rate of technical progress in the EC ( 2.4 per cent) and may thus be said to have contributed to the high rate of growth of wages in that country. France, Belgium and Germany experienced relatively low rates of technical progress.

Table 4.5 Model predictions ${ }^{11}$

\begin{tabular}{lccccccc}
\hline Country & R & $\beta B$ & $\begin{array}{c}\text { Parameter values } \\
(\beta / \sigma) \hat{\mathrm{k}}\end{array}$ & $\begin{array}{l}\text { Predic- } \\
\text { tion } \\
\text { of } \hat{\mathrm{w}}\end{array}$ & & $\begin{array}{l}\hat{\mathrm{w}} \text { actual } \\
\text { error }\end{array}$ \\
\hline Belgium & 0.0179 & 0.0038 & 0.0272 & 0.0413 & 0.0469 & 0.121 \\
tion & \\
Germany & 0.0232 & 0.0032 & 0.0268 & 0.0468 & 0.0470 & 0.003 \\
France & 0.0204 & 0.0039 & 0.0245 & 0.0410 & 0.0435 & 0.058 \\
Italy & 0.0337 & -0.0046 & 0.0182 & 0.0565 & 0.0560 & -0.012 \\
Netherlands & 0.0269 & 0.0041 & 0.0256 & 0.0484 & 0.0525 & 0.078 \\
\hline
\end{tabular}

Let us turn to a discussion now of how the values of all parameters have interacted and in how far they might be responsible for certain developments in intercountry wage differentials. In Table 4.5 we have listed the values of the various constituent elements of

${ }^{10}$ In order to obtain an estimate of this parameter, the overall rate of factor productivity growth re-written as (see David and Van de Klundert (1965), pp. 363 and 384)

$$
R \equiv \alpha R_{L}+\beta R_{K}
$$

where $\alpha$ and $\beta$ again refer to labour's and capital's share respectively, and where $R_{L}$ and $R_{K}$ are the efficiency growth parameters of labour and capital. It's also a well-known result from the literature on technological progress, that in case of linear-homogeneous production functions the percentage rate of growth of output, $\hat{Y}$, may be written as (see, among others, David and Van de Klundert (1965), p. 362)

$$
\hat{Y}=\alpha\left(\hat{L}+R_{L}\right)+\beta\left(\hat{K}+R_{K}\right)
$$

Recall next, that $\beta=1-\alpha$, so that (20) may be reduced to

$$
R=\alpha R_{L}+\beta R_{K}=(\hat{Y}-\hat{L})-(1-\alpha)(\hat{K}-\hat{L})
$$

This equation contains elements which are directly observable from our statistical data.

${ }^{11}$ Differences in this table are due to rounding, calculations were made using 7 decimals. 
equation (4.16). This allows us to infer which wage determining factors have been most important in the various EC- 5 countries. Before, it was already concluded that converging $\mathrm{K} / \mathrm{L}$ ratios could not completely explain the development of these wage differentials. As far as the influence of differences in elasticities of substitution are concerned, the following remarks are at order. Low estimates of the values of the elasticities of substitution in low-wage countries would, taken at itself, favour a rapid convergence of wages, provided that the $\mathrm{K} / \mathrm{L}$ ratios would have the same rate of growth as in the high-wage countries.

However, as is shown in Table 4.5 (column 3), the different magnitudes of the $\sigma \mathrm{s}$ in combination with the large differences in the values of the $\beta$ 's have very large numerical consequences for the effects of a 1 per cent increase in $\mathrm{K} / \mathrm{L}$ ratios. In the countries with the highest proportionate increase in wages, i.e., in Italy and The Netherlands, the relevant quotient of these parameters $(\beta / \sigma)$ amount to 0.42 and 0.65 respectively, whereas the mean for the EC countries is 0.56 . For Italy, this implies that the positive influence of a low elasticity of substitution is strongly counteracted by a relatively high share of labour in GNP. For The Netherlands the opposite holds: the relatively high quotient of $\beta / \sigma$ may have been important for its relatively high increases in wages. Notice also that the estimate of $\sigma$ for France does not explain the French transition from a high-wage country to a low-wage country.

The influence of the bias of technical progress on the development of wage differentials is perhaps the most interesting result of the calculations. Recall from Table 4.4 that all countries except Italy had labour-saving biases in their technical progress. According to expression (4.16) this typical Italian bias in technical progress might be a prominent counteracting force, offsetting the Italian disadvantage of a relatively low $\beta / \sigma$ quotient. This bias favours an Italian catch-up with the high-wage countries. As far as The Netherlands are concerned, the magnitude of the bias of technical progress cannot be held responsible for the high growth rate of wages. Needless to say, that the influence of a favourable bias in Italian technical progress was reinforced by a relatively high rate of overall productivity growth (R), which also tended to favour a catch-up with the high-wage countries. Finally, note that as can be seen in the one but last and in the last column, the model predicts surprisingly well. The average prediction error, defined as the difference between the actual and the estimated value divided by the estimated value, is $\mathbf{5 . 0}$ per cent only. Only in the case of Belgium, the model predicts an average wage that is 12 per cent too high, while Dutch and French wages are estimated 5.8 and 7.8 per cent too high, respectively. In the case of Italy and Germany, the prediction error is less than one per cent. ${ }^{2}$

Our results concerning the Italian catch-up movement are consistent with other literature on the subject. In this respect, the similarities between our results and the ones obtained in the study by Dollar c.s. (1988) is perhaps most worth mentioning. Recall that they also found different techniques in use in production in the various countries of their study and they concluded that as far as there has been a convergence, this would most probably be caused by the international diffusion of technology. It is obvious, that our results are not inconsistent with such approach to international differences in labour productivity.

${ }^{12}$ It should be emphasised, that the model's prediction error on a year to year basis might be substantially higher, since the time series of wages exhibit considerable cyclical variation over the estimation period. However, the model's purpose is to predict the rate of change of wages of a longer period of time, and not to predict the cyclical behaviour of wages. 
To summarize then, one might conclude that aggregate wage differentials may be the result of different factor proportions, as well as differences in the elasticities of substitution and overall rates and biases of technological progress. The parameter estimates reveal that the empirical values of the elasticity of substitution are such as to favour a movement in the direction of wage convergence, but that this movement is counteracted by the various values of labour's share in national income. An important conclusion of our analysis is that Italy's catching up with the other countries is primarily due to its rate and bias of technical progress, and cannot be explained by a faster rate of growth of $\mathrm{K} / \mathrm{L}$ ratios relative to the other countries.

\subsection{Conclusions}

This chapter discussed several empirical studies that have surfaced in the literature on international wage developments. We started with studies on international wage structure comparisons, which have produced similarity and stability of wage structures as main conclusions. These tendencies have in general been explained by traditional factors as skill- and industry-mix, labour productivity, and various institutional factors. None of the studies surveyed made an effort to incorporate elements of international trade theary.

The explanation of the international convergence of wages has mainly been the domain of trade theoretical studies. In these studies, elements of trade theory have been incorporated in a variety of ways. To start with, there are studies in which the most important assumptions underlying trade theory have been tested. Since these studies are too few in number to warrant any firm conclusions, we are not able to say wether or not factor intensity reversals are an empirically relevant phenomenon. Other studies have tested the implications of trade theory. These studies, which are also scarce, have not produced unambiguous results as to the wage effects of economic integration.

More promising therefore are those studies in which the parameters of production technology as estimated and used to produce inferences as to the wage effects of trade policies. We discussed two avenues which have been pursued in the literature. The results of both types of studies are that trade policies have clearly discernable income distribution effects, but that in addition to trade policies, other factors like technical progress should be taken into consideration as well.

A basic drawback of all studies presented in the present chapter concerns their inability to outline the distributional effects of economic integration. To model these effects in detail requires a multi-sectoral model of the economy. To develop that kind of a model shall be the purpose of the next chapter. 



\section{CHAPTER}

5

\section{DISTRIBUTIONAL CONSEQUENCES OF CUSTOMS UNIONS}

\subsection{Introduction}

The model presented at the end of the previous chapter suffers from at least two drawbacks and might be criticized on these grounds. First, the model fails to capture the integration effect on the development of wages. Second, the one-sector nature of the model precludes a disaggregated treatment of the labour markets. The present chapter seeks to improve upon both of these deficiencies, in that its aim is to present a multisectoral general equilibrium model that is capable of predicting the factor price effects of the establishment of customs unions. The parameters of the model presented below, will be estimated in the next chapter, and the parameter estimates will be used for the simulation of the effects of the EC on factor prices in Chapter 7.

Below we construct a general equilibrium model in which the production sector produces an arbitrary number of products $n$ with the aid of two primary factors, capital and labour, and with the aid of $m$ intermediate inputs, which may be obtained both from domestic and foreign suppliers. The industries all operate under constant returns to scale. Perfect competition is assumed to prevail in all markets. Invoking the Armington assumption, a production equilibrium characterised by the existence of intra-industry trade may be supported. Both a short-run and a long-run version of the model will be presented, the distinction being dependent on the role of intersectoral factor mobility. The distributional effects of economic integration are modelled through differential changes in the prices of final products and intermediate inputs emanating from various (foreign) sources, which are inherent in the process of integration.

The analysis of this chapter will show that one should be careful in applying trade theorems to situations of integration, since a convergence of factor prices is not necessarily guaranteed in all conceivable cases. Much seems to depend on the concrete representation of technology.

The chapter is organized as follows. Section $\mathbf{5 . 2}$ outlines the assumptions underlying the model, as well as its general structure. In section 5.3 the comparative statics of the short-run version of the model will be presented. Section 5.3 .1 presents a general discussion of these comparative static effects of trade policies. Then, in section 5.3.2, the shortrun distributional effects of the imposition of a common external tariff in a customs union will pass in review. Section 5.4 contains the long-run comparative static effects of economic integration. The concluding remarks follow in 5.5. 


\subsection{The model and its assumptions}

The following assumptions will underlie the model of this chapter:

1. factor price responses to the creation of customs unions can be modelled by means of a one-country general equilibrium model;

2. price of final commodities are determined with the aid of the Armington assumption;

3. firms produce outputs with the aid of primary and intermediate inputs;

4. firms are cost minimisers and determine simultaneously their requirements of all primary and intermediate factors;

5. all markets are characterised by perfect competition;

6. production technology exhibits constant returns to scale;

7. in the short run, there is no intersectoral factor mobility, whereas in the long run full intersectoral factor mobility applies.

In this section, we shall be concerned with outlining the implications of and the justifications for these assumptions.

To analyze the factor price consequences of customs unions, one of the possibilities at hand is the use of a general equilibrium model, incorporating at least six commodities and at least three countries. The use of general equilibrium models rather than partial equilibrium models may be justified on a number of grounds. First, they have as an advantage that the factor price equations reflect the maximizing behaviour on the part of both consumers and producers. Second, using general equilibrium models implies that one might avoid the pitfalls associated with the ad hoc approach which has been followed in an important part of the literature (see Van Mourik (1987) for an example). Third, the factor price equalisation and Stolper-Samuelson theorems refer to general equilibrium economies, and it is therefore hard to see how partial equilibrium models could accurately describe the factor price responses to the establishment of customs unions. Partial equilibrium models are incomplete and may result in misleading outcomes, since they do not take intersectoral resource pulls into consideration. Hence, they may either under- or overestimate the factor price responses. Fourth and finally, general equilibrium models enable one to fully exploit the duality theorems of international trade theory. In this chapter, the duality between production and cost functions will be used. ${ }^{1}$

To capture the effect of economic integration on factor rentals in a general equilibrium context, one should in principle take notice of the discriminative nature which is inherent in preferential trading agreements like customs unions. To recall, customs unions imply that member countries abolish the trade restrictions which have hitherto existed among themselves, whilst at the same time imposing a common external tariff vis-a-vis non-participating third countries. Needless to say, a model analyzing the distributional consequences of customs unions would have to take this "three-level-ness" into account. Obviously, the most satisfactory way to do so would be to model these consequences in a three-country general equilibrium framework.

The main problem associated with "conventional wisdom" general equilibrium models of preferential trading agreements is that they do not allow for the possibility of all conceivable trade patterns. A true general equilibrium model of economic integra-

${ }^{1}$ A summary of these duality theorems may be found in, e.g., Diewert (1974). Applications to trade theory are in Woodland (1982), and Dixit and Norman (1980). 
tion, however, should have at least three countries and six commodities and allow for all possible potential trade flows. Earlier general equilibrium models of economic integration could mostly not meet this requirement, since they only allowed for a trade pattern that was characterised by trade between just one member state and the outside world, and therefore one member country would never trade with a third country. The main reason for these models' peculiar prediction of trade flows lies in the application of the small country assumption. Since only one of the foreign countries will have the lowest price, the home country will only trade with one of the two potential foreign partners. This characteristic has made these models of preferential trade unduly unrealistic. Although Wooton $(1986,1988)$ developed a more general model of preferential trading that could accommodate to any pattern of trade, it is not unfair to say that the progress that has so far been made with three country models of trade is extremely low. Therefore, application of three country models to distributional problems does not seem to be particularly appropriate at this stage of the art. Besides, the complexity of relationships in three country models precludes general statements, and may not produce tractable relations for estimation purposes.

To overcome the difficulties mentioned here, we propose to formulate the problem in terms of a one country model which is capable of discriminating between partner and non-partner countries. The loss incurred by this treatment of the distributional impact of customs unions is that the feedbacks and interdependencies that exist in a three country world are washed out from the model. The discrimination between the foreign union partner and the non-partner will be modelled with the aid of the Armington (1969) assumption. According to Armington, imports from different sources cannot usually be considered as perfect substitutes, both for each other and for domestic products. The small country assumption, however, implies that goods from all sources are perfect substitutes, which means that foreign price changes will always be passed-through immediately and completely. The Armington assumption, on the other hand, implies that foreign price changes will only be followed when there exist substitution possibilities between domestic and foreign goods. In addition, the strength of the pass-through will vary with the extent of these substitution possibilities.

Armington distinguished between goods and products. "Goods" refer to commodity classes and consist of a collection of products. Thus, cars may be considered as goods and German, French, etc. cars may be labelled as products. Armington assumed that consumers maximise their utility in two stages. In the first stage, the consumer allocates a part of his budget to the goods that may be distinguished. In the second stage, the consumers decide what particular products they will buy.

In Armington's model, the price index for goods is a linear-homogeneous function of the prices of the products which make up that good. In the literature, two functional forms for the aggregator functions for goods have surfaced, notably Cobb-Douglas and CES functions. Assume that a commodity class contains three products, then a CES price aggregator function might be defined as follows

$$
\mathrm{P}=\left[\alpha_{1} \mathrm{P}_{1}^{-\rho}+\alpha_{2} \mathrm{P}_{2}^{-\rho}+\alpha_{3} \mathrm{P}_{3}{ }^{\rho}\right]^{-(1 / \rho)}
$$

where $\mathrm{p}=$ the price index for the good under consideration, $\alpha_{i}=$ the market share of product $i, i=1,2,3, \mathrm{p}_{\mathrm{i}}=$ the price of product $i$, and $\rho$ is a substitution parameter. Note that the elasticity of substitution between the various products is given by $\sigma=(1+\rho) / \rho$, which may take any value between 0 and $\infty$. Total differentiation of this expression gives the relative change of the price index, so 


$$
\hat{\mathrm{P}}=\alpha_{1} \hat{\mathrm{P}}_{1}+\alpha_{2} \hat{\mathrm{P}}_{2}+\alpha_{3} \hat{\mathrm{P}}_{3}
$$

where a hat " $\wedge$ " denotes a relative change (e.g., $\hat{p}=d p / p$ ). This equation says that the price changes for goods are a weighted average of the changes in the prices of individual products that make up that good, the weights being the respective market shares of the products.

Now let $p_{1}$ be the home country's product price and let $p_{2}$ and $p_{3}$ be the foreign countries' product prices. Country 1 can establish a customs union either with country 2 or country 3. Since products are no perfect substitutes, a change in foreign prices due to the change in the tariff policies vis-a-vis foreign nations will not be passed-through completely in the domestic country. To be more specific, the domestic product price change will be a weighted average of the foreign product price changes, the weights being again the market shares of the foreign products on the domestic market, so

$$
\hat{\mathrm{p}}_{1}=\alpha_{2} \hat{\mathrm{p}}_{2}+\alpha_{3} \hat{\mathrm{p}}_{3}
$$

Thus, countries having larger market shares in the domestic market will also have a stronger influence on domestic product price changes.

As Norman (1990) points out, the Armington assumption is normally used in perfectly competitive models. Below, we shall therefore assume the existence of perfect competition on all markets. It should be noted, however, that much attention has been given recently to the development of models of trade and imperfect competition (for a review, see Helpman and Krugman, 1985). In this respect, two kinds of model have surfaced. One explains trade from the existence of external economies of scale (which are compatible with perfect competition), the other explains trade from internal economies in combination with imperfect market structures like monopolistic competition. The two characteristics form independent explanations of trade. Some authors, like Smith and Venables (1992), seem to suggest that economic integration, by its very nature, involves the elimination of market segmentation and should therefore be studied with imperfectly competitive models allowing for the existence of (internal) economies of scale. For mainly practical reasons, we shall not follow this suggestion below. Models of imperfect competition in principle need not fundamentally reverse the "signs" of the factor price responses due to the creation of customs unions, although there is clear evidence that the magnitude of the effects is influenced (see Norman, 1990). The computational burden, on the other hand, increases substantially when elements of imperfect competition and economies of scale are added to the standard general equilibrium trade model.

Let us now turn to the behaviour of producers and the related issue of the characteristics of production technology. Firms are assumed to minimise costs. They produce their products with the aid of two primary factors, capital (K) and labour (L), and with the aid of intermediate inputs. The latter may be obtained from domestic and foreign sources. The primary input vector is denoted by $x$, the intermediate input vector by $X$, outputs for final demand by $y$, primary factor prices by $w$, and intermediate input prices by $\mathrm{q}$. The production sector of the economy employs two primary inputs, capital and labour, which are fixed in supply ( $\overline{\mathrm{K}}$ and $\overline{\mathrm{L}}$ resp.). The model assumes that imports may consist of both final commodities and intermediate inputs. This treatment of imports, which follows Burgess (1974, 1976), Kohli (1978) and others, may be justified on a number of grounds. Most importantly, it recognizes that most internationally traded goods are intermediates. Even finished goods delivered to households generally undergo some sort of treatment (transport, wholesaling etc.) before their delivery. The proces- 
sing of intermediate imported goods before their final delivery requires the use of domestic primary production factors. The effect of trade barriers on the distribution of factor income occurs through the changes in import prices, which will, given the specification of technology, alter the competitive returns to primary factors. As Diewert and Morrison (1989) point out, a major advantage of treating imports as intermediates is that one needs to model the private production sector only and that the difficult problem of modelling the consumer sector is sidestepped in this way. True, a complete general equilibrium model would specify demand functions for final outputs, and a balance of payments budget constraint ensuring that total income is exhausted for purchases of outputs. However, we shall assume that this constraint is not operative, for instance because balance of payments imbalances are financed through capital movements.

There is another advantage which results from modelling the distributional impact of trade policies through the prices of intermediate inputs, since the inclusion of intermediates implies that one will study the impact of effective in stead of nominal protection rates. As is well known from the theory of effective protection, effective rates provide a more adequate impression of the factorial protection than nominal rates. Usually, this theory employs the assumption that the industries under consideration are unable to substitute one input for another. Below, we shall not make the restrictive assumption of fixed production coefficients, but we do follow the assumption of more sophisticated versions of the theory of effective protection, which states that substitution possibilities of capital and labour on the one hand for intermediate inputs are exactly identical. This is what is usually referred to as the assumption of functional separability between primary inputs and intermediate inputs.

We assume next that the aggregate technology of the economy can be described by a joint cost function $C(y, w, g)$, which denotes the minimum cost of producing a vector $y$ of outputs when the primary factor prices $w$ and prices of intermediate inputs are given by the vector $\mathrm{g}$. Thus the joint cost function is defined from the transformation curve $T(x, X, y)=0$, in such a way that $C(y, w, g)=\min _{x} w^{\prime} x+X^{\prime} q$, subject to $T(x, X, y) \geq 0$, where $x$ is the vector of primary inputs and $X$ is the vector of intermediate inputs. The output prices are given, and so are the prices of intermediate inputs. $C$ is a real extended function, which is well defined for all sets of positive primary factor prices and intermediate input prices. The joint cost function is monotonically increasing in prices and quantities, concave in input prices and convex in output quantities (see Diewert (1974) for a proof).

Under conditions of perfect competition in all product and factor markets, as well as constant returns to scale, the production sector achieves an optimal output vector by setting the marginal cost of production equal to marginal revenue or the price. Thus the inverse output supply curves can be obtained by partial differentiation of the joint cost function (Hotelling): $\mathrm{p}_{\mathrm{i}} \equiv \mathrm{C}_{\mathrm{y}}=\partial \mathrm{C}(\mathrm{y}, \mathrm{w}, \mathrm{g}) / \partial \mathrm{y}_{\mathrm{i}}$. Also, as is well known, the partial derivatives of the joint-cost function with respect to primary input factor prices gives the factor demand equations (Shephard), so that $x_{i} \equiv C_{w}=\partial C(y, w, g) / \partial w_{i}$, or, since full-employment will be assumed $\overline{\mathrm{K}}=\mathrm{C}_{\mathrm{r}}(\mathrm{y}, w, g)$ and $\mathrm{L}=\mathrm{C}_{w}(\mathrm{y}, w, g)$. As is well-known, the full employment conditions implicitly determine the factor prices. Finally, note that $X_{i}=$ $\partial C(y, w, g) / \partial q_{i}$, where $X_{j}=$ the economy's total use of intermediate input $j$.

Let us, for the sake of simplicity, rule out the possibility of jointness in the technology of production and also assume that technology exhibits constant returns to scale. In that case the cost of producing all outputs equals the costs of producing each output separable (see Hall, 1973, for a proof): $C(y, w, g)=y_{1} c^{1}(w, g)+\ldots+y_{n} c^{n}(w, g)$, where $y_{i}$ is the output of sector $i$ and $c^{i}$ is that sector's unit cost function. The unit cost function is assumed to have all the properties of well-behaved cost functions, that is, it is assumed 
to be non-negative, twice differentiable over $w>0$ and $g>0$, homogeneous of degree one in its arguments, concave in its arguments and non-decreasing in its arguments.

The reader will observe that the number of commodities in this model may exceed the number of primary factors and that, as a consequence, the pattern of production and trade for this country may become indeterminate. Although this could imply that it is impossible to infer the direction of change in the resource allocation as the result of a change in the tariff structure, it does not preclude inferences concerning the direction of change of factor prices. Indeed, the latter are determined by commodity prices under perfect competition, and therefore if tariffs will induce changes in these commodity prices, we are in principle able to predict the impact of changes in the tariff structure on factor rentals.

As far as the possibilities for intersectoral factor mobility are concerned, two approaches may be found in the literature. First of all, one may assume complete intersectoral factor mobility. In the standard textbook $2 x 2$ setting, the Stolper-Samuelson theorem will predict that the factor used intensively in the import sector will gain (in real terms) from the imposition of a tariff, while the other factor will loose. Since capital and labour are considered to be perfectly mobile across sectors, intersectoral differentials in wages and capital costs will be absent, and consequently there will be a conflict of interest between labour and capital in the economy.

In reality, however, we do observe intersectoral factor price differentials which means that (some of) the conditions for factor price equalisation are not met. Among these, the possibility of intersectoral immobility of production factors has been at the centre of interest. In the second approach, the specific-factors model, developed by Jones, Mussa and others, it is assumed that there is only one mobile factor (labour), whereas the other factor is completely immobile, i.e., used only in the production of a particular sector. The model therefore in fact assumes the existence of three factors, viz. one mobile (labour) and two immobile factors (capital), so that the number of factors outgrows the number of goods. In that case, as is well-known, the possibility of factor price equalisation reduces to a fluke (see, o.a., Dixit and Norman, 1980, chapter 4). Furthermore, factor price equations can no longer be solved independently of the factor market clearing conditions.

As far as the influence of protective measures is concerned, the specific-factor model predicts that the imposition of a tariff will result in an increase in the real reward of the specific factor in the import sector, while at the same time reducing the real income of the specific factor in the non-import sector. The real earnings of the mobile factor (labour) will fall in terms of the commodity whose relative price has risen, and rise in terms of the commodity whose relative price has fallen. Thus, the question of whether or not labour actually benefits from protection is reduced to an index-number problem: in case the share of imported commodities in the budget of workers falls short of the percentage increase in the price of the imported commodity, labour will gain in real terms; in case the reverse holds, labour will loose in real terms.

Using these insights, Albert and Vosgerau (1989) were able to show the implications of imperfect intersectoral factor mobility for the European integration process. Their argument, in short, is that if the reallocation process would cost either time or money, factor prices were very likely to diverge in the short-run and need not necessarily converge in the long-run.

Burgess (1980) extended the standard specific-factors model to include interindustry flows. He concluded, that the inclusion of intermediate goods would free that model from its neo-classical ambiguity, and that "(u)nder plausible economic circumstances a 
tariff will raise (or lower) the real wage measured in terms of every connmodity even when labour is the only freely mobile factor"(1980, p. 784). Burgess' conclusion follows from the very fact that the inclusion of interindustry flows increases the number of arguments in the cost function. As a result more substitution elasticities than the one between labour and capital determine the distributional effects of trade policies.

In this chapter we shall use both the assumption of intersectoral factor mobility and the assumption of intersectoral factor immobility. Firstly, we shall investigate the factor price reactions under a regime of complete intersectoral factor immobility. This is what we refer to as "the short run". Secondly, we shall invoke the assumption of full intersectoral factor mobility, a situation we shall refer to as "the long run".

\subsection{Short-run factor price effects of trade policies}

In this section we shall outline the effects of trade policy measures on factor prices, under the assumption that both capital and labour are fully sector specific. Complete sector specificity implies that identical factors need not earn the same reward in all sectors. The justification for this sector specificity is that factors cannot be expected to move when the economy is hit by an external (or: policy) shock. Capital is frequently embodied in the form of machines that have been designed to produce a particular kind of output. Labour frequently also has sector specific skills and frequently cannot move to another sector overnight. Reallocation of factors therefore takes time to occur. Recall that in the standard version of the specific-factor model, only one factor is allowed to move between sectors. The specific factor will gain when tariffs are imposed. In our short-run model, which has no mobile factor at all, one might therefore expect that all factors would gain after the imposition of tariffs, since the value of marginal product of all specific factors will increase. Hence, contrary to the standard specific-factor model we expect to find that the neoclassical ambiguity is absent in our model. This result is independent of the inclusion of intermediate inputs in our model. Burgess (1980), in his earlier mentioned study, also found the possibility of absence of the neoclassical ambiguity when the specific-factor model was expanded to include intermediates. His results do rely on the assumption of intermediate goods, however.

To facilitate the interpretation of the results, we shall start our analysis ignoring the Armington assumption and assume for a moment that we are dealing with a small country (subsection 5.3.1). This will demonstrate the importance of such production technology characteristics as elasticities of substitution. Then, we explicitly introduce the Armington assumption in subsection 5.3.2 to capture the effects of economic integration on factor prices. 


\subsubsection{Short-run comparative statics ${ }^{2}$}

The following set of equations describes sector behaviour completely. First observe that under competitive conditions, prices should equal unit costs (zero profit condition) in all $i(=1, \ldots, n)$ sectors of the economy. Thus the commodity market clearing conditions are:

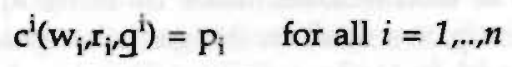

where $c^{i}(.$.$) is the i$-th sector unit cost function, $w_{\mathrm{i}}=$ unit labour costs in sector $i, \mathrm{r}_{\mathrm{i}}=$ unit capital cost in sector $i$, and where $g^{i}$ is the vector of (given) prices of the intermediate inputs. The intermediate inputs may, in principle, be obtained from different sources, viz. domestic and foreign producers. Note that the treatment of these intermediate products in the cost function is formally identical to that of the primary inputs, that is, the intermediate inputs are also treated as "specific" factors.

The derived conditional demand for labour must equal the fixed supply of labour. As is well-known from Shephard's lemma, the first partial derivative of the unit costfunction with respect to the wage rate, i.e., $\partial c^{i} / \partial w_{i}=c_{w^{\prime}}^{i}$ gives the per unit demand for labour in sector $i$ (Samuelson (1953), Diewert (1974)). Multiplication of per unit demand for labour with the output level gives total labour demand in sector $i$, which should be equal to total labour supply (labour market equilibrium):

$$
y_{i} \cdot c_{w}^{i}\left(w_{i}, r_{i}, g^{i}\right)=\bar{L}_{i}
$$

As far as the production factor capital is concerned, multiplication of the first derivative of the unit cost function with respect to the capital rate and $y_{i}$ gives:

$$
y_{\mathrm{i}} \cdot c_{\mathrm{r}}^{\mathrm{i}}\left(w_{\mathrm{i}}, \boldsymbol{r}_{\mathrm{i}}, \mathrm{g}^{\mathrm{i}}\right)=\overline{\mathrm{K}}_{\mathrm{i}}
$$

The model described in eqs. (5.1)-(5.3) consists of $3 x n$ equations in $3 x n$ unknowns, viz., $y_{i}, w_{\mathrm{i}}$ and $\mathbf{r}_{\mathrm{i}}$, for $i=1, \ldots, n$. Since both capital and labour are sector specific, system (5.1)(5.3) may be written as a block-diagonal matrix, in which each block constitutes an $n x n$ matrix of its own. Therefore, there is no interdependence in the behaviour of sectors, other than the interdependence occurring through intermediate inputs. The computational advantage of this block-diagonal structure of the system is obvious: it allows us to solve for output and factor prices in every individual sector, without taking this interdependence into account. Below we solve the system for sector $i$.

The equations (5.1)-(5.3) are always valid. Shocks resulting from tariff policies influence final commodity prices and intermediate input prices. To see how primary factor prices will respond after these shocks, totally differentiate the system (5.1)-(5.3) to obtain relative changes of the variables. Turn to equation (5.1) first.

2 The model presented in this section is completely different from a joint production model. To recall, the latter are models in which every sector produces all commodities. The model in this section is characterized by a non-joint production technology. Yet the reader will observe the remarkable similarity between the results derived in this section and those obtained in a joint production model. Cf. Burgess (1976) who discusses the results in case of a joint production technology which utilises a single imported intermediate input. 


$$
\theta_{\mathrm{iw}} \hat{\mathrm{w}}_{\mathrm{i}}+\theta_{\mathrm{ir}} \hat{\mathrm{r}}_{\mathrm{i}}=\hat{\mathrm{P}}_{\mathrm{i}}-\sum_{\mathrm{j}=1}^{\mathrm{m}} \theta_{\mathrm{iq}} \hat{\mathrm{q}}_{\mathrm{ij}} \quad i=1, \ldots, n \quad j=1, \ldots, m
$$

In these equations, a hat " ${ }^{\wedge} "$ indicates a relative change (i.e., $\hat{x}=d x / x$ ), $\theta_{i w}$ represents the cost share of labour in sector $i, \theta_{\mathrm{ir}}$ represents the cost share of capital in sector $i$, and $\theta_{\mathrm{iq}}$ represents the cost share of intermediate input $j$ used in the production of sector $i$.

The right-hand side of equation (5.1') shows that tariffs, through their influence on the prices of intermediate inputs will affect the entire tariff structure. According to Woodland (1982, p. 117) the right-hand side of eq. $\left(5.1^{\prime}\right)$ is the effective rate of protection. These effective rates of protection play the same role as the prices of final goods in the standard textbook analysis of the Stolper-Samuelson effect. Note that effective rates of protection need not necessarily be positive; in the case the share of intermediates in the production of outputs is high, and intermediates are at the same time taxed more heavily than final commodities, effective rates of protection may well be negative.

Equations (5.2) and (5.3) may be totally differentiated to obtain (set $\mathrm{dK}_{\mathrm{i}}=\mathrm{d} \overline{\mathrm{L}}_{\mathrm{i}}=0$ )

$$
\begin{aligned}
& \hat{y}_{i}=-\varepsilon_{w w}^{i} \hat{w}_{i}-\varepsilon_{w r}^{i} \hat{r}_{i}-\sum_{j=1}^{m} \varepsilon_{w q_{j}}^{i} \hat{q}_{i j} \\
& \hat{y}_{i}=-\varepsilon_{r w}^{i} \hat{w}_{i}-\varepsilon_{r r}^{i} \hat{i}_{i}-\sum_{j=1}^{m} \varepsilon_{r q}^{i} \hat{q}_{i j}
\end{aligned}
$$

where $\varepsilon_{\mathrm{jk}}^{\mathrm{i}}$ refers to the $i$-th sector price elasticity of demand for the $j$-th factor with respect to the k-th factor price, e.g., $\varepsilon_{\mathrm{wr}}^{i}=c_{\mathrm{wr}}^{\mathrm{i}} \cdot\left(\mathrm{r} / \mathrm{c}_{\mathrm{w}}^{1}\right)$. Note that, except by coincidence, $\varepsilon_{\mathrm{jk}}^{\mathrm{i}} \neq$ $\varepsilon_{\mathrm{kj}}^{\mathrm{i}}$

The system $\left(5.1^{\prime}\right)-\left(5.3^{\prime}\right)$ may be re-written if we make use of the Allen-Uzawa partial elasticities of factor substitution (hereafter AUES) between the $j$-th and $k$-th factor in the production of the $i$-th commodity. The AUES are defined as usual, i.e., (Woodland (1982, p. 31)),

$$
\sigma_{j k}=C_{j k} C / C_{j} C_{k}
$$

As is well-known, the matrix of AUES is a symmetric matrix, implying $\sigma_{j \mathrm{k}}^{\mathrm{i}}=\sigma_{\mathrm{kj}}^{\mathrm{i}}$ As is pointed out by Woodland (1982, p. 31), the following relationship between AUES and the (own- and cross-partial) elasticities of demand for the primary and intermediate factors must hold:

$$
\sigma_{\mathrm{jk}}^{\mathrm{i}}=\varepsilon_{\mathrm{jk}} / \theta_{\mathrm{ik}}
$$

Using the definition of the AUES, one may also write:

$$
\begin{aligned}
& \theta_{\mathrm{iw}} \hat{\mathrm{w}}_{\mathrm{i}}+\theta_{\mathrm{ir}} \hat{\hat{i}}_{\mathrm{i}}=\hat{\mathrm{p}}_{\mathrm{i}}-\sum_{\mathrm{j}=1}^{\mathrm{m}} \theta_{\mathrm{iq}} \hat{\mathrm{q}}_{\mathrm{ij}} \quad i=1, \ldots, n \text { and } j=1, \ldots, m \\
& \hat{y}_{\mathrm{i}}=-\theta_{\mathrm{iw}} \sigma_{\mathrm{ww}}^{\mathrm{i}} \hat{\mathrm{w}}_{\mathrm{i}}-\theta_{\mathrm{ir}} \sigma_{\mathrm{rw}}^{\mathrm{i}} \hat{\mathrm{r}}_{\mathrm{i}}-\sum_{\mathrm{j}=1}^{\mathrm{m}} \theta_{\mathrm{iq}} \sigma_{\mathrm{wq}}^{\mathrm{i}} \hat{\mathrm{q}}_{\mathrm{ij}}
\end{aligned}
$$




$$
\hat{y}_{i}=-\theta_{i w} \sigma_{r w}^{i} \hat{w}_{i}-\theta_{i r} \sigma_{r r}^{i} \hat{r}_{i}-\sum_{j=1}^{m} \theta_{i q_{j}} \sigma_{r q j}^{i} \hat{q}_{i j}
$$

Eqs. (5.2") and (5.3") may be combined to give

$$
\theta_{i w}\left(\sigma_{\mathrm{rw}}^{i}-\sigma_{w w}^{i}\right) \hat{w}_{i}+\theta_{i r}\left(\sigma_{\mathrm{rw}}^{i}-\sigma_{\mathrm{rr}}^{i}\right) \hat{r}_{\mathrm{i}}+\Sigma_{j} \theta_{i q_{j}}\left(\sigma_{\mathrm{rq}}^{i}-\sigma_{w}^{i}\right) \hat{q}_{\mathrm{ij}}=0
$$

In matrix formulation, the model now reads as

$$
\begin{aligned}
& {\left[\begin{array}{lll}
\theta_{i w} & \theta_{i r} \\
\theta_{i w}\left(\sigma_{r w}^{i}-\sigma_{w w}^{i}\right) & \theta_{i r}\left(\sigma_{r w}^{i}-\sigma_{r r}^{i}\right)
\end{array}\right)\left[\begin{array}{c}
\hat{w}_{i} \\
\hat{r}_{i}
\end{array}\right]=} \\
& \left(\begin{array}{lllllll}
1 & -\theta_{i q_{1}} & \ldots & -\theta_{i q_{j}} & \ldots & -\theta_{i q_{m}} \\
0 & \theta_{i q_{1}}\left(\sigma_{r q}^{i}-\sigma_{w q_{1}}^{i}\right) & \ldots & \theta_{i q_{j}}\left(\sigma_{r q_{j}}^{i}-\sigma_{w q_{j}}^{i}\right) & \ldots & \theta_{i q_{m}}\left(\sigma_{r q_{m}}^{i}-\sigma_{w q_{m}}^{i}\right)
\end{array}\right)\left(\begin{array}{l}
\hat{p}_{i} \\
\hat{q}_{i 1} \\
\ddot{q_{i j}} \\
. \\
q_{i m}
\end{array}\right)
\end{aligned}
$$

The reduced form equations for the factor prices are

$$
\begin{aligned}
& \hat{w}_{i}=\frac{\theta_{i r}\left(\sigma_{r w}^{i}-\sigma_{r r}^{i}\right)}{\Delta_{i}}\left\{\hat{p}_{i}-\Sigma_{j} \theta_{i q_{j}}\left(1+\frac{\sigma_{r q_{j}}^{i}-\sigma_{w q_{j}}^{i}}{\sigma_{r w}^{i}-\sigma_{r r}^{i}}\right) \hat{q}_{i j}\right\} \\
& \hat{r}_{i}=\frac{\theta_{i w}\left(\sigma_{r w}^{i}-\sigma_{w w}^{i}\right)}{\Delta_{i}}\left\{\hat{p}_{i}-\Sigma_{j} \theta_{i q_{j}}\left(1+\frac{\sigma_{w q_{j}}^{i}-\sigma_{r q_{j}}^{i}}{\sigma_{w w}^{i}-\sigma_{r w}^{i}} \hat{q}_{i j}\right\}\right.
\end{aligned}
$$

with

$$
\Delta_{\mathrm{i}}=\theta_{\mathrm{iw}} \theta_{\mathrm{ir}}\left(2 \sigma_{\mathrm{rw}}^{\mathrm{i}}-\sigma_{\mathrm{rr}}^{\mathrm{i}}-\sigma_{\mathrm{ww}}^{\mathrm{i}}\right) \quad(>0 \text {, see below })
$$

Equations (5.5) and (5.6) completely describe the short-run reaction of primary factor prices to changes in final commodity prices and intermediate input prices. As the equations reveal, the solution of the model is a rather complex function of the AUES ownand cross-partial elasticities of substitution between pairs of inputs, as well as the factor cost shares. However, some simplifications facilitating the interpretation of eqs. (5.5) and (5.6) are possible. Let us begin by evaluating the sign of the determinant $\Delta_{\mathrm{i}}$. Since it makes no difference whether we evaluate this determinant for the case of one intermediate input or $m$ intermediates, let us confine ourselves, for the sake of simplicity, to the case of a production technology that utilises only one intermediate. Firstly, the product $\theta_{\mathrm{iw}} \theta_{\mathrm{ir}}$ must be positive. Secondly, as was noted above, the matrix of AUES is a symmetric matrix. Thirdly, we know that the cost function is linear-homogeneous and concave in factor prices. The latter implies that the Hessian matrix of second-order partial derivatives of the cost function is negative semi-definite (see, Takayama (1987), p. 141, and pp. 151-52, n13). Therefore, the matrix of AUES own- and cross-partials, $\Sigma^{i}$, is also negative semi-definite, that is, $x \Sigma^{i} x<0$, for not all $x=0$. Thus, the expression $2 \sigma_{\mathrm{rw}}^{i}-\sigma_{\mathrm{rr}}^{i}-\sigma_{\mathrm{ww}}^{i}$ 
can be written as $-\left(-2 \sigma_{\mathrm{rw}}^{\mathrm{i}}+\sigma_{\mathrm{rr}}^{\mathrm{i}}+\sigma_{\mathrm{ww}}^{\mathrm{i}}\right)$. This expression in brackets is negative since it can be written as:

$\left(\begin{array}{lll}-1 & 1 & 0\end{array}\right) \quad\left[\begin{array}{lll}\sigma_{\mathrm{rr}}^{i} & \sigma_{\mathrm{rw}}^{i} & \sigma_{\mathrm{rq}}^{i} \\ \sigma_{\mathrm{rw}}^{i} & \sigma_{\mathrm{ww}}^{i} & \sigma_{\mathrm{wq}}^{i} \\ \sigma_{\mathrm{rq}}^{i} & \sigma_{\mathrm{wq}}^{i} & \sigma_{\mathrm{qq}}^{i}\end{array}\right]\left(\begin{array}{c}-1 \\ 1 \\ 0\end{array}\right)<0$

and it follows that $\Delta_{\mathrm{i}}>0 \mathrm{.}^{3}$

Fourthly, the possible effects of trade policy are constrained by the fact that all ownpartial AUES are negative whereas the cross-partials may both be positive and negative (they may usually be expected to have positive values, however). In addition, as is wellknown, weighted sums of the own- and cross-partial AUES must be zero. This implies

$$
\begin{aligned}
& \theta_{i r} \sigma_{r r}^{i}+\theta_{i w} \sigma_{r w}^{i}+\theta_{i q_{j}} \sigma_{r q_{j}}^{i}=0 \\
& \theta_{i r} \sigma_{r w}^{i}+\theta_{i w} \sigma_{w w}^{i}+\theta_{i q_{j}} \sigma_{w q_{j}}^{i}=0
\end{aligned}
$$

Thus, not all factors can be complements, and, in our case, at most one cross-partial AUES can be negative.

Fifthly, note that all own- partial AUES are always negative, whereas the cross-partials may take both positive and negative values. In the normal case, however, one may expect that most factors are substitutes instead of complements. Thus, in the majority of cases we may observe that the relevant cross-partials are positive. That would suggest that $\left(\sigma_{\mathrm{rw}}^{\mathrm{i}}-\sigma_{\mathrm{rr}}^{\mathrm{i}}\right)$ and $\left(\sigma_{\mathrm{rw}}^{\mathrm{i}}-\sigma_{\mathrm{ww}}^{\mathrm{i}}\right)$ are normally positive.

Sixthly and finally, as is pointed out in Woodland (1982) and Jones (1975), the standard theory of effective protection assumes that the production technology is characterised by functional separability between primary inputs on the one hand and intermediate inputs on the other. Early discussions of this theory were concerned with the very restricting case of production functions exhibiting fixed coefficients, so $\sigma_{\mathrm{wq}}=\sigma_{\mathrm{rq}}=0$. In less restrictive formulations, effective protection theory simply assumes $\sigma_{\mathrm{wq}}=\sigma_{\mathrm{rq}} \geq 0$, which means that there exist substitution possibilities between primary and intermediate factors, be it that both primary factors will react equally strong to changes in the price of intermediates.

Below, we shall follow the practice of the theory of effective protection and assume that $\sigma_{\mathrm{wq}}=\sigma_{\mathrm{rq}} \geq 0$. This implies that (5.5) and (5.6) reduce to

$$
\begin{aligned}
& \hat{w}_{i}=\left(\theta_{i r} / \Delta_{i}\right)\left(\sigma_{r w}^{i}-\sigma_{r r}^{i}\right)\left(\hat{p}_{i}-\Sigma_{j} \theta_{i q_{j}} \hat{q}_{i j}\right\} \\
& \hat{r}_{i}=\left(\theta_{i w} / \Delta_{i}\right)\left(\sigma_{r w}^{i}-\sigma_{w w}^{i}\right)\left(\hat{p}_{i}-\Sigma_{j} \theta_{i q_{j}} \hat{q}_{i j}\right\}
\end{aligned}
$$

These equations show that the effects of trade policies may occur through two channels, the first of which relates to the changes in the prices of final commodities, and the second of which occurs through the influence of changed intermediate input prices. These reactions may be called "direct" and "indirect" Stolper-Samuelson effects. Note that these effects have opposite signs: whereas a lower price of final commodities has a

${ }^{3}$ Note that the inclusion of $m$ intermediate inputs in the cost function increases the number of zeros to $m$ in the vectors with which the $\Sigma$-matrix is pre- and post-multiplied, and does not change the conclusion of the negative semi-definiteness of the $\Sigma$-matrix. 
negative effect on both factor rentals, the decline in prices of intermediate inputs will tend to increase the prices of both primary factors. Ruling out the exceptional possibility of negative effective rates of protection, the abolition of tariffs will cause $\hat{p}_{i}-\Sigma_{j} \theta_{i j_{j}} \hat{q}_{i j}<0$. Thus, the elimination of tariffs opens the possibility that both factors are made worse off. It follows theiefore that both primary factors do not have conflicting interests in the short-run. ${ }^{4}$ Also note that the strength of the reaction of both factor rentals need not be identical in quantitative terms. The magnitude of the change in both factor rentals is determined by the own elasticities of substitution and the primary factor shares. If the share of capital is relatively large and the own elasticity of substitution of labour is relatively large as well, labour's loss will be larger than capital's loss.

Figure 5.1 Short-run factor price responses following trade policy measures

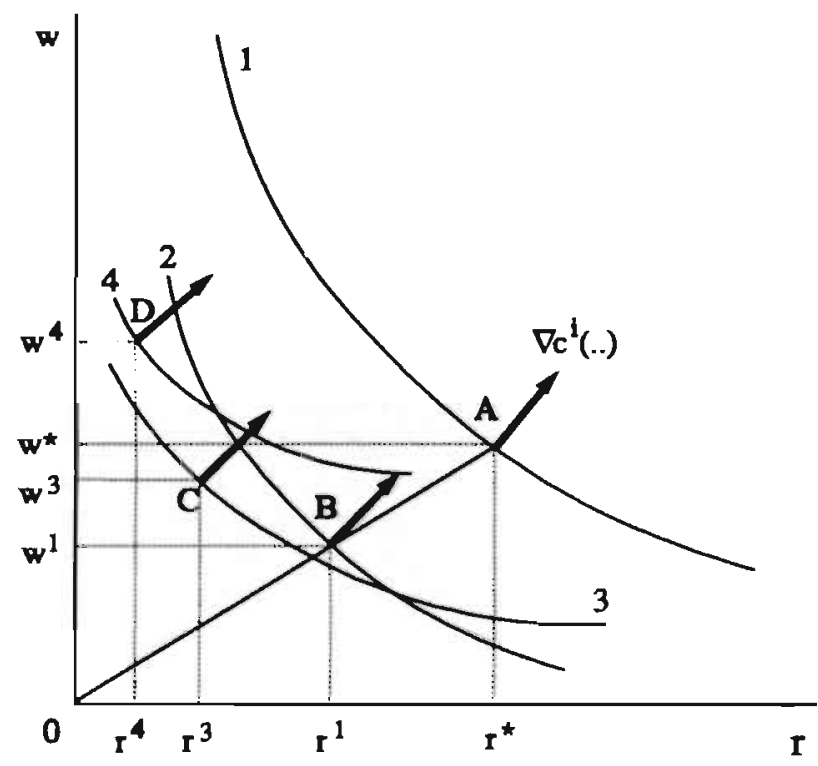

The model discussed above may also be illustrated graphically. Consider Figure 5.1, where we have drawn the iso-cost curve for sector $i$ in the factor price space. The curve $c(w, r, g)$ indicates the set of factor prices for which unit cost is equal to the price. The figure shows four iso-cost loci, labelled $1,2,3$ and 4 . Since $c^{\mathrm{i}}(.$.$) is concave in factor$ prices, the curve is convex, and since $c^{i}(.$.$) is increasing in w$, the curve is downward sloping. Let us start with the situation in which iso-cost locu's 1 is valid. Due to Shephard's lemma, the gradient vector (indicated by an arrow) represents the optimal input vector, i.e., the gradient vector is perpendicular to the support plane at any point of the

4 The possibility of conflicting interests between factor owners arises only when labour and capital are complements in stead of substitutes, causing $\sigma_{\mathrm{rw}}^{i}<0$. That might imply $\sigma_{\mathrm{rw}}^{\mathrm{i}}-\sigma_{\mathrm{m}}^{\mathrm{i}}>0$ and $\sigma_{\mathrm{rw}}^{\mathrm{i}}-\sigma_{\mathrm{wW}}^{\mathrm{i}}<0$, and therefore result in opposite factor price responses after trade policy measures are implemented. It should be noted, however, that this possibility is a rather extreme result. 
iso-cost line (see Woodland (1982), pp. 46-47). The gradient vector represents the input vector per unit of output. Let $\nabla c^{i}\left(w^{*}, r^{*}, g\right)$ be the endowment vector which is relevant for the sector under consideration. Then observe that, due to factor market equilibrium, the vector of optimal factor prices is given by $w^{*}=\left(w^{*}, r^{*}\right) .^{5}$ As the graph reveals, in this initial equilibrium, the factor price vector coincides with the endowment vector.

Now assume that tariffs are abolished as a result of which $\hat{\mathrm{p}}_{\mathrm{i}}-\Sigma_{j} \theta_{\mathrm{iq}} \hat{\mathrm{q}}_{\mathrm{ij}}<0$. In this case there will be less money available for payments to primary factors and the iso-cost locus will shift inwards. In the exceptional case where $\sigma_{\mathrm{wr}}^{i}=\sigma_{\mathrm{rr}}^{i}$ and at the same time $\theta_{i w}=\theta_{i r}$ a movement along the ray $\mathrm{OA}$ will occur, and the new equilibrium might, for instance, be given by B. However, that is usually not the case. Factor price reactions must normally lie in the $\mathrm{Ow}^{*} \mathrm{Ar} \mathrm{r}^{*}$ area. Hence, there may be biased shifts in the direction of either factor, but both factors must necessarily loose. If labour's loss is smaller than capital's loss, an allocation given by $\mathrm{C}$ might occur. Under the assumptions made above, an allocation like $D$ is not feasible, since it would imply an increase in the price of labour rather than a decrease. ${ }^{6}$

In sum, we have found that in the case capital and labour are both sector specific, the precise nature of the factor price response to a tariff depends on the concrete features of technology as embodied in the unit cost function. However, under plausible assumptions, both factors are likely to loose as a result of a liberalisation of trade. That result strips the standard textbook version of the specific-factors model of its neo-classical ambiguity and is in line with Burgess' (1980) modification of the specific-factors model, in which intermediate goods are also an essential feature and in which the absence of the neoclassical ambiguity is the result of the introduction and treatment of intermediate inputs in the production process.

\subsubsection{Capturing the integration effects}

Above we have discussed the problem of the distributional effects in a one country setting. We should now proceed to extend the analysis and investigate what relevance the previous section bears to the problems of economic integration. If we would follow the practice of well-known textbooks on economic integration, we might simply formulate the problem in a two-country world. Below, we shall analyze the distributional effects of customs unions, which are, as the reader will recall, agreements between two or more countries to abolish mutual tariffs on imports and by which a common commercial policy with respect to non-union members is imposed. The dominant view concerning the distributional effects of these customs unions is that, since they constitute a step closer toward free trade, factor prices must necessarily converge after their creation (see

5 The graph illustrates the well-known fact that, in case one or more factors are specific, we need the factor market equilibrium conditions in order to solve for $\mathbf{w}$.

${ }^{6}$ Allocation D is only possible if we would not have made the assumption of functional separability between primary inputs and intermediate inputs. According to Ramaswami and Srinivasan (1971) this is the general case the theory of effective protection should address. Note that this case may, for instance, occur when labour and intermediates are complements, so that $\sigma_{\mathrm{rg}}^{i}$ $\sigma_{w q_{i}}^{i}>0$. The decline in tariffs on intermediate inputs will in that case exert a direct upwards it fluence on wages through eq. (5.6). However, there will also be an indirect effect in that the decline in tariffs on intermediates increases the demand for those inputs. But since labour and intermediates are complements, the demand for labour will also increase, causing the wage rate to increase further. 
in this spirit, e.g., Molle (1990)). That view of distributional effects strongly resembles the classical view on the welfare effects of customs unions, which was replaced by the Vinerian trade creation/diversion analysis. According to Viner, the customs union may be detrimental to welfare when the (negative) effects of trade diversion are not sufficiently compensated by the (positive) effects of trade creation. The dominant view concerning the distributional effects of customs union formation could be modified in an analogous way as the classical view on the welfare effects of customs union formation. That is, in the short run, the formation of customs unions need not necessarily result in a convergence of factor prices, but might also produce a divergence of factor prices.

Before we substantiate this claim, it should be recalled, that the small country assumption proper is no longer feasible since we are now dealing with three countries. One must therefore invoke another assumption regarding the price formation in the home country. Assume that the Armington assumption is applicable, and that the percentage change in home country price of output $i$, that is $\mathrm{p}_{i 1}$, is a weighted average of the relative price changes of the same commodity imported from countries 2 and 3 , so

$$
\hat{\mathrm{p}}_{\mathrm{i} 1}=\Sigma_{\mathrm{k}} \alpha_{\mathrm{k}} \hat{\mathrm{p}}_{\mathrm{ik}} \quad k=2,3
$$

In this equation, the subscript 1 refers to the home country, and the subscripts 2 and 3 refer to the potential foreign customs union partners. The prices are tariff-inclusive prices. We assume that the prices for potential partner countries are given.?

Now to analyze what happens with international factor price differentials after formation of a customs union, let us introduce some simplifying assumptions and some stylised facts, which limit the number of possible outcomes. The first simplifying assumption is that we shall restrict the number of intermediate inputs to two in every sector. One intermediate input is purchased from a union member producer, the other from a third country producer. The second simplifying assumption is the small country assumption, which implies that the prices of final commodities and intermediate inputs are given for the union members. The first stylised fact concerns the non-equalisation of factor prices. Some countries tend to have high wages, whereas others may be classified as low-wage countries. In the EC context, a country like Italy is an example of the latter, the Benelux countries and Germany constitute an example of the former. The second stylised fact concerns the circumstance that most countries have different tariff regimes. Some countries, like Italy and France, tended to have high tariffs when the EC was

${ }^{7}$ The assumption of given foreign prices could be criticized on the grounds that the prices $p_{i k}$ are used both as endogenous and as exogenous variables, depending upon the situation under consideration. When the home price change is calculated, the partner and non-partner country prices are exogenous. At the same time, when the partner country price change is calculated, the home country price is used as exogenous variable. Clearly, this is an unsatisfactory procedure, since one does not take the interdependence between the two prices into account. However, it should be noted that the only way to endogenize both prices at the same time is that the model would be formulated as a genuine three-country model in which all demands and supplies determine prices. Unfortunately, this would make the model untractable and analytical solutions for all endogenous variables would yield extremely complex expressions, which would be difficult to interpret. As a justification for our treatment of foreign prices, the reader is referred to Dramais (1984), who studied the international interdependence between prices. He found that increases in import prices may have a substantial impact on domestic prices, but that the subsequent spill-over of changes domestic prices to foreign markets is extremely small. 
formed, whereas others, like the Benelux countries and Germany, tended to have low tariff rates.

With these remarks in mind, let us focus on the reaction of wages following the formation of a customs union in. The reduced form equation for wages is

$$
\hat{w}_{\mathrm{i}}=\frac{\theta_{\mathrm{ir}}\left(\sigma_{\mathrm{rw}}^{\mathrm{i}}-\sigma_{\pi}^{\mathrm{i}}\right)}{\Delta_{\mathrm{i}}}\left\{\Sigma_{\mathrm{k}} \alpha_{\mathrm{k}} \hat{P}_{\mathrm{ik}}-\Sigma_{\mathrm{j}} \theta_{\mathrm{iq}} \hat{\mathrm{q}}_{\mathrm{ij}}\right\} \quad k=2,3 \text { and } j=1, \ldots, m
$$

This equation is valid for both the high-wage and the low-wage country. Let us discuss the most important elements affecting the change in wages one by one and try to see if it is possible to single out some cases which might be considered to bear the greatest relevance for the experience of the EC. In the previous section, we have already outlined the role of the AUES. Suffice it to say, that the sign of the right-hand side of (5.8) may crucially depend on whether or not capital and labour are substitutes or complements. When they are substitutes, $\sigma_{\mathrm{rw}}^{\mathrm{i}}-\sigma_{\mathrm{rr}}^{\mathrm{i}}$ must be positive, and when they are complements, $\sigma_{\mathrm{rw}}^{\mathrm{i}}-\sigma_{\mathrm{rr}}^{\mathrm{i}}$ might (but need not be) negative.

As far as price movements are concerned, several key factors may be identified. First and foremost, market shares for final commodities are important. In the case the union is created between countries that hardly traded so far, the effects of the elimination of tariffs will be smaller than in the case of high pre-union market shares for the foreign partner country. Second, note that the entire structure of nominal protection is important. Below, we shall ignore the exceptional case of negative effective rates of protection. Third, note that the way in which the common external tariff is calculated, as well as the pre-union tariff rates are key factors in the overall reaction of prices. Usually, a common external tariff (CET) is calculated using some kind of average for pre-union tariff rates. In the EC, the CET was calculated as the simple arithmetic average of all member countries tariff rates. The implication of this averaging procedure is different for countries with high tariffs and countries with low tariffs. For tariff-shy countries, like the Benelux countries and Germany, the imposition of the CET implied higher tariffs, whereas for tariff-prone countries like France and Italy, the average outside tariff at their borders tended to increase due to the imposition of the CET.

Equation (5.8) may be used to derive the wage effects of the imposition of the CET. In Table 5.1, eight possible wage effects are listed after the CET is imposed. In the first four cases, it is assumed that capital and labour are substitutes (cases 1 and 2) or complements (cases 3 and 4 ) in both countries at the same time, and that the high-wage country and the low-wage country pursue opposite tariff regimes in the pre-union situation. In only two out of these four cases, viz. cases 1 and $\mathbf{4}$, an unambiguous movement in the direction of convergence is guaranteed. When capital and labour are substitutes, convergence is guaranteed only if the high-wage country has high pre-union tariffs and the low-wage country has low pre-union tariffs. In addition, when capital and labour are complements in stead of substitutes, a pre-union tariff regime whereby the highwage country employs low tariffs and the low-wage country employs high tariffs will result in a convergence of wages as well. In cases 2 and 3 on the other hand, the imposition of a common external tariff will lead to a short-run divergence of wages between the union members. In case 2, capital and labour are substitutes in both countries and the high-wage country employs low tariffs, whereas the low-wage country employs high tariffs. In case 3, capital and labour are complements in both countries and the high-wage country has high pre-union tariffs, whereas the opposite holds for the lowwage country. 
Table 5.1 A taxonomy of factor price effects of the imposition of a common external tariff in a customs union between a high-wage and a low-wage country

\begin{tabular}{|c|c|c|c|}
\hline \multicolumn{2}{|c|}{ High-wage country } & \multirow{2}{*}{$\begin{array}{l}\text { Low-wage country } \\
\left.\qquad \begin{array}{c}\sigma_{\mathrm{rw}}^{i}-\sigma_{\mathrm{m}}^{i}>0 \\
\text { tariffs low }\end{array}\right\} w \uparrow\end{array}$} & \multirow{2}{*}{$\begin{array}{l}\text { Development of wage } \\
\text { differential after } \mathrm{Cu}^{13} \\
\mathrm{C}\end{array}$} \\
\hline 1. & $\left.\begin{array}{l}\sigma_{r w}^{i}-\sigma_{\pi r}^{i}>0 \\
\text { tariffs high }\end{array}\right\} w \downarrow$ & & \\
\hline 2. & $\left.\begin{array}{l}\sigma_{\mathrm{rw}}^{i}-\sigma_{\mathrm{rr}}^{\mathrm{i}}>0 \\
\text { tariffs low }\end{array}\right\} w \uparrow$ & $\left.\begin{array}{l}\sigma_{r w}^{i}-\sigma_{r r}^{i}>0 \\
\text { tariffs high }\end{array}\right\} w \downarrow$ & D \\
\hline 3. & $\left.\begin{array}{l}\sigma_{\mathrm{nw}}^{\mathrm{i}}-\sigma_{\mathrm{rr}}^{\mathrm{i}}<0 \\
\text { tariffs high }\end{array}\right\} w \uparrow$ & $\left.\begin{array}{l}\sigma_{\mathrm{rw}}^{\mathrm{i}}-\sigma_{\mathrm{rr}}^{\mathrm{i}}<0 \\
\text { tariffs low }\end{array}\right\} \mathrm{w} \downarrow$ & D \\
\hline 4. & $\left.\begin{array}{l}\sigma_{\mathrm{rw}}^{i}-\sigma_{\pi}^{i}<0 \\
\text { tariffs low }\end{array}\right\} w \downarrow$ & $\left.\begin{array}{l}\sigma_{\mathrm{rw}}^{i}-\sigma_{\mathrm{r}}^{i}<0 \\
\text { tariffs high }\end{array}\right\} w \uparrow$ & C \\
\hline 5. & $\left.\begin{array}{l}\sigma_{\mathrm{rw}}^{\mathrm{i}}-\sigma_{\mathrm{rr}}^{\mathrm{i}}>0 \\
\text { tariffs high }\end{array}\right\} \mathrm{w} \downarrow$ & $\left.\begin{array}{l}\sigma_{\mathrm{rw}}^{\mathrm{i}}-\sigma_{\mathrm{rr}}^{i}<0 \\
\text { tariffs low }\end{array}\right\}_{\mathrm{w}} \downarrow$ & $?$ \\
\hline 6. & $\left.\begin{array}{l}a_{\mathrm{sw}}^{\mathrm{i}}-\sigma_{\mathrm{rr}}^{\mathrm{i}}>0 \\
\text { tariffs low }\end{array}\right\} w \uparrow$ & $\left.\begin{array}{l}\sigma_{\mathrm{rw}}^{\mathrm{i}}-\sigma_{\mathrm{rr}}^{\mathrm{i}}<0 \\
\text { tariffs high }\end{array}\right\} w \uparrow$ & $?$ \\
\hline 7. & $\left.\begin{array}{l}\sigma_{\mathrm{rw}}^{\mathrm{i}}-\sigma_{\mathrm{rr}}^{\mathrm{i}}<0 \\
\text { tariffs high }\end{array}\right\} w \uparrow$ & $\left.\begin{array}{l}\sigma_{\mathrm{rw}}^{i}-\sigma_{\mathrm{rr}}^{i}>0 \\
\text { tariffs low }\end{array}\right\} w \uparrow$ & $?$ \\
\hline 8. & $\left.\begin{array}{l}\sigma_{\mathrm{nw}}^{\mathrm{i}}-\sigma_{\mathrm{rr}}^{\mathrm{i}}<0 \\
\text { tariffs low }\end{array}\right\} \mathrm{w} \downarrow$ & $\left.\begin{array}{l}\sigma_{\mathrm{rw}}^{\mathrm{i}}-\sigma_{\mathrm{rr}}^{\mathrm{i}}>0 \\
\text { tariffs high }\end{array}\right\} w \downarrow$ & $?$ \\
\hline
\end{tabular}

Consider now cases 5 through 8 , where it is assumed that capital and labour are complements in one country and substitutes in the other. Clearly, an unambiguous movement in the direction of convergence or divergence of wages is excluded in all of these cases, since the wage rate moves in the same direction if both the high-wage and the lowwage country pursue different pre-union tariff regimes.

An interesting question is which of the above cases, on a priori grounds, one might expect to bear the greatest relevance for the EC experience. Note that we saw above, that, at the inception of the EC, the high-wage countries employed low tariff rates, whereas the low-wage countries could be classified as tariff-prone. Thus cases 2, 4, 6 and 8 are likely to be most applicable to the experience of the EC customs union. Note also, that if one would make the very reasonable assumption that capital and labour are either substitutes or complements in both countries at the same time, cases 2 and 4 would in fact be the only relevant cases. Barring negative effective rates of protection. and non-separability between primary and intermediate inputs, these cases would imply either a short-run divergence of wages in the customs union (substitutability between factors of production) or a short-run convergence of wages (complementarity of factors of production). 


\subsection{Long-run comparative statics}

To model the long-run behaviour of factor prices, several options exist. One could reformulate the entire model allowing for perfect long-run factor mobility. In the long run, intersectoral factor price differentials for one and the same factor cannot persist. In the two-sector model, this implies that we should modify the factor market clearing conditions:

$$
\begin{aligned}
& \sum_{i=1}^{n} c_{w}^{i}(. .) \cdot y_{i}=\bar{L} \\
& \sum_{i=1}^{n} c_{r}^{i}(.) \cdot y_{i}=\bar{K}
\end{aligned}
$$

The commodity market clearing conditions do not change, so

$$
\theta_{i w} \hat{w}+\theta_{i r} \hat{r}=\Sigma_{k} \alpha_{k} \hat{P}_{i k}-\Sigma_{j} \theta_{i q_{j}} \hat{q}_{i j}
$$

This equation is valid for all $i$ sectors. For purposes of simplification, write these equations as

$$
\theta_{i w} \hat{w}+\theta_{i r} \hat{r}=\hat{p}_{i}^{\prime}
$$

where $\hat{\mathrm{P}}_{\mathrm{i}}^{\prime}$ is the effective protection rate. Note that in order to solve these $i$ equations for the factor price changes we do not need to invert the system $\left(5.11^{\prime}\right)$. Since we have assumed the existence of only two factors, there is a problem of dimensionality when we distinguish more than two goods. In that case, the solution for outputs of the sectors are not unique and some industries must shut down until the number of industries is equal to two. The factor market clearing conditions are therefore not needed to solve for the factor price changes.

Obviously, the existence of a dimensionality problem is most inconvenient. Recall that this problem did not exist in our short-run model due to the existence of perfect factor immobility. Therefore, one solution to the dimensionality problem that immediately comes to mind is to amend the short-run model such as to take imperfect factor mobility into account. However, this solution, which was applied by, among others, Mussa (1982), Hill and Mendez (1982), and Albert and Vosgerau (1989), has its own problems. Mussa's paper discussed the effects of imperfect labour mobility in an $n$ goods framework with sector-specific capital, but his approach could not be generalised to incorporate imperfect capital mobility as well without loosing much of its intuitive appeal. Hill and Mendez encompass partially mobile capital and labour in the two sector model, but their approach does not yield meaningful results for an $n$ sector framework. Finally, Albert and Vosgerau's approach is too general to yield any estimable quantitative relations concerning the factor price responses of trade policy measures.

Below, we shall follow a much simpler approach to model the transition to the long run which has been suggested by Burgess (1980) and Murphy (1989). According to these authors, the long-run factor price changes are a weighted average of the short-run factor price changes. When, for instance, labour is free to move between industries, it may be expected that the new equilibrium wage will settle somewhere between the highest and the lowest wage in the absence of labour mobility. According to Burgess (1980, p. 794) the weights are determined by the elasticity of demand for labour in the various sectors 
and the shares of the labour force employed in these sectors. Thus, Burgess calculates the long-run wage change as:

$$
\hat{w}=\sum_{i=1}^{n} \alpha_{n} \hat{w}_{n}
$$

where the weights are determined as:

$$
\mathrm{a}_{\mathrm{j}}=\frac{\lambda_{\mathrm{j}}^{\mathrm{L}} \mathrm{e}_{\mathrm{Lj}}}{\sum_{\mathrm{i}=1}^{\mathrm{n}} \lambda_{\mathrm{j}}^{\mathrm{L}} \mathrm{e}_{\mathrm{L}}} \quad j=1,2
$$

with $\lambda_{\mathrm{j}}^{\mathrm{L}}=$ share of the labour force working in sector $i$ and $\mathrm{e}_{\mathrm{Li}}=$ elasticity of labour demand in sector $i$. The weights imply that, other things being equal, the higher the elasticity of demand for labour in sector $i$ relative to other sectors, the closer must be the equilibrium wage change in the vicinity of that in sector $i$. Also, the larger the proportion of the labour force employed by sector $i$, the more will the long-run wage change approximate the wage change in sector $i$.

The elasticity $e_{i j}$ bears an interesting relationship to the parameters of our model. As Burgess proves, this elasticity can be expressed as:

$$
e_{\mathrm{ij}}=-\Delta_{\mathrm{i}} / \theta_{\mathrm{ir}}
$$

Hence it turns out that the Allen-Uzawa partials, which determined our short-run results, continue to play a part in the long-run.

For rental rates on capital, we assume that these are also the weighted average of all industries' rates of changes:

$$
\hat{r}=\sum_{i=1}^{n} \alpha_{n} \hat{r}_{n}
$$

where the weights are determined as:

$$
\mathrm{a}_{\mathrm{j}}=\frac{\lambda_{j}^{k} \mathrm{e}_{\mathrm{Kj}}}{\sum_{\mathrm{i}=1}^{\mathrm{n}} \lambda_{\mathrm{j}}^{\mathrm{k}} \mathrm{e}_{\mathrm{ki}}} \quad j=1,2
$$

with $\lambda_{\mathrm{i}}^{\mathrm{K}}=$ share of the capital stock employed by sector $i$ and $\mathrm{e}_{\mathrm{Ki}}=$ elasticity of capital demand in sector $i$, and with

$$
e_{\mathrm{ki}}=-\Delta_{\mathrm{i}} / \theta_{\mathrm{iw}}
$$

It is worth noting, that our long-run results deviate from the ones predicted by HOS type of models discussed at the beginning of this subsection in several respects. First of all, in the two sector HOS context, with no intermediate goods, one factor will always loose in nominal and real terms, whereas the other factor will always gain in nominal and real terms. In a HOS type model which includes intermediate goods, things are no

The reader is referred to Burgess (1980, p. 794, n. 16) for the proof. 
longer that straightforward in a sense that whether or not primary factors gain depends on whether or not intermediate inputs are "extreme" or "middle" inputs. If intermediate goods are an extreme input, then iff capital (labour) is the middle input, an increase in the price of intermediates causes an increase in the wage rate (rental rate) and a decrease in the rental rate (wage rate). However, if intermediate inputs are a middle input, an increase in their price causes a decrease in both the wage rate and the rental rate. In our model, an increase in the price of intermediates will, in the long run, cause a decline in wage and rental rates. Except by coincidence, i.e., when $\theta_{\mathrm{iw}}=\theta_{\mathrm{ir}}$ for all $i=1$, $n$, the percentage reductions in wages and rental rates will not be equal. Thus, it is conceivable that capital gains relative to labour, which will probably be the case when $\theta_{\text {ir }}<$ $\theta_{i w}$ in all sectors. Also, not that there may be conflicts of interest between the short-run and the long-run interests of a primary factor.

Secondly, changes in the prices of final goods in a HOS type model with intermediate goods also exert their influence on prices of primary factors through the factor intensities in a way described above. Once again, in our long-run model, an increase in final goods' prices will increase both primary factor rentals, be it that the magnitude of the increase will not be equal for capital and labour. Thus, relative changes in factor prices are not impossible and one of the factors may even gain in real terms. We may conclude, therefore, that weak Stolper-Samuelson properties will be preserved in our model.

\subsection{Concluding remarks}

In this chapter we have tried to capture the factor price effects of international economic integration and have tried to answer the question under what circumstances customs unions might produce a convergence of factor rentals. This problem was addressed with the aid of two models which are based on the standard textbook versions of two popular international trade model, viz. the specific-factor model and a Heckscher-Ohlin type model of a production sector characterised by full intersectoral factor mobility. We modified the specific-factor model in two directions. The first change consisted of the assumption that both factors are completely sector specific in the short run. The second modification was the inclusion of intermediate inputs in the cost function, which, due to the existence of intra-industry trade, gives the model a higher degree of generality than the standard specific-factor model. The effects of economic integration on factor rentals in this model depend on the concrete characteristics of the production technology (AUES), factor proportions and the direction of changes in final commodity prices and intermediate input prices. We identified a few cases where factor prices might diverge in the short run after the creation of a customs union. Some of these cases might bear some relevance to the short-run responses of factor prices in the circumstances at which the EC was incepted.

As far as the long-run responses of factor prices are concerned, the possibility may not be ruled out that international factor price convergence still does not break down since in the reality of the EC high-wage countries were frequently tariff shy, whereas low-wage countries were typically tariff prone at the time the EC was created. The high wages in the Northern part of Europe could therefore not have been the consequence of high levels of protection. Elimination of their low tariff rates could therefore not have been a major factor hurting either labour or capital to a large extent. In the low-wage countries imports are likely to have been capital intensive, and therefore the creation of the EC has probably been to the detriment of capital in these countries and benefited labour. A wage convergence in the EC, should therefore have been the result of lowwage countries catching up with high-wage countries. 


\section{CHAPTER}

6

ESTIMATION OF THE MODEL

\subsection{Introduction}

This chapter seeks to discuss the estimation of the parameters of the model developed in the previous chapter. Models like the one discussed in the previous chapter have rarely been estimated in the context of international trade theory (for succinct exceptions, see Leamer (1985) and Kohli (1991)). It is only a recent development in the trade literature that economists have started to estimate the parameters of general equilibrium models. As far as empirical work in the trade literature is concerned, most efforts have been put in the estimation of partial equilibrium models. However, the partial nature of these models may not always be consistent with the optimising behaviour on the part of both consumers and producers which is implied by general equilibrium analysis.

Fortunately, the increasing use of the principles of duality in trade models in combination with the development of flexible functional forms for production and cost functions, seems to have made the estimation of a complete set of parameters of a general equilibrium model a more tractable problem, which the growing literature in this field testifies. ${ }^{1}$ Indeed, the estimation of our model rests on the use of a so-called flexible functional form, notably the translog cost function, which will be introduced in section 6.2. Section 6.3 is devoted to a discussion of the equations that we shall estimate. In section 6.4 we shall discuss the data used in the estimations, as well as the estimation procedures and other estimation technicalities. In section 6.5 the equations of the model will be applied to the five most important founding countries of the EC, viz., The Netherlands, Belgium, the Federal Republic of Germany, France and Italy and contains a discussion of the estimation results. We finalise our analysis with the concluding remarks in section 6.6 .

${ }^{1}$ Among others, we may mention Burgess (1976, 1980), Wong (1988), Kohli (1991), Jorgenson and Fraumeni (1983), Jorgenson, Gallop and Fraumeni (1987), Leamer (1984), Woodland (1978), Diewert and Morrison (1988). 


\subsection{The functional form for the cost functions}

There are numerous functional forms for the unit cost function from which one might choose. Among others, the various functional forms distinguish themselves from one another by the implied restrictions on the substitution possibilities between the various inputs. As we saw before, a widely used measure of substitution possibilities between inputs is the AUES, which is defined as

$$
\sigma_{i j}=\frac{C_{i j} C}{C_{i} C_{j}}=\frac{\varepsilon_{i j}}{\theta_{j}}
$$

where $C(w, y)$ is the total cost function, $\varepsilon_{\mathrm{ij}} \equiv \partial \ln \mathrm{C}_{\mathrm{i}}(w, y) / \partial \ln w_{\mathrm{i}}$ is the elasticity of demand for factor $i$ with respect to factor price $j$, and $\theta_{j} \equiv w_{j} C_{j} / C$ is the cost share of factor $j$.

The econometric literature has produced a variety of well-known functional forms. The most widely used functional forms are the Leontief, Cobb-Douglas and CES functions, which are characterized by elasticities of substitution which take values of 0 , 1 , and $\geq 0$, respectively. Due to its greater degree of generality, the CES form is clearly to be preferred over the other forms. In our context, the CES cost function would contain wages, capital costs and the prices of all intermediate inputs as arguments. However, as Uzawa (1962) and McFadden (1963) have shown, the CES function cannot very easily be extended beyond the two input case, since substitution among more than two inputs implies very strong restrictions on the substitution possibilities for these inputs.

To date, the most popular functional form for cost functions is the translog or transcendental logarithmic function, which was pioneered by Christensen, Jorgenson and Lau (1971, 1973). The translog form, which belongs to the family of so-called flexible functional forms, is a second-order Taylor series approximation of an arbitrary function $f(x)$. The Taylor series is expanded in the powers of $\ln (x)$. Within a region of convergence, this Taylor series expansion of $f(x)$ will converge to the underlying function if it contains a sufficient number of higher order terms. In other words, within this region of convergence, the difference between the values of the function and its approximation decreases when higher order terms are included.

The second-order translog cost function $\mathrm{c}(w)$ may be written as follows:

$$
\operatorname{lnc}(w)=\alpha_{0}+\Sigma \beta_{\mathrm{i}} \ln \left(w_{\mathrm{i}}\right)+1 / 2 \Sigma \Sigma \phi_{\mathrm{ij}} \ln \left(w_{\mathrm{i}}\right) \ln \left(w_{\mathrm{i}}\right)
$$

with $\Sigma_{i} \beta_{i}=1, \phi_{i j}=\phi_{i j}$ (Young's theorem and symmetry of the Hessian) and $\Sigma_{j} \phi_{i j}=0$. Note that this function collapses into a Cobb-Douglas function in case $\phi_{\mathrm{ij}}=0$.

Because of its generality, the translog function has several desirable properties. Among the most important of these, one could mention that the translog function does not a priori restrict the value and sign of the various elasticities of substitution, i.e., it permits the AUES partials to differ between pairs of inputs. However, in the econometric estimation of this function, the important problem arises, that the translog function takes a quadratic form. As a result, the number of variables in the function soon increases substantially, and the computational burden may be too large indeed.

The problem of too large a number of parameters for estimation may be resolved by assuming separability of technology with respect to a certain partition of inputs, as Berndt and Christensen (1973) have shown. Separability of the (homothetic) technology with respect to a certain partition of inputs imposes equality constraints on the AUES of 
inputs belonging to different input groups corresponding to the partition. Thus, the number of parameters to be estimated may be reduced significantly. In section 6.3 we shall come back to this problem.

By logarithmic differentiation of the translog cost function, derived unit input demand functions may be obtained in share form, i.e.,

$$
x_{i} / c=c_{i} \equiv \partial c / \partial w_{i}
$$

Now let $\theta_{i w}=\left(x_{i} w_{i}\right) / c$. Then it follows that $\theta_{i w}=\left(x_{i} w_{i}\right) / c=\partial \ln (c) / \partial \ln \left(w_{i}\right)$. Application of this result to the translog cost function in eq. (5) gives

$$
\theta_{i w}=\alpha_{0 \mathrm{i}}+\sum_{j=1}^{n} \phi_{\mathrm{ij}} \ln \left(w_{\mathrm{i}}\right) \quad \forall i=1, \ldots, n
$$

Hence the share of each input in sector $i$ is a simple linear function of the logarithm of all input prices.

One of the advantages of the translog cost function is that one can readily estimate the substitution matrix $\Sigma$. The elements of $\Sigma$ are obtained using the definition of the AUES. Note from the definition of the translog function that

$$
\phi_{\mathrm{ij}}=\frac{\partial^{2} \ln (c)}{\partial \ln \left(w_{\mathrm{i}}\right) \partial \ln \left(\mathrm{w}_{\mathrm{j}}\right)}=\mathrm{w}_{\mathrm{i}} \mathrm{w}_{\mathrm{j}} \frac{\partial}{\partial \mathrm{w}_{\mathrm{i}}}\left(\frac{1}{\mathrm{c}} \cdot \frac{\partial \mathrm{c}}{\partial \mathrm{w}_{\mathrm{i}}}\right) \quad \forall i \neq j
$$

and

$$
\phi_{\mathrm{ii}}=\mathrm{w}_{\mathrm{i}}^{2} \frac{\partial}{\partial \mathrm{w}_{\mathrm{i}}}\left(\frac{1}{\mathrm{c}} \cdot \frac{\partial \mathrm{c}}{\partial \mathrm{w}_{\mathrm{i}}}\right)+\left(\frac{1}{\mathrm{c}} \cdot \frac{\partial \mathrm{c}}{\partial \mathrm{w}_{\mathrm{i}}}\right) \mathrm{w}_{\mathrm{i}} \quad \forall i=j
$$

Recalling that $\partial c / \partial w_{i}=x_{i}$ (Shephard) and that $\sigma_{i j}=\varepsilon_{i j} / \theta_{j}$ one finds the following expressions for the AUES:

$$
\begin{array}{ll}
\sigma_{\mathrm{ij}}=\left(\phi_{\mathrm{ij}}+\theta_{\mathrm{i}} \theta_{\mathrm{j}}\right) /\left(\theta_{\mathrm{i}} \theta_{\mathrm{j}}\right) & \forall i \neq j \\
\sigma_{\mathrm{ii}}=\left(\phi_{\mathrm{ii}}+\theta_{\mathrm{i}}^{2}-\theta_{\mathrm{i}}\right) /\left(\theta_{\mathrm{i}}^{2}\right) & \forall i=j
\end{array}
$$

Since $\theta_{j}$ may change in the course of time, $\sigma_{i j}$ and $\sigma_{i i}$ will in general not be constant, but vary as well in time. The same is true for the factor demand elasticities, which may be obtained by post-multiplication of the $\Sigma$-matrix with the matrix of factor shares. ${ }^{2}$

Other functional forms that have been proposed in the literature are mostly, like the translog form, linear in parameter functions which have interpretations as Taylor series approximations of the underlying cost function. Variations on these functional forms distinguish themselves either by the fact that they are not linear in parameters or by the fact that the have no interpretation as a (second-order) Taylor series approximation.

2 Note that recent literature has added a variety of functional forms to the ones discussed here. Examples include the third-order translog form, the Generalised-Leontief $(\mathrm{GL})$ form, the square-rooted quadratic function, the generalised Cobb-Douglas function, the Fourier form, the Minflex-Laurent form, and several others. See Kohli (1991, p. 94) for details. 
The above discussion goes to show, that one may in principle choose from a wide variety of possible functional forms. The question will arise why the translog form has been chosen below in stead of a different functional form. To a large extent, this choice is completely arbitrary. Although the translog function, due to its generality, is capable of generating Cobb-Douglas and CES functions as special cases, there does not seem to be an a priori reason to prefer this particular function to, say, the GL-form, or any other form that satisfies the requisite theory. Indeed, as Chambers (1988, p. 159) points out, "classical statistical theory is silent about the choice of a functional form. It presumes that the researcher knows the most general model against which hypotheses can be tested" (italics added). It should be evident, that the presumption of a translog form as the most ideal functional form is implicit in our empirical analysis. However, for reasons of space, this presumption is not tested below. ${ }^{3}$

One reason to choose the translog functional form, apart from the relative ease with it can be estimated, is that it enables us to focus attention on those characteristics of production which are of most interest, viz. factor shares, AUES, and marginal products. These three characteristics of production technology are not only important for decision making at the firm level, but also at the macroeconomic level of policy making. Factor shares are important, since they refer to the functional distribution of income. Elasticities of substitution are important, since their value determines the magnitude of the effects of price changes on the functional distribution of income. Finally, marginal products are important, since they measure the efficiency of the allocation, both at the firm level and at the macro level.

A second important reason to prefer the translog cost function to other forms concerns the fact that the requirement of global concavity of these other forms frequently reduce the flexibility of these forms when the number of inputs exceeds two. ${ }^{4}$ For instance, some of these forms imply that inputs cannot be complements as a result of certain restrictions. It goes without saying, that there are no a priori reasons to impose this kind of restriction on the technology.

Another problem related to the use of translog function forms is the fact that, although the cost function will necessarily be linear homogenous in factor prices, there is no $a$ priori guarantee that it will also satisfy the required curvature conditions for all conceivable observations. Strictly speaking this implies that one should check for concavity in factor prices for the entire sample. For Cobb-Douglas and CES functions, this problem does not arise, since the (global) curvature conditions are imposed automatically. We shall come back to this problem in section 6.4.2.

\subsection{Estimated equations}

\subsubsection{The share equations}

In our model we assumed that the demand for the inputs of the production process can be satisfied through primary and intermediate inputs. In this subsection, we shall focus our attention on the treatment of the latter. Intermediate inputs, it will be recalled,

${ }^{3}$ Following Lau (1975) one might consider the particular empirical situation as an important indicator for the preferred functional form. According to Lau, the GL function is most appropriate when elasticities of substitution are low, whereas the translog is suitable in situations of higher elasticities of substitution.

${ }^{4}$ This is particularly true for the Generalized-Leontief form. 
might be purchased domestically and abroad. In principle, we distinguished between $k$ kinds of intermediate inputs. However, in the estimations reported below, we shall assume the existence of a single composite intermediate input. The reason for this simplified treatment of intermediates is, first of all, a very practical one: not all the relevant data are available for a sufficiently long period of time and for a sufficiently diversified number of sources. Secondly, without making additional assumptions regarding the nature of technology, allowing for a large number of intermediate inputs makes the estimation of the model a cumbersome task. Imagine, for instance, a total of 200 intermediate inputs. The particular translog function to be estimated would contain an impossible number of parameters and would be very difficult, if not impossible, to estimate. In addition, the cost minimisation problem could certainly not be solved overnight.

The problem mentioned above was addressed in a seminal paper by Armington (1969). According to the latter, imports are generally considered as homogeneous commodities, which are mostly aggregated into a single commodity. This procedure, which is quite common in trade models, implicitly assumes perfect substitutability between imports coming from different sources. However, if one does not accept the assumption of perfect substitutability, one should in principle distinguish between imports coming from different sources as being different products, and the utility maximisation process of the consumer becomes quite complicated indeed. Armington solved this problem by distinguishing between "goods" and "products". Commodity classes were referred to as goods and goods produced in a particular country were referred to as products. Making use of this distinction, Armington showed how the consumer utility optimisation process might be split up into two stages. In the first stage, the consumer would allocate his budget over the goods that might be distinguished. In the second stage, the budget available for the various kinds of goods would be allocated to the products that might be distinguished. The first stage is normally also referred to as upper level optimisation, the second as lower level optimisation.

As was shown by Armington, a necessary and sufficient condition for this two-stage optimisation process is that there is a (weak) separability between the distinguished commodities. The Armington approach has frequently been applied in so-called import allocation models. For reasons outlined above, we are not able to invoke the Armington assumption in our estimations. This implies that we shall confine ourselves to the first stage of the Armington optimisation process. We shall assume, that producers minimise the costs of capital, labour and intermediate goods. Making use of Shephard's lemma, this will enable us to derive demands for these factors.

Hence, one must find the parameters of the cost function $c^{i}\left(w_{i}, r_{i}, q_{j}\right)$. The translog expression for this function is

$$
\begin{aligned}
\ln (c)= & \beta_{0}+\beta_{w} \ln \left(w_{i}\right)+\beta_{i} \ln \left(r_{i}\right)+\beta_{q} \ln \left(q_{i}\right)+1 / 2 \phi_{w w} \ln \left(w_{i}\right)^{2}+1 / 2 \phi_{r i} \ln \left(r_{i}\right)^{2}+1 / 2 \phi_{q q} \ln \left(q_{i}\right)^{2} \\
& +1 / 2 \phi_{w r} \ln \left(w_{i}\right) \ln \left(r_{i}\right)+1 / 2 \phi_{w q} \ln \left(w_{i}\right) \ln \left(q_{i}\right)+1 / 2 \phi_{r w} \ln \left(r_{i}\right) \ln \left(w_{i}\right)+1 / 2 \phi_{r q} \ln \left(r_{i}\right) \ln \left(q_{i j}\right) \\
& +1 / 2 \phi_{q w} \ln \left(q_{i}\right) \ln \left(w_{i}\right)+1 / 2 \phi_{q} \ln \left(q_{i}\right) \ln \left(r_{i}\right)
\end{aligned}
$$

with

$\begin{array}{ll}\Sigma_{\mathrm{j}} \beta_{\mathrm{j}}=1 & (j=w, r, q) \\ \phi_{\mathrm{ij}}=\phi j i & (i, j=w, r, q) \\ \Sigma_{j} \phi_{\mathrm{ij}}=0 & (i, j=w, r, q) \\ \Sigma_{\mathrm{i}} \phi_{\mathrm{ij}}=0 & (i, j=w, r, q)\end{array}$


The inverse conditional factor demand functions can be obtained in share form by partial differentiation of the translog cost function. For labour, for example, this implies

$$
\theta_{i w}=\beta_{w}+\phi_{w w} \ln \left(w_{i}\right)+\phi_{w r} \ln \left(r_{i}\right)+\phi_{w q} \ln \left(q_{i}\right)
$$

For capital, one finds

$$
\theta_{\mathrm{ir}}=\beta_{r}+\phi_{\mathrm{rw}} \ln \left(w_{\mathrm{i}}\right)+\phi_{\mathrm{rr}} \ln \left(\mathrm{r}_{\mathrm{i}}\right)+\phi_{\mathrm{rq}} \ln \left(\mathrm{q}_{\mathrm{i}}\right)
$$

Finally, for the intermediate input, we have

$$
\theta_{\mathrm{iq}}=\beta_{\mathrm{q}}+\phi_{\mathrm{qw}} \ln \left(\mathrm{w}_{\mathrm{i}}\right)+\phi_{\mathrm{qr}} \ln \left(\mathrm{r}_{\mathrm{i}}\right)+\phi_{\mathrm{qq}} \ln \left(\mathrm{q}_{\mathrm{i}}\right)
$$

Thus, we are left with three share equations to be estimated. The model contains 12 parameters to be estimated. However, the symmetry and equality restrictions which are imposed upon it, result in fewer parameters to be estimated. Since $\beta_{w}+\beta_{r}+\beta_{q}=1$, we know that $\beta_{\mathrm{g}}=1-\left(\beta_{\mathrm{w}}+\beta_{\mathrm{r}}\right)$. Furthermore, we know that $\phi_{\mathrm{ww}}+\phi_{\mathrm{wr}}+\phi_{\mathrm{wq}}=0$, so that $\phi_{\mathrm{wq}}=-$ $\left(\phi_{\mathrm{ww}}+\phi_{\mathrm{wr}}\right)$. Similarly, $\phi_{\mathrm{ww}}+\phi_{\mathrm{rw}}+\phi_{\mathrm{gw}}=0$, so that $\phi_{\mathrm{gw}}=-\left(\phi_{\mathrm{ww}}+\phi_{\mathrm{rw}}\right)$, and so on. Finally, we have $\phi_{\mathrm{rw}}=\phi_{\mathrm{wr}}, \phi_{\mathrm{rg}}=\phi_{\mathrm{gr}}$, and $\phi_{\mathrm{wq}}=\phi_{\mathrm{qw}}$. Thus we are left with 5 out of 12 parameters to be estimated. Since the three factor shares add up to unity, the system (6.5)-(6.7) is linearly dependent. As a result, the covariance matrix becomes singular and one share equation must be dropped for estimation purposes. Fortunately, as Barten (1969) has shown, the estimation is invariant with respect to the equation which is deleted. Hence, the equation to be dropped may be selected arbitrarily by the researcher. In our estimations below, we drop the share equation for intermediate inputs. Note, that the share equations (6.5)-(6.7) are linear in the logarithms of all input prices.

\subsubsection{The treatment of technical change}

We begin with a very general treatment of (biased) technical change, allowing the model to exhibit various patterns of technical change. Technical change may be incorporated into the model in a variety of ways (for details, see Kohli (1991)). Below we shall assume that technological change occurs through a shift parameter $t$ in the cost function. This implies that we shall use time $t$ as a proxy variable representing the state of technology. Since production technology is assumed to exhibit a putty-putty nature, technological progress may be classified as disembodied in the model. The implication of this treatment of technological change is that primary and intermediate input prices held constant, costs will change as time elapses.

The treatment of technological change that we propose is very general and allows several patterns of technical change to occur. Thus the model allows for both biased and neutral technical change. Recall from Chapter 4 that in the literature, the bias of technological change is most frequently modelled using Hicks' definition of biases. Call the bias of technological change for input $i$ in sector $j \mathrm{~B}_{\mathrm{ij}}$. According to Hicks, technological change is said to be $i$-factor-using if it increases the value share of the input at constant input prices, or if $\mathrm{B}_{\mathrm{ij}}>\mathbf{0}$. If, on the other hand, technological change results in a declining share of factor $i$, it is called $i$-factor saving, which implies $\mathrm{B}_{\mathrm{ij}}<0$. Finally, if technological change does not influence the value share of factor $i$ in sector $j$, i.e., $B_{i j}=0$, then technological progress is said to be neutral with respect to factor $i$.

The bias of technological change may thus be determined as follows: 
$B_{i j}=\frac{\partial \theta_{i j}}{\partial t}$

Since the cost function is considered to be linear homogeneous in factor prices, we know that

$\Sigma_{\mathrm{i}} \theta_{\mathrm{ij}}=1 \quad$ for all $i$

and hence

$$
\Sigma_{\mathrm{j}} \mathrm{B}_{\mathrm{ij}}=1 \quad \text { for all } i
$$

Disembodied technical progress may be introduced into the cost function in a variety of ways (see, e.g., Kohli (1991), pp. 103-106 and pp. 312-321). Below we shall adopt the simplest possible assumption, notably that the technology shifts in time, that is, we add a time index to the cost function, so

$$
c=c(w, r, q, t)
$$

The technology shift in time can occur in either direction, which makes it inaccurate to impose a priori restrictions on the shift. The reader will recognize our approach to incorporate technical progress as the one followed by Binswanger (1974), Jorgenson and Fraumeni (1983), and others.

Taking the technological shift into consideration in out translog cost function changes this function into

$$
\begin{aligned}
& \ln (c)=\beta_{0}+\beta_{w} \ln \left(w_{i}\right)+\beta_{r} \ln \left(r_{i}\right)+\beta_{q} \ln \left(q_{i}\right)+1 / 2 \phi_{w w} \ln \left(w_{i}\right)^{2}+1 / 2 \phi_{r r} \ln \left(r_{i}\right)^{2}+1 / 2 \phi_{q q} \ln \left(q_{i}\right)^{2} \\
& +1 / 2 \phi_{w r} \ln \left(w_{i}\right) \ln \left(r_{i}\right)+1 / 2 \phi_{w q} \ln \left(w_{i}\right) \ln \left(q_{i}\right)+1 / 2 \phi_{r w} \ln \left(r_{i}\right) \ln \left(w_{i}\right)+1 / 2 \phi_{r q} \ln \left(r_{i}\right) \ln \left(q_{i}\right) \\
& +1 / 2 \phi_{q w} \ln \left(q_{i}\right) \ln \left(w_{i}\right)+1 / 2 \phi_{q} \ln \left(q_{i j}\right) \ln \left(r_{i}\right)+\phi_{w t} \ln \left(w_{i}\right) t+\phi_{r t} \ln \left(r_{i}\right) t+\phi \ln \left(q_{i}\right) t+\phi_{i} t^{2}
\end{aligned}
$$

with an additional restriction

$$
\Sigma_{\mathrm{j}} \phi_{\mathrm{it}}=0
$$

$$
(i, j=w, r, q)
$$

The inverse conditional factor demand functions can be obtained in share form by partial differentiation of the translog cost function. For labour, for example, this implies

$$
\theta_{i w}=\beta_{w}+\phi_{w w} \ln \left(w_{i}\right)+\phi_{w I} \ln \left(r_{i}\right)+\phi_{w q} \ln \left(q_{i}\right)+\phi_{w t} t
$$

For capital, one finds

$$
\theta_{\mathrm{ir}}=\beta_{\mathrm{r}}+\phi_{\mathrm{rw}} \ln \left(w_{\mathrm{i}}\right)+\phi_{\mathrm{rr}} \ln \left(\mathrm{r}_{\mathrm{i}}\right)+\phi_{\mathrm{rq}} \ln \left(\mathrm{q}_{\mathrm{i}}\right)+\phi_{\mathrm{rt}} \mathrm{t}
$$

Finally, for the intermediate input, we have

$$
\theta_{\mathrm{iq}}=\beta_{\mathrm{q}}+\phi_{\mathrm{qw}} \ln \left(w_{\mathrm{i}}\right)+\phi_{\mathrm{q}} \ln \left(\mathrm{r}_{\mathrm{i}}\right)+\phi_{\mathrm{qq}} \ln \left(\mathrm{q}_{\mathrm{i}}\right)+\phi_{\mathrm{q}} \mathrm{t}^{\mathrm{t}}
$$


The inclusion of technical progress parameters increases the number of parameters to be estimated to 7 (out of a total number of 15 ).

\subsection{Data and estimation techniques}

\subsubsection{The data}

Most of the data for our estimations were taken from Eurostat's National Accounts, Detailed Tables by Branch. The cost functions in the model were estimated for the manufacturing sectors from the database. In classifying economic sectors, Eurostat uses two nomenclatures: Nace R25 and Nace R44, which correspond to a subdivision of sectors into 24 and 44 sectors, respectively. In all our estimations, we have used the R25 classification. These sectors are listed in Table 6.1.

The data which are available in the database concern the following variables: actual production and value added (factor cost and market prices) at constant and current prices, total yearly compensation of employees, employment data (occupied population and number of salaried employees), imports and exports by branch at current prices (and partly at constant prices), gross fixed capital formation by branch, and fixed capital stocks, also at constant and current prices. we shall comment on these variables before continuing the discussion of estimation results.

First of all, note that the data on production value and value added imply a value for intermediate products used in the production process. These intermediates have both domestic and foreign origins. Since the value of production data are given only in current prices, we could not calculate a price deflator for intermediate inputs. However, since GDP price deflators for all sectors were available in the database, this enabled us to construct a price deflator for intermediates through aggregation. The aggregation procedure for price indexes was the Thornqvist index, which is a discrete approximation of the translog form, as Diewert (1971) has pointed out. The translog or Thornqvist index is defined as:

$$
q_{t}=1 / 2 \Sigma_{i}\left(s_{i t}+s_{i t-1}\right)\left(\ln q_{i t}-\ln q_{i t-1}\right)
$$

where $q_{t}=$ the translog price index for the intermediates in period $t, q_{i t}=$ the price of intermediate component $i$, and $\mathrm{s}_{\mathrm{it}}=$ the share of intermediate component $i$ in period $\mathrm{t}$. The components that we have used to calculate the intermediate input price index are the prices of energy, all manufacturing goods, building and construction, market services, and government services. The Thornquist index has been used in the empirical literature by many authors, among which Jorgenson and Fraumeni (1983), Kohli (1991), and others. Although its main use has been the international comparison of outputs, inputs, and productivity, it has also been applied for the purpose of measuring prices (see, e.g., Aw and Roberts (1988)). The primary disadvantage of working with this Thornqvist approximation of the true intermediate prices is that this procedure yields the same intermediate input prices for all sectors of industry. Therefore, differences be- 
tween industries in the intensity of the use of certain intermediates are not accounted for, other than througih the intermediate's shares. ${ }^{5}$

Table 6.1 Manufacturing sectors according to the NACE R25 classification in the Eurostat National Accounts Database

\begin{tabular}{|c|c|c|c|}
\hline $\begin{array}{l}\text { Number of } \\
\text { the sector }\end{array}$ & $\begin{array}{l}\text { NACE R25 } \\
\text { code }\end{array}$ & $\begin{array}{l}\text { NACE R } 44 \\
\text { correspondence }\end{array}$ & Name of the sector \\
\hline 03 & 30 & 30 & Manufacturing products \\
\hline 05 & 13 & 13 & $\begin{array}{l}\text { Ferrous and non-ferrous ores and metals, other } \\
\text { than radioactive }\end{array}$ \\
\hline$\infty$ & 15 & 15 & Non-metallic minerals and mineral products \\
\hline or & 17 & 17 & Chemical products: \\
\hline 08 & 19 & 19 & $\begin{array}{l}\text { Metal products, except machinery and transport } \\
\text { equipment }\end{array}$ \\
\hline$\infty$ & 21 & 21 & Agricultural and industrial machinery \\
\hline 10 & 23 & 23 & $\begin{array}{l}\text { Office and data processing machines, precision } \\
\text { and optical instruments }\end{array}$ \\
\hline 11 & 25 & 25 & Electrical goods \\
\hline 12 & 28 & $27 / 29$ & Transport equipment \\
\hline 13 & 36 & $31 / 33 / 35 / 37 / 39$ & Food, beverages and tobacco \\
\hline 14 & 42 & $41 / 43$ & Textiles and clothing, leather and footwear \\
\hline 15 & 47 & 47 & Paper and printing products \\
\hline 16 & 49 & 49 & Rubber and plastic products \\
\hline 17 & 48 & $45 / 51$ & Other manufacturing products \\
\hline
\end{tabular}

The wages used in our estimations were calculated as the total compensation of employees divided by the number of wage and salary earners. Thus, for each sector, we calculated:

$$
\mathrm{w}_{\mathrm{j}}=\frac{\text { total compensation of employees in sector } j}{\text { number of employees in sector } j}
$$

where the number of wage earners corresponds to annual averages. The total compensation of employees covers all payments in cash and in kind made by the employers in remuneration for work. Among others, these payments include gross wages, employers' social security contributions, and imputed social security contributions. Obviously, the wage rate obtained in this way varies per sector. The existence of these intersectoral differences in wages is consistent with our assumption of imperfect (short-run) intersectoral factor mobility.

5 Obviously, it would have been preferable to use different intermediate input price indices for different sectors. However, as we remarkecl above, these price indices are not reaclily available, nor can they be calculated for each sector on the basis of the available data. Therefore we had to use the kind of proxy discussed in the text. 
For the calculation of capital costs, several procedures have been suggested in the literature. Some authors have suggested to measure capital cost by relating both operating surplus and depreciation allowances to the capital stock. Thus, capital cost could be defined as

$$
\mathbf{r}_{j}=\frac{\text { depreciation }+ \text { gross operating surplus }}{\text { fixed capital stock }}
$$

Several alternative definitions of capital cost have been suggested in the econometric literature. For instance, capital costs can be based on gross operating surplus, depreciation plus a theoretical user cost of capital. The latter is usually defined as the return on save investments. Various procedures can be applied to calculate the theoretical user cost of capital. Some authors have suggested that firms base their investment decisions on the short-run safe real rate of return. Alternatively, one might use the long-run real interest rate. However, both rates of return have fluctuated considerably over the period of investigation, primarily due to large fluctuations in the inflation rates. For this reason, some authors prefer to use a long-run theoretical user cost of capital which is constant (see, e.g., Dargay (1987) and Kohli (1991), p. 118). Kohli, for instance, fixes the safe rate of return at 4 per cent.

Dargay (1987, p. 21) uses another definition of capital costs. She defines capital cost as

$$
\mathbf{r}_{\mathrm{j}}=\mathrm{p}_{\mathrm{j}}(\mathrm{o}+\delta)
$$

where $p_{j}=$ the price of investment goods, $0=$ operating surplus or the rate of return, and $\delta=$ the depreciation rate.

The real capital stock is usually taken as the quantity of the capital service input. Combination of total costs and the capital stock then allows one to calculate the price for the capital service. The capital stock figures which are supplied by Eurostat are based on the perpetual inventory method (PIM), and have as a very important advantage their harmonized nature (i.e., they are calculated for all countries using the same definitions). The implementation of PIM implies that the capital stock is primarily determined by investment data and the average life time of capital goods. To calculate the average life time, Eurostat uses a log-normal survival function.

Unfortunately, our database does not allow the use of these theoretically more advanced definitions of capital costs. Since depreciation allowances were not available or could not be calculated in our database, we were forced to use the simplest possible definition of capital costs. This definition of capital costs relates operating surplus to the fixed capital stock and is also known as the entity concept of capital cost or profit rates. It has been used by several other authors who used the same capital stock data as we did (see Mortenson (1984), pp. 35-36). How this influences our estimation is hard to tell, but obviously entity capital cost will be lower than capital costs which are calculated in the more sophisticated manner enunciated above. In principle, this could lead to values for $\phi_{m}$ that are biased in an upward direction and therefore to biased (upward) estimates of the own AUES for capital.

The data values for wages, capital costs and intermediate input prices were all normalised to 1 in the starting year. 


\subsubsection{Estimation technicalities}

In this subsection we shall outline the econometric procedures that were followed in order to obtain estimates of the translog cost function system described above. The translog cost functions were empirically implemented by estimation of eqs. (6.8)-(6.10). The stochastic specification of the model included the specification of additive disturbance terms for each of the equations. These additive disturbance terms reflect alternatively random errors in cost-minimizing behaviour or random influences of excluded explanatory variables. It may be expected, that the disturbance terms for the different equations are related and the estimation method should in principle allow for non-zero contemporaneous correlation between the error terms.

Let us assume that the vector of error terms for the three equations is denoted by $\omega_{t}$ and that $\omega_{t}$ is normally distributed with zero mean and with associated variance-covariance matrix $\Omega$, i.e.,

$$
\omega_{\mathrm{t}} \sim \mathrm{N}(0, \Omega) \text { s.t. } \mathrm{E}\left(\omega_{\mathrm{t}}, \sigma_{\mathrm{t}}^{\prime}\right)=\delta_{\mathrm{ts}} \Omega \delta_{\mathrm{ts}}=\left\{\begin{array}{l}
1 \text { if } t=s \\
0 \text { if } t \neq s
\end{array}\right.
$$

In this specification, the error terms have a constant variance-covariance matrix. In addition, it allows for non-zero correlation between contemporaneous error terms in the equations. Finally, we assume zero intertemporal correlation between all error terms.

Since the share equations must add up to unity, the estimated disturbance covariance matrix is singular. As we saw above, the most common method to overcome this problem is to drop one of the estimating equations from the system. In our estimations, we dropped the share equation for intermediates.

As the equations had identical coefficients, the system of equations had to be estimated simultaneously. We used the full-information maximum likelihood estimation procedure in order to get our estimates of the parameters. We used (single equation) OLS estimates of the parameters as starting values for the FIML procedure which is available in versions 4.0 and 4.1 of the TSP package. The full-information maximum likelihood estimator is consistent, and, given the normality assumption, normal asymptotically. Furthermore, the FIML estimation is invariant with respect to the equation that is dropped. The algorithm used is GAUSS, which is a gradient method that uses exact analytical derivatives of the likelihood function.

We should devote a few more words to the problem of the curvature conditions which should be met by the estimated cost function. One should in principle check whether or not the estimated cost functions satisfy the required curvature conditions. This check should be performed for all observations in the sample. As Diewert and Wales (1987) pointed out, estimates of cost functions have sometimes failed to meet the curvature requirements. The implication for a cost function that is found to be convex rather than concave, for instance, is that the researcher finds a maximum rather than a minimum for this function, and that the implied factor shares may become negative. Needless to say, this would deprive the estimation results of economic meaningfulness and relevance.

Fortunately, the econometric literature has produced several clues as to how to solve this intricate problem when it should arise. As the reader may well recall, concavity of the cost function can be checked by inspection of the Hessian of the cost function $c($.$) .$ The cost function will only be concave if and only if this Hessian is negative semi-defi- 
nite. This condition may also be expressed in terms of the matrix of substitution elasticities, $\Sigma$. Given that costs are positive, a necessary and sufficient condition for the Hessian of the cost function to be negative semi-definite is that the matrix of substitution elasticities itself is negative semi-definite.

Wiley, Schmidt and Bramble (1973) proposed a technique to impose the correct curvature conditions on the cost function. ${ }^{6}$ This technique imposes concavity locally. In other words, the technique does not guarantee that the cost function will also satisfy the criterion of global concavity. In principle, as Jorgenson and Fraumeni (1983) have shown, concavity may also be imposed globally, but the disadvantage of that procedure is that it destroys a good deal of the flexibility of the functional form. As Wiley, Schmidt and Bramble point out, a matrix $A$ is negative semi-definite if it can be written as

$$
A=-T^{\prime}
$$

where $T \equiv\left[\tau_{j k}\right]$ is a lower triangular matrix. Thus, in the $3 \times 3$ case, we have

$$
T \equiv\left[\begin{array}{lll}
\tau_{11} & 0 & 0 \\
\tau_{21} & \tau_{22} & 0 \\
\tau_{31} & \tau_{32} & \tau_{33}
\end{array}\right]
$$

This matrix can be used to reparametrize the estimating functions. The implication of this is that the matrix A may be written as:

$$
\begin{aligned}
& A \equiv\left[\begin{array}{lll}
a_{11} & a_{12} & a_{13} \\
a_{21} & a_{22} & a_{23} \\
a_{31} & a_{32} & a_{33}
\end{array}\right]= \\
& T^{\prime}=\left[\begin{array}{lll}
\tau_{11}^{2} & \tau_{11} \tau_{21} & \tau_{11} \tau_{31} \\
\tau_{11} \tau_{21} & \tau_{22}^{2}+\tau_{22}^{2} & \tau_{21} \tau_{31}+\tau_{22} \tau_{32} \\
\tau_{11} \tau_{31} & \tau_{21} \tau_{31}+\tau_{22} \tau_{32} & \tau_{31}^{2}+\tau_{32}^{2}+\tau_{33}^{2}
\end{array}\right]
\end{aligned}
$$

Now recall that the elasticities of substitution have been defined as follows:

$$
\sigma_{j k}= \begin{cases}\left(\phi_{j k}+s_{k} s_{j}\right) / s_{k} s_{j} & \text { for } j \neq k \\ \left(\phi_{j i}+s_{j}^{2}-s_{j}\right) / s_{j}^{2} & \text { for } j=k\end{cases}
$$

The next step is to normalize the values of all input prices in the year in which violation of the concavity occurs to 1 and the value of the time-trend (which is the technical progress parameter) to 0 . Then it can immediately be seen from the share equations that $\theta_{i}$ $=\beta_{\mathrm{j}}$ at that point. Therefore, at this point we may write

' Note that Kohli (1991) uses this technique intensively. 


$$
\sigma_{\mathrm{jk}}=\left\{\begin{array}{lll}
\left(\phi_{\mathrm{jk}}+\beta_{\mathrm{k}} \beta_{\mathrm{j}}\right) / \beta_{\mathrm{k}} \beta_{\mathrm{j}} & \text { for } j \neq k & (j, k=w, r, q) \\
\left(\phi_{\mathrm{jj}}+\beta_{\mathrm{j}}^{2}-\beta_{\mathrm{j}}\right) / \beta_{\mathrm{j}}^{2} & \text { for } j=k & (j, k=w, r, q)
\end{array}\right.
$$

Now set $\beta \equiv\left[\beta_{j}\right], B=\operatorname{diag}[\beta]$ and $\Lambda=B \Sigma B$, with $\Sigma$ evaluated at the point of violation of the curvature conditions. Then

$$
T T^{\prime}=\left[\begin{array}{lll}
\phi_{r r}+\beta_{r}^{2}-\beta_{r} & \phi_{r w}+\beta_{r} \beta_{w} & \phi_{r q}+\beta_{r} \beta_{q} \\
\phi_{w r}+\beta_{w} \beta_{r} & \phi_{w w}+\beta_{w}^{2}-\beta_{w} & \phi_{w q}+\beta_{q} \beta_{w} \\
\phi_{q r}+\beta_{q} \beta_{r} & \phi_{q w}+\beta_{q} \beta_{w} & \phi_{q q}+\beta_{q}^{2}-\beta_{q}
\end{array}\right]
$$

A necessary and sufficient condition for $\Sigma$ to be negative semi-definite is that $\Lambda$ itself is negative semi-definite. This can be ensured by setting

$\Lambda=-\mathrm{TT}^{\prime}$

Hence, the reparametrisation results in the following estimates for the parameters: ${ }^{7}$

$$
\begin{aligned}
& \phi_{\mathrm{rr}}=-\left(\tau_{11}^{2}+\beta_{\mathrm{r}}^{2}-\beta_{\mathrm{r}}\right) \\
& \phi_{\mathrm{rw}}=-\left(\tau_{11} \tau_{21}+\beta_{\mathrm{r}} \beta_{\mathrm{w}}\right) \\
& \phi_{\mathrm{rq}}=-\left(\tau_{11} \tau_{31}+\beta_{\mathrm{r}} \beta_{\mathrm{q}}\right) \\
& \phi_{\mathrm{ww}}=-\left(\tau_{2}^{2}+\tau_{2}^{2}+\beta_{w}^{2}-\beta_{w}\right) \\
& \phi_{\mathrm{wq}}=-\left(\tau_{21} \tau_{31}+\tau_{22} \tau_{32}+\beta_{w} \beta_{\mathrm{q}}\right) \\
& \phi_{\mathrm{qq}}=-\left(\tau_{31}^{2}+\tau_{32}^{2}+\tau_{33}^{2}+\beta_{\mathrm{q}}^{2}-\beta_{\mathrm{q}}\right)
\end{aligned}
$$

The above reparametrisation only guarantees local concavity. Therefore, once concavity has been imposed locally, one needs to check whether concavity will hold for all observations. As Kohli (1992) points out, it is frequently sufficient to impose the curvature conditions at the point that seems to be the most serious offender.

\subsection{Estimation results}

This section presents and discusses the results obtained from the econometric estimation of the model parameters. We estimated the model using the data described above. We start with a presentation of the estimated coefficients of the model and proceed with a discussion of the implied elasticities of substitution between factors of production.

Table 6.2 reveals the estimation results for the parameters of the three-equation system of Hicksian conditional factor demand functions for Germany. The value shares are obtained by relating the payments to a factor to the value of total production. We estimated the parameters for the 13 manufacturing industries in the database. The estimation period was 1970-1986.

One may observe that the majority of parameters are significantly different from zero in all of the industries. As to the interpretation of the parameters, one may note the fol-

${ }^{7}$ Note that Kohli's (1991, p. 110) expression (8.15) contains some disturbing misprints, which we did not reproduce in (6.12). 
lowing. The parameters $\left\{\beta_{k}, \beta_{1}\right\}$ might be interpreted as average value shares of capital and labour for the concerning sector. The parameters $\left\langle\phi_{\mathrm{wW}^{\prime}} \phi_{\mathrm{wr}}, \phi_{\pi^{\prime}} \phi_{\mathrm{wq}}, \phi_{\mathrm{rq}}\right\rangle$ may be interpreted as constant share elasticities with respect to the price of the corresponding factor. Similarly, $\left\{\phi_{\mathrm{kt}}, \phi_{1 \mathrm{t}}\right\}$ are the constant biases of technical change. Note that the parameters $\phi_{r w}$ are all statistically significantly different from zero, which makes it inappropriate to describe the German production technology by a Cobb-Douglas production function.

Special attention deserve the estimates for the office and data processing machines, precision and optical instruments sector. It turned out (see the discussion of the AUES below) that the estimates for the cost function of this sector were not consistent with the curvature requirements. Therefore, we had to impose concavity for this sector using the Bramble, Schmidt and Wiley technique. The reparametrised estimates are listed underneath the original ones. Rather than presenting the estimates for the $\tau$ parameters, we listed the implied values of the $\phi_{\mathrm{ij}}$ 's to ease a comparison of the results. The latter parameters were obtained with the ANALYSE procedure in the TSP package. The estimated cost function thus satisfied the required regularity conditions, including concavity, for all observations.

We did not report Durbin-Watson test statistics, since these have no meaning unless they have been obtained with OLS residuals. Also, there appears to be some evidence that the appearance of low DW values may be attributed to the imposition of the symmetry and homogeneity restrictions in the estimation. Deaton and Muelbauer (1980) reported a substantial drop in DWs after imposing the homogeneity restrictions. Nevertheless, it should be mentioned that the calculated Durbin-Watson statistics were low for a number of sectors, and the possibility of first-order serial auto-correlation could certainly exist. However, attempts to correct for auto-correlation had only little effect on the estimated parameters.

In order to evaluate the parameters of technical change, we constructed Table 6.3 , in which the estimated biases of technical progress are summarised. Recall that a positive value of the technical progress parameter indicates that technical progress is factorusing with respect to the corresponding factor, and that a negative value implies that technical progress is factor-saving with respect to that factor. Technical progress turned out to be capital-using in all industries included in our study and labour-saving in all but one industry. Note also, that technical progress is intermediate-using in the vast majority of cases. Finally, it is interesting to see that our findings are almost completely in accordance with Nakamura's (1984) detailed sectoral cost function study on 12 branches of the German economy. The latter also reports a capital-using and laboursaving bias in all industries. Nakamura quotes evidence from several other studies (among others, for the Japanese economy), where a similar pattern of technical progress was found to exist in the majority of cases. Finally, the existence of a capital-using and labour-saving bias has been found in Binswanger's (1974) influential study on the measurement of technical change biases. ${ }^{8}$

In order to analyse price responsiveness and factor substitution possibilities, we computed the Allen-Uzawa partial elasticities of substitution. These are reported in Table 6.4 for two years, notably 1970 and 1985 . Inspection of these elasticities shows that we found negative own elasticities of substitution in the vast majority of cases. This is in accordance with cost minimizing principles and is well in keeping with the results of

${ }^{8}$ See also Dargay (1988, ch. 4/5), who finds the same tendencies for Sweden's industrial branches. 
Table 6.2 Estimation results for manufacturing sectors: Germany

\begin{tabular}{|c|c|c|c|c|c|c|c|}
\hline Coeff:: & $B_{r}$ & $\phi_{\text {Iw }}$ & $\phi_{\mathrm{r}}$ & $\phi_{\mathrm{st}}$ & $\beta_{w}$ & $\phi_{w w}$ & $\phi_{\mathrm{wt}}$ \\
\hline erro & 0.00 & $\begin{array}{l}-0.015 \\
-9.949\end{array}$ & $\begin{array}{r}0.01 \\
13.84\end{array}$ & $\begin{array}{l}\text { ther } t \\
0.00 \\
(3.50\end{array}$ & $\begin{array}{r}\text { radioacti } \\
0.2911 \\
(13.1980\end{array}$ & $\begin{array}{c}0.0294 \\
(4.3108)\end{array}$ & $\begin{array}{r}-0.0023 \\
(-6.1273)\end{array}$ \\
\hline
\end{tabular}

Non-metallic minerals and mineral products

$\begin{array}{ccccccc}0.0906 & -0.0651 & 0.0732 & 0.0021 & 0.6919 & 0.0928 & -0.0057 \\ (0.6264) & (-4.8877) & (5.4143) & (1.0167) & (6.1026) & (5.6865) & (-3.5499)\end{array}$

Chemical products

$\begin{array}{ccccccc}-0.0466 & -0.0649 & 0.0577 & 0.0028 & 0.5253 & 0.0858 & -0.0050 \\ (-1.8251) & (-21.3684) & (16.8494) & (6.5686) & (12.6557) & \{8.6903) & (-7.6280)\end{array}$

Metal products, except machinery and transport equipment
0.0723
0.0042 . 0.8438
$0.0881-0.0084$
$(-1.7926) \quad(-10.4597) \quad(8.6027)$
$(4.5193) \quad(18.3404)$
$(8.2621) \quad(-11.3925)$

Agricultural and industrial machinery

$\begin{array}{ccccccc}-0.0536 & -0.0579 & 0.0545 & 0.0029 & 0.6529 & 0.0440 & -0.0053 \\ (-1.4008) & (-7.9975) & (10.5606) & (4.5173) & (9.1159) & (6.1670) & (-4.1189)\end{array}$

Office and data processing machines, precision and optical instruments
$(-0.0854) \quad(-13.3861)$
0.1267
0.0088
1.8964
0.1053
$-0.0245$
$\begin{array}{llllll}(8.7933) & (4.4607) & (11.4476) & (1.3549) & (-8.9531)\end{array}$

Reparametrisation:

$\begin{array}{lllllll}0.2414 & -0.0542 & 0.0488 & 0.0042 & 0.3609 & -0.1893 & -0.0151 \\ (38.7864) & (-1.7029) & (3.543) & (1.4177) & (9.5304) & (-0.9837) & (-1.7114)\end{array}$

Electrical goods

$\begin{array}{ccccccc}-0.3358 & -0.0734 & 0.0719 & 0.0072 & 0.7678 & 0.0595 & -0.0065 \\ (-7.6877) & (-18.5843) & (15.4705) & (9.6853) & (20.0871) & (5.8679) & (-9.4617)\end{array}$

Transport equipment

$\begin{array}{ccccccc}-0.1883 & -0.0507 & 0.0582 & 0.0050 & 0.3996 & 0.0550 & -0.0023 \\ (-9.2528) & (-10.7633) & (23.6020) & (15.1469) & (7.6350) & (2.1975) & (-5.8684)\end{array}$

Food, beverages and tobacce
$\begin{array}{lr}0.1356 & -0.0530 \\ (3.2585) & (-11.6075)\end{array}$
0.0480
$0.0017 \quad 0.3611$
$0.0526-0.0041$
(8.9909)
(2.3848)
(7.1635)
$(-9.5683)$

Textiles and clothing, leather and footwear
$-0.0369$
$-0.0658$
0.0588
0.0032
0.7856
0.0507
$-0.0083$
$(-0.9911) \quad(-15.2201)$
$\begin{array}{llll}(16.6970) & (5.1787) & (22.4534)\end{array}$
$(6.2047) \quad(-14.6541)$

Paper and printing products 0.2168 ô. 0553

$(-5.7758) \quad(-9.0995)$

$\begin{array}{lllll}0.0673 & 0.0065 & 0.5902 & 0.0514 & -0.0058\end{array}$ $\begin{array}{lllll}(11.7147) & (10.1959) & (16.4472) & (4.1154) & (-11.2470)\end{array}$

Rubber and plastic proctucts
$\begin{array}{lr}0.1409 & -0.0716 \\ (2.4437) & (-11.1591)\end{array}$
0.0589
$\begin{array}{cc}0.0016 & 0.8377 \\ (1.5446) & (20.1297)\end{array}$
$0.0722-0.0090$
(2.4437) (-11.1591) $(10.6999)$
$(8.6549) \quad(-11.7533)$

Other manufacturing products;

$\begin{array}{ccccccc}0.3015 & -0.1057 & 0.0840 & 0.0067 & 1.0108 & 0.1055 & -0.0111 \\ (-2.5428) & (-13.7018) & (5.4516) & (3.3972) & (18.0288) & (4.3404) & (-13.8226)\end{array}$

Note: t-values between brackets 
Table 6.3 Summary of technical progress biases: Germany

Industry

Ferrous and non-ferrous ores and metals, other than radioactive

Non-metalisc minerals and mineral products

Chemical products.

Metal products, except machinery and transport equipment

Agricultural and industrial machinery

Office and data processing machines, precision and optical instruments

Electrical goods

Transport equipment

Food, beverages and tobacco

Textiles and clothing, leather and footwear

Paper and printing products

Rubber and plastic products

Other manufacturing products

Note: $\mathrm{K}=$ capital, $\mathrm{L}=\mathrm{labour}, \mathrm{X}=$ intermediates.

$+=$ input-using, $-=$ input-saving, $0=$ input-neutral
Nature of bias for production factor:

$X$

$\mathrm{K}$

L.

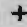

$+$

$+$

$+$

$+$

$+$

$+$

$+$

$+$

$+$

$+$

$+$

$+\quad-\quad+$

$+\quad-\quad+$ 
Table 6.4 Estimated values of the Allen-Uzawa elasticities of substitution, 1970 and 1985: Germany

\begin{tabular}{|c|c|c|c|c|c|c|}
\hline & $\sigma_{\mathrm{rr}}$ & $\sigma_{w w}$ & $\sigma_{q q}$ & $\sigma_{\mathrm{rw}}$ & $a_{\mathrm{rg}}$ & $\sigma_{\text {iwg }}$ \\
\hline \multicolumn{6}{|c|}{ 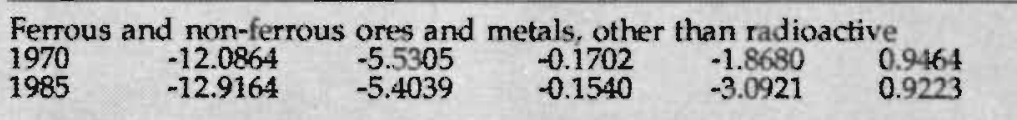 } & $\begin{array}{l}0.8559 \\
0.8620\end{array}$ \\
\hline \multicolumn{7}{|c|}{ 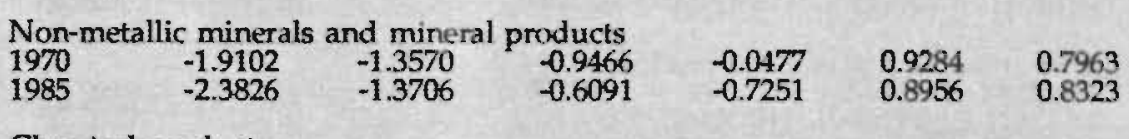 } \\
\hline $\begin{array}{l}\text { Chemical F } \\
1970 \\
1985\end{array}$ & $\begin{array}{r}\text { products } \\
-3.3291 \\
-3.3068\end{array}$ & $\begin{array}{l}-1.8471 \\
-1.7878\end{array}$ & $\begin{array}{l}-0.4443 \\
-0.4875\end{array}$ & $\begin{array}{l}-1.6911 \\
-1.3950\end{array}$ & $\begin{array}{l}1.0896 \\
1.0875\end{array}$ & $\begin{array}{l}0.8478 \\
0.8535\end{array}$ \\
\hline $\begin{array}{l}\text { Metal prod } \\
1970 \\
1985\end{array}$ & Metal products, except machinery and transport equipment & $\begin{array}{l}\text { machinery a } \\
-1.3251 \\
-1.2362\end{array}$ & $\begin{array}{l}\text { nd transpor } \\
0.9593 \\
-0.8167\end{array}$ & $\begin{array}{l}\text { equipment } \\
-0.6367 \\
-1.3660\end{array}$ & $\begin{array}{l}1.1542 \\
1.2206\end{array}$ & $\begin{array}{l}0.9875 ; \\
0.9891\end{array}$ \\
\hline $\begin{array}{l}\text { Agricultur } \\
1970 \\
1985\end{array}$ & $\begin{array}{l}\text { al and indus } \\
-3.5883 \\
-3.2160\end{array}$ & $\begin{array}{l}\text { trial machin } \\
-1.5767 \\
-1.5258\end{array}$ & $\begin{array}{l}-0.8710 \\
-0.8084\end{array}$ & $\begin{array}{l}-0.5420 \\
-0.9778\end{array}$ & $\begin{array}{l}1.0560 \\
1.0711\end{array}$ & $\begin{array}{l}1.0747 \\
1.0706\end{array}$ \\
\hline $\begin{array}{l}\text { Office and } \\
1970 \\
1985 \\
\text { Reparamet }\end{array}$ & $\begin{array}{c}\text { data process } \\
0.9641 \\
1.1819 \\
\text { terisation: }\end{array}$ & $\begin{array}{l}\text { sing machine } \\
-0.9563 \\
-1.1739\end{array}$ & $\begin{array}{l}\text { s, precision } \\
-2.1068 \\
-1.0126\end{array}$ & $\begin{array}{c}\text { and optical in } \\
-0.8998 \\
-3.4573\end{array}$ & $\begin{array}{l}\text { nstruments } \\
1.3923 \\
1.5190\end{array}$ & $\begin{array}{l}1.4053 \\
1.3415\end{array}$ \\
\hline $\begin{array}{l}1970 \\
1985\end{array}$ & $\begin{array}{l}-2.3400 \\
-3.8912\end{array}$ & $\begin{array}{l}-3.1911 \\
-4.5107\end{array}$ & $\begin{array}{l}-3.0660 \\
-1.4684\end{array}$ & $\begin{array}{r}0.3743 \\
-0.4701\end{array}$ & $\begin{array}{l}1.0561 \\
1.0743\end{array}$ & $\begin{array}{l}2.6810 \\
2.4172\end{array}$ \\
\hline $\begin{array}{l}\text { Electrical g } \\
1970 \\
1985\end{array}$ & $\begin{array}{l}\text { goods } \\
-2.4396 \\
-2.4431\end{array}$ & $\begin{array}{l}-1.2724 \\
-1.1982\end{array}$ & $\begin{array}{l}-1.0611 \\
-1.1314\end{array}$ & $\begin{array}{l}-0.5206 \\
-0.4530\end{array}$ & $\begin{array}{l}1.0222 \\
1.0228\end{array}$ & $\begin{array}{l}1.0754 \\
1.0748\end{array}$ \\
\hline $\begin{array}{l}\text { Transport } \\
1970 \\
1985\end{array}$ & $\begin{array}{c}\text { equipment } \\
-2.3590 \\
-3.2849\end{array}$ & $\begin{array}{l}-1.8504 \\
-1.8721\end{array}$ & $\begin{array}{l}-0.5380 \\
-0.6113\end{array}$ & $\begin{array}{l}-1.2569 \\
-0.6197\end{array}$ & $\begin{array}{l}0.8503 \\
0.8885\end{array}$ & $\begin{array}{l}0.9759 \\
0.9745\end{array}$ \\
\hline $\begin{array}{l}\text { Food, beve } \\
1970 \\
1985\end{array}$ & $\begin{array}{l}\text { erages and to } \\
-2.5899 \\
-3.0933\end{array}$ & $\begin{array}{l}\text { bacco } \\
-3.6599 \\
-3.6657\end{array}$ & $\begin{array}{l}-0.5247 \\
-0.4393\end{array}$ & $\begin{array}{l}-1.0013 \\
-1.4428\end{array}$ & $\begin{array}{l}1.0344 \\
1.0394\end{array}$ & $\begin{array}{l}1.0041 \\
1.0039\end{array}$ \\
\hline $\begin{array}{l}\text { Textiles and } \\
1970 \\
1985\end{array}$ & $\begin{array}{l}\text { ad clothing, le } \\
-3.0005 \\
-3.1157\end{array}$ & $\begin{array}{l}\text { eather and fo } \\
-1.8461 \\
-2.1565\end{array}$ & $\begin{array}{l}\text { otwear } \\
-0.8744 \\
-0.5992\end{array}$ & $\begin{array}{l}-0.4610 \\
-1.5994\end{array}$ & $\begin{array}{l}1.0809 \\
1.1080\end{array}$ & $\begin{array}{l}1.0940 \\
1.0922\end{array}$ \\
\hline $\begin{array}{l}\text { Paper and } \\
1970 \\
1985\end{array}$ & $\begin{array}{l}\text { printing pro } \\
-2.6697 \\
-2.6005\end{array}$ & $\begin{array}{l}\text { ducts } \\
-2.2299 \\
-2.5814\end{array}$ & $\begin{array}{l}-0.6333 \\
-0.5784\end{array}$ & $\begin{array}{l}-0.4924 \\
-0.6010\end{array}$ & $\begin{array}{l}0.8687 \\
0.8824\end{array}$ & $\begin{array}{l}1.0263 \\
1.0295\end{array}$ \\
\hline $\begin{array}{l}\text { Rubber and } \\
1970 \\
1985\end{array}$ & $\begin{array}{l}\text { d plastic prox } \\
-2.3677 \\
-3.1396\end{array}$ & $\begin{array}{l}\text { ducts } \\
-1.6020 \\
-1.6840\end{array}$ & $\begin{array}{l}-1.0651 \\
-0.7429\end{array}$ & $\begin{array}{l}-0.1510 \\
-0.8650\end{array}$ & $\begin{array}{l}1.1184 \\
1.1549\end{array}$ & $\begin{array}{l}0.9959 \\
0.9963\end{array}$ \\
\hline $\begin{array}{l}\text { Other ma } \\
1970 \\
1985\end{array}$ & $\begin{array}{l}\text { ufacturing p } \\
-1.9676 \\
-1.3850\end{array}$ & $\begin{array}{r}\text { roducts } \\
-1.2357 \\
-1.1641\end{array}$ & $\begin{array}{l}-0.8455 \\
-0.7746\end{array}$ & $\begin{array}{l}-1.3836 \\
-2.0400 \\
\end{array}$ & $\begin{array}{l}1.2404 \\
1.3191 \\
\end{array}$ & $\begin{array}{l}1.0014 \\
1.0013\end{array}$ \\
\hline
\end{tabular}


Table 6.5 Estimation results for manufacturing sectors: Italy

\begin{tabular}{cccccccc}
\hline Coelff: & $\beta_{\mathrm{r}}$ & $\phi_{\mathrm{rw}}$ & $\phi_{\mathrm{rr}}$ & $\phi_{\mathrm{rt}}$ & $\beta_{\mathrm{w}}$ & $\phi_{\mathrm{ww}}$ & $\phi_{\mathrm{wt}}$ \\
\hline Ferrous and non-ferrous ores and metals, other than radioactive & & \\
-0.3085 & -0.0799 & 0.0789 & 0.0078 & 1.7005 & 0.1030 & -0.0214 \\
$(-1.2754)$ & $(-10.3629)$ & $(6.7583)$ & $(2.1674)$ & $(11.4751)$ & $(8.5763)$ & $(-9.9495)$ \\
Reparametrisation: & & -0.0022 & -0.0061 & -0.0121 & 0.4683 & 0.0156 & -0.0037 \\
1.0565 & $(-0.1370)$ & $(-0.9482)$ & $(-4.9027)$ & $(1.6793)$ & $(0.7108)$ & $(-0.9324)$
\end{tabular}

Non-metallic minerals and mineral products
$\begin{array}{lll}-1.2219 & -0.1425 & 0.1321\end{array}$

$(-8.1381)$

Reparametrisation:

$\begin{array}{lllllll}0.4854 & -0.0046 & -0.0038 & -0.0036 & 0.8989 & 0.0180 & -0.0078 \\ (1.8996) & (-0.3224) & (-0.3173) & (-0.9402) & (3.9075) & (0.9933) & (-2.4836)\end{array}$

Chemical products
-0.2517
$(-3.9955)$
$-0.0585$
0.0549
0.0058
$(6.4804)$
$\begin{array}{rr}1.3042 & 0.0680 \\ (8.5454) & (6.3405)\end{array}$
$-0.0151$
$(-5.8332) \quad(9.5235)$
$(-6.7508)$

Metal products, except machinery and transport equipment
$(-2.1654)$
$-0.0493$
0.0688
0.0093 1.2400
$0.0225-0.0138$
$(-2.1654) \quad(-2.3564) \quad(3.9535)$
$\begin{array}{ll}(3.4633) & (5.3719)\end{array}$
$(0.8093) \quad(-4.1825)$

Agricultural and industrial machinery

$(-3.2686) \quad(-5.8236) \quad(3.0516)$

0.0091

1.4197

$0.0646-0.0162$

(3.6619)

(8.1245)

(3.1140)

$(-6.3855)$

Office and dattas processing machines, precision and optical instruments

$\begin{array}{ccccccc}-0.1174 & -0.0660 & 0.0033 & 0.0039 & 1.4378 & -0.0999 & -0.0163 \\ (-0.8083) & (-0.5716) & (0.1827) & (2.4032) & (8.8310) & (-2.6309) & (-8.2813)\end{array}$

Electrical goods

$\begin{array}{lllllll}-0.5373 & -0.0612 & 0.0555 & 0.0095 & 1.7048 & 0.0296 & -0.0196\end{array}$

$\begin{array}{lllllll}(-4.3622) & (-3.2949) & (3.8318) & (5.2754) & (5.2609) & (1.5632) & (-4.3035)\end{array}$

Transport ecuipment

$\begin{array}{ccccccc}-0.8332 & -0.0702 & 0.0729 & 0.0139 & 1.3443 & 0.0637 & -0.0156 \\ (-3.9284) & (-6.1149) & (5.8463) & (4.4425) & (7.2503) & (3.3969) & (-5.8362)\end{array}$

Food, beverages and tobacco

$\begin{array}{ccccccc}-0.2289 & -0.0079 & 0.0359 & 0.0061 & 0.1699 & 0.0009 & -0.0012 \\ (-1.0433) & (-0.4219) & (1.9641) & (1.9038) & (0.7098) & (0.0286) & (-0.3609)\end{array}$

Textiles and clothing, leather and footwear
-0.7008
$(-2.4225)$
$-0.0735$
$0.0719 \quad 0.0120$
0.0120
$(2.9467)$
$1.3149 \quad 0.0708$
$-0.0149$

Paper and printing products

$\begin{array}{ccccccc}-0.5722 & -0.0831 & 0.0781 & 0.0103 & 1.4311 & 0.0713 & -0.0166 \\ (-8.8107) & (-8.1908) & (9.4977) & (11.0325) & (13.4813) & (5.3508) & (-11.1973)\end{array}$

Rubber and plastic products

$\begin{array}{lllllll}-0.5672 & -0.0715 & 0.0850 & 0.0111 & 1.3044 & 0.0529 & -0.0150\end{array}$

$\begin{array}{lllllll}(-3.7300) & (-3.3554) & (5.1559) & (5.0630) & (4.5865) & (20881) & (-3.6821)\end{array}$

Other manufacturing products
$\begin{array}{ll}-0.7901 & -0.0658 \\ (-1.5585) & (-1.6148)\end{array}$
\begin{tabular}{ll}
$0.0980 \quad 0.0150$ \\
\hline
\end{tabular}
(2.0144)
1.3775
$0.0972 \quad-0.0158$
$(3.3649) \quad(1.4858) \quad(-2.7142)$

Note: t-values, between brackets 
Table 6.6 Summary of technical progress biases: Italy

Industry

Ferrous and non-ferrous ores and metals, other than radioactive

Non-metallic minerals and mineral products

Chemical products

Metal products, except machinery and transport equipment

Agricultural and industrial machinery

Office and data processing machines, precision and optical instruments

Electrical goods

Transport equipment

Food, beverages and tobacco

Textiles and clothing, leather and footwear

Paper and printing products

Rubber and plastic products

Other manufacturing products

\footnotetext{
Note: $\mathrm{K}=$ capital, $\mathrm{L}=$ labour, $\mathrm{X}=$ internediates.

$+=$ input-using, - = input-saving, $0=$ input-neutral
}

\section{$\underset{\mathrm{K}}{\text { Nature of bias for production factor: }}$}

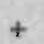

$+$
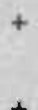

$+$

$+$

$+$

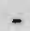

$+$

$+$

$+$

$+$ 
Table 6.7 Estimated values of the Allen-Uzawa elasticities of substitution, 1970 and 1985: Italy

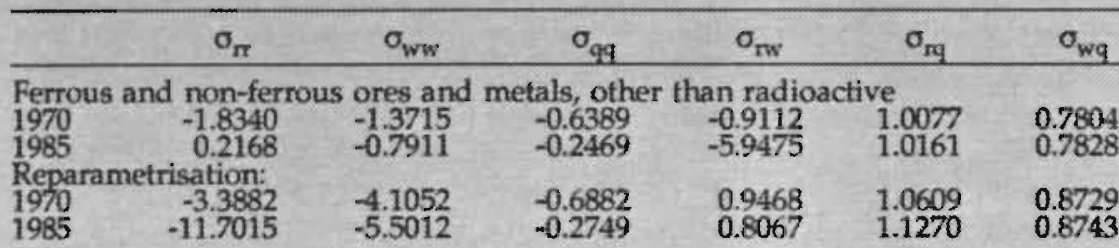

Non-metallic minerals and mineral products

$\begin{array}{lllllll}\text { Non-metallic minerals and mineral products } & & & \\ 1970 & -0.8225 & -0.6196 & -1.2595 & -0.9137 & 1.1064 & 0.9283 \\ 1985 & -0.6099 & -0.5462 & -0.7832 & -2.0043 & 1.0976 & 0.9236 \\ \text { Reparametrisation: } & & & & & \\ 1970 & -3.5936 & -1.8146 & -1.2349 & 0.9384 & 1.0851 & 0.9099 \\ 1985 & -4.3539 & -2.7261 & -0.7679 & 0.9033 & 1.0781 & 0.9040\end{array}$

Chemical products

$\begin{array}{lllllll}1970 & -3.2041 & -2.0679 & -0.5996 & -0.6827 & 1.0379 & 0.9328 \\ 1985 & -3.5451 & -2.6441 & -0.3462 & -2.4429 & 1.0426 & 0.9135\end{array}$

Metal products, except machinery and transport equipment
1970
$-1.9016$
$-1.1219 \quad 0.2735$
0.8370
1.2063
$-2.4515 \quad-2.8816$
$-0.7164 \quad-0.1944$
0.8139
1.1954

Agricultural and industrial machinery
1970
$-3.4529$
$-1.7452$
$-0.7919$
$-1.3898$
1.3542
1.1012
1985
$-3.1814$
$-2.1272$
$-0.7261$
$-1.3525$
1.2762
1.1191

Office and data processing machines, precision and optical instruments
1970
$\begin{array}{ll}-5.1455 & -2.1096\end{array}$
$-1.8474 \quad-0.8964$
1.0479
1.6040
$\begin{array}{ll}-3.6678 & -6.3925\end{array}$
$-1.0224$
$-0.8445$
1.8977
1.0271

Electrical goods
1970
$-3.4101$
$-1.7826$
$-0.9658$
$-0.4461$
1.1781
$-1.0479$
1.0807
1.2145

Transport equipment
1970
-2.4301
-2.0784
$-1.9566$
$-0.6683$
1985
$-1.9338$
$-0.5883$
$-0.9335$
0.9697
1.0431
$-1.4852$
0.9625
1.0405

Food, beverages and tobacco
1970
$\begin{array}{lr}-3.2396 & -10.4094 \\ -4.0908 & -9.0102\end{array}$
$-0.3454$
0.5278
0.7971
1.1116
0.4682
1.0939

Textiles and clothing, leather and footwear
1970
$-2.4769$
$-1.8174$
1985
$-2.3268$
$-2.2715$

$-0.6915$

$-0.6137$

$-0.9412 \quad 1.0190$

1.0177

Paper and printing products

$\begin{array}{lll}1970 & -2.1953 & -1.819 \\ 1985 & -2.1933 & -2.1698\end{array}$

$-0.7291$

$-1.0831$

1.0224

Rubber and plastic products
1970
$-1.8107 \quad-2.2252$
1985
$\begin{array}{ll}-1.9198 & -2.4360\end{array}$
$-0.8616$
$-0.3695$
0.8846
1.1414

$-0.5914$

$-1.1751$

1.0568

1.0778

$-1.7091$

1.0527

1.0889

Other manufacturing products

\begin{tabular}{lllllll} 
& & & \\
1970 & -1.4014 & -1.4581 & -0.7588 & -0.0347 & 0.7483 & 0.7421 \\
1985 & -1.5118 & -1.5709 & -0.4226 & -0.9498 & 0.7081 & 0.7425 \\
\hline
\end{tabular}




\section{Table 6.8 Estimation results for manufacturing sectors: Belgium}

\begin{tabular}{|c|c|c|c|c|c|c|c|}
\hline Coeff: & $\beta_{r}$ & $\phi_{\mathrm{rw}}$ & $\phi_{\mathrm{nr}}$ & $\phi_{n}$ & $\beta_{w}$ & $\phi_{w w}$ & $\phi_{w t}$ \\
\hline & .222 & $\begin{array}{l}-0.013 ? \\
-3.960\end{array}$ & $\begin{array}{l}0.0144 \\
8.018\end{array}$ & $\begin{array}{l}-0.001 \\
-0.827\end{array}$ & $\begin{array}{l}0.2890 \\
(2.245\end{array}$ & $\begin{array}{c}0.0350 \\
(2.6609)\end{array}$ & $\begin{array}{r}-0.0015 \\
(-0.8269)\end{array}$ \\
\hline
\end{tabular}

Non-metallic minerals and mineral products

$\begin{array}{ccccccc}-0.2082 & -0.0532 & 0.0690 & 0.0060 & 1.2564 & 0.0232 & -0.0130 \\ (-2.2055) & (-2.4912) & (4.9649) & (4.3889) & (18.2186) & (0.5011) & (-14.7576)\end{array}$

Chemical products
$\begin{array}{cc}-0.1857 & -0.0488 \\ (-2.7440) & (-11.9807)\end{array}$
0.0778
0.0058
$0.5097 \quad 0.1000 \quad-0.0035$
$\begin{array}{llll}(5.9692) & (10.2743) \quad(10.7906) & (-4.9921)\end{array}$

Metal products, except machinery and transport equipment
0.4708
$-0.0057$
$-0.0001$
$-0.0050-0.9293$
$(-2.5474)$
$(6.7287)$
$\begin{array}{cc}-0.0125 & -0.0075 \\ (-0.5073) & (-3.4097)\end{array}$
$(3.2600) \quad(-0.3165) \quad(-0.0087)$

Agriculturai and industrial machinery

$\begin{array}{ccccccc}-0.1788 & -0.0414 & 0.0531 & 0.0048 & 1.0015 & 0.0180 & -0.0096 \\ (-3.3189) & (-7.3758) & (14.7489) & (6.2238) & (11.9492) & (1.1153) & (-8.6303)\end{array}$

Office and data processing machines, precision and optical instruments
0.6701
(1.3786)
$-0.0481$
0.0405
$-0.0099$
$2.0556-0.0040$
$\begin{array}{llll}(-1.9682) & (6.4988) & (-0.1460) & (-4.6675)\end{array}$

Electrical goods $(-0.6786)$

$$
\begin{array}{cc}
-0.0215 & 0.0391 \\
(-2.6608) & (6.7233)
\end{array}
$$

0.0033

$0.8027-0.0189$

$-0.0063$

$(-2.6608) \quad(6.7233)$

(1.9138)

$(7.3278) \quad(-1.2375)$

$(-3.7502)$

Transport equipment

$\begin{array}{ccccccc}-0.0940 & -0.0142 & 0.0218 & 0.0025 & 0.5654 & -0.0149 & -0.0052 \\ (-3.2824) & (-1.5984) & (8.4409) & (6.0783) & (6.3728) & (-0.5697) & (-3.9782)\end{array}$

Food, beverages and tobacco
$0.1049-0.0512$
$(2.0232) \quad(-4.0495)$
0.0496
$(3.9891)$
0.0013
$(1.3245)$
0.5516
$0.0519-0.0062$
$(8.5648) \quad(3.3303) \quad(-7.7313)$

Textiles and clothing, leather and footwear
$-0.0800$
$-0.0266$
$0.0387 \quad 0.0031$
$0.9744-0.0007$
$-0.0099$
$(-1.1365) \quad(-1.3705)$
$(3.2940) \quad(3.0884)$
$\begin{array}{lll}(16.1435) & (-0.0119) \quad(-15.6756)\end{array}$

Paper and printing products $\begin{array}{ccccccc}-0.31109 & -0.0496 & 0.0493 & 0.0062 & 0.5703 & 0.0218 & -0.0039 \\ (-0.5211) & (-0.2400) & (0.8277) & (1.3326) & (0.2747) & (0.0295) & (-0.2438)\end{array}$

Rubber and plastic products
$-0.1822 \quad-0.0491$
$(-3.4176) \quad(-9.4184)$
$0.0658 \quad 0.005$
(15.0235) (6.6983)
$\begin{array}{cc}0.9290 & 0.0600 \\ (12.1541) & (8.0037)\end{array}$
$-0.0084$
$(-7.9487)$

Other nsanufiacturing products

\begin{tabular}{ccccccc}
-0.2879 & -0.1063 & 0.0860 & 0.0067 & 1.1958 & 0.1097 & -0.0140 \\
$(-4.5011)$ & $(-5.6245)$ & $(8.2309)$ & $(5.8926)$ & $(17.6996)$ & $(3.1918)$ & $(-14.5651)$ \\
\hline
\end{tabular}

Note: $t$-values between brackets 
Table 6.9 Summary of technical progress biases: Belgium

\section{Industry}

Nature of bias for production factor:

Ferrous and non-ferrous ores and metals, other than radioactive

Non-metallic minerals and minerai products

Chemical products

Metal products, except machinery and transport equipment

Agricultural and industrial machinery

Office and data processing machines, precision and optical irstruments

Electrical goods

Transport equipment

Food, beverages and tobacco

Textiles and clothing, leather and footwear

Paper and printing products

Rubber and plastic products

Other manufacturing products

Note: $\mathrm{K}=$ capital, $\mathrm{L}=$ labour, $\mathrm{X}=$ intermediates.

$+=$ input-using, $-=$ input-saving, $0=$ input-neutral 
Table 6.10 Estimated values of the Allen-Uzawa elasticities of substitution, 1970 and 1985: Belgium

\begin{tabular}{lllllll}
\hline & $\sigma_{r r}$ & $\sigma_{w w}$ & $\sigma_{q q}$ & $\sigma_{r w}$ & $\sigma_{r q}$ & $\sigma_{w q}$ \\
\hline Ferrous and non-ferrous ores and metals, other than radioactive & & \\
1970 & -6.1627 & -3.9235 & -0.3469 & 0.2958 & 0.9859 & 0.8127 \\
1985 & -13.3924 & -4.2633 & -0.2025 & -0.9872 & 0.9679 & 0.8166
\end{tabular}

Non-metallic minerals and mineral products
1970
$-2.0976$
$-1.7441$
$-1.3592$
0.2974
0.8380
1.2016
$-2.5987$
$-1.8863$
$\begin{array}{ll}-0.8604 & -0.2998\end{array}$
0.7748
1.1690

1905

Chemical products
1970
$-1.9739$
$-1.3286$
$-0.6395$
0.1577
0.7375
0.6332
1985
$-2.1541$
$-1.4976$
$-0.3358$
$-0.7340$
0.6783
0.6216

Metal products, except machinery and transport equipment
1970
$-4.7472$
$-1.8394$
$-1.2782$
0.9100
$1.0717 \quad 1.1081$
1985
$-11.7993$
$-2.0835$
$-0.7778$
0.7830
$1.1259 \quad 1.0923$

Agricultural and industrial machinery
1970
$-3.1588$
$-1.8678$
$-1.0091$
0.2216
0.8567
1.1393
1985
$-2.4139 \quad-1.8167$
$\begin{array}{ll}-0.7157 & -0.7657\end{array}$
0.7162
1.1171

Office and data processing machines, precision and optical instruments
1970
$-3.3883$
$-1.3114$
$-1.9722$
0.3712
1.1117
1985
$\begin{array}{ll}-3.8277 & -5.1798\end{array}$
$\begin{array}{ll}-0.5935 & -0.9107\end{array}$
1.0732
1.3074
1.4605

Electrical goods

$\begin{array}{lllllll}1970 & -3.6510 & -2.0312 & -1.1422 & 0.6218 & 0.7798 & 1.2377 \\ 1985 & -0.6926 & -1.6492 & -0.8502 & -0.2916 & 0.2570 & 1.1816\end{array}$

Transport equipment
1970
$-8.4810$
$-3.9957$
$-0.4488$
0.1122
0.8578
1.1912
1985
$-4.6953$
$-0.3844 \quad-0.1142$
0.8489
1.2068

Food, beverages and tobacco.
1970
$-2.7838$
$-3.7809$
$-0.4557$
$-1.2681$
1.0120
0.9915
1985
$-3.8237 \quad-3.7160$
$\begin{array}{lll}-0.3294 & -2.3630 & 1.0173\end{array}$
0.9927

Textiles and clothing, leather and footwear
1970
$-4.2679$
$-2.5325$
$-0.7676$
0.3078
0.8467
1.1658
1985
$-5.3232$
$-0.4679$
$-0.6668$
0.7438
1.1662

Paper and printing products

1970

$-3.7558 \quad-2.0984$

$-0.8423$

$-0.2637$

$1.0040 \quad 1.1630$

1985

$-2.5542$

$-0.4246$

$-2.7548$

1.0065

1.1839

Rubber and plastic products
1970
$-2.5694$
$-1.4507$
$-0.9240$
$0.1602 \quad 0.8052$
0.7895
0.9335
1985
$\begin{array}{ll}-2.7995 & -1.9579\end{array}$
$-0.5649$
$-0.4539$
0.9311

Other manufacturing products

1970

$-1.8840$

-1.2720
-1.2540

$\begin{array}{lll}-0.7050 & -1.7018 & 1.1781\end{array}$

0.9724

1985

$-1.8850$

$-0.5969$

$-2.3703$

1.1988

0.9729 
Table 6.11 Estimation results for manufacturing sectors: The Netherlands

\begin{tabular}{|c|c|c|c|c|c|c|c|}
\hline Coeff: & $\beta_{r}$ & $\phi_{\mathrm{rw}}$ & $\phi_{\pi}$ & $\phi_{\mathrm{rt}}$ & $\beta_{w}$ & $\phi_{w w}$ & $\phi_{w t}$ \\
\hline & $\begin{array}{l}.058 \\
.788\end{array}$ & 4.591 & $\begin{array}{r}0.0667 \\
21.779\end{array}$ & $\begin{array}{r}0.0027 \\
(2.0179\end{array}$ & $\begin{array}{r}\text { radioact } \\
0.5402 \\
(4.829)\end{array}$ & $\begin{array}{c}0.0832 \\
(2.0460)\end{array}$ & $\begin{array}{r}-0.0047 \\
(-3.1753)\end{array}$ \\
\hline
\end{tabular}

Non-metallic minerals and mineral products

$\begin{array}{ccccccc}-0.2854 & -0.0887 & 0.0807 & 0.0072 & 1.2747 & 0.0856 & -0.0142 \\ (-4.9416) & (-8.1303) & (9.3387) & (8.2849) & (14.4365) & (20397) & (-10.2685)\end{array}$

Chemical products
0.2205
(1.1163)
$-0.0317$
0.0593
0.0003
0.8094
$0.0595-0.0081$
$(0.4256) \quad(-5.7076)$

Metal products, except machinery and transport equipment

$\begin{array}{cccccccc}-0.2825 & 0.0448 & 0.0563 & 0.0061 & 0.9883 & 0.0325 & -0.0093 \\ (-3.0668) & (-5.5468) & (7.1131) & (4.6350) & (18.2493) & (1.0923) & (-9.9591)\end{array}$

Agricultural and industrial machinery

$\begin{array}{ccccccc}0.0465 & -0.0760 & 0.0531 & 0.0004 & 10.9974 & 0.7810 & -0.0156 \\ (0.1915) & (-1.3412) & (13.3491) & (0.1366) & (0.9241) & (-0.2760) & (-1.1536)\end{array}$

Office and data processing machines, precision and optical instruments
0.8182
$(-1.7052)$
0.0196
(1.8624) $\quad(-1.2449)$
$3.8647-0.1351$
$-0.0515$
$(1.4666) \quad(-0.1467) \quad(-1.9734)$

Electrical goods $-8.2841$

$(-6.9357)$

$0.0664, \quad 0.0691 \quad 0.0066$

$1.0203 \quad 0.0594 \quad-0.0102$ $\begin{array}{llllll}(-22.6311) & (26.8398) & (10.7566) & (20.5941) & (4.4271) & (-12.7488)\end{array}$

Transport equipment

$\begin{array}{ccccccc}0.0185 & -0.0028 & 0.0079 & 0.0006 & 0.6890 & -0.0239 & -0.0059 \\ (0.2232) & (-2.1096) & (3.7001) & (0.5268) & (6.7879) & (-1.6116) & (-3.9540)\end{array}$

Food, beverages and tobacco
$-0.0164-0.0244$
$(-0.2677)$
$(-7.9314)$
$\begin{array}{cc}0.0289 & 0.0019 \\ (7.9178) & (2.1000)\end{array}$
0.4109
$(13.0178)$
$0.0224-0.0042$
$(2.2983) \quad(-8.6906)$

Textiles and clothing, leather and footwear $\begin{array}{ccccccc}-0.2037 & -0.0337 & 0.0338 & 0.0039 & 0.8246 & 0.0271 & -0.0080 \\ (-6.6169) & (-11.8256) & (13.3515) & (8.7945) & (37.0903) & (3.3130) & (-22.9423)\end{array}$

Paper and printing products

$\begin{array}{ccccccc}-0.1023 & -0.0509 & 0.0465 & 0.0034 & 0.8416 & 0.0517 & -0.0077 \\ (-1.3487) & (-3.3577) & (4.0413) & (2.3342) & (10.1051) & (3.1976) & (-5.9364)\end{array}$

Rabber and plastic products

$\begin{array}{ccccccc}-0.1243 & -0.0646 & 0.0532 & 0.0039 & 1.1290 & 0.0854 & -0.0116 \\ (-2.2968) & (-7.1245) & (12.7481) & (5.4258) & (11.0332) & (27535) & (-7.7968)\end{array}$

Other manufacturing products

$\begin{array}{ccccccc}-0.2596 & -0.0493 & 0.0529 & 0.0057 & 0.9394 & 0.0530 & -0.0090 \\ (-2.0551) & (-7.6936) & (6.9381) & (3.1463) & (25.7317) & (2.6721) & (-15.2122)\end{array}$

Note: $t$-values between brackets 
Table 6.12 Summary of technical progress biases: The Netherlands

Industry

Ferrous and non-ferrous ores

and metals, other than radioactive

Non-metallic minerals and mineral products

Chemical products

Metal products, except machinery and transport equipment

Agricultural and industrial machinery

Office and data processing machines, precision and optical instruments

Electrical goods

Transport equipment

Focd, beverages and tobacco

Textiles and clothing, leather and footwear

Paper and printing products

Rubber and plastic products

Other manufacturing products
$\underset{K}{\text { Nahure of bias for production factor: }}$

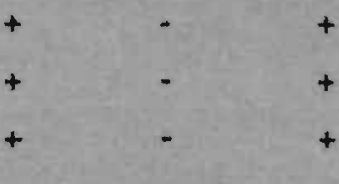

$+$

$+$

$+$

$+$

$+$

4

$+$

$+$

$+$

$+$

$+$

$+$

$+$

Note: $\mathrm{K}=$ capital, $\mathrm{L}=$ labour, $\mathrm{X}=$ intermediates.

to in in ut-using, $-=$ input-saving, $0=$ input-neutral 
Table 6.13 Estimated values of the Allen-Uzawa elasticities of substitution, 1970 and 1985: The Netherlands

\begin{tabular}{|c|c|c|c|c|c|c|}
\hline & $\sigma_{\pi}$ & $\sigma_{w w}$ & $\sigma_{q q}$ & $\sigma_{\mathrm{rw}}$ & $\sigma_{\mathrm{rq}}$ & $\sigma_{w q}$ \\
\hline $\begin{array}{l}\text { Ferrous and } \\
1970 \\
1985\end{array}$ & $\begin{array}{l}\text { non-ferrot } \\
-2.4370 \\
-2.7455\end{array}$ & $\begin{array}{c}\text { us ores and } \\
-1.9855 \\
-1.9893\end{array}$ & $\begin{array}{l}\text { tetals, other } \\
-0.5054 \\
-0.3884\end{array}$ & $\begin{array}{l}\text { han radioac } \\
-0.7544 \\
-1.4970\end{array}$ & $\begin{array}{l}\text { ive } \\
0.9385 \\
0.9203\end{array}$ & $\begin{array}{l}0.7927 \\
0.8079\end{array}$ \\
\hline $\begin{array}{l}\text { Non-metalli } \\
1970 \\
1985\end{array}$ & $\begin{array}{l}\text { ic minerals } \\
-1.9559 \\
-2.0517\end{array}$ & $\begin{array}{c}\text { and minera } \\
-1.5294 \\
-1.6501\end{array}$ & $\begin{array}{l}\text { products } \\
-0.9470 \\
-0.7891\end{array}$ & $\begin{array}{l}-0.5996 \\
-0.9597\end{array}$ & $\begin{array}{l}1.0747 \\
1.0768\end{array}$ & $\begin{array}{l}1.0221 \\
1.0223\end{array}$ \\
\hline $\begin{array}{l}\text { Chemical pr } \\
1970 \\
1985\end{array}$ & $\begin{array}{l}\text { roducts } \\
-2.4406 \\
-2.9808\end{array}$ & $\begin{array}{l}-2.2973 \\
-3.1685\end{array}$ & $\begin{array}{l}-0.5831 \\
-0.2001\end{array}$ & $\begin{array}{r}0.3137 \\
-1.5289\end{array}$ & $\begin{array}{l}0.7670 \\
0.6274\end{array}$ & $\begin{array}{l}0.7801 \\
0.7246\end{array}$ \\
\hline $\begin{array}{l}\text { Metal produ } \\
1970 \\
1985\end{array}$ & $\begin{array}{l}\text { ucts, except } \\
-3.2991 \\
-3.3888\end{array}$ & $\begin{array}{l}\text { machinery } \\
-1.7227 \\
-2.1114\end{array}$ & $\begin{array}{c}\text { nd transpo } \\
-0.8830 \\
-0.6991\end{array}$ & $\begin{array}{c}\text { equipment } \\
0.0124 \\
-0.2490\end{array}$ & $\begin{array}{l}0.8415 \\
0.8445\end{array}$ & $\begin{array}{l}1.0699 \\
1.0734\end{array}$ \\
\hline $\begin{array}{l}\text { Agricultural } \\
1970 \\
1985\end{array}$ & $\begin{array}{l}1 \text { and indus } \\
-3.3440 \\
-3.6090\end{array}$ & $\begin{array}{l}\text { strial machir } \\
-5.2030 \\
-11.1452\end{array}$ & $\begin{array}{r}\text { ry } \\
-5.0603 \\
-3.0139\end{array}$ & $\begin{array}{l}-1.0547 \\
-1.7432\end{array}$ & $\begin{array}{l}1.5813 \\
1.4037\end{array}$ & $\begin{array}{l}5.0817 \\
5.7206\end{array}$ \\
\hline $\begin{array}{l}\text { Office and d } \\
1970 \\
1985\end{array}$ & $\begin{array}{l}\text { data process } \\
-4.9006 \\
-10.2309\end{array}$ & $\begin{array}{l}\text { sing machin } \\
-4.2243 \\
-3.1860\end{array}$ & $\begin{array}{l}\text { precision } \\
-1.6851 \\
-1.4807\end{array}$ & $\begin{array}{l}\text { ad optical i } \\
-1.2551 \\
-3.6662\end{array}$ & $\begin{array}{l}\text { struments } \\
1.8847 \\
3.0447\end{array}$ & $\begin{array}{l}2.4186 \\
2.1285\end{array}$ \\
\hline $\begin{array}{l}\text { Electrical go } \\
1970 \\
1985\end{array}$ & $\begin{array}{l}\text { oods } \\
-2.4670 \\
-2.5798\end{array}$ & $\begin{array}{l}-1.6889 \\
-1.8974\end{array}$ & $\begin{array}{l}-0.9071 \\
-0.7458\end{array}$ & $\begin{array}{l}-0.2855 \\
-0.6048\end{array}$ & $\begin{array}{l}0.9711 \\
0.9702\end{array}$ & $\begin{array}{l}1.0446 \\
1.0452\end{array}$ \\
\hline $\begin{array}{l}\text { Transport eq } \\
1970 \\
1985\end{array}$ & $\begin{array}{l}\text { quipment } \\
-11.5975 \\
-19.1252\end{array}$ & $\begin{array}{l}-2.7741 \\
-3.5440\end{array}$ & $\begin{array}{l}-0.6087 \\
-0.4339\end{array}$ & $\begin{array}{l}0.8590 \\
0.7036\end{array}$ & $\begin{array}{l}0.8874 \\
0.8216\end{array}$ & $\begin{array}{l}1.1450 \\
1.1539\end{array}$ \\
\hline $\begin{array}{l}\text { Food, bevera } \\
1970 \\
1985\end{array}$ & $\begin{array}{l}\text {.ges and to } \\
-5.9034 \\
-7.5431\end{array}$ & $\begin{array}{l}\text { bacco } \\
6.2780 \\
-6.5825\end{array}$ & $\begin{array}{l}-0.2690 \\
-0.1997\end{array}$ & $\begin{array}{l}-1.1252 \\
-2.6071\end{array}$ & $\begin{array}{l}0.9462 \\
0.9184\end{array}$ & $\begin{array}{l}1.0240 \\
1.0240\end{array}$ \\
\hline $\begin{array}{l}\text { Textiles and } \\
1970 \\
1985\end{array}$ & $\begin{array}{l}\text { clothing, } 1 \\
-6.3865 \\
-6.3296\end{array}$ & $\begin{array}{l}\text { eather and f } \\
-2.3859 \\
-3.3465\end{array}$ & $\begin{array}{l}\text { otwear } \\
-0.5080 \\
-0.3885\end{array}$ & $\begin{array}{l}-0.9479 \\
-1.2726\end{array}$ & $\begin{array}{l}0.9980 \\
0.9984\end{array}$ & $\begin{array}{l}1.0372 \\
1.0457\end{array}$ \\
\hline $\begin{array}{l}\text { Paper and p } \\
1970 \\
1985\end{array}$ & $\begin{array}{l}\text { orinting pro } \\
-3.8620 \\
-4.0605\end{array}$ & $\begin{array}{l}\text { xlucts } \\
-1.8165 \\
-2.0699\end{array}$ & $\begin{array}{l}-0.7558 \\
-0.6331\end{array}$ & $\begin{array}{l}-0.2926 \\
-0.5854\end{array}$ & $\begin{array}{l}1.0573 \\
1.0585\end{array}$ & $\begin{array}{l}0.9949 \\
0.9947\end{array}$ \\
\hline $\begin{array}{l}\text { Rubber and } \\
1970 \\
1985\end{array}$ & $\begin{array}{l}\text { plastic pro } \\
-3.3968 \\
-3.6787\end{array}$ & $\begin{array}{l}\text { ducts } \\
-1.4149 \\
-1.6778\end{array}$ & $\begin{array}{l}-0.7441 \\
-0.5275\end{array}$ & $\begin{array}{l}-0.5438 \\
-1.3579\end{array}$ & $\begin{array}{l}1.1417 \\
1.1553\end{array}$ & $\begin{array}{l}0.8745 \\
0.8665\end{array}$ \\
\hline $\begin{array}{l}\text { Other manus } \\
1970 \\
1985\end{array}$ & $\begin{array}{l}\text { Ifacturing p } \\
-3.5565 \\
-3.5881\end{array}$ & $\begin{array}{r}\text { roducts } \\
-1.7098 \\
-2.1151\end{array}$ & $\begin{array}{l}-0.7474 \\
-0.5973\end{array}$ & $\begin{array}{l}-0.2404 \\
-0.5230\end{array}$ & $\begin{array}{l}0.9501 \\
0.9534\end{array}$ & $\begin{array}{l}0.9785 \\
0.9764\end{array}$ \\
\hline
\end{tabular}


Table 6.14 Estimation results for manufacturing sectors: France

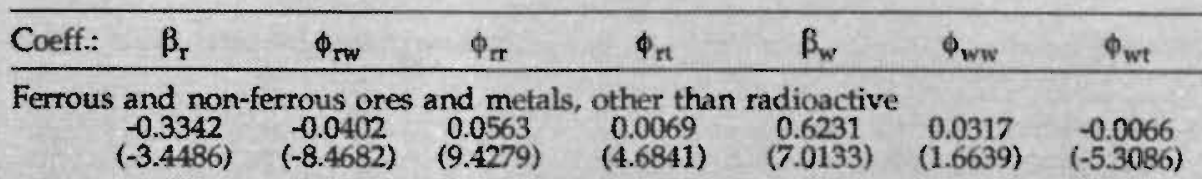

Non-metallic minerals and mineral products
$-0.4663$
$-0.0690$
0.0696
0.0094
1.0823
$0.0643-0.0111$
$(-2.3149)$
$(-5.6972) \quad(3.8577)$
$(3.0921)$
(7.4303)
(2.9505) $\quad(-5.1449)$

Chemical products

$\begin{array}{ccccccc}-0.1470 & -0.0441 & 0.0507 & 0.0044 & 0.8019 & 0.0528 & -0.0081 \\ (-1.6964) & (-5.0899) & (4.9478) & (3.3921) & (6.0354) & (3.4975) & (-4.6867)\end{array}$

Metal products, except machinery and transport equipment
$-0.2877 \quad-0.0604$
$(-4.8215)$
$(-4.7514)$
0.0619
0.0064
1.1290
(7.9991)
(8.4197)
$0.0348 \quad-0.0115$
$(2.4669) \quad(-5.7581)$

Agriculturai and industrial machinery
$-0.1374$
$\begin{array}{ll}-0.0412 & 0.0397\end{array}$
0.0039
1.0509
$0.0195-0.0104$
$\begin{array}{llll}(-1.2643) & (-7.7482) & (6.5873)\end{array}$
$\begin{array}{lll}(2.4962) & (10.2174) \quad(2.3201)\end{array}$
$(-7.0307)$

Office and data processing machines, precision and optical instruments $\begin{array}{cccccccc}-0.8100 & -0.0497 & 0.0980 & 0.0151 & 0.9615 & 0.0468 & -0.0086 \\ (-9.3743) & (-5.1793) & (11.4083) & (12.0021) & (5.8871) & (1.6259) & (-4.5573)\end{array}$

Electrical goods

$\begin{array}{ccccccc}-0.6476 & -0.0429 & 0.0625 & 0.0110 & 0.8366 & 0.0246 & -0.0071 \\ (-4.8080) & (-6.9156) & (6.3118) & (5.4161) & (6.6782) & (1.8383) & (-3.7676)\end{array}$

Transport equipment
$\begin{array}{cc}-0.2517 & -0.0321 \\ (-3.7483) & (-3.2543)\end{array}$
$(-3.7483) \quad(-3.2543)$
0.0333
$\begin{array}{cccc}0.0044 & 0.8478 & 0.0118 & -0.0078 \\ (4.8651) & (7.6775) & (0.2402) & (-3.5879)\end{array}$

Food, beverages and tobacco
$\begin{array}{cc}-0.1887 & -0.0485 \\ (-2.2411) & (-4.4730)\end{array}$
$0.0455 \quad 0.0048$
0.5264
$0.0454 \quad-0.0057$
$(4.4106) \quad(3.5260)$
(5.0597)
$(3.9159) \quad(-3.7700)$

Textiles ancl clothing, leather and footwear
$-0.3632$
$-0.0447$
$0.0448 \quad 0.0066$
$\begin{array}{lll}(6.3038) & (7.0715) & (6.5518)\end{array}$
0.6376
0.0367
$(1.5405)$
$-0.0051$
$(-5.3745) \quad(-3.7551)$
$(1.5405) \quad(-3.9066)$

Paper and printing products
$\begin{array}{lll}-0.2511 & -0.0472\end{array}$
$(-4.5968) \quad(-7.5926)$
$0.0412 \quad 0.0052$
0.6562
$0.0307-0.0059$
$\begin{array}{ll}(10.4751) & (6.2955)\end{array}$
(5.2629)
(1.5554) (-3.1453)

Rubber and plastic products
$\begin{array}{ll}-0.2711 & -0.0538 \\ (-4.5378) & (-6.0052)\end{array}$
0.0655
0.0062
$(7.3825)$
0.9960
0.0617
$-0.0094$
(10.8408)
(7.5759)
$(6.2908) \quad(-5.1067)$

Other manufacturing products

$\begin{array}{ccccccc}-0.6479 & -0.0549 & 0.0649 & 0.0112 & 0.5573 & 0.0600 & -0.0043 \\ (-7.2983) & (-7.2545) & (9.1294) & (8.3314) & (4.5511) & (3.8276) & (-2.3090)\end{array}$

Note: t-values between brackets 
Table 6.15 Summary of technical progress biases: France

Industry

Ferrous and non-ferrous ores and metals, other than radioactive

Non-metallic minerals and mineral products

Chemical products

Metal products, except machinery and transport equipment

Agricultural and industrial machinery

Office and data processing machines, precision and optical instruments

Electrical goods

Transport equipment

Food, beverages and tobacco

Textiles and clothing, leather and footwear

Paper and printing products

Rubber and plastic products

Other manufacturing products

Note: $\begin{aligned} \mathrm{K} & =\text { capital, } \mathrm{L}=\text { labour, } \mathrm{X}=\text { intermediates. } \\ & +=\text { input-using, }-=\text { input-saving, } 0=\text { input-neutral }\end{aligned}$

$\begin{aligned} \text { Note: } & \mathrm{K}=\text { capital, } \mathrm{L}=\text { labour, } \mathrm{X}=\text { intermediates. } \\ & +=\text { input-using, }-=\text { input-saving, } 0=\text { input-neutral }\end{aligned}$
$\underset{K}{\text { Nature of bias for production factor: }}$

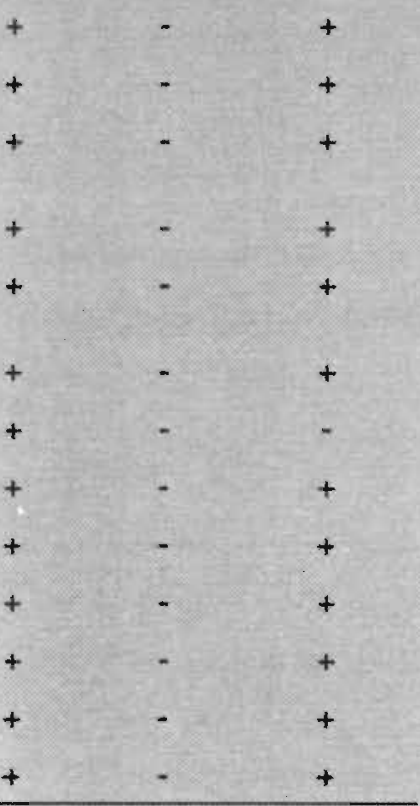


Table 6.16 Estimated values of the Allen-Uzawa elasticities of substitution, 1970 and 1985: France

\begin{tabular}{llllllll}
\hline & $\sigma_{\mathrm{rr}}$ & $\sigma_{w w}$ & $\sigma_{\mathrm{qq}}$ & $\sigma_{\mathrm{rw}}$ & $\sigma_{\mathrm{rq}}$ & $\sigma_{\mathrm{wq}}$ \\
\hline Ferrous and non-ferrous & ores and metals, other than radioactive & \\
1970 & -3.2133 & -4.0683 & -0.4196 & -0.7530 & 0.8419 & 1.0773 \\
1985 & -2.6986 & -3.5686 & -0.3379 & -1.7931 & 0.7285 & 1.0636
\end{tabular}

Non-metallic minerals and mineral products

$\begin{array}{lllllll}1970 & -2.3181 & -1.5854 & -1.0077 & -0.1753 & 0.9942 & 1.0312 \\ 1985 & -2.5454 & -1.6131 & -0.8598 & -0.4598 & 0.9934 & 1.0293\end{array}$

Chemical products

$\begin{array}{lllllll}1970 & -3.2223 & -2.3234 & -0.6129 & -0.1625 & 0.9329 & 0.9380 \\ 1985 & -3.9198 & -2.7470 & -0.3971 & -1.1504 & 0.9105 & 0.9359\end{array}$

Metal products, except machinery and transport equipment

$\begin{array}{lllllll}1970 & -2.8297 & -1.7799 & -1.0173 & -0.1749 & 0.9827 & 1.1543 \\ 1985 & -3.0245 & -1.7671 & -0.8590 & -0.6101 & 0.9780 & 1.1419\end{array}$

Agricultural and industrial machinery

$\begin{array}{lllllll}1970 & -4.3552 & -2.0142 & -0.8609 & -0.0227 & 1.0207 & 1.1244 \\ 1985 & -5.2027 & -1.9883 & -0.7442 & -0.4485 & 1.0277 & 1.1158\end{array}$

Office and data processing machines, precision and optical instruments

$\begin{array}{lllllll}1970 & -1.4498 & -1.4457 & -1.2153 & 0.4279 & 0.5073 & 1.0205 \\ 1985 & -1.5212 & -1.6897 & -0.9472 & 0.2864 & 0.5261 & 1.0198\end{array}$

Electrical goods

$\begin{array}{lllllll}1970 & -2.9872 & -1.7492 & -0.8330 & -0.0746 & 0.6963 & 1.1000 \\ 1985 & -2.9994 & -1.6382 & -0.9087 & 0.0235 & 0.6995 & 1.0996\end{array}$

Transport equipment

$\begin{array}{lllllll}1970 & -6.1292 & -2.1473 & -0.6086 & -0.9397 & 0.9675 & 1.1039 \\ 1985 & -6.4547 & -2.5723 & -0.5329 & -0.9523 & 0.9709 & 1.1131\end{array}$

Food, beverages and tobacco

$\begin{array}{lllllll}1970 & -3.6615 & -4.1427 & -0.3840 & -1.6593 & 1.0279 & 1.0347 \\ 1985 & -3.9865 & -3.6624 & -0.4010 & -1.4815 & 1.0322 & 1.0288\end{array}$

Textiles and clothing, leather and footwear

$\begin{array}{lllllll}1970 & -4.5196 & -2.0741 & 0.6413 & -0.5778 & 0.9974 & 1.0454 \\ 1985 & -4.4160 & -2.0705 & -0.6647 & -0.4569 & 0.9976 & 1.0460\end{array}$

Paper and printing products

$\begin{array}{lllllll}1970 & -4.5762 & -2.5437 & -0.6233 & -0.6615 & 1.0817 & 1.1050 \\ 1985 & -4.7513 & -2.3149 & -0.6539 & -0.6597 & 1.0898 & 1.0989\end{array}$

Rubber and plastic products

$\begin{array}{lllllll}1970 & -2.7233 & -1.4843 & -0.8555 & -0.0615 & 0.8535 & 0.9531 \\ 1985 & -2.6203 & -1.7434 & -0.5933 & -0.7590 & 0.8186 & 0.9542\end{array}$

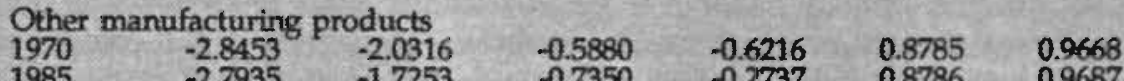

$\begin{array}{lllllll}1970 & -2.8453 & -2.0316 & -0.5880 & -0.6216 & 0.8785 & 0.9668 \\ 1985 & -2.7935 & -1.7253 & 0.7350 & -0.2737 & 0.8786 & 0.9687\end{array}$


studies based on other static models. In the cases where we found positive own elasticities of substitution, we imposed concavity using the Bramble, Schmidt and Wiley technique. Note also, that we find that the own elasticity of substitution of intermediates is generally quite low in all sectors. Thus, we find that intermediates are not particularly sensitive to changes in prices in the majority of sectors. This low price sensitivity of intermediates is in agreement with the findings of other empirical studies (see, e.g., Dargay (1988)).

If we compare the own substitution elasticities of labour and capital, we find that the AUES for capital are larger (in absolute terms) than those for labour in the majority of cases. This also happens to be true for the own price elasticities of capital and labour. The low value of the own elasticities for labour, which is also documented in several other studies, might reflect an aggregation bias, since we treated labour as a homogeneous factor. In case we could have distinguished more types of labour (skilled, unskilled) the values of the corresponding elasticities might well turn out to be higher.

As far as the cross-elasticities of substitution are concerned, we find that most of these partial elasticities between capital and intermediates and between labour and intermediates are positive, indicating that these pairs of production factors are substitutes in all cases. Note, however, also that in a large number of cases, the values of the cross-elasticities of substitution is rather low, in many sases in the vicinity of 1 . This indicates the existence of but weak substitution possibilities between pairs of factors.

As far as the substitution possibilities between capital and labour are concerned, we evidence of complementarity between these two factors of production in all sectors. The finding that capital and labour are complements is remarkable, indeed, since it runs counter to many economists' intuition. However, it is well in accordance with Nakamura's (1984, pp. 210-212) above mentioned study. He finds evidence of complementarity in 10 out of 12 industries in his sample, substitutability between capital and labour in only one sector, and a sign reversal in one sector as well. Admitting that capitallabour complementarity might seem unusual, Nakamura remarks that similar findings have been made by several other authors for Japanese and German industrial sectors. Capital-labour complementarity therefore seems to be a quite normal finding of sectoral production and cost function studies (most notably in the so-called KLEMS studies). Furthermore, the finding that capital and labour are complements rather than substitutes can be given some degree of plausibility by the following considerations. First of all, one should bear in mind that we are estimating a short-run production model. As is well-known, substitution possibilities between capital and labour might be rather low in the short run. Secondly, we do not distinguish between different types of labour and our finding of K-L complementarity might reflect the existence of an aggregation bias. In the applied econometric literature complementarity between skilled labour and capital is an unusual phenomenon. Note also, that capital need not be homogenous. In many studies the production factor capital is split up into equipment on the one hand and structures on the other. Thirdly and finally, K-L complementarity can be reconciled with our results on the biases of technical change. Strong K-using and Lsaving biases in technical change imply that, given the prices of capital and labour, K-L ratios will increase in the course of time as a result of this technical change. Since the price of labour increased relative to the price of capital in all industries during the estimation period, it is not surprising at all that we find evidence of K-L complementarity. Additionally, the increase in the relative price of labour may have induced the observed pattern of technical change, and may well have lead to a substitution of capital for labour through an influence on the nature of technical change. Thus, the effects of technical change biases on the $\mathrm{K}-\mathrm{L}$ ratio seems to be quantitatively much more important 
than the technical K-L complementarity. Fourthly, even though one might find K-L substitution in a two-factor model, this does not necessarily imply the same when more factors of production are considered jointly. Fifthly, we should admit that admit that the parameters and AUES of our empirical model are based on a theoretical model derived from static equilibrium theory. This implies that the dynamics of the adjustment proces cannot be discussed at all. In other words, we are not able to say something about the price sensitivity of factor demand and the substitution relationships in different time perspectives. Using static equilibrium models implies that one takes the adjustment process for granted in that adjustment to price or output changes is more or less instantaneous and costless. Thus it is hard, if not impossible, to distinguish between short- and long-run responses. Assuming that firms can switch from one technique to another without time delays or costs is, needless to say, particularly problematic in the case of physical capital, for instance, machinery. As is well known, capital cannot be replaced immediately, and frequently there is a large delay before an investment results in productive use of capital goods. In one would be able to take the peculiarities of the adjustment process into account, one might find that capital and labour are substitutes in the long run (see in this vein, Dargay (1988), chapter 6).

We now turn to a discussion of the results for the remaining countries, notably Italy, Belgium, The Netherlands and France. Note that the parameter estimates are in general quite satisfactory. Also, closer inspection of the results reveals some interesting similarities between all countries. It turns out, firstly, that the pattern of technical change is almost identical in all countries. We find K-using and L-saving biases in the vast majority of cases. Secondly, we find evidence of K-L complementarity for almost all sectors in all countries. In Belgium, this tendency towards K-L complementarity is less pronounced, since the results for this country show several sign reversals. In Italy, three out of twelve sectors exhibit K-L substitutability. However, one might safely conclude that in these country, as in the others, the trend in K-L elasticities of substitution is one in the direction of increasing "complementarisation" as time elapses.

\subsection{Conclusions}

The estimation of the parameters of our production model for the Nace-R25 manufacturing sectors of the five most important founding fathers of the EC has given us quite a plausible description of the production technology in these countries. We have achieved these results by estimating translog unit cost functions. The vast majority of AllenUzawa own elasticities substitution elasticities turned out to be negative, which is in accordance with economic theory. Occasionally, we found evidence of non-concavity of the cost function, but we were able to correct for this, at least locally. Our results seemed to imply that capital and labour are complements in the majority of cases. Capital and intermediate inputs turned out to be substitutes, as were labour and intermediate inputs. We also found evidence of capital-using and labour-saving biases in technical change for the majority of cases. Technical change was also predominantly intermediate-using.

Needless to say, our results may be vulnerable to criticism on a number of grounds. The model that we estimated is a static equilibrium model, which does not take into account the existence of adjustment costs and time lags. Also, we assume homogeneous capital, which takes the form of "jelly". In addition, we did not distinguish between various types of labour. We did not take into account the existence of a non-traded 
goods sector. ${ }^{9}$ Nevertheless, we believe that our results are a fully acceptable description of technology, and provide, at least as an approximation, plausible estimates for the elasticities of substitution. The latter will be used in the next chapter for simulation purposes.

${ }^{9}$ Woxdland (1988) has shown how the effects of a non-traded goods sector may be "netted out" of the model. 


\section{CHAPTER}

7

\section{TWO SIMULATION EXPERIMENTS}

\subsection{Introduction}

This chapter's primary purpose is to simulate the wage effects of the internal trade policies of the European Community. The analysis will make use of the model that was developed in the previous chapters, and is based on the parameters that were estimated in the last chapter. The model is used to simulate the wage effects of the creation of the European Community for the EC-5 region.

Two simulation experiments will be conducted in this chapter. First of all, we shall discuss the effects of the formation of the customs union in 1968. This experiment involves an exercise with the internal liberalisation of trade and the (external) imposition of the common external tariff in the customs union. The distributional effects of the customs union will be simulated using the pre-1968 tariff rates in the various branches of industry. In the simulation exercise, we shall assume that the Member States abolish the customs union in 1970 and re-implement the pre-union 1959 trade policies. Second, we shall discuss the distributional effects of the programme to complete the internal market in 1992. These effects are determined using tariff equivalents of the most important nontariff barriers distinguished in the 1992 programme. The analysis of both the simulation of the imposition of the common external tariff as well as the simulation concerning the achievement of the internal market, are concerned with the static effects of the trade policy changes.

The plan for the chapter is as follows. We start with a discussion of the importance and magnitude of trade barriers in the founding countries of the EC (section 7.2). The 1958 tariff barriers in the various sectors of industry will be quantified, as well as the non-tariff barriers that existed in the 1980s. Subsequently, simulation methodologies which have surfaced in the empirical literature and which will serve as our example will pass in review. Sections 7.3 and 7.4 contain a discussion of the above-mentioned simulation experiments. Finally, in section 7.5 we try to evaluate the plausibility of our findings. The concluding remarks follow in section 7.7. 


\subsection{Tariff and non-tariff barriers in the EC, 1958-1992}

\subsubsection{Tariffs and the creation of the customs union}

The level of tariffs imposed by different countries might be compared by simple calculation of ad valorem tariff rates for each industrial branch and each country under consideration. However, the most important problem with the calculation of these ad valorem tariff rates is the incompatibility of pre-union national tariff schedules, which employed different international trade nomenclatures and in which also some duties tended to be expressed in specific or physical terms. Hence, comparison of tariff rates must be restricted to those commodities which may be identified easily and which were in addition to that consistently classified.

Specific duties are usually converted to ad valorem rates by relating total tariff revenue in the sector under consideration to the total c.i.f. value of imports in that sector. In theory, this should not lead to distorted ad valorem rates. The calculation of industry averages of ad valorem rates is, however, extremely difficult. When highly aggregated industry classifications like the NACE-R25 nomenclature are used, problems of aggregation are likely to arise, since the average tariff of a sector is usually obtained as a weighted average of the desaggregated sectoral tariffs. When the tariffs are completely prohibitive, the corresponding weight of a sub-sector will be zero, causing an underestimation of the true preferential impact of the aggregated tariff rate. Obviously, this problem could be overcome by calculating unweighed tariffs, but that procedure tends to give unfair weights to extremes as well as to relatively unimportant sectors.

The above goes to show that various factors will influence the comparability and calculation of NACE-Clio tariff rates, especially average tariffs. The process of the combining of the tariffs of sub-sectors will produce averaging and weighting problems which are very difficult to solve the wider and broader the list of goods that must be combined.

The EC's common external tariff (CET) was calculated as an unweighed average of member states' tariffs on various products. During the transition period, which started in 1960 and which formally ended in 1970, external and internal tariffs were adjusted simultaneously, be it at a different pace. Thus the trade preferences conveyed by the tariffs varied considerably during the transition period. The elimination of tariffs vis-avis partner countries started in July 1960, and the adjustment of external tariffs to the level of the CET started in 1963.

For estimates of tariff rates we based ourselves on El-Agraa (1980). From this source we derived data on nominal tariffs for sectors. Table 7.1 (column 1) lists for each EC-5 country the nominal tariff rates for final products. As a comparison between these countries reveals a well-known fact, notably that France and Italy were basically tariff-ridden economies, whereas the Benelux countries and Germany might be characterised as tariff-shy. The elimination of internal tariffs therefore implied that the latter countries were given larger preferences than the former. On the other hand, the Benelux and Germany were obliged to raise their external tariffs vis-a-vis the outside world considerably, on average some twenty per cent. The approximation of external tariffs to the CET was, however, at the same time accompanied by a twenty per cent reduction through the GATT Kennedy Round negotiations of 1960-62. In 1963, the reduction in internal tariffs roughly matched the approximation to this GATT negotiated newly imposed external tariff in these countries. The entire operation of eliminating internal tariffs and fully approximating to the CET was completed on July 1, 1968, one and a half year ahead of schedule. 
Table 7.1 Average ad-valorem (equivalents of) tariff barriers (1958) in the industrial sectors of the EC (NACE-R25), effective rates of protection, CET and value shares

\section{$(1)^{1}$}
(2)
(3)
(4)
(5)
$(6)^{2)}$

13 Ferrous and non-ferrous ores and metals, other than radioactive

15 Non-metallic minerals and mineral products

17 Chemical products

19 Metal products, except machinery and transport equipment

21 Agricultural and industrial machinery

23 Office and dataprocessing machines, precision and optical instruments

25 Electrical goods

28 Transport equipment

29 Food, beverages and tobacco

42 Textiles and clothing, leather and footwear

47 Paper and printing products

$\begin{array}{rcrrrr}9.0 & 14.1 & 7.0 & 0.72 & 0.36 & 9.4 \\ 12.0 & 17.6 & 4.9 & 0.44 & 0.66 & 11.0 \\ 7.0 & 8.9^{3)} & 5.2 & 0.52 & 0.69 & 9.6\end{array}$

$\begin{array}{llllll}11.0 & 18.0 & 2.8 & 0.46 & 0.85 & 128\end{array}$

$\begin{array}{llllll}8.0 & 11.3 & 4.8 & 0.51 & 0.66 & 10.2\end{array}$

$\begin{array}{llllll}11.0 & 16.0 & 3.2 & 0.39 & 0.58 & 11.4\end{array}$

$\begin{array}{llllll}11.0 & 16.2 & 5.6 & 0.49 & 0.78 & 11.4\end{array}$

$\begin{array}{lllllll}17.0 & 21.8 & 15.0 & 0.71 & 0.84 & 18.4\end{array}$

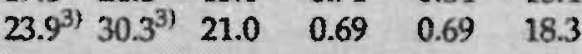

49 Rubber and plastic products

$\begin{array}{rrrrrr}18.5 & 31.8 & 8.9 & 0.58 & 0.84 & 13.9 \\ 14.0 & 14.7 & 13.5 & 0.57 & 0.59 & 11.2 \\ 17.0 & 30.4 & 3.1 & 0.49 & 0.85 & 12.6\end{array}$

\section{GERMANY}
$(1)^{1)}$
(2)
(3)
(4)
(5)
$(6)^{2)}$

13 Ferrous and non-ferrous ores and metals, other than radioactive

15 Non-metallic minerals and mineral products

17 Chemical products

19 Metal products, except machinery and transport equipment

21 Agricultural and industrial machinery

23 Office and dataprocessing machines, precision and optical instruments

25 Electrical goods

28 Transport equipment

29 Food, beverages and tobacco

42 Textiles and clothing, leather and footwear

47 Paper and printing products

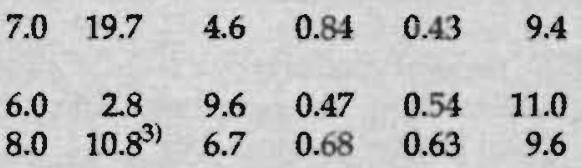

49 Rubber and plastic products

$\begin{array}{rrrrrr}6.0 & 7.5 & 3.8 & 0.40 & 0.51 & 11.4 \\ 6.0 & 9.2 & 2.8 & 0.50 & 0.62 & 11.4 \\ 12.0 & 17.3 & 9.0 & 0.64 & 0.56 & 18.4 \\ 14.9^{3)} & 19.4^{3)} & 12.6 & 0.66 & 0.49 & 18.3 \\ & & & & & \\ 11.5 & 15.5 & 8.2 & 0.55 & 0.56 & 13.9 \\ 8.0 & 7.7 & 8.2 & 0.60 & 0.32 & 11.2 \\ 10.0 & 121 & 7.8 & 0.49 & 0.68 & 12.6\end{array}$


Table 7.1

(Continued)

FRANCE

$\begin{array}{llllll}(1)^{1)} & \text { (2) } & \text { (3) } & \text { (4) } & \text { (5) } & \left.(6)^{2}\right)\end{array}$

13 Ferrous and non-ferrous ores and metals, other than radioactive

15 Non-metallic minerals and mineral products

17 Chemical products

19 Metal products, except machinery and transport equipment

21 Agricultural and industrial machinery

23 Office and dataprocessing machines, precision and optical instruments

25 Blectrical goods

28 Transport equipment

29 Food, beverages and tobacco

42 Textiles and clothing, leather and footwear

47 Paper and printing products

49 Rubber and plastic products

$\begin{array}{llllll}14.0 & 8.1 & 16.6 & 0.69 & 0.51 & 9.4\end{array}$

$\begin{array}{llllll}16.0 & 21.6 & 10.4 & 0.50 & 0.59 & 11.0\end{array}$

$\begin{array}{llllll}16.0 & 20.1^{3)} & 13.3 & 0.60 & 0.62 & 9.6\end{array}$

$\begin{array}{llllll}20.0 & 37.2 & 4.1 & 0.52 & 0.75 & 12.8\end{array}$

$\begin{array}{llllll}18.0 & 36.7 & 3.3 & 0.56 & 0.65 & 10.2\end{array}$

$\begin{array}{llllll}19.0 & 32.7 & 3.3 & 0.40 & 0.49 & 11.4\end{array}$

$\begin{array}{lllllll}19.0 & 31.5 & 8.4 & 0.54 & 0.62 & 11.4\end{array}$

$\begin{array}{llllll}29.0 & 54.9 & 14.4 & 0.64 & 0.83 & 18.4\end{array}$

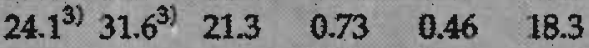

$\begin{array}{llllll}18.5 & 31.9 & 10.3 & 0.62 & 0.67 & 13.9\end{array}$

$\begin{array}{rrrrrr}16.0 & 20.6 & 13.4 & 0.64 & 0.43 & 11.2\end{array}$

$\begin{array}{llllll}17.0 & 34.8 & 0.6 & 0.52 & 0.65 & 12.6\end{array}$

ITALY

$(1)^{13} \quad(2) \quad(3) \quad$ (4) $\quad$ (5) $\quad(6)^{2}$

13 Ferrous and non-ferrous ores and metals, other than radioactive

15 Non-metallic minerals and mineral products

17 Chemical products

19 Metal products, except machinery and transport equipment

21 Agricultural and industrial machinery

23 Office and dataprocessing machines, precision and optical instruments

25 Electrical goods

28 Transport equipment

29 Food, beverages and tobacco

42 Textiles and clothing, leather and footwear

47 Paper and printing products

49 Rubber and plastic products

\begin{tabular}{rrrrrr}
17.0 & 26.5 & 10.4 & 0.59 & 0.35 & 9.4 \\
\hline 21.0 & 35.0 & 3.2 & 0.44 & 0.49 & 11.0 \\
17.0 & $22.1^{3)}$ & 13.9 & 0.62 & 0.63 & 9.6 \\
\hline 23.0 & 41.0 & 3.5 & 0.48 & 0.66 & 12.8 \\
\hline 20.0 & 31.5 & 12.3 & 0.60 & 0.62 & 10.2 \\
\hline 21.0 & 31.5 & 7.6 & 0.44 & 0.53 & 11.4 \\
21.0 & 36.2 & 8.1 & 0.54 & 0.62 & 11.4 \\
34.0 & 57.2 & 18.5 & 0.60 & 0.89 & 18.4 \\
$27.3^{3}$ & $35.5^{3}$ & 24.1 & 0.72 & 0.51 & 18.3 \\
21.0 & 18.3 & 22.8 & 0.60 & 0.45 & 13.9 \\
18.0 & 18.4 & 17.7 & 0.59 & 0.21 & 11.2 \\
19.0 & 34.5 & 5.8 & 0.54 & 0.71 & 12.6
\end{tabular}




\section{THE NETHERLANDS}
(1)
(2)
(3)
(4)
(5)
$(6)^{2)}$

13 Ferrous and non-ferrous ores and metals, other than radioactive

15 Non-metallic minerals and mineral products

17 Chemical products

19 Metal products, except machinery and transport equipment

$\begin{array}{llllll}9.0 & 19.3 & 3.0 & 0.63 & 0.68 & 9.4\end{array}$

21 Agricultural and industrial machinery

23 Office and dataprocessing machines, precision and optical instruments

25 Electrical goods

28 Transport equipment

29 Food, beverages and tobacco

42 Textiles and clothing, leather and footwear

47 Paper and printing products

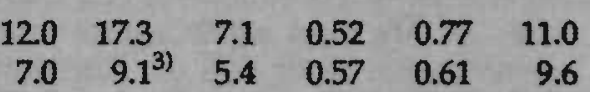

$11.0 \quad 14.9$

7.5

$\begin{array}{lll}0.53 & 0.79 & 12.8\end{array}$

8.013 .5

1.8

0.47

$0.66 \quad 10.2$

$\begin{array}{llrlll}11.0 & 23.0 & 1.9 & 0.57 & 0.48 & 11.4 \\ 11.0 & 12.7 & 9.5 & 0.53 & 0.70 & 11.4 \\ 17.0 & 21.2 & 14.6 & 0.64 & 0.83 & 18.4 \\ 24.0^{3} & 31.6^{37} & 21.9 & 0.79 & 0.64 & 18.3 \\ 18.5 & 33.2 & 11.3 & 0.67 & 0.81 & 13.9 \\ 14.0 & 19.5 & 9.9 & 0.57 & 0.46 & 11.2 \\ 17.0 & 19.8 & 14.8 & 0.56 & 0.78 & 12.6\end{array}$

49 Rubber and plastic products

1) The columns refer to the following information:

(1) Nominal tariffs;

(2) Effective rates of protection;

(3) Nominal tariffs on intermediate goods;

(4) Share of intermediates in the production (1959);

(5) Share of EC-5 imports (1970);

(6) Cammon External Tariff.

2) Calculated as the unweighed average of country tariff rates, minus $20 \%$ Kennedy Round reductions in tariffs.

3) Estimate; based on information from Deardorf and Stern (1990) and Laird and Yeats (1990).

Source; A.M. E1-Agraa (1980), p. 65, Balassa, (1966), p. 762-63, Eurostat, InputOutput Tables for 1959 and 1970 , and own calculations.

Table 7.1 also reveals data on effective rates of protection (column 2). This information was taken from Balassa's (1967) study on nominal tariffs and effective rates of protection (ERP) in 1959 for the Common Market countries. ${ }^{1}$ We required the information

1 We made certain corrections to Balassa's data due to apparent inconsistencies in his material. First of all, Balassa's data on nominal tariff rates show a considerable variation for the BENELUX countries. This is a most peculiar finding, since these countries had established a customs union already as early as 1948 and were supposed to have identical tariffs. Therefore, we did not use Balassa's estimates of these tariff rates and had to avail of El-Agraa's (1980) 
on effective rates of protection to calculate the nominal tariffs on intermediate inputs. Since Balassa's effective rates of protection were based on Eurostat's first (1959) series of Input-Output Tables for the EC-5 region, we were able to use the input-output coefficients from these tables to calculate nominal tariff rates on intermediate inputs. We obtained these nominal tariffs on intermediate inputs using the well-known formula for the ERP (see, e.g., Lindert (1986)), i.e.,

$$
\operatorname{ERP}_{\mathrm{i}}=\frac{t_{i}-\Sigma a_{i j} t_{j}}{1-\Sigma a_{i j}}
$$

in which: $\mathrm{ERP}_{\mathrm{i}}=$ effective rate of protection in sector $i, \mathrm{t}_{\mathrm{i}}=$ nominal tariff on sector $i$ goods, $\mathrm{t}_{\mathrm{j}}=$ nominal tariff on intermediate input from sector $j$, and, finally, $\mathrm{a}_{\mathrm{ij}}$ is an input-output coefficient that represents the value added share of intermediate input $j$ in sector $i$. We used the Input-Output Tables to obtain information about $\mathrm{a}_{\mathrm{ij}}$ and were thus able to obtain estimates of $t_{j}$. Obviously, all the usual qualifications and criticisms apply to the use of the above formula for effective protection, most notably the criticism that the assumption of fixed input-output coefficients for situations of both protection and trade is not particularly realistic. This is an assumption that leads to an unpredictable bias. $^{2}$

Table 7.1 also lists the share of EC-5 imports in each country and the CET for each sector of industry. These data have been included in the table in order to facilitate the interpretation of our simulation results.

The information discussed above confined itself to a presentation of nominal and effective tariffs. Thus, we reduced the establishment of the customs union to a mere exercise in tariff realignments. However, it should be recalled that, during the transition period, tariffs were not the only trade impediment that were removed between Member States. We should mention in particular the removal of internal quota's, which were not compliant with the Rome Treaty. Art. 3, title a, in principle called for the abolition of all customs duties, quantitative restrictions and all trade measures having a similar effect. In our simulation experiments reported below, we were not able to simulate the effects of the abolition of internal quota's, simply because quantitative information on the effects of quota's were not available.

\subsubsection{Non-tariff barriers and the 1992 programme}

Non-tariff barriers (NTBs) may be defined as all government measures not being tariffs and quota's, that affect volume, structure and direction of international trade in goods and services. NTBs may take a host of forms, among others, they usually refer to variable import levies, (in-)voluntary export restraints (VERs), discriminating government procurement policies, countervailing and anti-dumping duties, technical standards, frontier delays, differences in VAT rates, and so on. In the EC, things like quota's and all kinds of import levies have been abolished with the creation of the customs union in the 1960s. However, in 1985, it was realised, that many barriers still existed in the Com-

estimates. Balassa's relationship between ERPs and nominal tariffs was subsequently imposed on El-Agraa's nominal tariffs, which resulted in our own estimates of ERPs. Strange as it may sound, these did not deviate from Balassa's estimates in a large number of cases. Secondly, Balassa's sector classification is more detailed than ours, so we had to calculate average tariffs for a number of sectors.

2 See Balassa (1967), p. 764. 
munity. In that year, the EC Commission published its so-called White Paper "Completing the Internal Market", which contained a list of almost 300 non-tariff barriers to trade. These were considered to be at the basis of the fragmentation of the European market and were held responsible for Europe's losing competitive ground to the Americans and the Japanese. The White Paper particularly emphasised physical barriers (like border controls), fiscal measures (like VAT and excise tax differences), and technical and other regulatory barriers (standards and product testing).

The impact of all barriers distinguished in the White Paper is simply to raise the cost of production of goods and services (intermediate and final) and to restrict the ability of enterprises to compete both internationally and against firms from the EC. With the adoptation of the Single European Act (SEA) in 1987, the first major amendment of the Rome Treaty, the EC adopted a comprehensive plan to do away with the bulk of its non-tariff barriers. The SEA stipulated that the Community should aim to complete the internal market no later than December 31st, 1992.

The EC Commission initiated several studies in which the potential welfare effects of the completion of the internal market have been evaluated, the Cecchini report and the more detailed Emerson report (1988) being the most well-known. The Emerson report primarily discusses microeconomic effects of the completion of the internal market, and makes the familiar distinction between short-term or static (stage 1 and 2) and longterm or dynamic effects (stage 3 and 4).

NTBs may statistically be represented in several forms (see, among others, Laird and Yeats (1990), ch. 2). The usual methodology applied in empirical studies to quantify non-tariff barriers is either coverage ratios or so-called tariff equivalents. ${ }^{3}$ The most important drawback of the use of coverage ratio is their inability to quantify the economic effects of the application of non-tariff barriers. To make these inferences, one will need the price impact of the non-tariff barriers. ${ }^{4}$

Estimates of the price effects of the completion of the internal market programme on a sectoral and country basis are not readily available in the literature. Although many aspects of internal market completion have been discussed at great length in the Studies on the Cost of Non-Europe (CEC, 1988) for individual measures or sectors, a detailed account of expected price changes for all sectors and all countries is lacking. The most complete source in this respect is the Cawley and Davenport (1988) study on the partial equilibrium effects of internal market barriers in the EC, in which an attempt is made to estimate the expected cost reductions due to the internal market programme. Although these authors immediately admit that the use of a partial equilibrium analysis conceals possible spill-overs between sectors and that a general equilibrium approach would therefore be preferable, they were forced to work with a partial equilibrium model for each sector under consideration, since general equilibrium exercises are simply not

${ }^{3}$ Cooerage ratios result from the "inventory approach" to non-tariff barrier measurement. The most notable example of this approach is UNCTAD's Data Base on Trade Measures, which contains detailed information concerning the nature of measures, at who or what it is directed, and as of when it has been in effect.

4 The calculation of tariff equivalents of NTBs is also fraught with many difficulties. Apart from the fact that different definitions and methods are employed by different authors, NTB ad oalorem tariff equivalents seem to be extremely unstable and vary from year to year. A notable example that immediately comes to mind is the textiles and clothing sector, where NTBs have been tightened to a large extent in the last two decades and in which the incidence of NTBs has consequently changed significantly. In addition, several new NTBs have been added to the existing list. 
available in the literature. Cawley and Davenport are also not able to disentangle the interaction effects of all individual barriers which are involved in the 1992 progranume, and therefore acknowledge the possibility of overlaps and double counting. Finally, they distinguish between cost and price reductions. In sectors characterized by significant market imperfections, prices may be expected to fall further than cost reductions, reflecting the reduction in excess profits due to increased technical efficiency and fiercer competition.

Cawley and Davenport present sectoral data on price reductions for the entire Community. They distinguish three stages in the liberalisation process. The first two stages deal with static effects of the internal market, the third with dynamic effects. Below, we shall focus only on the first two stages. ${ }^{5}$ In stage 1 , administrative (border) formalities which result in higher costs for producers, public authorities and consumers are abolished. For firms, these costs, among others, consist of the internal administrative costs borne by importing and exporting firms, which include the staff and the paper work associated with importing and exporting. In addition, firms bear external costs, such as the costs of hiring the services of customs agents. Finally, the loss of time due to delays caused at the borders could also be used more productively and therefore represents forgone revenues. For the governments the costs mainly consist of the resources involved in maintaining and staffing customs posts.

The administrative formalities which are abolished in stage 1 do not only pertain to border formalities, but also include the impact of the abolition of discriminatory government procurement policies on prices. These costs are not confined to the extra outlays that the government or public authorities must make because they do not buy from the cheapest source. They also consist of the static welfare loss which is involved in allowing relatively inefficient firms to survive.

Stage 2 emphasizes the reduction in regulatory activity across the countries of the Community. These differences in regulatory activity, among others, are primarily due to differences in technical standards which also result in higher costs for firms, public authorities and consumers. For firms, variation in technical standards imply that various (unnecessary) duplications in product development will take place, that gains from econornies of scale cannot be realised, and that companies operate from a narrow national rather than European or global base, which makes them vulnerable on the world markets. For governments, the implication of different technical standards are, among others, that certification and testing procedures should be duplicated, and that they frequently do not get the best goods when buying from national producers. For consumers, all this wili result in higher prices as well as losses due to the industries competitive weakness and inefficient structure.

For stage 1, Cawley and Davenport produce two sets of estimates. One set excludes the impact of the reduction in the prices of intermediate goods, the other set includes the effect of the reduction of the price of intermediate goods. The second set is derived using information from Eurostat's Input-Output Tables. The first data set could be regarded as giving nominal tariff equivalents for final goods, whereas the second set could be considered as giving an indication of the effective tariff equivalents of the barriers concerned. We used the share of intermeciliate goods in the final goods to calculate the nominal tariff equivalents for intermediate goods. Thus, we obtained the two series that we shall need for the simulation experiments.

${ }^{5}$ Unfortunately, we were not able to simulate the wage effects of the third stage due to absence of estimated price and cost changes for this stage. 
Table 7.2 Tariff equivalents of 1992 non-tariff barriers on final and intermediate goods, effective tariff equivalents, and value shares

\begin{tabular}{|c|c|c|c|c|c|c|c|c|c|}
\hline & & & & & & LGIUN & & & \\
\hline & & (1) & (2) & (3) & (4) & (5) & (6) & (7) & (8) \\
\hline 13 & $\begin{array}{l}\text { Ferrous and non-ferrous ores and } \\
\text { metals, other than radioactive }\end{array}$ & 0.64 & 0.87 & 0.59 & 0.85 & 154 & 0.69 & 081 & 0.65 \\
\hline 15 & Non-metallic minerals and & & & & & & & & \\
\hline & mineral products & 0.64 & 0.87 & 0.45 & 0.85 & 1.54 & 0.29 & 0.55 & 0.79 \\
\hline 17 & Chemical products & 0.30 & 0.47 & 0.21 & 0.94 & 1.34 & 0.72 & 0.65 & 0.71 \\
\hline 19 & Metal products, except machinery & & & & & & & & \\
\hline & and transport equipment & 0.39 & 0.96 & 0.00 & 0.59 & 2.35 & 0.03 & 0.59 & 0.82 \\
\hline 21 & Agricultural and industrial machinery & y 0.93 & 0.92 & 0.94 & 0.69 & 1.09 & 0.41 & 0.59 & 0.75 \\
\hline 23 & Office and dataprocessing machines, & & & & & & & & \\
\hline & precision and optical instruments & 0.62 & 0.35 & 0.75 & 0.88 & 0.97 & 0.84 & 0.68 & 0.57 \\
\hline 25 & Electrical goods & 0.74 & 0.99 & 0.54 & 1.06 & 1.43 & 0.77 & 0.56 & 0.67 \\
\hline 28 & Transport equipment & 0.16 & 0.64 & 0.00 & 0.57 & 1.50 & 0.24 & 0.74 & 0.66 \\
\hline 29 & Food, beverages and tobacco & 0.76 & 2.03 & 0.34 & 0.99 & 3.10 & 0.29 & 0.75 & 0.72 \\
\hline 42 & Textiles and clothing, & & & & & & & & \\
\hline & leather and footwear & 1.04 & 0.44 & 1.31 & 1.06 & 1.22 & 0.99 & 0.69 & 0.57 \\
\hline 47 & Paper and printing products & 0.68 & 0.61 & 0.71 & 0.83 & 0.96 & 0.78 & 0.73 & 0.60 \\
\hline 49 & Rubber and plastic products & 0.75 & 1.27 & 0.42 & 0.90 & 1.48 & 0.53 & 0.61 & 0.84 \\
\hline & & & & & & MAN & & & \\
\hline & & (1) & (2) & (3) & (4) & (5) & (6) & (7) & (8) \\
\hline 13 & Ferrous and non-ferrous ores and & & & & & & & & \\
\hline & metals, other than radioactive & 0.74 & 0.77 & 0.73 & 1.00 & 1.41 & 0.93 & 0.85 & 0.42 \\
\hline 15 & $\begin{array}{l}\text { Non-metallic minerals and } \\
\text { mineral products }\end{array}$ & 0.74 & 0.77 & 0.72 & 1.00 & 1.41 & 0.70 & 0.58 & 0.58 \\
\hline 17 & Chemical products & 0.24 & 0.58 & 0.10 & 0.77 & 1.63 & 0.4 .2 & 0.71 & 0.63 \\
\hline 19 & Metal products, except machinery & & & & & & & & \\
\hline & and transport equipment & 1.18 & 0.94 & 1.37 & 1.76 & 2.48 & 1.19 & 0.56 & $0.5 \%$ \\
\hline 21 & Agricultural and industrial machinery & $y 1.09$ & 1.25 & 0.97 & 0.82 & 1.48 & 0.32 & 0.57 & 0.49 \\
\hline 23 & Office and dataprocessing machines, & & & & & & & & \\
\hline & precision and optical instruments & 0.52 & 0.20 & 0.75 & 0.74 & 0.55 & 0.88 & 0.58 & $0.3 \%$ \\
\hline 25 & Electrical goods" & 0.54 & 0.81 & 0.25 & 0.7 & 0.91 & 0.62 & 0.48 & $8.3 \%$ \\
\hline 28 & Transport equipment & 0.23 & 0.63 & 0.01 & 0.94 & 1.50 & 0.58 & 0.61 & 0.53 \\
\hline 29 & Food, beverages and tobacco & 0.75 & 0.56 & 0.83 & 0.93 & 2.09 & 0.43 & 0.70 & 0.72 \\
\hline 42 & Textiles and clothing, & & & & & & & & \\
\hline & leather and foctwear & 0.92 & 0.58 & 1.10 & 0.95 & 0.63 & 1.12 & 0.65 & 0.49 \\
\hline 47 & Paper and printing products & 0.90 & 0.64 & 1.05 & 1.10 & 3.11 & 1.09 & 0.63 & $0.4 \epsilon_{1}$ \\
\hline 49 & Rubber and plastic products & 1.00 & 1.45 & 0.69 & 1.20 & 1.69 & 0.89 & 0.59 & 0.67 \\
\hline
\end{tabular}


Table 7.2 (Continued)

\begin{tabular}{|c|c|c|c|c|c|c|c|c|c|}
\hline & & & & & & RANCF & & & \\
\hline & & (1) & (2) & (3) & (4) & (5) & (6) & (7) & (8) \\
\hline \multirow[t]{2}{*}{13} & & & & & & & & & \\
\hline & metals, other than radioactive & 0.83 & 0.79 & 0.84 & 1.09 & 1.39 & 0.98 & 0.74 & 0.55 \\
\hline 17 & Chemical products & $\begin{array}{l}0.83 \\
0.37\end{array}$ & 0.79 & $\begin{array}{l}0.86 \\
0.33\end{array}$ & 1.09 & $\begin{array}{l}1.39 \\
1.34\end{array}$ & 0.83 & $\begin{array}{l}0.54 \\
0.70\end{array}$ & 0.00 \\
\hline \multirow[t]{2}{*}{19} & Metal products, except machinery & & & & & & & & \\
\hline & and transport equipment & 0.57 & 0.69 & 0.48 & 0.85 & 1.81 & 0.10 & 0.56 & 0.71 \\
\hline 21 & Agricultural and industrial machinery & 2.32 & 1.69 & 2.74 & 1.72 & 2.02 & 1.52 & 0.60 & 0.67 \\
\hline \multirow[t]{2}{*}{23} & Office and dataprocessing machines, & & & & & & & & \\
\hline & precision and optical instruments & 0.69 & 0.40 & 1.03 & 0.98 & 1.11 & 0.83 & 0.46 & 0.35 \\
\hline 25 & Electrical goods & 0.57 & 0.76 & 0.39 & 0.95 & 1.24 & 0.68 & 0.52 & 0.46 \\
\hline 28 & Transport equipment & 0.22 & 0.57 & 0.06 & 0.75 & 1.33 & 0.48 & 0.69 & 0.53 \\
\hline 29 & Food, beverages and tobacco & 0.40 & 1.07 & 0.14 & 0.96 & 1.63 & 0.70 & 0.72 & 0.63 \\
\hline \multirow[t]{2}{*}{42} & Textiles and clothing, & & & & & & & & \\
\hline & leather and footwear & 1.00 & 0.41 & 1.38 & 1.03 & 1.03 & 1.03 & 0.61 & 0.58 \\
\hline 47 & Paper and printing products & 0.98 & 0.67 & 1.17 & 1.15 & 1.06 & 1.21 & 0.62 & 0.41 \\
\hline \multirow[t]{2}{*}{49} & Rubber and plastic products & 1.13 & 1.15 & 1.12 & 1.36 & 1.34 & 1.37 & 0.60 & 0.77 \\
\hline & & (1) & (2) & (3) & (4) & $\begin{array}{l}\text { CALY } \\
\text { (5) }\end{array}$ & (6) & (7) & (8) \\
\hline 13 & $\begin{array}{l}\text { Ferrous and non-ferrous ores and } \\
\text { metals, other than radioactive }\end{array}$ & & & & $x$ & & 16 & & \\
\hline \multirow[t]{2}{*}{15} & Non-metallic minerals and & .02. & 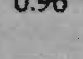 & & 9 & 1.75 & 10 & 0.78 & 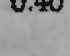 \\
\hline & mineral products & 0.82 & 0.96 & 0.71 & 1.29 & 1.75 & 0.93 & 0.56 & 0.55 \\
\hline 17 & Chemical products & 0.66 & 1.14 & 0.49 & 2.11 & 3.23 & 1.72 & 0.74 & 0.68 \\
\hline \multirow[t]{2}{*}{19} & Metal products, except machinery & & & & & & & & \\
\hline & and transport equipment & 0.83 & 0.84 & 0.82 & 1.25 & 2.21 & 0.58 & 0.59 & 0.67 \\
\hline 21 & Agricultural and industrial machinery & 2.32 & 2.28 & 2.34 & 1.72 & 2.72 & 1.11 & 0.62 & 0.65 \\
\hline \multirow[t]{2}{*}{23} & Office and dataprocessing machines, & & & & & & & & \\
\hline & precision and optical instruments & 0.70 & 0.40 & 0.91 & 1.00 & 1.11 & 0.92 & 0.59 & 0.54 \\
\hline 25 & Electrical goods & 0.69 & 0.85 & 0.60 & 0.99 & 1.24 & 0.85 & 0.64 & 0.60 \\
\hline 28 & Transport equipment & 0.39 & 0.51 & 0.32 & 1.74 & 1.41 & 1.93 & 0.63 & 0.70 \\
\hline 29 & Food, beverages and tobacco & 0.59 & 1.28 & 0.36 & 0.72 & 1.96 & 0.31 & 0.75 & 0.74 \\
\hline \multirow[t]{2}{*}{42} & Textiles and clothing, & & & & & & & & \\
\hline & leather and footwear & 0.44 & 0.40 & 0.46 & 0.58 & 1.10 & 0.26 & 0.62 & 0.43 \\
\hline 47 & Paper and printing products & 0.43 & 0.76 & 0.24 & 1.31 & 1.20 & 1.37 & 0.64 & 0.39 \\
\hline 49 & Rubber and plastic products & 1.19 & 1.15 & 1.21 & 1.43 & 1.34 & 1.47 & 0.62 & 0.75 \\
\hline
\end{tabular}


Table 7.2 (Continued)

THE NETHERL_ANDS ${ }^{1)}$
(1) (2)
(3) (4)
(5)
(6)
(7) $(8)^{2}$

13 Ferrous and non-ferrous ores and metals, other than radioactive

$\begin{array}{llllllll}0.66 & 0.71 & 0.64 & 0.97 & 1.36 & 0.79 & 0.69 & 0.65\end{array}$

15 Non-metallic minerals and mineral products

17 Chemical products

19 Metal products, except machinery and transport equipment

\subsection{6}

$\begin{array}{lllllllll}0.60 & 0.68 & 0.58 & 1.90 & 1.94 & 1.89 & 0.77 & 0.71\end{array}$

$\begin{array}{lllllll}0.71 & 0.62 & 0.97 & 1.36 & 0.68 & 0.57 & 0.79\end{array}$

$\begin{array}{llllllll}0.39 & 0.62 & 0.23 & 0.59 & 1.64: & 0.56 & 0.59 & 0.82\end{array}$

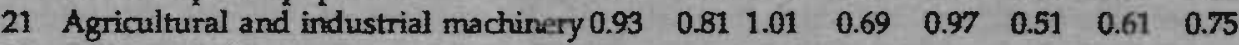

23 Office and dataprocessing machines, precision and optical instruments

25 Electrical goods

28 Transport equipment

29 Food, beverages and tobacco

0.85

$\begin{array}{lllllll}0.52 & 1.07 & 1.22 & 1.43 & 1.08 & 0.60 & 0.57\end{array}$

$\begin{array}{llllllll}0.60 & 0.81 & 0.45 & 0.85 & 1.17 & 0.62 & 0.58 & 0.67\end{array}$

$\begin{array}{llllllll}0.23 & 0.43 & 0.15 & 0.94 & 1.20 & 0.84 & 0.72 & 0.66\end{array}$

42 Textiles and clothing. leather and footwear

47 Paper and printing products

49 Rubber and plastic products

0.37

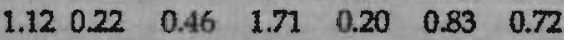

Source. Cawley and Davenport (1988), tables A3, A5, B1 and B2. Eurostat, Input-Output Tables, 1980, 1985, and ount calculations

Notes:

1) The columns in the table refer to the following information:

(1) Stage 1 price reduction of goods excluding impact of reduction of prices intermediate goods;

(2) Stage 1 price reduction of goods including impact of reduction of prices intermediate goods;

(3) Stage 1 price reduction of intermediate goods;

(4) Stage 2 price reduction of goods excluding impact: of reduction of prices intermediate goods;

(5) Stage 2 price reduction of goods including impact of reduction of prices intermediate goods;

(6) Stage 2 price reduction of intermediate goads;

(7) Share of intermediate goods(1985);

(8) Share of EC-12 imports (1985).

2)

3)

Data from 1980 Input-Output Tables.

Estimate(s).

As the data on price reductions relate only to the aggregate Community, the Cawley and Davenport study does not allow us to look at the price reductions in each individual country. Clearly, this is an unsatisfactory situation, since it may be expected that the price reductions will vary in each country. However, since Cawley and Davenport do provide estimates of the cost reductions in the EC-5 region, we decided to upgrade or downgrade their figures on EC-5 price reductions with the aid of these figures. We calculated the ratio of each country's cost reduction relative to the EC-5 average and multiplied the aggregate EC-5 price reduction in each sector with this ratio. Thus we ob- 
tained the price reductions for each country's sectors, both including and excluding the impact of intermediate goods' price reductions.

The disadvantage of price reductions calculated in this way is that we may over- or underestimate the true amount of price reductions in some countries. Recall that Cawley and Davenport argued that prices might be expected to fall more than costs because of increased competition and technical efficiency. Thus, in member states where competition and technical efficiency increase more than the EC-5 average, we may understate the true extent of the price reductions, whereas for the already more competitive member states we may have overstated the true extent of the price reductions.

For stage 2, Cawley and Davenport also provide two sets of estimates of EC-5 price reductions, one including and one excluding the impact of the reduction of prices in intermediate goods. We differentiated these data again by county using the above described weights that were obtained from stage 1 . In addition, we applied the effective protection formula in order to obtain nominal tariff equivalents for intermediate goods.

The resulting figures for tariff equivalents of barriers in the final and intermediate goods markets are presented in Table $7.2 .^{6}$ Columns (1) and (2) of that table reveal the expected price reductions in stage 1 . Column (1) represents the price reduction of final goods excluding the impact of the reduction of prices of intermediate goods. This information is comparable to the final tariffs from Table 7.1. Column (2), which reveals the expected price reductions including the impact of the reduction of the price of intermediate goods, is a kind of effective rate of protection equivalent, and, together with the information from column (1) and the shares of intermediates, was used to calculate nominal tariff equivalents for intermediate inputs (see column (3)). Columns (4)-(6) reveal the same information for stage 2 price reductions.

The data presented in Tables 7.1 and 7.2 were, together with the information on elasticities of substitution and factor shares, used in our simulations, to the discussion of which we shall turn now.

\subsection{Methodology for simulations}

In the integration literature, there have been many attempts to quantify the trade and welfare effects of the EC customs union. Two approaches to measurement have surfaced. Firstly, there are the so-called ex ante or analytical studies in which knowledge of all parameters of a concrete model is available for simulation. These $\varepsilon x$ antc studies have been applied to the determination of the static welfare effects of customs unions. The usual procedure in these kind of studies is to acquire estimates of the values of the elasticities of demand and supply for commodities, in conjunction with information concerning the prices of all trade partners as well as information concerning tariffs. ${ }^{8}$ These data are subsequently used to assess the influence of the declining partner country's prices. The most important difficulty with this kind of analysis concerns the fact that not

5 We compared our information regarding the tariff equivalents of the 1992 non-tariff barriers with the information in Deardorf and Stern (1991), Table A9. These authors calculated ad valorem tariff equivalents for a large number of countries, including EC-5. In the majority of cases, the Cawley and Davenport estimates are slightly higher than those of Deardorf and Stern. The exceptions are ferrous and non-ferrous ores and metals, food, beverages and tobacco, and rubber and plastics.

${ }^{7}$ Reviews of these studies may be found in Mayes (1978).

${ }^{8}$ The earlier mentioned Cawley and Davenport study is an example of the ex ante approach. 
all information necessary to infer the welfare effects is available, and that our knowledge of the determinants of international trade is far from complete.

Secondly, researchers have used so-called ex post models, which may be defined as econometric models based on historical relationships. It is usually assumed, that these historical relationships do not change during the period under consideration. Therefore, the econometric model allows the researcher to make forecasts of how the variables of the model, such as trade flows and GDP and employment would have developed had there been no customs union, a situation that is usually referred to as the "anti-monde". The residual is then imputed to the formation of the customs union, hence also the label residual imputation method. Clearly, one might expect that the inclusion of more explanatory variables improves the specification of the anti-monde, but needless to say, the extrapolation of the historical development prior to the customs union is highly questionable: several other factors than the formation of a customs union might have been responsible for the development of the residual.

The simulations presented below have many things in common with the above mentioned ex ante studies, but also incorporate elements of residual imputation. Accordingly, they share many of the shortcomings of these models and should therefore be interpreted with care. Our conclusions may be expected to have the same degree of reliability as is customary in applied economic research, i.e., there may be some margin of uncertainty as to the correctness of the figures, but we think their sign and order of magnitude may be established with reasonable confidence.

At the basis of our simulations is equation (5.5) which measures the short-run wage effects of the liberalisation of trade. Recall that

$$
\hat{w}_{i}=\frac{\theta_{i r}\left(\sigma_{r w}^{i}-\sigma_{m}^{i}\right)}{\Delta_{i}}\left\{\hat{p}_{i}-\sum_{j} \theta_{i q_{j}}\left(1+\frac{\sigma_{r q_{j}}^{i}-\sigma_{w q_{j}}^{i}}{\sigma_{r w}^{i}-\sigma_{r r}^{i}}\right) \hat{q}_{i j}\right\}
$$

The long-run wage response to the creation of the customs union can is given by:

$$
\hat{w}=\sum_{i=1}^{n} \alpha_{n} \hat{w}_{n}
$$

where the weights are determined as:

$$
a_{j}=\frac{\lambda_{j}^{L} e_{L j}}{\sum_{i=1}^{n} \lambda_{i}^{L} e_{L i}} \quad j=1,2
$$

with $\lambda_{\mathrm{i}}^{\mathrm{L}}=$ share of the labour force working in sector $i$ and $\mathrm{e}_{\mathrm{Li}}=-\Delta_{\mathrm{i}} / \theta_{\mathrm{ir}}=$ elasticity of labour demand in sector $i$.

The next step involves the establishment of a relevant anti-monde. Since we have historical data on actual developments of wages, a comparison of the actual and predicted values might give an idea of the integration effects, i.e., the residual of calculated and actual wages is imputed to the establishment of the customs union.

We start with an analysis of the sign-determining elasticities of substitution and factor shares for both 1970 and 1985 . Consider Table 7.3 where we have listed the calculated values of $\theta_{i r}\left(\sigma_{r w}^{i}-\sigma_{r r}^{i}\right) / \Delta_{i}$ and $\Sigma_{j} \theta_{i q_{i}}\left(1+\left(\sigma_{r q}^{i}-\sigma_{w q_{i}}^{i}\right) /\left(\sigma_{r w}^{i}-\sigma_{r r}^{i}\right)\right\}$ for all five countries. These two terms measure the responsiveness of wages for changes in final goods prices, and prices of intermediates, respectively. Several inferences can be made on the basis of this table. 


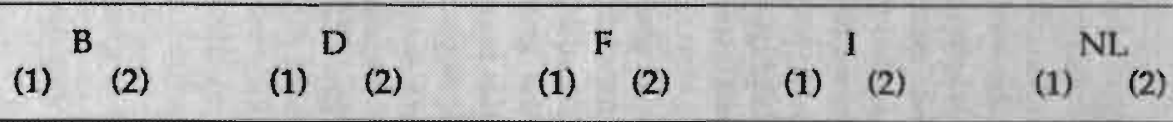

1970:

Ferrous and non-ferrous ores and metals, other than radioactive

Non-metallic minerals and mineral products

Chemical products

$\begin{array}{llll}4.03 & 0.74 & 6.69 & 0.85\end{array}$

$\begin{array}{ll}2.66 & 0.62\end{array}$

$2.57 \quad 0.62$

$3.21 \quad 0.68$

$\begin{array}{llll}1.59 & 0.37 & 2.01 & 0.92\end{array}$

$\begin{array}{ll}1.95 & 0.49\end{array}$

1.830 .46

$2.20 \quad 0.54$

$\begin{array}{ll}2.18 & 0.55\end{array}$

$\begin{array}{ll}4.57 & 0.78\end{array}$

$2.44 \quad 0.60$

$2.81 \quad 0.65$

$\begin{array}{ll}2.33 & 0.57\end{array}$

Metal products, except machinery

and transport equipment

Agricultural and industrial machinery

$1.87 \quad 0.46$

$\begin{array}{ll}2.31 & 0.57\end{array}$

$\begin{array}{lllll}1.95 & 0.49 & 1.67 & 0.40\end{array}$

$\begin{array}{ll}1.99 & 0.49\end{array}$

$1.87 \quad 0.36$

$2.20 \quad 0.55$

2.210 .55

$\begin{array}{ll}3.05 & 0.67\end{array}$

$0.79-0.30$

Office and dataprocessing machines,

precision and optical instruments

$0.92 \quad 0.42$

$1.20 \quad 0.16$

$\begin{array}{ll}1.39 & 0.29\end{array}$

$1.67 \quad 0.40$

$1.97 \quad 0.45$

$\begin{array}{lll}1.76 & 0.63\end{array}$

$\begin{array}{ll}1.94 & 0.49\end{array}$

$\begin{array}{lll}1.87 & 0.47\end{array}$

$\begin{array}{lll}2.09 & 0.52\end{array}$

$\begin{array}{ll}2.03 & 0.62\end{array}$

Transport equipment

$\begin{array}{ll}2.32 & 0.57\end{array}$

$\begin{array}{lll}2.62 & 0.62\end{array}$

$\begin{array}{lll}2.28 & 0.57\end{array}$

$\begin{array}{lll}2.67 & 0.77\end{array}$

Food, beverages and tobacco

Textiles and clothing, leather and footwear

$\begin{array}{lll}3.42 & 0.59\end{array}$

$\begin{array}{lll}3.12 & 0.67\end{array}$

$\begin{array}{lll}3.72 & 0.73\end{array}$

$2.85 \quad 0.66$

$\begin{array}{lll}4.37 & 0.66\end{array}$

$\begin{array}{ll}2.20 & 0.53\end{array}$

$\begin{array}{ll}2.23 & 0.55\end{array}$

$\begin{array}{lll}2.59 & 0.61\end{array}$

$\begin{array}{lll}2.55 & 0.60\end{array}$

$\begin{array}{ll}3.04 & 0.57\end{array}$

Paper and printing products

$\begin{array}{lll}2.19 & 0.54\end{array}$

$2.22 \quad 0.56$

$\begin{array}{lll}2.81 & 0.64\end{array}$

$2.36 \quad 0.58$

$\begin{array}{lll}2.42 & 0.58\end{array}$

Rubber and plastic products

$1.85 \quad 0.47$

$\begin{array}{ll}2.75 & 0.52\end{array}$

$2.04 \quad 0.50$

1.560 .44

$\begin{array}{ll}2.55 & 0.61\end{array}$

The columns have the following meaning:

$(1)=\theta_{i r}\left(\sigma_{r w}^{i}-\sigma_{r w}^{i}\right) / \Delta_{i}$
$(2)=\theta_{i q_{j}}\left(1+\left(\sigma_{r q_{j}}^{i}-\sigma_{w q_{j}}^{i}\right) /\left(\sigma_{r w}^{i}-\sigma_{r r}^{i}\right)\right\}$ 
Table 7.3 (Continued)

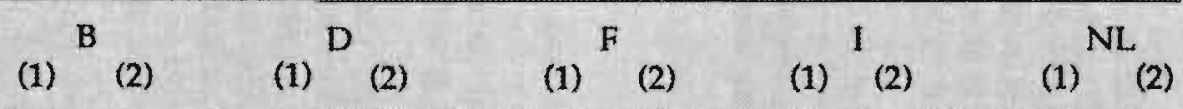

\section{5}

Ferrous and non-ferious ores and metals, other than radioactive

Non-metallic minerals and mineral products

Chemical products

Metal products, except machinery

and transport equipment.

Agricultural and industrial machinery

Office and dataprocessing machines,

precision and optical instruments

Electrical goods

Transport equipment

Food, beverages and tobacco

Textiles and clothing, leather and footwear

Paper and printing products

Rubber and plastic products

\begin{tabular}{rrrrrrrrrr}
5.65 & 0.82 & 6.75 & 0.86 & 1.88 & 0.47 & 4.75 & 0.80 & 3.98 & 0.75 \\
1.85 & 0.46 & 2.48 & 0.60 & 2.15 & 0.53 & 2.37 & 0.58 & 2.45 & 0.60 \\
3.10 & 0.68 & 4.15 & 0.80 & 3.34 & 0.69 & 5.64 & 0.83 & 3.61 & 0.72 \\
& & & & & & & & & \\
2.40 & 0.59 & 3.63 & 0.72 & 2.11 & 0.52 & 1.98 & 0.49 & 2.24 & 0.55 \\
1.80 & 0.51 & 2.30 & 0.58 & 2.44 & 0.59 & 3.05 & 0.64 & 0.55 & -0.79 \\
& & & & & & & & & \\
2.39 & 0.49 & 1.53 & 0.29 & 1.49 & 0.33 & 1.92 & 0.52 & 3.17 & 0.66 \\
0.57 & -0.97 & 1.91 & 0.59 & 1.79 & 0.45 & 2.51 & 0.59 & 2.24 & 0.69 \\
3.48 & 0.72 & 2.43 & 0.68 & 2.66 & 0.67 & 2.19 & 0.65 & 3.43 & 0.82 \\
4.33 & 0.70 & 3.55 & 0.66 & 3.56 & 0.72 & 3.25 & 0.57 & 5.54 & 0.71 \\
2.68 & 0.66 & 2.93 & 0.64 & 2.54 & 0.60 & 2.69 & 0.64 & 3.55 & 0.61 \\
-2.64 & 1.38 & 2.39 & 0.58 & 2.64 & 0.62 & 3.42 & 0.59 & 2.69 & 0.63 \\
2.34 & 0.57 & 2.72 & 0.63 & 2.26 & 0.56 & 1.75 & 0.42 & 3.66 & 0.73 \\
\hline & & & & & & & & & \\
\hline
\end{tabular}

The columns have the following meaning:

$$
\begin{aligned}
& (1)=\theta_{i x}\left(\sigma_{r w}^{i}-\sigma_{r w}^{i}\right) / \Delta_{i} \\
& (2)=\theta_{i q_{j}}\left(1+\left(\sigma_{r q_{j}}^{i}-\sigma_{w q_{j}}^{i}\right) /\left(\sigma_{r w}^{i}-\sigma_{r r}^{i}\right)\right\}
\end{aligned}
$$

(1) (2)

(1) (2)

(1)


First of all, note that all these terms are positive, except in a few cases ${ }^{9}$, which implies that wages will respond positively to increases in final goods prices and negatively to changes in the prices of intermediate goods. Secondly, note that the values of the second term are all less than unity, which implies that the wage response to changes in the prices of final goods is quantitatively stronger than the wage response to changes in the prices of intermediate goods. Finally, note that, in general, the responsiveness of wages to changes in both the prices of final goods and intermediate goods, is stronger in 1985 than it is in 1970. This is the result of (generally) increased values of the own elasticities of substitution in 1985.

The next step is to substitute the price changes into equation (7.2). For the customs union, we proceeded as follows. Referring back to our discussion of price changes in Chapter 5 , we assumed that price changes could be calculated as the weighted average of partner and non-partner country price changes, i.e.,

$$
\hat{\mathrm{p}}=\alpha_{2} \hat{\mathrm{P}}_{2}+\alpha_{3} \hat{\mathrm{P}}_{3}
$$

where $\alpha_{i}$ are the weights (import shares) pertaining to partner and non-partner countries, and $\hat{\mathrm{p}}_{\mathrm{i}}$ are partner and non-partner country price changes due to the establishment of the customs union or the implementation of the internal market programme. We assumed that this formulae could be applied to both final goods' prices and intermediate goods' prices.

With the aid of the above formulae we calculated the price changes for the the customs union implementation. In this respect, it was assumed that partner country prices decline with the full amount of the pre-union tariff. For non-partner country prices, we assumed that these would change with the full amount of the realignment of home country tariffs to the CET. For Benelux countries and Germany this implied increases in non-partner prices, and for France and Italy, this implied reductions in non-partner country prices. Both partner country price reductions and non-partner country price changes were weighed with the import shares $\alpha_{2}$ and $\alpha_{3}$.

In order to find the price changes due to the implementation of the 1992 project, we did not make use of the above formulae. In stead, we directly inserted the final and intermediate goods price changes from Table 7.2 in our simulations.

\subsection{Static effects: the creation of the customs union}

We proceeded differently in order to calculate the effects of the customs union on the one hand and the effects of the 1992 programme on the other. Let us first discuss the effects of the customs union. Since the available data for most countries start in 1970, we propose to construct the anti-monde of the customs union for that year, even though the customs union was completed in 1968. More specifically, the anti-monde could be created by undoing the imposition of the CET and by assuming that all Member States would return to the pre-customs union situation. A comparison of wage dispersion between the anti-monde and the existing situation in 1970 could then be used to infer the wage effects of the establishment of the customs union.

9 These cases can be explained quite easily. In the Dutch agricultural and industrial machines sector, the second term is negative due to relatively large values for $\sigma_{w q}^{i}$. The same is true for the Belgian electrical goods sector in 1985. In the Belgian paper and printing industry, the absolute value of $\sigma_{\mathrm{rm}}^{\mathrm{i}}$ is smaller than that of $\sigma_{\mathrm{rw}}^{\mathrm{i}}$, causing the first term $\sigma_{\mathrm{rw}}^{\mathrm{i}}-\sigma_{\mathrm{rr}}^{\mathrm{i}}<0$ in 1985 . 
Table 7.4 Changes $(\%)$ in prices of final goods $(\hat{\mathrm{p}})$, intermediate goods $(\hat{\mathrm{q}})$ and in nominal wages $(\hat{\mathrm{w}})$; customs union antimonde

\begin{tabular}{|c|c|c|c|c|c|c|c|c|c|c|c|}
\hline B & & & & & & $F$ & & & & & \\
\hline$\hat{\mathbf{q}}$ & $\hat{\boldsymbol{w}}$ & $\hat{\mathbf{p}}$ & $\hat{\mathbf{q}}$ & $\hat{\mathbf{w}}$ & $\hat{\mathbf{p}}$ & $\hat{\mathbf{q}}$ & $\hat{\mathbf{w}}$ & $\hat{\mathrm{p}}$ & & v & $\hat{a} \hat{\omega}$ \\
\hline
\end{tabular}

\section{SHORT-RUN EFEECTS:}

Ferrous, and non-ferrous ores and metals, other than madionctive

$$
\begin{array}{lll}
3.0 & 1.7 & 7.0
\end{array}
$$

$\begin{array}{lll}1.6 & -0.2 & 11.9\end{array}$

Non-metallic minerals and mineral products

Chemical products

$8.3 \quad 2.5 \quad 11.6$

$\begin{array}{lll}0.9 & 5.9 & -9.1\end{array}$

$\begin{array}{llll}4.4 & 3.3 & 8.6\end{array}$

$\begin{array}{lll}11.5 & 7.1 & 15.6\end{array}$

$12.4 \quad 9.3 \quad 16.6$

Metal products, except machinery

$$
\text { and transport equipment }
$$

Agricultural and industrial machinery

Office and dataprocessing machines,

$$
\text { precision and optical instruments }
$$

Electrical goods

Transport equipment

Food , beverages and tobacco

Textiles and clothing, leather and footwear

Paper and printing products

Rubber and plastic products

LONG-RUN EFFECTS:

\begin{tabular}{rrrrrrrrrrrrrrrr}
9.1 & 2.0 & 15.2 & 6.2 & 5.3 & 7.3 & 16.8 & 2.8 & 30.1 & 18.6 & 1.8 & 30.0 & 8.3 & 6.5 & 10.2 \\
\hline 4.5 & 3.0 & 6.5 & 1.3 & 2.5 & -0.0 & 14.4 & 1.6 & 30.0 & 16.1 & 9.7 & 29.1 & 4.5 & -0.0 & 3.6 \\
& & & & & & & & & & & & & & & \\
6.2 & 1.5 & 5.1 & 0.4 & 1.8 & 0.2 & 13.2 & 1.2 & 17.8 & 15.6 & 5.4 & 22.5 & 5.1 & -0.1 & 10.1 \\
8.5 & 4.1 & 10.4 & 1.7 & 0.4 & 2.9 & 14.7 & 5.5 & 22.6 & 16.7 & 5.3 & 29.1 & 7.6 & 7.4 & 6.0 \\
14.1 & 12.7 & 18.0 & 3.9 & 3.2 & 4.8 & 25.9 & 12.0 & 48.1 & 32.0 & 16.9 & 51.0 & 13.9 & 12.2 & 11.8 \\
18.2 & 14.8 & 32.7 & 5.6 & 3.1 & 10.8 & 14.2 & 18.4 & 3.0 & 18.3 & 13.9 & 26.1 & 17.4 & 14.7 & 33.8 \\
16.3 & 6.9 & 27.8 & 5.4 & 2.9 & 8.5 & 13.9 & 6.1 & 26.3 & 13.4 & 14.5 & 11.8 & 15.9 & 8.9 & 32.9 \\
9.4 & 8.3 & 10.7 & 0.4 & 0.4 & 0.4 & 9.6 & 6.3 & 15.8 & 9.2 & 7.2 & 11.8 & 8.0 & 3.1 & 14.9 \\
15.1 & 2.1 & 26.1 & 6.0 & 5.5 & 8.6 & 12.6 & -1.5 & 27.2 & 15.3 & 3.8 & 21.3 & 14.2 & 13.4 & 15.4
\end{tabular}

$\begin{array}{lllllllllllllll}9.7 & 5.2 & 16.4 & 3.2 & 2.8 & 4.2 & 14.0 & 6.8 & 27.2 & 16.2 & 7.8 & 25.3 & 9.5 & 6.2 & 15.3\end{array}$ 
In Table 7.4 we present the anti-monde changes in nominal wages for the sectors and countries of our analysis. Note firstly, that these changes in nominal wages are considerable in a number of cases, well in excess of 10 per cent. Thus, it seems that tariffs have conferred a considerable amount of protection to the labour of all EC-5 countries. Although this might seem unreasonable, it should be recalled that our bounds of magnitude for the wage effects are smaller than the results found by Köhler (1991). Recall from Chapter 4 that he found substantial factor price effects for specific factors, which in a number of cases exceeded 100 per cent. In addition, recall from the same chapter that Kohli (1991) also found Stolper-Samuelson elasticities in excess of 1 . Therefore, it seems fair to say that tariffs have had a profound effect upon the nominal wages of workers in EC-5 countries.

Secondly, consider the nominal wage responses to the implementation of the customs union. Tariff-prone countries like France and Italy, which were at the same time low-wage countries, would experience the largest increases in nominal wages if the customs union would be abolished. Conversely, the high-wage and tariff-shy countries like Germany and The Netherlands would experience comparatively moderate wage increases. The moderate wage responses in Germany, which are related to the low level of nominal protection, are reinforced by relatively low rates of effective protection due to comparatively high tariffs on intermediate goods. In some cases (non-metallic minerals and agricultural and industrial machinery), the German anti-monde wages would even be lower than would be the case in the presence of the customs union. This is primarily due to tariffs on intermediates exceeding those on final goods. In Belgium and The Netherlands, the effective rates of protection are all positive and the difference between nominal tariffs on final and intermediate goods are relatively large compared to Germany, causing the wage responses in these countries to be larger than is the case in Germany.

Thirdly, to get an idea of the changes in real wages (expressed in domestic currencies), assume that the change in the consumer price index is some kind of average of the final goods price changes listed in the table. Note that nominal wage increases are in all but a few cases larger than the average change of final good prices. This finding holds true for all EC-5 countries. Consequently, workers in most sectors are confronted with increases in their real wages, and the 1958 tariff protection also seems to have conferred a considerable amount of real wage protection to the workers. Quantitatively, the biggest real wage increases occur in France and Italy, whereas the smallest real wage increases occur in Belgium, The Netherlands and Germany.

The implication of this highly diffuse pattern of nominal and real wage increases is that abolishing the customs union would lead to a convergence of wages among EC-5 countries in at least some sectors. If we would reverse this argument, then it could easily be concluded that the establishment of the customs union must have produced a diverging trend in EC-5 wages in these sectors.

However, such a conclusion would be highly premature. The low-wage countries' stronger wage response is in part due to higher price increases in these countries as a result of the anti-monde. Therefore, the establishment of the anti-monde in these countries would generate higher levels of inflation than will be the case in the other countries. Consequently, their PPP exchange rates would depreciate. In Germany, Belgium and The Netherlands the opposite would occur and their PPP exchange rates would appreciate. If we take these exchange rate reactions into account, the picture that emerges is revealed by Table 7.5 . In that table, we have listed the sector-wise coefficients of variation of wages for three situations. These are: 1 . the actual coefficient of 
Table 7.5 Coefficients of variation; customs union's anti-monde

CV CV excl. Conv $/ \mathrm{CV}$ incl. Conv:

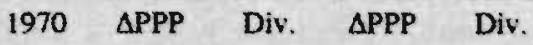

\section{SHORT-RUN EFFECTS:}

Ferrous and non-ferrous ores

and metals, other than radioactive

$\begin{array}{llll}0.12 & 0.13 & C & 0.70\end{array}$

$\begin{array}{llll}0.15 & 0.12 & D & 0.65\end{array}$

Non-metallic minerals and mineral products

Chemical products

0.09

0.06

D $\quad 0.76$

C

Metal products, except machinery

and transport equipment

Agricultural and industrial machinery

0.16

0.09

0.11

D

0.71

0.10

C

0.73

Office and dataprocessing machines,

precision and optical instruments

Electrical goods

$0.36 \quad 0.40$

0.12

0.11

C

0.65

Transport equipment

0.17

0.11

D

0.61

Food, beverages and tobacco

Textiles and clothing, leather and foorwear

Paper and printing products

Rubber and plastic products

0.12

0.14

0.15

0.21

0.11

0.12

0.12

0.14

D

0.74

C $\quad 0.66$

C $\quad 0.65$

C $\quad 0.68$

C $\quad 0.62$

c

C

LONG-RUN EFFECTS:

0.13

0.13

0.68

C

variation as measured in 1970 (see Table 3.7, pp. ?-?); 2 . the coefficient of variation of wages under the assumption that PPP exchange rates do not change; and, 3 . the coefficient of variation of wages under the assumption that the PPP exchange rate changes in the indicated above.

The data in Table 7.5 give rise to some interesting observations. If we do not adjust the PPP exchange rates, the imposition of the customs union's anti-monde would result in higher coefficients of variation in seven cases, and lower coefficients of variation in five cases. Thus, it could be argued that the customs union produced convergence of wages in seven industries and a divergence of wages in the remaining five industries. Note, however, that most of the changes in the coefficients of variation are marginal, and one could easily maintain that these changes are too small to be significant. Thus, if we do not correct the PPP exchange rate for different levels of inflation following the imposition of the customs union's anti-monde, the conclusion must either be that the customs union had ambivalent effects of a minor order or that the wage effects of the imposition of the customs union were negligible.

That conclusion would change rather drastically, if we do allow for a correction of the PPP exchange rates, as columns 4 and 5 reveal. In all cases, the return to the 1959 trade policies would cause a dramatic effect on the coefficient of variation of wages. Needless to say, the increase in the coefficient of variation is the result of an appreciation of the low-inflation currencies and a depreciation of the high-inflation currencies. The DM and the Guilder would appreciate considerably, whereas the Italian Lira and the French Franc would depreciate considerably. The Belgian Franc would appreciate marginally. The result of these PPP realignments is that the German and Dutch wage 
would increase significantly, whereas the Italian and French wages, measured at the corrected PPP exchange rates, would fall significantly below the EC-5 average. Thus, a return to the 1959 trade policies would significantly reinforce the pre-union wage hierarchy of high-wage and low-wage countries. In other words, abolishing the customs union would substantially increase wages of the high-wage countries, and would only marginally increase the wages of the low-wage countries. Consequently, it may be concluded that the imposition of the customs union caused a good deal of convergence of real wages.

We also calculated the long-run effects of the customs union's anti-monde. In Tables 7.6 and 7.7 we also reveal the results of these calculations. The strongest price reactions again occur in France and Italy, the weakest price reactions occur in Germany. Belgium and The Netherlands have intermediate price increases. Not surprisingly, France and Italy also experience the highest nominal wage changes, whereas Germany would witness a very modest wage change. Belgium and The Netherlands are again in the intermediate range. The long-run international wage dispersion seems to confirm the short-run trends. If one does not correct the PPP exchange rate, wage dispersion remains relatively constant. Thus, it could be argued that, in the long run, the customs union had a negligible effect on international wage differentials. However, if we allow for a correction of the PPP exchange rate, there is once more clear evidence of wage convergence.

\subsection{Static effects: the programme for the completion of the internal market}

To calculate the factor price effects of the 1992 programme, we have used our information concerning the price impacts of the NTBs. In the simulation, we assumed that the abolition of the White Paper barriers took effect immediately and instantaneously in 1985. We assumed that the barriers would result in the reductions of proces of final and intermediate goods which are given in Table 7.2. For the price reductions of final goods, we used the information from columns (1) and (4). For the price changes of intermediate goods we used the information from columns (3) and (6). The effects of these price reductions on wages are shown in Table 7.6 and Table 7.7.

As Table 7.6 shows, the price reactions following the implementation of the internal market programme are very modest, indeed, certainly in comparison with those following the imposition of the customs union's anti-monde. The expected price changes are less than 4.0 per cent in the vast majority of cases. Consequently, the resulting wage nominal changes are also moderate, on average something in the vicinity of some two per cent, with few exceptions exceeding this number. Note that the strongest wage responses occur in Italy, which also happens to have the largest changes in the prices of both final and intermediate goods.

If we compare the magnitude of the average reduction in the prices of final goods with the magnitude of nominal wage changes, we may conclude that the real wage changes are negative in the vast majority of cases. In addition, note that these real wage changes are very modest, at least in comparison with the changes induced in the customs union simulation. 
Table 7.6 Changes $(\%)$ in prices of final goods $(\hat{\beta})$, intermediate goods $(\hat{\mathrm{q}})$ and nominal wages $(\hat{\mathrm{w}})$; internal market

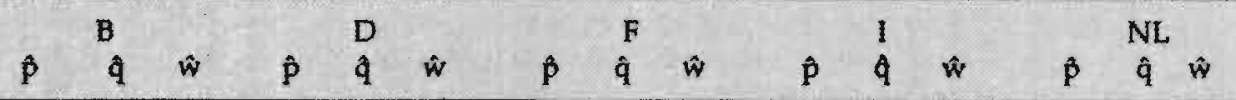

\section{SHORT-RUN EFFECTS:}

Ferrous and non-ferrous ores

$\begin{array}{llllllllllllllllll}\text { and metals, other than radioactive } & -1.5 & -1.3 & -2.5 & -1.7 & -1.7 & -2.1 & -1.9 & -1.8 & -2.0 & -2.1 & -1.9 & -2.7 & -1.6 & -1.4 & -2.2\end{array}$

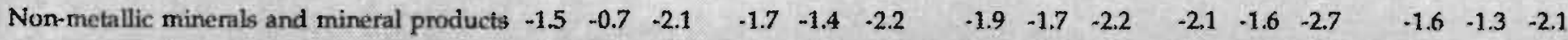

Chemical products

$\begin{array}{llllll}-1.2 & -0.9 & -1.9 & -1.0 & -0.5 & -2.5\end{array}$

$\begin{array}{lll}-1.6 & -1.4 & -1.8\end{array}$

$\begin{array}{lll}-2.8 & -2.2 & -5.3\end{array}$

$-2.5-2.5-2.6$

Metal products, exoept machinery and tmansport equipment

Agricultural and industrial machinery

$\begin{array}{lll}-1.0 & -0.0 & -2.3\end{array}$

$\begin{array}{lll}-2.9 & -2.6 & -3.9\end{array}$

$\begin{array}{lll}-1.4 & -0.6 & -2.4\end{array}$

$\begin{array}{llll}-2.1 & -1.4 & -2.8\end{array}$

$-1.0 \quad-0.8 \quad-1.2$

$+1.6+1.3-1.7$

$\begin{array}{lll}-1.9 & -1.3 & -2.7\end{array}$

$\begin{array}{lll}-4.0 & -4.3 & -3.7\end{array}$

$\begin{array}{lll}-4.0 & -3.5 & -5.6\end{array}$

$\begin{array}{lll}-1.6 & -1.5 & -1.6\end{array}$

Office and dataprocessing machines, precision and optical instruments

Electrical goods

$\begin{array}{lll}-1.5 & -1.6 & -1.7\end{array}$

$\begin{array}{lll}-1.3 & -1.6 & -1.2\end{array}$

$-1.7-1.9-1.6$

$\begin{array}{lll}-1.7 & -1.8 & -1.4\end{array}$

$\begin{array}{lll}-2.1 & -2.2 & -2.1\end{array}$

$\begin{array}{lll}-1.8 & -1.3 & -1.7\end{array}$

$\begin{array}{lll}-1.3 & -0.9 & -1.5\end{array}$

$\begin{array}{lll}.1 .5 & -1.1 & -1.9\end{array}$

$\begin{array}{llll}-1.7 & -1.4 & -2.1\end{array}$

$\begin{array}{lll}-1.5 & -1.1 & -1.6\end{array}$

$\begin{array}{lll}-0.7 & -0.2 & -1.9\end{array}$

$\begin{array}{lll}-1.2 & -0.6 & -1.9\end{array}$

$\begin{array}{rrrr}-1.0 & -0.6 & -1.6\end{array}$

$\begin{array}{llll}-2.1 & -2.3 & -1.5\end{array}$

$\begin{array}{llll}-1.2 & -1.0 & -1.2\end{array}$

Food, beverages and tobacco

$\begin{array}{llll}-1.8 & -0.6 & -5.7\end{array}$

$\begin{array}{lll}-1.7 & -1.3 & -3.0\end{array}$

$\begin{array}{lll}-1.4 & -0.8 & -2.7\end{array}$

$\begin{array}{llll}-1.3 & -0.7 & -3.0\end{array}$

$\begin{array}{lll}-0.8 & -0.4 & -2.9\end{array}$

Textiles and clothing, leather and footwear

Paper and printing products

$\begin{array}{lll}1.5 & -1.5 & -1.4\end{array}$

$\begin{array}{lll}-1.9 & -2.2 & -1.3\end{array}$

$\begin{array}{llll}-2.0 & -2.4 & -1.5\end{array}$

$\begin{array}{llll}-1.0 & -0.7 & -1.5\end{array}$

$\begin{array}{lll}-1.8 & -1.7 & -2.5\end{array}$

$\begin{array}{lll}-2.0 & -2.1 & -1.8\end{array}$

$\begin{array}{lll}-2.1 & -2.4 & -1.7\end{array}$

$\begin{array}{llll}-1.7 & -1.6 & -2.7\end{array}$

$-1.9-2.0-1.7$

$\begin{array}{llll}-1.7 & -0.9 & -2.6\end{array}$

$\begin{array}{lll}-2.2 & -1.5 & -3.3\end{array}$

$\begin{array}{lll}-2.5 & -2.5 & -2.5\end{array}$

$\begin{array}{llll}-2.6 & -2.7 & -2.6\end{array}$

$\begin{array}{llll}-2.1 & -2.1 & -2.1\end{array}$

LONG-RUN EFFECTS:

$\begin{array}{lllllllllllllllll}-1.5 & -1.1 & -2.2 & -1.7 & -1.5 & -2.1 & -1.9 & -1.8 & -2.1 & -2.1 & -1.8 & -2.7 & -1.6 & -1.5 & -1.7\end{array}$ 
Table 7.7 Coefficients of variation; internal market programme

\section{CV excl. Cony.t CV incl. Conv $J$ \\ $1985 \triangle P P P$ Div. $\triangle P P P$ Div.}

\section{SHORT-RUN EFFECTS:}

$\begin{array}{llllll}\begin{array}{l}\text { Ferrous and non-ferrous ores } \\ \text { and metals, other than radioactive }\end{array} & 0.08 & 0.08 & - & 0.07 & \text { C } \\ \text { Non-metallic minera's and mineral products } & 0.09 & 0.09 & - & 0.10 & \text { D } \\ \text { Chernical products } & 0.09 & 0.10 & \text { D } & 0.09 & \text { - } \\ \begin{array}{l}\text { Metal products, except machinery } \\ \text { and transport equipment }\end{array} & 0.10 & 0.10 & - & 0.08 & \text { C } \\ \text { Agricultural and industrial machinery } & 0.09 & 0.10 & \text { D } & 0.10 & \text { D } \\ \text { Office and dataprocessing machines. } & & & & & \\ \text { precision and optical instruments } & 0.25 & 0.25 & - & 0.31 & \text { D } \\ \text { Electrical goods } & 0.07 & 0.07 & - & 0.08 & \text { D } \\ \text { Transport equipment } & 0.11 & 0.11 & - & 0.13 & \text { D } \\ \text { Food, beverages and tobacco } & 0.11 & 0.11 & - & 0.15 & \text { D } \\ \text { Textiles and clothing, leather and footwear } & 0.11 & 0.11 & - & 0.13 & \text { D } \\ \text { Paper and printing products } & 0.08 & 0.08 & - & 0.12 & \text { D } \\ \text { Rubber and plastic products } & 0.07 & 0.07 & - & 0.07 & \text { - }\end{array}$

\section{LONG-RUN EFFECTS:}

$0.09 \quad 0.09 \quad-\quad 0.09$

Table 7.7 reveals the coefficients of variation. If we do not correct the PPP exchange rate, the dispersion of wages shows no change in ten out of twelve cases, whereas in two cases the implementation of the internal market programme would result in a divergence of wages. However, in both cases the coefficient of variation increases from 0.09 to 0.10 , which is a negligible change. All in all, it seems fair to say that, at constant PPP exchange rates, the internal market programme has a negligible effect on the dispersion of wages.

In case we allow for a correction of the PPP exchange rate, this conclusion hardly changes. As one may observe from columns 4 and 5 , there will be a convergence of wages in two cases, a divergence in eight cases, and a neutral result in the remaining two cases. Again, it should be noted that the changes in the magnitude of wage dispersion are extremely small and may be too small to be statistically significant. Therefore, it seems quite safe to conclude that the implementation of the internal market programme will not result in large changes in the international hierarchy of wages.

The long-run effects of the internal market programme are revealed by the bottom lines of Tables 7.6 and 7.7. Note that these effects are very modest, indeed. Inspection of the coefficients of variation in Table 7.7 reveals that the internal market programme has no effects whatsoever for the dispersion of wages. Therefore, we cannot conclude that, in the long run, the internal market programme has a distinct influence on the magnitude of international wage differentials.

How plausible are our results concerning the wage effects of the internal market? Unfortunately, we found only one study indicating bounds of magnitude for the expected 
wage changes: Gasiorek, Smith and Venables (1991) analyzed the factor demand effects of the completion of the internal market using a general equilibrium model containing elements of imperfect competition. They considered two policy experiments, notably a reduction in trade barriers due to the implementation of the internal market programme on the one hand and a reduction of trade barriers combined with true market integration on the other. They first considered the effects of these experiments on factor demands in each country at constant factor prices. Subsequently, it was assumed that factor markets would clear, and factor price consequences of the experiments were calculated.

Like our own model, Gasiorek, Smith and Venables' model is also characterized by the use of intermediate goods. However, as far as the primary factors of production are concerned, they assume that the economy is endowed with quantities of four factors of production: capital, professional, scientific and managerial labour, other non-manual. labour, and manual labour. The authors assume that categories of labour are mobile between various industrial sectors. Rather than estimating the parameters of their model, they calibrate them using Eurostat's Detailed National Accounts database.

As far as the experiment of reduced trade barriers is concerned, they find increases in factor demands in all countries, except for Italy and the UK, where the demand fro some factors decreases. Professional etc. labour demand increases most in Germany and the UK. Non-manual labour demand increases strongest in Italy. The quantitative importance of these changes, however, is only modest: a few per cents. That is even more true for the factor price reactions, which are minimal. In three countries, France, Germany and Italy, the price of manual labour was found to increase, the highest increase being 0.80 per cent (Germany) and the lowest increase being 0.03 per cent (France). Also, the price of professional etc. labour is found to increase in France and Germany (0.27 and 0.89 per cent, resp.), and seems to decline in Italy $(-0.49)$. Other non-manual labour's wages, finally, decreases in France and Germany (-0.12 and -1.02 per cent, resp.) and increases in Italy ( 0.11 per cent).

In their second policy experiment, which entailed the reduction of trade barriers and the integration of various national markets, the order of magnitude of the factor price changes hardly differs from the first experiment. Thus, if we summarize the results obtained by Gasiorek, Smith and Venables "then we may safely conclude that the labour market effects of the internal market programme are not particularly spectacular. On the contrary, their results seem to indicate that the changes following the implementation of the internal market are not very likely to cause serious labour market disruptions.

That conclusion must also be true for our own internal market programme simulation. Therefore, our results are not at odds with other estimates of the wage effects of the internal market, that were obtained with a different kind of model.

\subsection{A critical assessment of our results}

Our results are vulnerable for criticism on a number of grounds. First of all, as far as our customs union simulation is concerned, we have based ourselves upon the (unrealistic) assumption that the only effect of economic integration in Europe consisted of a discriminatory tariff removal. Yet, as we saw before, tariffs were only one kind of trade impediment that were removed in Europe. Needless to say, this is a highly unsatisfactory premise, but the complete absence of data on both trade coverage and tariff equivalents of quota's and trade measures having a similar effect for all sectors preclu- 
ded any statements pertaining to the factor price effects of these measures. Many economists, however, would say that these effects have been at least as important as the effects of the elimination of tariffs. Our results therefore underestimate the true factor price effects of the establishment of the customs union on this score.

Secondly, terms of trade effects are ignored in our analysis. It is not possible to take into account the reactions of third countries who did not become member of the customs union. Yet it is likely that third countries' prices have responded to the both the creation of the customs union and the implementation of the 1992 programme, since both changes constituted a change in external protection levels. Some third countries may have decided to absorb these changes into lowering profit margins rather than changing their prices.

That brings us to the more general problem of the translation of tariff changes into prices. We have assumed that both decreases and increases in protection levels are fully passed-through into prices. That may not necessarily the case. In addition, the accuracy of our forecasts depends to a large extent on the reliability of our elasticities. However, as Waelbroeck (1977) points out, the reaction of business to tariff changes may differ from that of an equivalent price change. In the case tariff changes are not fully passed through, our results might overestimate the wage effects of economic integration considerably.

Thirdly, our analysis does not take into account the impact of dynamic effects. However, the impact of these effects might be considerable. The reasons for the omission of dynamic effects are twofold. Firstly, estimates of the expected price reductions due to economies of scale or increased competition are lacking. No author has so far tried to produce any. Secondly, capturing the impact of economies of scale or increased competition requires a different modelling approach, since these effects usually involve the existence of market imperfections. However, our model does not incorporate these elements of imperfect competition and is therefore ill-equipped to make any plausible predictions as to the distributional effects of, say, economies of scale. As Helpman and Krugman (1985) have shown, the model might be amended to incorporate external economies of scale, but as these authors also showed, the general equilibrium model of trade cannot be adapted to deal with the impact of internal economies of scale, which are typical for most imperfect markets. Needless to say, our neglect of the impact of these dynamic effects results in a bias whose sign and magnitude is unknown.

Fourthly, one might object to the treatment of non-traded goods. ${ }^{10}$ Our model is formulated as if non-tradeable goods do not exist. This means that our model contains a deficiency in its specification. However, as Woodland (1988) has shown, non-traded commodities can easily be netted out and the results need not be biased by this omission.

Related to the issue of the omission of the non-traded goods sector is the limitation of our analysis to manufacturing wages. In other words, we did not pay any attention to the importance of developments in the various service sectors, even though the quantitative significance of this sector is considerable, indeed, and growing. The reason for this ormission is a simple one: suitable wage data for the service sectors are just not available for a sufficiently long period of time. Therefore, it is impossible to analyze the extent to which developments in manufacturing carry over to the service sector.

Fifthly, our analysis focused exclusively on the liberalisation of trade, and did not take account of the fact that the integration process in the EC went above and beyond the stage of a mere commodity trade liberalisation process. Thus it could be argued that

${ }^{10} \mathrm{Cf}$. Woodland's (1988) comment on Wong's paper. 
our simulations underestimate the true extent of wage convergence, since factor movements are usually considered to be substitutes to trade in commodities. Commenting on the international convergence of wages, Leamer (1992) suggested that increased foreign capital formation inevitably should have lead to American wages converging with those in other countries. In the European context, Molle (1991, ch. 10) found that direct investments tended to flow from the richer nothern European countries to the poorer southern European countries, producing a movement in the direction of wealth convergence. Assuming that marginal labour productivities depend on $\mathrm{K} / \mathrm{L}$ ratios, we may postulate that these capital flows would also tend to generate a movement in the direction of international wage convergence. Similar remarks hold for the migration of labour. As Molle (1991, ch. 9) shows, intra-EC-5 labour migration has become less important as the integration process proceeded, but migration from third countries to the high-wage EC-5 countries has been considerable. In itself, this labour immigration has tended to produce a movement in the direction of wage convergence as well.

Our remarks concerning factor mobility implicitely assume that factor movements and trade are substitutes (see Mundell (1957)). Alternatively, it could be argued that factor movements and trade in goods are complements in the context of the EC. Consequently, as Markusen (1984) has shown, the factor price equalisation result need not occur, and factor prices might diverge as a result of free trade. Our results would, in that case, overestimate the true amount of wage convergence. However, as Molle (1994) points out, no clear evidence of complementarity has been found in the EC context. Thus it seems fair to assume that trade and factor movements have been substitutes and that our simulations under- rather than overstate the true amount of wage convergence due to the integration process.

Sixthly, it should be noted that our simulations refer to an internal liberalisation process in the EC and that we did not take the external liberalisation of EC. trade adequately into account. Yet this external dimension has played a considerable part. In the last two decades, the EC participated in the Tokyo and Uruguay Rounds of GATT negotiations and concluded a variety of trade agreements with different parts of the world. In Europe, Mediterranean countries obtained free trade agreements or association status, for the developing world LOME and GSP regimes are in force, and with the former socialist countries in Central and Eastern Europe association and partnership and cooperation agreements have been concluded or are currently under negotiation. Needless to say, all these liberalisations of external EC trade will have implications for intra-EC wage differentials. Although our model in principle enables us to analyze the wage effects of these external trade liberalizations, data considerations precluded us from conducting the relevant policy simulations. Nevertheless, on the basis of our two policy simulations, we think it is reasonable to assume that these external trade liberalisations may contribute significantly to a convergence of (EC-5) wages.

Seventh, for obvious reasons we did not pay any attention to the effects of EC integration on third countries' wages. To do so implies that we would have to model these economies as well and that would go beyond the scope of the present research project and could very well be a project on its own. On the basis of our model, no a priori statements concerning the external wage effects of EC integration would be highly speculative.

Eighth, the present model does not allow us to assess the wage effects of changes in the institutional framework of the EC-5 member states. Yet it is unlikely, that the integration process did not have an influence on the nature and functioning of these institutions. In this respect, we may refer to a study by Larre and Torres (1991), who examined the catch-up of Spain, Portugal and Greece's GDP per capita. According to these 
authors, the economies of the southern member states were at the beginning of the 1970 s characterized by weak economic and social institutional structures. Their membership of the EC forced them to increase the pace of structural adjustment, to improve the functioning of markets, to introduce market reforms and microeconomic policy reforms, and to improve the economic infrastructure. These policy changes subsequently stimulated the inflow of foreign direct investment, improved the working of factor and commodity markets and so contributed to the economic performance of these countries. The authors conclude that the catch-up of the southern member states depended to a large degree on the development of market mechanisms and the improvement in the quality of the social and economic infrastructures. Obviously, the influence of these factors cannot be quantified in our model, but might have played a considerable role in the case of Italy as well.

Despite all the possible criticisms and obvious limitations that can be levelled against our analysis, we believe that the basic message of our simulations is rather insensitive to different model specifications. That message is that, on the whole, the customs union produced a considerable amount of wage convergence, in particular compared to the experience of the internal market programme. The reason for this seems to be extremely simple, notably that the customs union represented much farther-reaching integration than anything which has come above and beyond it. This would also explain the finding in Chapters 3 and 4 that EFTA countries also showed a considerable convergence of wages and that NAFTA wages diverged in the recent past.

\subsection{Conclusions}

In this chapter we tried to establish bounds of magnitude for the factor price effects of both the imposition of both the customs union and the internal market. As far as the customs union was concerned, we addressed the issue of the wage effects of the imposition of the CET. Although this implies that we could not produce any meaningful statements as to the effects of other aspects of the customs union (e.g., the abolition of internal quotas), we believe that our simulation exercises provide a reasonable impression of what has happened with wages as a result of the customs union. To obtain an impression of these effects, we analyzed what would happen with the dispersion of wages if the Member States would decide to undo the customs union in 1970 and would return to the pre-union (1959) trade policies. We found that, as far as the short-run wage effects are concerned, that the customs union may have resulted in an impressive amount of wage convergence. This conclusion was achieved under the assumption of an adjusted PPP exchange rate. In case one would not want to make the assumption of adjusted PPP exchange rates, the conclusion should be that the customs union produced both convergence and divergence of wages, depending upon the sector under consideration. However, these converging and diverging trends would be extremely small in the majority of cases, too small to conclude the existence of significant wage effects.

The long-run wage effects of the customs union seem to confirm the short-run results. Correction of the PPP exchange rate would result in a considerable long-run convergence of wages, whereas absence of this correction would lead to the conclusion that the customs union had a negligible effect on international wage dispersion.

As far as the completion of the internal market programme is concerned, we may point at the following. The internal market programme had a negligible effect on wage dispersion, both measured at constant and adjusted PPP exchange rates, and both in the 
short run and the long run. These results proved to be consistent with other studies, and therefore appear to be rather robust.

Thus, it seems fair to conclude that the static wage effects produced by the customs union produced much more wage convergence than the programme to complete the internal market resulted in. This is hardly surprising, since it could be argued that the customs union was a much more far-reaching integration attempt than any other integration measures which have come above and beyond it. 


\section{CHAPTER}

\section{8}

\section{SUMMARY AND CONCLUSIONS}

The creation of the EEC in the 1960s and the programme to complete the internal market in the late 1980 s involved exercises that could have had considerable distributional effects. As the theory of international trade predicts, such changes in the internal and external protection of a country generally produces "winners" and "losers". This study's primary purpose was to attempt to isolate the wage effects of the EC's integration process on the five main founding countries of the EC (EC-5).

Since the theory of international economic integration has usually based its predictions concerning the factor price effects of integration on the most important theorems of international trade theory, we started our investigation with a selective review of the relevant trade literature. We focused primarily on the factor price equalisation model, the Stolper-Samuelson theorem and the specific factors model. According to the factor price equalisation and Stolper-Samuelson models, a liberalisation of trade may be expected to result in a convergence of factor prices between the trading nations. However, detailed analysis of the factor price equalisation and Stolper-Sannuelson theorems showed that the assumptions underlying these theorems are rather restrictive, indeed. Thus to predict that economic integration will result in a full factor price equalisation would most probably be too optimistic, and all that one could expect is a tendency in the direction of factor price equalisation. The specific factors model, on the other hand, predicts that the results of a trade liberalisation will be ambiguous and definitive statements as to the effects for the mobile factor cannot be made without further information. In this respect, much seems to depends on the precise nature of production technology, as well as on factor proportions. All three models served as a basis for our own empirical analysis.

In Chapter 3, we analyzed the behaviour of wages in the EC-5 region for the 19641989 period. We looked at the behaviour of gross hourly wages, hourly labour costs and labour costs per manyear. We started that analysis verifying some tendencies found in the literature on wage structures. In conformity with the results of these studies, our data reveal a considerable degree of stability and international similarity of wage structures in the EC-5 countries. Subsequently, we analyzed the question whether our data reveal any movement in the direction of a convergence or divergence of international wage differentials. Gross hourly wages, measured in current ECU exchange rates, did not reveal a good deal of wage convergence in the EC-5 region. However, working with 
current exchange rates results in interpretation difficulties due to inflation differences between countries. Therefore, we also analyzed the development of wages in purchasing power parities. When wages were expressed in purchasing power parities we found evidence a considerable amount of international wage convergence. This convergence is due to the fact that low-wage countries seemed to catch up with high-wage countries. In addition, our results indicated that this convergence also takes place if one analyses other definitions of wages, viz. hourly labour costs and labour costs per manyear. Although there seems to have been convergence of wages and labour costs, we also found that wage differentials between countries are rather persistent. In addition, our data confirmed findings of older studies, which had concluded that there is a remarkable temporal stability in a country's wage structure, as well as a substantial degree of similarity between the wage structures of various countries.

In Chapter 4 we reviewed the empirical literature on models that could explain the stability and similarity of wage structures, as well as the development of and the persistence in international wage differentials. We identified several approaches and concluded that a very small number of authors have systematically attempted to capture the distributional effects of preferential trading agreements. As far as researchers did study international wage structures, they have usually done so as labour economists. As far as international economists have considered the influences of trade on the development of wages, they have either done so in an ad hoc manner or in a one-country setting. Therefore, it proved useful to consider the problem of the wage effects of economic integration with the aid of a trade model that specifically tries to identify these wage effects.

In Chapter 5 we developed our model of the factor price effects of customs unions. Basing ourselves on the theory of international trade, we distinguished a short-term and a long-term version of the model. The difference between the short and long run was formed by the degree of intersectoral factor mobility, which was considered to be absent in the short-run model. The model incorporated three factors of production, viz. capital, labour and intermediate inputs and was formulated in terms of duality. We derived the comparative statics of the short-run model first, and identified the factors influencing the sign and pattern of factor price responses to trade policy measures. We found that an economic integration scherne does not necessarily result in a convergence of wages. In this respect, the wage effects of integration proved to depnd on the concrete specification of technology, factor proportions and the direction of change of final commodity prices and intermediate input prices. We identified several situations in which the magnitude of international wage differentials could increase after a country enters into an economic integration scheme with other countries. For example, in case a high-wage country would owe its high wages to high tariffs and would at the same time have low values of the own Allen-Uzawa elasticities of substitution, wages could easily show a perverse response following a trade liberalisation and might even increase. Conversely, if tariffs in a low-wage country would be low and if the own Allen-Uzawa elasticities of substitution would be close to zero, wages in that country could decline following a trade liberalisation.

In Chapter 6 we estimated the parameters of our model as well as the implied values of the Allen-Uzawa elasticities of substitution. To empirically represent the structure of the economy, we used the translog functional form, which is flexible and has no a priori restrictions at all. In addition to these advantages, the translog form enables us to derive easily the elasticities of substitution that we needed for the model simulations. Using the translog form, we derived explicit share (and therefore conditional factor demand) equations for all factors of production. The translog cost function was estimated to describe the production technology of thirteen industrial sectors in the EC-5 countries. We 
found that, as far as the substitution possibilities between pairs of factors are concerned, that labour and capital were predominantly complements, and that capital and intermediates on the one hand and labour and intermediates on the other tended to be substitutes. In addition, we found evidence of a predominantly capital-using and labour-saving bias in technical progress.

The elasticities of substitution that were estimated in Chapter 6 were used for simulation of the wage responses to the creation of the customs union and the implementation of the internal market programme in Chapter 7. We started to assess the quantitative importance of the tariff barriers prior to the customs union and the quantitative importance of the internal market non-tariff barriers prior to the launching of the 1992 programme. In our simulations, we created anti-mondes for both the creation of the customs union and the internal market. As far as the creation of the customs union is concerned, the results of our experiments indicated that the creation of the customs union resulted in a substantial convergence of wages. However, this conclusion was achieved under the assumption of purchasing power parity exchange rates that were adjusted for the changes in prices that occur after a trade policy measure. In case one would not want to make this assumption, the short-run effects of economic integration are much less pronounced, i.e., both convergence and divergence seem to occur. In the long run these tendencies appear to be confirmed, i.e., with the correction of purchasing power parity exchange rates convergence is clearly visible, but without that adjustment there seem to be only a minor wage effects following the imposition of the customs union.

The internal market programme was found to have very small effects on the magnitude of the international wage differential. This conclusion holds irrespective of whether or not we correct the purchasing power parity exchange rate for inflation changes due to trade policy measures. In the long run, the internal market programme even fails to show any effects at all on wage dispersion. 



\section{REFERENCES}

AIZENMAN, J. (1983), Dynamics of Trade Liberalisation, Jisumal of Development Economics, 13, pp. 133-142.

ALBERT, M., and H.-J. VOSCEERAL (1989), "The Role of Imperfect Factor Mobility, in: W.T.M. Molle and A. van Mourik (eds.). Wage Differentials in the European Community, (Gower, Aldershot).

ARROW, K.J., H.B. CHENERY, B.S. MINHAS, and R.M. SOL.OW (1961), "Capital-Labour Substitution and Economic Efficiency", Review of Economics and Statistics, 43, August, Pp. 225-250.

BALASSA, B. (1965), "Tariff Protection in Industrial Countries: An Evaluation", Journal of Political Economy, 73, pp. 573-594.

BARTEN, A.P. (1969), "Maximum Likelyhood Estimation of a Complete System of Demand Equations", European Economic Review, 1, pp. 7-73.

BATRA, R.N. (1973), Studies in the Pure Theory of International Trade, (St. Martin's Press, New York).

BATRA, R.N. and G.W. SCULLY, "Technical Progress, Economic Growth, and the North-South Wage Differential", Joumal of Regional Science, 12, No. 3, 1972, pp. 375-386.

BERGLAS, E. (1979), "Preferential Trading Theory: the n Commodity Case", Joumal of Political Economy, 87, No. 2, pp. 315-331.

BERNDT, E.R. and L.R. CHRISTENSEN (1973), 'The Internal Structure of Functional Relationships: Separability, Substitution and Aggregation", Revriew of Economic Studies, 40, pp. 403410.

BHAGWATI, J. (1964), "The Pure Theory of International Trade: A Survey", Economic Joumal, 74, pp. 1-84.

BINSWANGER, H.P. (1974), "The Measurement of Technical Change Biases with Many Factors of Production", American Economic Reciew, 64, pp. 964-976.

BLOCH, J.W. (1948), "Regional Wage Differentials: 1907-46", Monthly Labor Review, 66, pp. 371377.

BORTS, G.H. (1960), "The Equalisation of Returns and Regional Economic Growth", American Economic Review, 50, pp. 319-347.

BORTS, G.H. and J.L. STEIN (1964), Economic Growth in a Free Market, (Columbia University Press, New York/London).

BOUTEILLER, J. (1971), "Comparaison de Structures inter-industrielles de salaires dans les pays du Marché Commun", Annales de L'INSEE, no. 8, pp. 3-24.

BOWLEY, A.L. (1930), "Comment on International Comparisons of Real Wages", Joumal of the Royal Statistical Society, 93.

BRUNO, M. and J. SACHS (1985), Economics of Worldwide Stagflation, (Basil Blackwell, Oxford).

BURGESS, D.F. (1976), 'Tariffs and Income Redistribution: Some Empirical Evidence for the United States", Joumal of Political Economy, 84, No. 1, pp. 103-117.

BURGESS, D.F. (1980), "Protection, Real Wages, and the Neoclassical Ambiguity with Interindustry Flows", Joumal of Political Economy, 88, No. 4, pp. 783-802.

BUTLER, A.D. (1967), "Labor Costs in the Common Market", Industrial Economics, 6, no. 2, pp. 166-183.

CALMFORS, L. and J. DRIFFIL (1988), "Bargaining Stucture, Corporatism and Macroeconomic Performance", Economic Policy, No. 6, pp. 14-61.

CAREY, H.C. (1835), Essay on the Rate of Wages, (Carey, Lee and Blanchard, Philadelphia).

CAVES, R.E. (1960), Trade and Economic Structure, (Harvard University Press, Cambridge, Mass).

CHAMBERS, R.G. (1988), Applied Production Analysis, (Cambridge University Press, Cambridge).

CHANG, W.W. (1979), "Some Theorems of Trade and General Equilibrium with Many Goods and Factors", Econometrica, 47, no. 3, May, pp. 709-726.

CAWLEY R., and M. DAVENPORT (1988), "Partial Equilibrium Calculations on the Impact of Internal Market Barriers in the EC', in: CEC, Studies on the Cost of Non-Europe, (Office for Official Publications, Luxembourg). 
CHIPMAN, J.S. (1966), "A Survey of the Theory of International Trade: Part 3, The Modern Theory", Econometrica, 34, January, pp. 18-76.

CHIPMAN, J.S. (1969), "Factor Price Equalization and the Stolper-Samuelson Theorem", Intemational Economic Review, 10, pp. 399406.

CHRISTENSEN, L.R., D.W. JORGENSON, and L.J. LAU (1973), "Transcendental Logarithmic Production Frontiers", Review of Economics and Statistics, 55, February, pp. 28-45.

COMMISSION OF THE EUROPEAN COMMUNITIES (CEC) (1988), Studies on the Cost of NonEurope, (Office for Official Publications, Luxembourg).

DARGAY, J. (1987), Factor Demand in Swedish Manufacturing: Econometric Analyses, (Almqvist and Wiksell, Stockholm).

DEARDORF, A.V. and R.M. STERN (1986), The Michigan Model of World Production and Trade, (MIT Press, Cambridge, MA).

DEARDORF, A.V. and R.M. STERN (1990), Computational Analysis of Global Trading Arrangements, (Harvester Wheatsheaf, London).

DEATON, A. and J. MUELBAUER (1980), "An Almost Ideal Demand System", American Economic Review, 70, pp. 312-326.

DIEWERT, W.E. (1974), "Applications of Duality Theory", in: M.D. Intrilligator and D.A. Kendrick (eds.), Frontiers of Quantitative Economics, Vol. 2, (North-Holland, Amsterdam).

DIEWERT, W.E. and C.J. MORRISON (1988), "Export Supply Functions and Import Demand Functions: A Production Theory Approach", in: R.C. Feenstra (ed.), Empirical Methods for International Trade, (MIT Press, Cambridge, MA), pp. 207-229.

DIEWERT, W.E. and T.J. WALES (1987), "Flexible Functional Forms for Profit Functions and Global Curvature Conditions", Econometrica, 55, pp. 43-68.

DIXIT and NORMAN (1980), The Theory of Intemational Trade, (Cambridge University Press, Cambridge).

DOLLAR, D., E.N. WOLFF, and W.J. BAUMOL (1988), 'The Factor-Price Equalization Model and Industry Labor Productivity: An Empirical Test Across Countries", in: R.C. Feenstra (ed.), Empirical Methods for Intemational Trade, (MIT Press, Cambridge, MA).

DRAMAIS, A. (1977), "Transmission of Inflationary Pressures Between the EEC Members", European Economic Review, 9, pp. $21-42$.

DUNLOP, J.T. and M. ROTHBAUM (1955), "International Comparions of Wage Structures", Intermational Labour Review, 71, pp. 347-363.

EGAWA, 1. (1978), "Some Remarks on the Stolper-Samuelson and Rybczynski Theorems", Journal of International Economics, 8, pp. 525-536.

EL-AGRAA, A.M. (1980), The Economics of the European Community, Second Ed., (Phillip Allen, London)

ETHIER, W.J. (1974), "Some of the Theorems of International Trade with Many Goods and Factors", Journal of International Economics, 4, pp. 199-206.

ETHIER, W.J. (1984), "Higher Dimensional Issues in Trade Theory", in: R.W. Jones and P.B. Kenen (eds.), Handbook of International Economics, (North-Holland, Amsterdam).

EUROSTAT (various years), National Accounts, Detailed Tables by Branch, (Office for Official Publications, Luxembourg).

FEENSTRA, R.C. (ed.) (1988), Empirical Methods for International Trade, (MIT Press, Cambridge Mass).

FERGUSON, C.E. (1979), The Neo-Classical Theory of Production and Distribution, (Cambridge University Press, Cambridge).

FISHER, M.R. (1966), Wage Determination in an Integrating Europe, (Sijthof, Leyden).

FUCHS, V.R., and R. PERLMAN (1962), "Recent Trends in Southern Wage Differentials", Review of Economics and Statistics, 46, pp. 292-300.

GALLAWAY, L.E. (1963), "The North-South Wage Differential", Review of Economics and Statistics, 45, pp. 264-272.

GALE, D. and H. NIKAIDO (1965), "The Jacobian Matrix and Global Univalence of Mappings", Mathematische Annalen, 159, pp. 81-93. 
GASIOREK, M., A. SMITH and AJ VENABLES (1991), "Completing the Internal Market in the EC: Factor demands and Comparative Advantage", in: L.A. Winters and A.J. Venables, European Integration: Trade and Industry (Cambridge Unioersity Press, Cambdrige), pp. 9-33.

GHALI, M., M. AKIYAMA and J. FUIIWARA (1978), "Factor Mobility and Regional Growth", Reoiew of Economics and Statistics, 60, pp. 78-84.

GREENAWAY, D. (1985), The Theory of International Trade Policy, (Macmillan, London).

GREMMEN, H.J. (1985), "Testing Factor Price Equalisation in the EC: An Alternative Approach", Joumal of Common Market Studies, 23, pp. 277-286.

GRUBEL, H.G. and H.G. JOHNSON (1967), "Nominal Tariffs, Indirect Taxes and Effective Rates of Protection: The Common Market Countries 1959", Economic Journal, 77, December, pp. 761-776.

HALL, R.E. (1973), "The Specification of Technology with Several Kinds of Output", Journal of Political Economy, 81, pp. 878-92.

HANHAM, R.Q. and H. CHANG (1981), "Wage Inflation in a Growth Region: The American Sunbelt", in: R.L. Martin (ed.), Regional Wage Inflation and Unemployment, (Pion Ltd., London), pp. 75-95.

HARROD, R.F. (1958), "Factor-Price Relations Under Free Trade", Economic Joumal, 68, June, pp. 245-255.

HECKSCHER, E.T. (1919), "Utrikshandels verkan pa inkomstfordelingen", Ekonomist Tidskrift, 21, del 2, pp. 1-32, English translation: "The Effect of Foreign Trade on the Distribution of Income", reprinted in H.S. Ellis and L.A. Metzler (eds.), Readings in the Theory of Intemational Trade, (The Blakiston Co., Philadelpia), 1949, pp. 272-300.

HELPMAN, E. and P. KRUGMAN (1985), Market Structure and Foreign Trade, (MIT Press, Cambridge MA).

HICKS, J.R. (1932), The Theory of Wages, (Macmillan, London).

HICKS, J.R. (1959), "The Factor Price Equalization Theorem", in: J.R. Hicks, Essays in World Ecanomics, (Oxford University Press, Oxford).

HILL, J.K. and J.A. MENDEZ (1983), "Factor Mobility and the General Equilibrium Model of Production", Journal of Intermational Eco- nomics, 15, pp. 19-25.

HUTCHESON, T.L. (1969), "Factor Intensity Reversals and the CES Production Function", Review of Economics and Statistics, 51, November, pp. 468-470.

INADA, K. (1971), "The Production Coefficient Matrix and the Stolper-Samuelson Condition", Econometrica, 39, No. 2, pp. 219-239.

INTERNATIONAL LABOUR ORGANISATION (1954), International Comparisons of Real Wages: $A$ Study of Methods, Report III, (ILO, Geneva).

JACOBS, H. (1986), De Loonstructuur, (Ph.D. thesis, University of Groningen).

JAMES, S.F. and I.F. PEARCE (1951-52), "The Factor Price Equalisation Myth: Mathematical Appendix", Reoiew of Economic Studies, 19, pp. 119-120.

JOHNSON, H.G. (1957), "Factor Endowments, International Trade and Factor Prices", Manchester School of Economic and Social Studies, 25, September, pp. 270-283.

JONES, R.W. (1965), "The Structure of Simple General Equilibrium Models", Joumal of Political Economy, 73, pp. 557-572.

JONES, R.W. (1971), "Distortions of Factor Markets and the General Equilibrium Model of Production", Joumal of Political Economy, 79, no. 3, pp. 437-459.

JONES, R.W. (1974), "The Small Country in a Many-Commodity World", Australian Economic Papers, 13, pp. 225-236.

JONES, R.W. (1975), "Income Distribution and Effective Protection in a Multicommodity Trade Model", Joumal of Economic Theory, 11, pp. 1-15.

JONES, R.W. and I. COELHO (1986), "The Theory of International Factor Flows: The Basic Model", Joumal of Intemational Economics, 20, pp. 313-327.

JONES, R.W., and P.B. KENEN (1984), Handbook of Intemational Economics, Vol. I, (North-Holland Publishing Company, Amsterdam).

JONES, K.W. and J.A. SCHEINKMAN (1977), "The Relevance of the Two-Sector Production Model in Trade Theory", Journal of Political Economy, 85, no. 5, pp. 909-935. 
JORGENSON, D.W and B. FRAUMENI (1981), "Relative Prices and Technical Change", in: W. Eichhom et al., Quantitative Studies on Production and Prices, (Physica Verlag, Würzburg), pp. 241-268.

KATZ, L.F., and L.H. SUMMERS (1989), "Industry Rents: Evidence and Implications", Brookings Papers on Economic Activity, Microeconomics, pp. 209-275.

KEMP, M.C. and L.L.F. WEGGE (1969), "On the Relation Between Commodity Prices and Factor Rewards", International Economic Review, 10, pp. 407-413.

KENEN, P.B. (1989), The International Economy, Second Edition, Prentice Hall, Englewood Cliffs, N.J.

KMENTA, J. (1967), "On Estimation of CES Production Function", Intemational Economic Reoiew, 8, No. 2, June, pp. 180-189.

KOHLER, U. (1991), "Income Distribution and Labor Market Effects of Austrian pre- and postTokyo Round Tariff Protection", European Economic Review, 35, pp. 139-154.

KOHLI, U. (1978), "A Gross National Product Function and the Derived Demand for Imports and Supply of Exports", Canadian Journal of Economics, 11, pp. 167-182.

KOHLI, U. (1991), Technology, Duality and Foreign Trade, The GNP Function Approach to Modeling Imports and Exports, (Harvester Wheatsheaf, London).

KOPITS, G. (1982), "Factor Prices in Industrial Countries", IMF Staff Papers, 29, pp. 437-466.

KRAUSS, M.B. (1972), The Economics of Integration, (Allen \& Unwin, London).

KRUEGER, A.B. and L.H. SUMMERS (1987), "Reflections on the Inter-Industry Wage Structure", in: K. Lang and J.S. Leonard (eds.), Unemployment and the Structure of Labour Markets, (Basil Blackwell, Oxford), pp. 17-47.

KRUEGER, A.B. and L.H. SUMMERS (1988), "Efficiency Wages and the Inter-Industry Wage Structure", Econometrica, 56, No. 2, March, pp. 259-293.

KUGA, K. (1972), "The Factor-Price Equalization Theorem", Econometrica, 40, pp. 723-736.

LAWRENCE, R.Z. and M.J. SLAUGHTER (1993), "International Trade and American Wages in the 1980s: Giant Sucking Sound or Small Hiccup?", Brookings Papers on Economic Activity, No. 2, pp. 161-210.

LAING, N.F. (1961), "Factor Price Equalisation in International Trade and Returns to Scale", Economic Record, 37, September, pp. 339-351.

LAIRD, S. and A. YEATS (1990), Quantitative Methods for Trade-Barrier Analysis, (Macmillan, London).

LAND, A.H. (1959), "Factor Endowments and Factor Prices", Economica, N.S., 26, May, pp. 137142.

LARRE, B. and R. TORRES (1991), "Is Convergence a Spontaneous Process? The Experience of Spain, Portugal and Greece", OECD Economic Studies, No. 16, Spring, pp. 169-198.

LEAMER, EE. (1984), Sources of Comparative Adoantage, Theory and Eoidence, (MIT Press, Cambrige Mass).

LEAMER, E.E. (1992), "Wage Effects of a U.S.-Mexico Trade Agreement", Working paper, NBER, no. 3991.

LEBERGOTT, S. (1947), "Wage Structures", Review of Economics and Statistics, 29, pp. 274-285.

LEONTIEF, W.W. (1964), "An International Comparison of Factor Costs and Factor Use", American Economic Reoiew, 54, June, pp. 335-345.

LERNER, A.P. (1933), "Factor Prices and International Trade", published in Economica, N.S., 19, February 1952, pp. 1-15.

LINDBECK, A. and D.J. SNOWER (1988), "Inter-Industry Wage Structure and the Power of Incumbant Workers", Seminar Paper, no. 418, Institute for International Economic Studies, University of Stockholm, Stockholm.

MACKSCHEIDT, K. (1967), Der Internationale Ausgleich der Faktorpreise, (Duncker und Humblot, Berlin).

MARKUSEN, J.R. (1984), "Factor Movements and Commodity Trade as Complements", Joumal of International Economics, 14, pp. 341-356. 
MARTIN, R.L. (1981), "Wage-Change Interdependence Amongst Regional Labour Markets: Conceptual Issues and Some Empirical Studies", in: R.L. Martin (ed.), Regional Wage Inflation and Unemployment, (Pion Ltd., London), pp. 75-95.

MAS-COLELL, A. (1979), "Two Propositions on the Global Univalence of Systems of Cost Functions", in: J.R. Green and J.A. Scheinkman (eds.), General Equilibrium, Growth and Trade, Academic Press, New York.

MAYER, W. (1974), "Short-Run and Long-Run Equilibrium for a Small Open Economy", Journal of Political Economy, 82, no. 5, pp. 955-967.

MCCULLOCH R. and J.L. YELLEN (1977), "Factor Mobility, Regional Development, and the Distribution of Income", Journal of Political Economy, 85, no. 1, pp. 76-96.

McKENZIE, L.W. (1955), "Equality of Factor Prices in World Trade", Econometrica, 23, July, pp. 239-257.

MEADE, J.E. (1950), "The Equalisation of Factor Prices: The Two-Country Two-Factor ThreeProduct Case", Metroeconomica, 2, December, pp. 129-133.

MELVIN, J.R. (1968), "Production and Trade with Two Factors and Three Goods", American Economic Review, 58, pp. 1249-1268.

METZLER, L.A. (1949), "Tariffs, the Terms of Trade and the Distribution of Income", Journal of Political Economy, 57, No. 1, February, pp. 1-29.

MINHAS, B.S. (1963), An International Comparison of Factor Costs and Factor Use, (North-Holland Publishing Co., Amsterdam).

MOKHTARI, M. and F. RASSEKH (1989), "The Tendency Towards Factor Price Equalization Among OECD Countries", Review of Economics and Statistics, 71, pp. 636-642.

MOLLE, W.T.M. (1989), The Economics of European Integration, (Dartmouth, Aldershot).

MOLLE, W.T.M. (1994), The Economics of European Integration, second revised edition, (Dartmouth, Aldershot).

MOLLE, W.T.M., and A. VAN MOURIK $\left(1989^{\circ}\right)$, Wage Differentials in the European Community, (Gower, Aldershot).

MOLLE, W.T.M., and A. VAN MOURIK (1989'), "A Static Explanatory Model of International Migration to an in Western Europe", in: I. Gordon and A.P. Thirwall (eds.), European Factor Mobility, (MacMillan, London).

MORONEY, J.R. (1970), "Factor Prices, Factor Proportions, and Regional Factor Endowments", Joumal of Political Economy, 78, pp. 158-164.

MORTENSEN, J. (1984), "Profitiability, Relative Factor Prices and Capital/Labour Substitution in the Community, the United States and Japan, 1960-83", European Economy, No. 20, July, Pp. 33-67.

MUNDELL, R.A. (1957), "International Trade and Factor Mobility", American Economic Review, 47, pp. 321-335.

MURPHY, B. (1989), "Factor Price Changes and Imported Intermediate Goods", International Economic Journal, Vol. 3, No. 4, pp. 19-36.

MUSSA, M. (1974), "Tariffs and the Distribution of Income: The Importance of Factor Specifity, Substitutability, and Intensity in the Short and Long Run", Joumal of Political Economy, 82, No. 6, pp. 1191-1203.

MUSSA, M. (1979), "The Two-Sector Model in Terms of its Dual", Journal of International Economics, 9, pp. 513-526.

MUSSA, M. (1982), "Imperfect Factor Mobility and the Distribution of Income", Joumal of Internetional Economics, 12, pp. 125-141.

NAKAMURA, S. (1984), An Inter-Industry Translog Model of Prices and Technical Change for the West-German Economy, (Springer Verlag, Berlin).

NEARY, J.P. (1978), "Short Run Capital Specificity and the Pure Theory of International Trade", Economic Journal, 88, pp. 488-510.

OECD (1985), "Relative Wages, Industrial Structure and Employment Performance", Employment Outlook, pp. 83-99.

OHLIN, B. (1933), Interregional and International Trade, (Harvard University Press, Cambridge Mass.). 
OLSEN, E. (1971), International Trade Theory and Regional Income Differences, (North-Holland, Amsterdam).

PANAGARIYA, A. (1980), "Variable Returns to Scale in General Equilibrium Theory Again", Joumal of International Economics, 10, pp. 499-526.

PAPOLA, T.S. and V.P. BHARADWAJ (1970), "Dynamics of Industrial Wage Structure: An Intercountry Analysis", Economic Journal, 80, March, Pp. 72-90.

PEARCE, I.F. (1951-52), "The Factor Price Equalisation Myth", Review of Economic Studies, 19, pp. 111-119.

PEARCE, I.F. (1959), "A Further Note on Factor-Commodity Price Relationships", Economic Joumal, 2, January, pp. 29-64.

PEARCE, I.F. (1970), International Trade, (W.W. Norton \& Co., New York).

POLZIN, P.E. (1972), "State and Regional Wage Differences", Southern Economic Joumal, 38, No. 3, pp. 371-378.

POMFRET, R. (1986), "The Theory of Preferential Trading Arrangements", Weltwirtschaftliches Archiv, 122, No. 3, pp. 439-465.

RAMASWAMI V.K. and T.N. SRINIVASAN (1971), "Tariff Structure and Resourcec Allocation in the Presence of Substitution", in: J.N. Bhagwati (ed.), Trade, Balance of Payments and Growth, (North-Holland, Amsterdam).

REITER, S. (1961), "Efficient International Trade and Equalisation of Factor Prices", International Economic Review, 2, January, pp. $29-64$.

RICHARDSON, J.H. (1930), "International Comparisons of Real Wages", Journal of the Royal Statistical Society, 93, pp. 398-423.

ROBINSON, J. (1964), "Factor Prices Not Equalized", Quarterly Journal of Economics, 78, pp. 202207.

ROBSON, P. (1987), The Economics of International Integration, Third Edition, (Allen and Unwin, London).

ROTHBAUM, M. (1957), "National Wage-structure Comparisons", in: G.W. Taylor and F.C. Pierson (eds.), New Concepts in Wage Determination, (McGraw-Hill, New York).

RUFFIN, R. and R.W. JONES (1977), "Protection and Real Wages: The Neoclassical Ambiguity", Journal of Economic Theory, 14, pp. 337-348.

SAMUELSON, P.A. (1948), "International Trade and the Equalisation of Factor Prices", Economic Journal, 58, June, pp. 163-184.

SAMUELSON, P.A. (1949), "International Factor-Price Equalisation Once Again", Economic Journal, 59, June, pp. 184-197.

SAMUELSON, P.A. (1951-52), "A Comment on Factor Price Equalisation", Reoiew of Economic Studies, 19, pp. 121-122.

SAMUELSON, P.A. (1953), "Prices of Factors and Goods in General Equilibrium", Review of Economic Studies, 21, pp. 1-20.

SAMUELSON, P.A. (1967), "Summary on Factor Price Equalisation", International Economic Review, 8, pp. 286-295.

SAUNDERS, C. and D. MARSDEN (1981), Pay Differentials in the European Community, (Butterworths, London).

SCHWEINBERGER, A.G. (1975), "Pure Traded Intermediate Products and the Heckscher-Ohlin Theorem", American Economic Review, 65, pp. 634-645.

SCULLY, G.W. (1969), "Interstate Wage Differentials: A Cross Section Analysis", American Economic Review, 59, pp. 757 - 773.

SCULLY, G.W. (1971), "The North-South Manufacturing Wage Differential, 1869-1919", Journal of Regional Science, 11, No. 2, pp. 235-252.

SEIDEL, B. (1983), Wage Policy and European Integration, (Gower, Aldershot).

SEGAL, M. (1961), "Regional Wage Differences in Manufacturing in the Postwar Period", Revicw of Economics and Statistics, 43, pp. 248-255.

SLICHTER, S.H. (1950), "Notes on the Structure of Wages", Reciew of Economics and Statistics, 32 , pp. $80-91$. 
SMITH, D.M.(1975), "Neoclassical Growth Models and Regional Growth in the US", Joumal of Regional Science, 15, No. 2, pp. 165-181.

SMITH, D.M. (1976), "Regional Growth: Interstate and Intersectoral Factor Reallocations", Review of Economics and Statistics, 56, August, Pp. 353-359.

STEINHERR, A. (1985), "Income Distribution and Employment in the European Communities 1960-82", Zeitschrift für Wirtschafts- und Sozialwissenschaften, 105, pp. 223-269.

STOLPER, W.F. and P.A. SAMUELSON (1941), "Protection and Real Wages", Review of Economic Studies, 9, November, pp. 58-71.

SVENSSON, L.E.O. (1984), "Factor Trade and Goods Trade", Journal of Intemational Economics, 16, pp. 365-378.

SWEDISH EMPLOYERS' CONFEDERATION (SAF) (1972), Direct and Total Wage Costs for Workers, Intemational Survey 1960-1970, SAF Research Department, Stockholm.

SWEDISH EMPLOYERS' CONFEDERATION (SAF) (1982), Wages and Total Labour Costs for Workers, Intemational Survey 1970-1980, SAF Research Department, Stockholm.

SWEDISH EMPLOYERS' CONFEDERATION (SAF) (1992), Wages and Total Labour Cosis for Workers, International Survey 1980-1990, SAF Research Department, Stockholm.

TAKAYAMA, A. (1972), International Trade, An Approach to the Theory, (Holt, Rinehart and Winston, Inc., New York).

TAKAYAMA, A. (1987), Mathematical Economics, 2nd edition, (Cambridge University Press, Cambridge).

TINBERGEN, J. (1949), "The Equalisation of Factor Prices between Free-Trade Areas", Metroeconomica, 1, July, pp. 39-47.

TOVIAS, A. (1982), "Testing Factor Price Equalization in the EEC", Journal of Common Market Studies, 20, No. 4, June, pp. 375-388.

UEKAWA, Y. (1971), "Generalization of the Stolper-Samuelson Theorem", Econometrica, 39, pp. 197-217.

UEKAWA, Y., M.C. KEMP and L.L. WEGGE (1972), "P- and PN-Matrices, Minkowski- and Metzler Matrices, and Generalizations of the Stolper-Samuelson and Samuelson-Rybczynski Theorems", Journal of Intermational Economics, 3, pp. 53-76.

UNITED NATIONS ECONOMIC COMMISSION FOR EUROPE (1950), "Changes in the Structure of Wages in European Countries", Economic Bulletin for Europe, 2, pp. 52-63.

UZAWA, H. (1959), "Prices of the Factors of Production in International Trade", Econometrica, 27, July, Pp. 448-468.

VAN MOURIK, A. (1987), "Testing Factor Price Equalisation Theorem in the EC, An Alternative View: A Comment", Joumal of Common Market Studies, 26, pp. 79-86.

VAN MOURIK, A. (1989), "A Neoclassical Model of International Wage Differentials", in: W. T. M. Molle and A. van Mourik (eds.), Wage Differentials in the European Community, (Gower, Aldershot).

VARIAN, H. (1984), Microeconomic Analysis, Second Edition, (W.W. Norton, New York).

VASILLE, L. (1989), "Industries: The Role of Productivity, Skill and Other Factors" in: W.T.M. Molle and A. van Mourik (eds.), Wage Differentials in the European Community, (Gower, Aldershot).

WAELBROECK, J. (1977), "Measuring the Degree of Progress of Economic Integration", in F. Machlup (ed.), Economic Integration, Worldwide Regional, Sectoral, (Macmillan, London).

WILEY, D.E., W.H. SCHMIDT, and W.J. BRAMBLE (1973), "Studies on a Class of Covariance Structure Models", Joumal of the American Statistical Association, 68, pp. 317-323.

WONG, K.Y. (1988), "International Factor Mobility and the Volume of Trade: An Empirical Study", in: R.C. Feenstra (ed.), Empirical Methods for International Trade, (MIT Press, Cambridge Mass), pp. 232-250.

WOODLAND, A.D.(1977), "A Dual Approach to Equilibrium in the Production Sector in International Trade Theory", Canadian Joumal of Economics, 10, pp. 50-68.

WOODLAND, A.D. (1982), International Trade and Resource Allocation, (North-Holland Publishing Company, Amsterdam). 
WOODLAND, A.D. (1988), "Comment on International Factor Mobility", in: R.C. Feenstra (ed.), Empirical Methods for International Trade, (MIT Press, Cambridge Mass), pp. 251-260.

YEUNG, P. and H. TSANG (1972), "Generalised Production Functions and Factor-Intensity

Cross-Overs: An Empirical Analysis", Economic Record, 48, No. 123, September, pp. 387-399. 
Het economische integratieproces in de EEG heeft twee belangrijke momenten gekend, waarop de interne handel in de Gemeenschap in aanzienlijke mate werd geliberaliseerd. Enerzijds werd in de jaren zestig de douane unie tussen de lidstaten een feit. Anderzijds werd in de jaren tachtig serieus werk gemaakt met het tot stand brengen van de interne markt.

De economische theorie van de internationale integratie leert ons, dat dergelijke processen van handelsliberalisatie aanzienlijke effecten kunnen hebben voor de functionele inkomensverdeling in de integrerende staten. In dit proefschrift staan deze verdelingseffecten centraal. Meer in het bijzonder tracht het proefschrift een antwoord te geven op de vraag, welke effecten de intra-Europese handelsliberalisatie heeft gehad voor de lonen in de lidstaten. Het onderzoek beperkt zich daarbij tot de looneffecten in de vijf belangrijkste oprichters van de EEG (EG-5).

De centrale vraag, namelijk de vraag naar de looneffecten van het Europese integratieproces, is door de theorie van de internationale integratie altijd beantwoord onder verwijzing naar de (reële) theorie van de internationale economische betrekkingen. Daarom begint het eigenlijke onderzoek in hoofdstuk 2 met een overzicht van de meest relevant geachte handelstheoretische literatuur. Daarbij is overwegend aandacht geschonken aan het factorprijsegalisatie theorema, het theorema van Stolper-Samueison en het "specific-factors" model. Volgens het factorprijsegalisatie theorema leidt een vrijmaking van de internationale goederenhandel tot een internationale gelijkmaking van de lonen en kapitaalkosten. Het theorema van Stolper-Samuelson, dat kan worden opgevat als een comparatief-statische versie van het factorprijsegalisatie theorema, leidt tot de conclusie, dat een verlaging van een invoertarief zal resulteren in een daling van de prijs van de intensieve factor in de importsector.

Het factorprijsegalisatie theorema en het theorema van Stolper-Samuelson worden in the economische theorie van de internationale integratie doorgaans geacht van toepassing te zijn op de handelsliberalisatie in de EG, d.w.z. dat door de aanhangers van die theorie allerwege een convergentieproces van de lonen wordt voorspeld. Nadere bestudering van de literatuur omtrent beide theorema's leert ons evenwel, dat een volledige egalisatie van de factorprijzen onwaarschijnlijk moet worden geacht en dat men hoogstens een tendens tot factorprijsegalisatie kan verwachten. Die conclusie wordt bevestigd door een studie van de comparatief-statische effecten in het "specific-factors" model, waaruit blijkt dat de factorprijseffecten vooral afhankelijk zijn van de concrete specificatie van de produktietechnologie en van de factorintensiteiten.

In hoofdstuk 3 wordt nagegaan, hoe de lonen zich hebben ontwikkeld in de EG-5 landen in de periode 1964-1989. Daarbij is het verloop onderzocht van de bruto uurlonen, de arbeidskosten per uur en de arbeidskosten per manjaar voor ISIC en NACE industriële sectoren op een 2 digit niveau. De gegevens omtrent lonen en arbeidskosten die in die analyse worden gebruikt, zijn geconverteerd met behulp van twee wisselkoersdefinities, namelijk de lopende ECU wisselkoers en de koopkrachtpariteit wisselkoers. Een analyse van de industriële loonstructuur in de EG-5 landen doet enkele interessante, deels bekende feiten aan het licht komen. Allereerst wordt geconstateerd, dat de loonstructuur in alle onderzochte landen gekenmerkt wordt door een hoge mate van stabiliteit. In de tweede plaats blijken de loonstructuren in de verschillende landen een verrassende mate van gelijkvormigheid te bezitten. Zowel de stabiliteit als de gelijkvormigheid van de loonstructuur in verschillende landen zijn in de literatuur uitvoerig gedocumenteerd. Ten derde blijkt dat internationale loonverschillen tussen landen tot op zekere hoogte persistent te zijn. Uitgedrukt in de lopende ECU wisselkoers blijkt er nauwelijks sprake te zijn van een loon- en arbeidskostenconvergentie. Indien de lonen 
en arbeidskosten echter worden uitgedrukt in koopkrachtpariteiten blijkt er sprake te zijn van een substantiële convergentie. Deze convergentie is vooral terug te voeren op het feit, dat de lage-lonen-landen in de loop der tijd steeds meer aansluiting hebben gevonden bij de hoge-lonen-landen. Daarnaast kan worden geconstateerd, dat deze ontwikkeling zich niet alleen voordoet in de EEG, maar zich ook (wellicht zelfs in sterkere mate) voordoet in de landen van de EFTA.

In hoofdstuk 4 wordt een overzicht gegeven van de belangrijkste bijdragen aan de empirische literatuur, waarin getracht is de waargenomen stabiliteit en gelijkvormigheid van de loonstructuren te verklaren, alsmede waarin een poging is gedaan de ontwikkeling van de internationale loonverschillen te verklaren. De stabiliteit en gelijkvormigheid van loonstructuren is vooral het onderzoeksobject geweest van arbeidseconomen. In arbeidseconomische verklaringen worden de stabiliteit en de gelijkvormigheid van loonstructuren traditioneel verklaard uit variabelen als het gemiddelde opleidingsniveau in een sector, het aandeel van vrouwen in die sector, kapitaalintensiteiten, en een aantal institutionele variabelen. Daarentegen hebben weinig economen, meestal uit de internationaal economische hoek, aandacht besteed aan de verklaring van de ontwikkeling van internationale loonverschillen. Wanneer aan dit vraagstuk al aandacht wordt besteed, wordt dat vaak op een ad hoc wijze gedaan en slechts zelden wordt de relatie tussen internationale loonverschillen en economische integratiє gelegd. Empirische modellen gebaseerd op optimaliseringsgedrag van economische subjecten zelfs bijzonder schaars, hetgeen merkwaardig is indien men bedenkt dat de theorema's van de handelstheorie juist een dergelijk optimaliseringsgedrag veronderstellen.

In hoofdstuk 5 wordt een model gepresenteerd waarin de relatie tussen de ontwikkeling van loonverschillen en economische integratie centraal staat. Het model komt op wezenlijke punten overeen met standaardmodellen uit de theorie van de internationale handel (zoals deze o.a. beschreven zijn in Woodland (1982)). In het model, dat in een duale formulering wordt gepresenteerd, worden drie produktiefactoren onderscheiden, te weten arbeid, kapitaal en intermediaire leveringen, welke op korte termijn geacht worden sector specifiek te zijn. Op lange termijn zijn arbeid en kapitaal volledig intersectoraal mobiel. Analyse van de comparatieve statica in het korte termijn model leert, dat de looneffecten van handelspolitieke maatregelen vooral afhankelijk zijn van de produktietechnologie, alsmede van de factorintensiteiten. Teneinde de looneffecten van economische integratie nader in te vullen wordt voorgesteld om de prijsveranderingen, die optreden nadat een douane unie wordt gevormd, te berekenen als een gewogen gemiddelde van enerzijds prijsveranderingen die hun origine hebben in partnerlanden van de douane unie, en anderzijds van prijsveranderingen die hun origine hebben in derde landen. Het belangrijkste resultaat, dat op basis van het model kan worden afgeleid is, dat de implementatie van een douane unie niet noodzakelijk hoeft te leiden tot een loonconvergentie tussen de lidstaten van de douane unie. Met andere woorden, er zijn situaties denkbaar, waarin de implementatie van een douane unie leidt tot grotere, in plaats van kleinere internationale loonverschillen tussen de lidstaten. Dit is bijvoorbeeld het geval, indien de lage lonen in lage-lonen-landen gepaard gaan aan lage invoerbarrières en lage waarden voor de eigen Allen-Uzawa partiële substitutie elasticiteiten. In dat geval zullen de lonen in dit land dalen na de implementatie van een douane unie, hetgeen een internationale convergentie van de lonen uiteraard ernstig bemoeilijkt. Omgekeerd kan het voorkomen, dat er in een land met hoge lonen sprake is van hoge invoerbarrières en lage waarden van de eigen Allen-Uzawa partiële substitutie elasticiteiten. De instelling van een douane unie zal alsdan leiden tot nòg hogere lonen, hetgeen uiteraard eveneens een internationale loonconvergentie in de weg staat. 
In hoofdstuk 6 worden de parameters van het in hoofdstuk 5 besproken model empirisch geschat en worden op basis van de parameterschattingen waarden afgeleid voor de relevante Allen-Uzawa partiële substitutie elasticiteiten. De produktietechnologie van de verschillende sectoren wordt daarbij in beeld gebracht door translog kostenfuncties. Dit soort kostenfunctie behoort tot de familie van $\mathrm{zg}$. flexibele functionele vormen, die geen a priori restricties opleggen aan de specificatie van de kostenfunctie. De translog kostenfunctie heeft als belangrijk voordeel, dat de verschillende Allen-Uzawa partiële substitutie elasticiteiten er eenvoudig uit kunnen worden afgeleid. De translog kostenfunctie wordt in hoofdstuk 5 geschat voor de 13 onderscheiden industriesectoren in ieder EG-5 land. Wat de waarden van de Allen-Uzawa partiële substitutie elasticiteiten betreft wordt geconcludeerd dat arbeid en kapitaal in de meerderheid der gevallen moeten worden beschouwd als complementen, terwijl arbeid en intermediaire leveringen enerzijds en kapitaal en intermediaire leveringen anderzijds in de meerderheid der gevallen substituten blijken te zijn. Verder vinden we dat de produktietechnologie wordt gekenmerkt door een arbeidsbesparende en een kapitaalvermeerderende tendentie.

De in hoofstuk 6 afgeleide waarden van de substitutie elasticiteiten worden in hoofdstuk 7 gebruikt voor twee simulatie experimenten. In het eerste experiment wordt nagegaan, wat de looneffecten zijn geweest van de implementatie van de douane unie in de jaren zestig. In deze simulatie worden die effecten verkregen door een vergelijking van de feitelijke loonontwikkeling met een hypothetische situatie, die ontstaat indien in douane unie in 1970 zou worden afgeschaft en de EG-5 lidstaten zouden besluiten tot herinvoering van het uit 1958 daterende handelspolitieke instrumentarium. De conclusie van dit experiment is, dat de douane unie heeft geleid tot een aanzienlijke loonconvergentie. Hierbij dient evenwel te worden opgemerkt, dat deze conclusie werd afgeleid onder de veronderstelling dat de als gevolg van de afschaffing van de douane unie optredende prijswijzigingen zich vertalen in gewijzigde koopkrachtpariteiten. In het geval men deze veronderstelling niet wenst te maken en uitgaat van ongewijzigde koopkrachtpariteiten, dan blijkt dat de loonconvergentie veel minder sterk zichtbaar wordt.

In het tweede simulatie experiment wordt nagegaan, wat de looneffecten van het interne marktprogramma zouden kunnen zijn. Daarbij wordt verondersteld, dat het programma in 1985 onmiddellijk zou zijn uitgevoerd. De conclusie waartoe dat experiment aanleiding geeft is, dat de implementatie van het 1992 programma tot verwaarloosbare looneffecten leidt en nauwelijks tot enige ontwrichting van de arbeidsmarkten aanleiding zal geven. In enkele industriesectoren treedt er een (overigens geringe) loonconvergentie op, in enkele andere gevallen treedt er een (geringe) divergentie op en tenslotte is in een enkele sector helemaal geen effect waarneembaaar. 

